\begin{tabular}{|l|l|}
\hline $\begin{array}{l}\text { 2. To: (Receiving Organization) } \\
\text { Distribution }\end{array}$ & $\begin{array}{l}\text { 3. From: (Originating Organization) } \\
\text { Process Engineering Analys is }\end{array}$ \\
\hline 5. Proj./Prog./Dept./Div.: & $\begin{array}{l}\text { 6. Design Authority/ Design Agent/Cog. } \\
\text { Engr.: } \\
\text { DNF } / \text { CITS6. Ogden }\end{array}$ \\
\hline
\end{tabular}

8. Originator Remarks: For Release
4. Related EDT No.:

$N / A$

7. Purchase Order No.:

$N / A$

9. Equip./Component No.:

$N / A$

10. System/Bldg./Facility:

$N / A$

11. Receiver Remarks: 11A. Design Baseline Document? [] Yes [X] No

12. Major Assm. Dwg. No.: $N / A$

13. Permit/Permit Application No.: $N / A$

14. Required Response Date: NFA

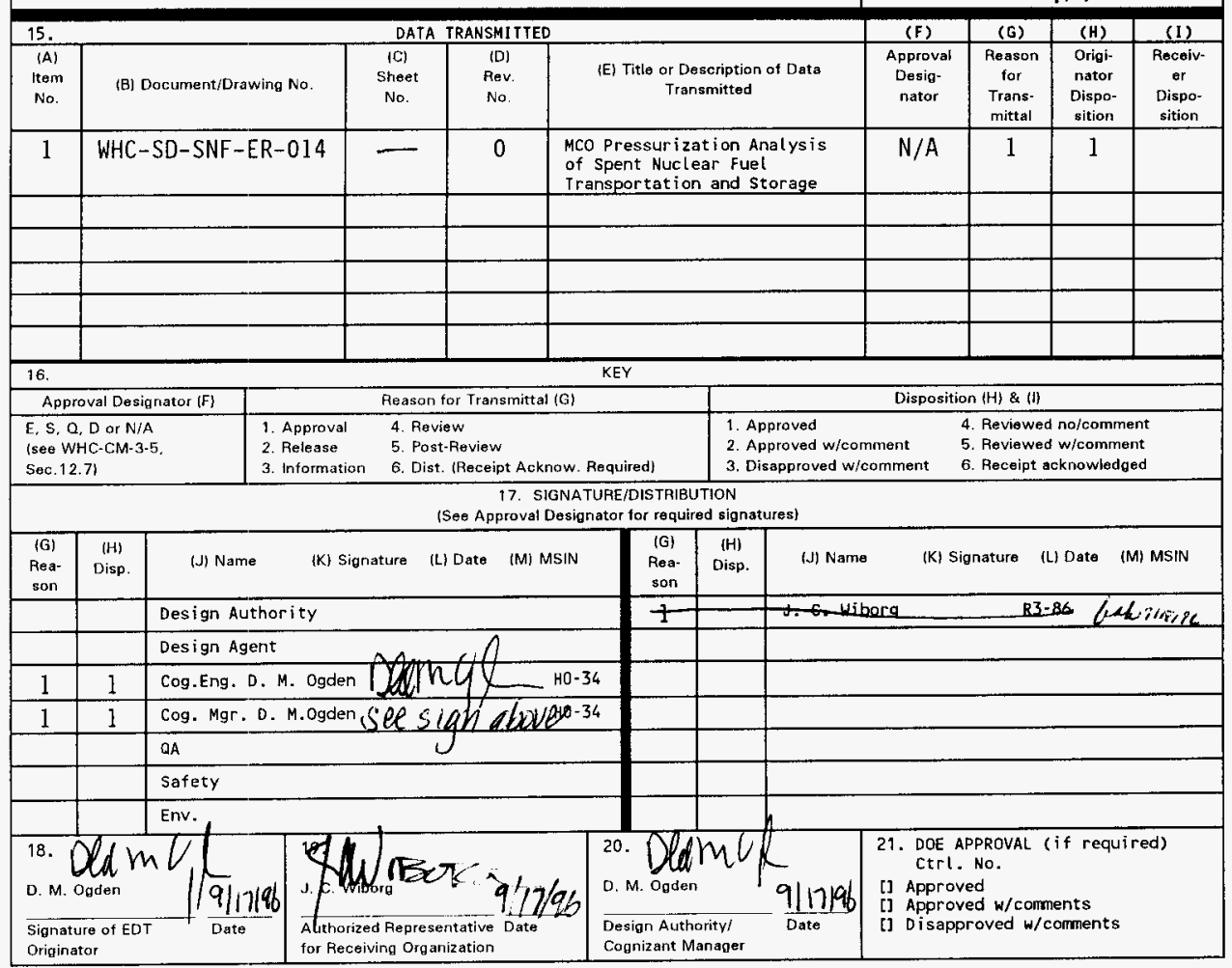




\section{MCO Pressurization Analysis of Spent Nuclear Fuel Transportation and Storage}

\section{M. Ogden}

Westinghouse Hanford Company, Richland, WA 99352

U.S. Department of Energy Contract DE-AC06-87RL10930

$\begin{array}{lll}\text { EDT/ECN: } & 614689 & \text { UC: } 2020 \\ \text { Org Code: } & 74 \text { A50 } & \text { Charge Code: C17862 } \\ \text { B\&R Code: } & \text { EW3135040 } & \text { Total Pages: } 235 \text { 736 } 235\end{array}$

Key words: MCO, thermal hydraulic, corrosion, GOTH, COBRA-TF, shipping, storage

Abstract: A series of analyses were performed to evaluate the pressurization of the Multi-Canister Overpack (MCO) during the stages of transport, processing and storage for expected operational and off normal events. The study examined both MCO sealing and venting issues. Computer models were developed for the MCO and its transport and storage environments using the GOTH and COBRA-TF computer codes. These thermalhydraulic models included chemical corrosion and ranged in complexity from simple scoping models to full three-dimensional models. Results of the evaluation indicate that overpressurization of the MCO can occur within hours given the bounding reaction surface area and $3.0 \mathrm{Kg}$ of residual water during shipping or $2.5 \mathrm{~kg}$ of residual water during storage. Overpressurization can be prevented during shipping if the MCO reaction surface area is shown to be less than $80,000 \mathrm{~cm}^{2}$. During storage the overpressurization can be prevented by limiting the available water.

TRADEMARK DISCLAIMER. Reference herein to any specific commercial product, process, or service by trade name, trademark, manufacturer, or otherwise, does not necessarily constitute or imply its endorsement, recommendation, or favoring by the United states Government or any agency thereof or its contractors or subcontractors.

Printed in the United States of America. To obtain copies of this document, contact: WHC/8CS Document Control Services, P.O. Box 1970, Maitstop H6-08, Richland WA 99352, Phone (509) 372-2420; Fax (509) 376-4989.
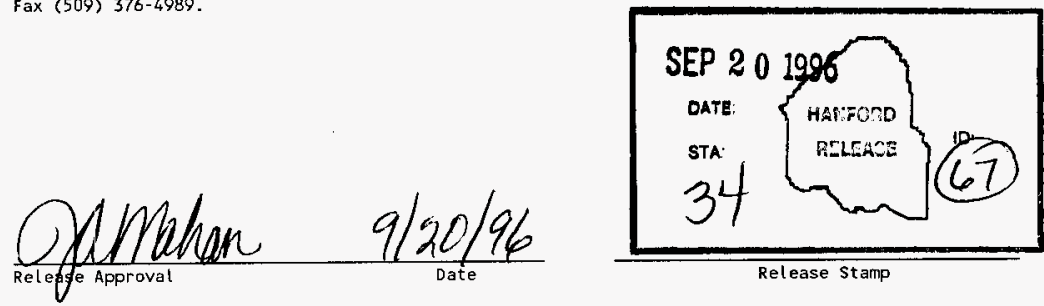

Release Stamp

\section{Approved for Public Release}


WHC-SD-SNF-ER-014, Rev. 0

\title{
MCO Pressurization Analysis of Spent Nuclear Fuel Transportation and Storage
}

\author{
Prepared by \\ B. C. Fryer \\ M. J. Thurgood \\ John Marvin, Inc. \\ for Westinghouse Hanford Company \\ D. M. Ogden \\ Westinghouse Hanford Company
}

September 1996

\author{
Issued by \\ WESTINGHOUSE HANFORD COMPANY \\ for the \\ U.S. DEPARTMENT OF ENERGY \\ RICHLAND OPERATIONS OFFICE \\ RICHLAND, WASHINGTON
}




$$
\text { WHC-SD-SNF-ER-014, Rev. } 0 \text {. }
$$

\section{TABLE OF CONTENTS}

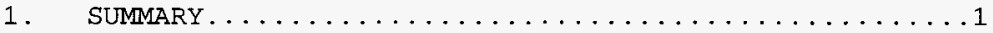

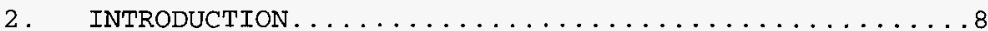

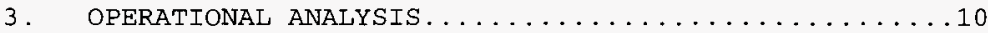

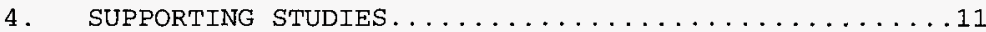

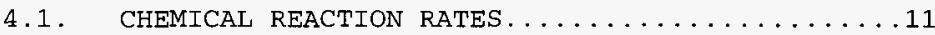

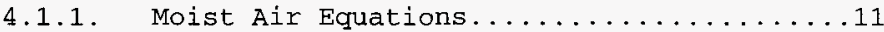

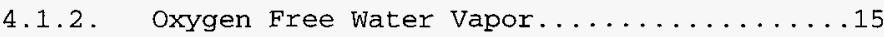

4.1.3. Uranium Oxidation (Oxygen in Dry Air) ....16

4.1.3.1. Ritchie Equation for Uranium In Dry

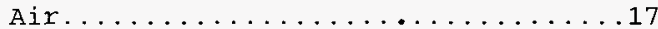

4.1.3.2. Pearce Equation for Dry Air........19

4.1.3.3. Ritchie Equation Modified for Variable Concentration of oxygen....21

4.1.3.4. Cooper's Equation for Dry Air with

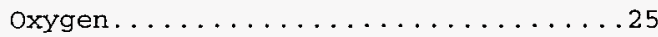

4.1.4. Hydriding and Dehydriding...........32

4.1.5. Hydrate Decomposition.............. . 34

4.1.5.1. Dehyration Rate under Vacuum Conditions.........................

4.1.5.2. Dehydration Rate In the Pressence of

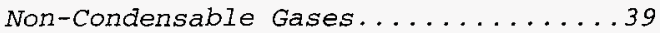

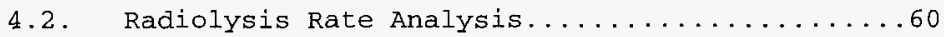

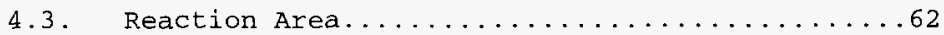

4.4. Oxidation Product Inventory and Chemical

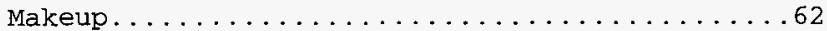

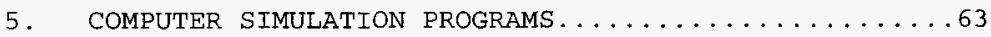

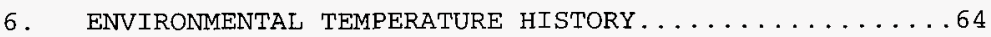

6.1. COMPUTATIONAL MODELS FOR ENVIRONMENTAL

TEMPERATURE HISTORY ................65

6.1.1. CSB Computational Models.............66

6.1 .1 .1 Lumped Parameter Model...........66

6.1.1.2. Two-Dimensional Model..........69 


$$
\text { WHC-SD-SNF-ER-014, Rev. } 0 \text {. }
$$

6.1.1.3. Three-Dimensional Model..........69

6.1.2. MCO Computational Models............73

6.1.2.1. Two-Dimensional FIDAP Model. ......73

6.1.2.2. Detailed COBRA-TF Model. ........73

6.1.2.3. Simple MCO Model. ............76

6.1.2.3.1. COBRA-TF Simple MCO Radiation

Plus Radial Conduction

Simulation Model...........78

6.1.2.3.2. Application of the Simple MCO

Model to MCO Pressurization....85

6.2. CSB VAULT TEMPERATURE HISTORY...........86

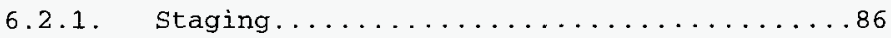

6.2.1.1. Nominal Fully Loaded CSB.........86

6.2.1.1.1. Flow and Temperature

Distribution Using Two-

Dimensional Model..........89

6.2.1.1.2. Flow and Temperature

Distribution Using Three-

Dimensional Model..........992

6.2.1.2. Loading Sequence Evaluation...... . .992

6.2.1.2.1. CSB with one Fourth of the Tubes

Filled..................92

6.2.1.2.2. CSB with One Half of the Tubes

Filled...................95

6.2.1.2.3. CSB with Three Fourths of the

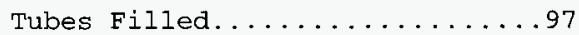

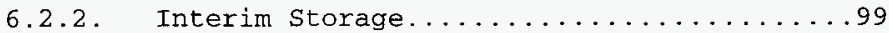

6.3. MCO SHIPPING TEMPERATURE HISTORY.............99

6.3.1. Results for Shipping From Basin to CVDF...99

6.3.1.1. Nominal Shipping Conditions and

Shipping Delay..................................

6.3.1.2. Design Basis Fire............... 105

6.3.2. Results for Shipping From CVDF to CSB...107

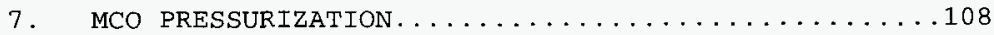

7.1. PRESSURIZATION DURING STORAGE. .......... 110

7.1.1. Staging .................... 110

7.1.1.1. MCO Thermal Solution without Chemical

Reactions.................................

7.1.1.2. Bounding Case................. 


$$
\text { WHC-SD-SNF-ER-014, Rev. } 0 \text {. }
$$

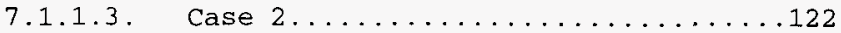

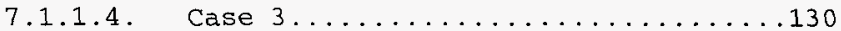

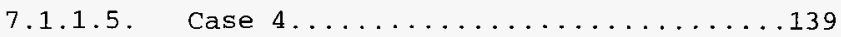

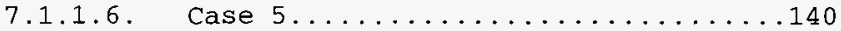

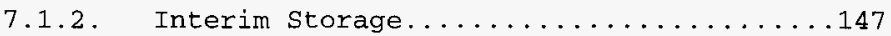

7.2. MCO PRESSURIZATION DURING SHIPPING. . . . . . 149

7.2.1. Results for Shipping From Basin to CVDF......................149

7.2.1.1. Nominal Shipping and Shipping Delay Conditions, Case 1A..............151

7.2.1.2. Design Basis Fire, Case 1B....... 154

7.2.1.3. Conclusions and Recommendations for Shipping From Basin to CVDF.......157

7.2.2. Results for Shipping From CVDF to CSB...158

7.2.2.1. Thermal and Pressure Transient Without Chemical Reactions........159

7.2.2.2. Bounding Case.........................

7.2.2.3. Bounding Case with Reduced Decay Heat....................... 169

7.2.2.4. High Nominal Case with 750 watts of Decay Heat and $80,000 \mathrm{~cm}^{2}$

Reaction Area in the Rubble Basket. . . . . . . . . . . . . 176

7.2.2.5. Minimum sludge Case...........183 7.3. MCO PRESSURIZATION DURING COLD VACUUM DRYING DRAINING FAILURE. . . . . . . . . . . 190

7.4. EQUILIBRIUM PRESSURE VERSUS WATER MASS . . . . . 194

8. PRESSURE RELIEF FLOW RATES . . . . . . . . . . . . 197

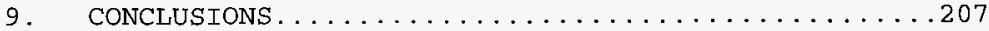

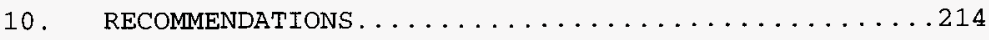

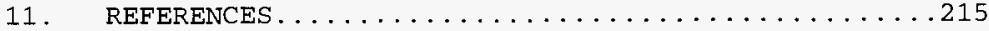


WHC-SD-SNE-ER-014, Rev. 0 .

\section{LIST OF TABLES}

1.1 Summary of Key Parameters and Results for Simulation

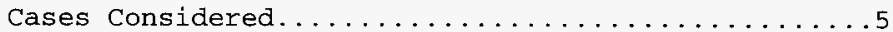

4.1 Hydrate Water Mass on Each Fuel Surface for $150 \mathrm{~kg}$ of

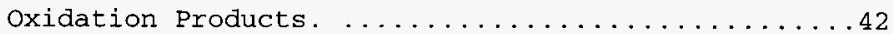

4.2 Hydrate Water Mass On Each Fuel Surface for $70 \mathrm{~kg}$ of Oxidation Products..................43

4.3 Hydrate Water Mass on Each Fuel Surface for $16 \mathrm{~kg}$ of Oxidation Products. ..................44

4.4 Structure Thermal Emissivities. ............. 52

4.5 Lower Bound on Chemical Heat That Can be Transferred Out From Center Ring as a Function of Temperature for Transport In Cask. .................. 53

4. 6 Best Estimate of Chemical Heat That Can be

Transferred Out From Center Ring as a Function of Temperature for Transport In Cask. ..........54

4.7 Chemical Heat Generated Based on Minimum Possible

Pearce Equations...................... 55

4.8 Chemical Heat Generated Based on Maximum Possible

Pearce Equations Using $\mathrm{Al}_{2} \mathrm{O}_{3} \cdot 3 \mathrm{H}_{2} \mathrm{O}$

Equilibrium Pressure................... 56

4.9 Oxidation Product Chemical Makeup. ..........63

7.1 Key Transients and Important Parameters. ..........109

9.1 Summary of Key Parameters and Simulation Results for

Cases Currently Considered................209 


\section{LIST OF FIGURES}

1.1 Comparison of Heat That Can be Removed Versus Heat

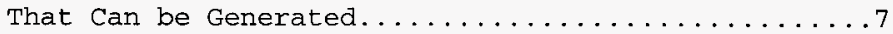

4.1 Reaction Rate in Dry Air versus Temperature. ......20

4.2 Comparison of Modified Ritchie Equation and Cooper's Equation for Dry Air, $\mathrm{mf}_{\mathrm{O} 2}=0.2323$,

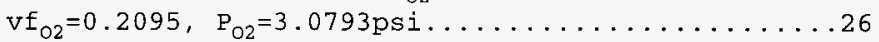

4.3 Comparison of Modified Ritchie Equation and Cooper's Equation, $\mathrm{mf}_{\mathrm{O} 2}=0.1126, \mathrm{vf}_{\mathrm{O} 2}=0.10, \mathrm{P}_{\mathrm{O} 2}=1.47 \mathrm{psi} \ldots .27$

4.4 Comparison of Modified Ritchie Equation and Cooper's Equation, $\mathrm{mf}_{\mathrm{O} 2}=0.0567, \mathrm{vf}_{\mathrm{O} 2}=0.05, \mathrm{P}_{\mathrm{O} 2}=0.735 \mathrm{psi} \ldots 28$

4.5 Comparison of Modified Ritchie Equation and Cooper's Equation, $\mathrm{mf}_{\mathrm{O} 2}=0.0454, \mathrm{vf}_{\mathrm{O} 2}=0.04$,

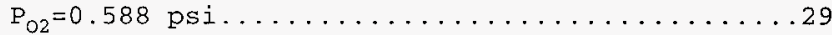

4.6 Comparison of Modified Ritchie Equation and Cooper's Equation, $\mathrm{mf}_{\mathrm{O} 2}=0.0341, \mathrm{vf}_{\mathrm{O} 2}=0.03, \mathrm{P}_{\mathrm{O} 2}=0.4410 \mathrm{psi} \ldots 30$

4.7 Comparison of Modified Ritchie Equation and Cooper's

Equation, $\mathrm{mf}_{\mathrm{O} 2}=0.0228, \mathrm{vf}_{\mathrm{O} 2}=0.02, \mathrm{P}_{\mathrm{O} 2}=0.294 \mathrm{psi} \ldots .31$

4.8 Comparison of Modified Ritchie Equation and Cooper's

Equation, $\mathrm{mf}_{\mathrm{O} 2}=0.0114, \mathrm{vf}_{\mathrm{O} 2}=0.01, \mathrm{P}_{\mathrm{O} 2}=0.147 \mathrm{psi} \ldots 32$

4.9 Hydrate Equilibrium Temperatures. . . . . . . . . . . 37

4.10 Reaction Rate In Oxygen Free Water Vapor at a

Pressure of $30 \mathrm{kPa} \ldots \ldots \ldots \ldots \ldots \ldots \ldots \ldots$

4.11 Reaction Rate In Oxygen Free water Vapor for the Pearce Equations and Using the Hydrate Equilibrium Pressures........................49

4.12 Reaction Heat Flux In Oxygen Free Water vapor for the Pearce Equations and Using the Hydrate Equilibrium Pressures.................50

4.13 Reaction Heat Flux In Oxygen Free Water Vapor for the Pearce Equations and Using the Hydrate Equilibrium Pressures.................. 51 
WHC-SD-SNF-ER-014, Rev. 0 .

4.15 Reaction Heat Flux In Oxygen Free water Vapor for the Pearce Equations and Using the Hydrate

Equilibrium Pressures.................... 59

6.1 Lumped Parameter CSB Model. .................68

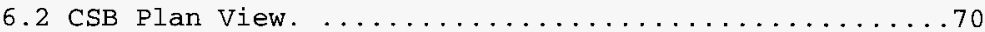

6.3 CSB Nodalization Detail - Inlet End. . . . . . . . . 71

6.4 CSB Nodalization Detail - outlet End. ..........72

6.5 New Subchannel Numbers for 30 Degree Sector of $\ldots .74$

6.6 Gap numbers. . . . . . . . . . . . . . . . . . . . . 75

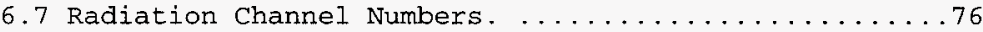

6.8 Mark IV Basket Bottom Plate with Fuel Socket Holes,

Support Pipe, Support Rods, Sheet Metal Shroud,

Mark IV Inner and outer Fuel Elements, MCO, and

Cask. . . . . . . . . . . . . . . . . . . . . . 79

6.9 Mark IV Basket Bottom Plate with Fuel Socket Holes,

Support Pipe, Support Rods, Sheet Metal Shroud,

Mark IV Inner and Outer Fuel Elements, MCO, and

Cask--Zoomed Up......................... 80

6.10 Thermal Conductivity of air, argon, steam versus

Temperature............................ . . . .

6.11 Temperature versus Radial Location ............84

6.12 Vault Inlet and outlet Volumetric Flows. . . . . . .86

6.13 Inlet, Vault and outlet Air Temperatures. ........87

6.14 Temperature Profile in Soil At Bottom of CSB at

Different Times During the Year. ..........87

6.15 Temperature Profile in Soil To Side of CSB at

Different Times During the Year. ............88

6.16 Difference Between Inlet and Outlet Air

Temperatures. ..................... . . . . .

6.17 Velocity vectors In CSB. . . . . . . . . . . . .90

6.18 Temperature Profile in CSB. ..............91

6.19 Difference Between Vault Inlet and Vault outlet

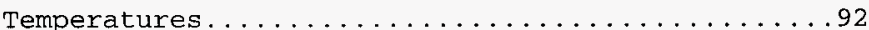

6.20 Vault Inlet and Outlet Volumetric Flows. . . . . . . .93

6.21 Vault Inlet and outlet Air Temperatures. . . . . . .994

6.22 Difference Between Inlet and Outlet Air

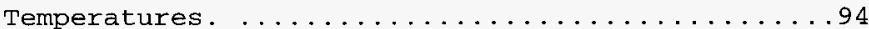

6.23 Vault Inlet and Outlet Volumetric Flow. . . . . . . .95

6.24 Vault Inlet and Outlet Air Temperatures. ........96 
WHC-SD-SNF-ER-014, Rev. 0 .

6.25 Difference Between Inlet and outlet Air

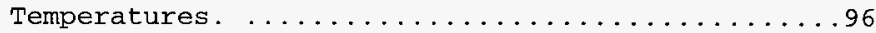

6.26 Inlet and Outlet volumetric Flow. . . . . . . . .97

6.27 Inlet, Vault and outlet Air Temperatures. .......98

6.28 Difference Between Inlet and outlet Air

Temperatures. ..................... . 98

6.29 Diurnal Temperature Variations - Summer of 1994. .103

6.30 Solar Heat Flux on Cask Surface. . . . . . . . . . 103

6.31 MCO Rod and Structure Temperatures For the Top

Rubble Basket During Heat Up With An Air Filled

Gap for a High Powered MCO - No Reactions. .....105

6.32 MCO Rod and structure Temperatures For the top

Rubble Basket During Heat Up with An Air Filled

Gap for a High Powered MCo During A 30 Minute

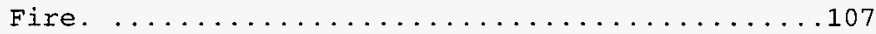

7.1 CSB Diurnal Temperature Variations - Summer of

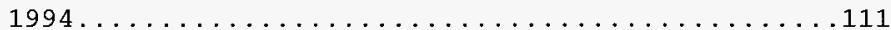

7.2 MCO Rod and Structure Temperatures For the Rubble

Basket Heat Up During Staging in the CSB With

Helium Filled Tube/MCO Gap and MCO and Without Any

Chemical Reactions for a High Powered MCO $(929$

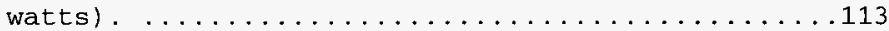

7.3 MCO Pressurization Rates For the Rubble Basket Heat

Up During Staging With Helium Filled Tube/MCO Gap

and $\mathrm{MCO}$ and Without Any Chemical Reactions for a

High Powered MCO (929 watts). . . . . . . . . . . . 114

$7.4 \mathrm{MCO}$ Rod and structure Temperatures For the Rubble

Basket Heat Up During Staging in the CSB With

Helium Filled Tube/MCO Gap and MCO and With

Chemical Reactions Due to the Decomposition of the

Reaction Product Hydrates. $A_{R}=800,000 \mathrm{~cm}^{2}$;

$\mathrm{m}_{\mathrm{RP}}=150 \mathrm{Kg} ; \mathrm{Q}_{\mathrm{DH}}=929$ watts. ..............

7.5 MCO Rod and Structure Temperatures For the Rubble

Basket Heat Up During Staging in the CSB with

Helium Filled Tube/MCO Gap and MCO and With

Chemical Reactions Due to the Decomposition of the

Reaction Product Hydrates. $\mathrm{A}_{\mathrm{R}}=800,000 \mathrm{~cm}^{2}$;

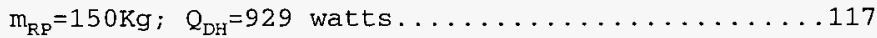




$$
\text { WHC-SD-SNF-ER-014, Rev. } 0 \text {. }
$$

7.7 Hydrogen Gas Volume Fractions in the Rubble Basket For Rubble Basket Heat Up During Staging in the CSB With a Helium Filled Tube/MCO Gap and MCO and with Chemical Reactions Due to the Decomposition of the Reaction Product Hydrates. $\mathrm{A}_{\mathrm{R}}=800,000 \mathrm{~cm}^{2}$; $\mathrm{m}_{\mathrm{RP}}=150 \mathrm{Kg} ; \mathrm{Q}_{\mathrm{DH}}=929$ watts. . . . . . . . . . . 119

$7.8 \mathrm{Fe}_{2} \mathrm{O}_{3} \cdot 3 \mathrm{H}_{2}$ Water Mass in the Rubble Basket For Rubble Basket Heat Up During staging in the CSB With a Helium Filled Tube/MCO Gap and MCO and with Chemical Reactions Due to the Decomposition of the Reaction Product Hydrates.

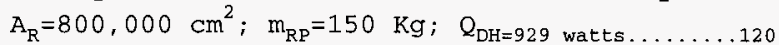

$7.9 \mathrm{Al2O} \cdot 3 \mathrm{H} 2$ Water Mass in the Rubble Basket For Rubble Basket Heat Up During Staging in the CSB With a Helium Filled Tube/MCO Gap and MCO and with Chemical Reactions Due to the Decomposition of the Reaction Product Hydrates. $\mathrm{AR}=800,000 \mathrm{~cm} ; \mathrm{mRP}=150 \mathrm{Kg} ; \mathrm{QDH}=929$ watts $\ldots \ldots 121$

$7.10 \mathrm{UO} 3.2 \mathrm{H} 2$ Water Mass in the Rubble Basket

For Rubble Basket Heat Up During Staging in the CSB With a Helium Filled Tube/MCO Gap and MCO and with Chemical Reactions Due to the Decomposition of ${ }_{2}$ the Reaction Product Hydrates. $A R=800,000$ $\mathrm{Cm} ; \mathrm{mRP}=150 \mathrm{Kg} ; \mathrm{QDH}=929$ watts. .............

7.11 MCO Rod and Structure Temperatures For the Rubble

Basket Heat Up During staging in the CSB With Helium Filled Tube/MCO Gap and MCO and With Chemical Reactions Due to the Decomposition of the Reaction Product Hydrates. $\mathrm{AR}=80,000 \mathrm{~cm}$; $\mathrm{mRP}=150 \mathrm{Kg} ; \mathrm{QDH}=750$ watts..................

$7.12 \mathrm{MCO}$ Rod and structure Temperatures For the Rubble Basket Heat Up During staging in the CSB with Helium Filled Tube/MCO Gap and MCO and With Chemical Reactions Due to the Decomposition of the Reaction Product Hydrates. $A R=80,000 \mathrm{~cm}^{2}$; $\mathrm{mRP}=150 \mathrm{Kg} ; \mathrm{QDH}=750$ watts ............... 
WHC-SD-SNF-ER-014, Rev . 0 .

7.14 Hydrogen Gas Volume Fractions in the Rubble Basket For Rubble Basket Heat Up During Staging in the CSB with a Helium Filled Tube/MCO Gap and MCO and with Chemical Reactions Due to the Decomposition of the Reaction Product Hydrates. $A_{R}=80,000$ $\mathrm{cm}^{2} ; \mathrm{m}_{\mathrm{RP}}=150 \mathrm{Kg} ; \mathrm{Q}_{\mathrm{DH}}=750$ watts. . . . . . . . 127

$7.15 \mathrm{Fe}_{2} \mathrm{O}_{3} \cdot 3 \mathrm{H}_{2}$ water Mass in the Rubble Basket For Rubble Basket Heat Up During Staging in the CSB with a Helium Filled Tube/MCO Gap and MCO and with Chemical Reactions Due to the Decomposition of the Reaction Product Hydrates. $A_{R}=80,000 \mathrm{~cm}^{2} ; m_{R P}=150 \mathrm{Kg} ; Q_{D H}=750$ watts. $\ldots \ldots 128$

$7.16 \mathrm{Al}_{2} \mathrm{O}_{3} \cdot 3 \mathrm{H}_{2}$ Water Mass in the Rubble Basket For Rubble Basket Heat Up During Staging in the CSB With a Helium Filled Tube/MCO Gap and MCO and with Chemical Reactions Due to the Decomposition of the Reaction Product Hydrates. $A_{\mathrm{R}}=80,000 \mathrm{~cm}^{2} ; \mathrm{m}_{\mathrm{RP}}=150 \mathrm{Kg} ; \mathrm{Q}_{\mathrm{DH}}=750$ watts. . . . 129

$7.17 \mathrm{JO}_{3} \cdot 2 \mathrm{H}_{2}$ Water Mass in the Rubble Basket For Rubble Basket Heat Up During Staging in the CSB with a Helium Filled Tube/MCO Gap and MCO and with Chemical Reactions Due to the Decomposition of the Reaction Product Hydrates. ............. 130

$7.18 \mathrm{MCO}$ Rod and structure Temperatures For the Rubble Basket Heat Up During staging in the CSB with Helium Filled Tube/MCO Gap and MCO and With Chemical Reactions Due to the Decomposition of the Reaction Product Hydrates. $A_{R}=80,000 \mathrm{~cm}^{2}$;

$\mathrm{m}_{\mathrm{RP}}=70 \mathrm{Kg} ; \mathrm{Q}_{\mathrm{DH}}=750$ watts. . . . . . . . . . . 132

7.19 MCO Rod and Structure Temperatures For the Rubble Basket Heat Up During staging in the CSB with Helium Filled Tube/MCO Gap and MCO and With Chemical Reactions Due to the Decomposition of the Reaction Product Hydrates. $A_{R}=80,000 \mathrm{~cm}^{2}$;

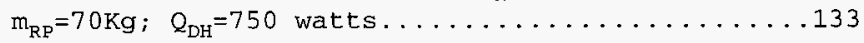


7.21 Hydrogen Gas Volume Fractions in the Rubble Basket For Rubble Basket Heat Up During Staging in the CSB With a Helium Filled Tube/MCO Gap and MCO and with Chemical Reactions Due to the Decomposition of the Reaction Product Hydrates. $A_{R}=80,000$

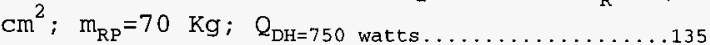

7.22 Axial Hydrogen Volume Fraction Distribution at the

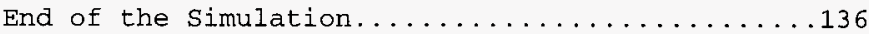

$7.23 \mathrm{Fe}^{2} \mathrm{O} 3 \cdot 3 \mathrm{H}^{2}$ Water Mass in the Rubble Basket For Rubble Basket Heat Up During staging in the CSB with a Helium Filled Tube/MCO Gap and MCO and with Chemical Reactions Due to the Decomposition of the Reaction Product Hydrates. $\mathrm{AR}=80,000 \mathrm{~cm} ; \mathrm{mRP}=70 \mathrm{Kg} ; \mathrm{QDH}=750$ watts......137

$7.24 \mathrm{Al2O} \cdot 3 \mathrm{H} 2$ Water Mass in the Rubble Basket For Rubble Basket Heat Up During Staging in the CSB with a Helium Filled Tube/MCO Gap and MCO and with Chemical Reactions Due to the Decomposition of the Reaction Product Hydrates. $\mathrm{AR}=80,000 \mathrm{~cm} ; \mathrm{mRP}=70 \mathrm{Kg} ; \mathrm{QDH}=750$ watts $\ldots \ldots \ldots 138$

$7.25 \mathrm{UO} 32 \mathrm{H} 2$ Water Mass in the Rubble Basket For Rubble Basket Heat Up During Staging in the CSB With a Helium Filled Tube/MCO Gap and MCO and with Chemical Reactions Due to the Decomposition of the Reaction Product Hydrates. $A R=80,000$ $\mathrm{cm} ; \mathrm{mRP}=70 \mathrm{Kg} ; \mathrm{QDH}=750$ watts ................

7.26 MCO Rod and Structure Temperatures For the Rubble Basket Heat Up During staging in the CSB with Helium Filled Tube/MCO Gap and MCO and With Chemical Reactions Due to the Decomposition of the Reaction Product Hydrates. Ar $=57,000 \mathrm{~cm}$; $\mathrm{mRP}=70 \mathrm{Kg} ; \mathrm{QDH}=750$ watts. .............. 140

7.27 MCO Rod and Structure Temperatures For the Rubble Basket Heat Up During Staging in the CSB with Helium Filled Tube/MCO Gap and MCO and with Chemical Reactions Due to the Decomposition of the Reaction Product Hydrates. $A R=80,000 \mathrm{~cm}^{2}$; $\mathrm{mRP}=16 \mathrm{Kg} ; \mathrm{QDH}=750$ watts............... 141 


$$
\text { WHC-SD-SNF-ER-014, Rev. } 0 \text {. }
$$

7.29 MCO Pressurization Rates for the Rubble Basket Heat Up During Staging in the CSB with Helium Filled Tube/MCO Gap and MCO and with Chemical Reactions Due to the Decomposition of the Reaction Product Hydrates. $A_{R}=80,000 \mathrm{~cm}^{2} ; m_{R P}=16 \mathrm{Kg}$; $\mathrm{Q}_{\mathrm{DH}}=750$ watts.

7.30 Hydrogen Gas Volume Fractions in the Rubble Basket For Rubble Basket Heat Up During Staging in the CSB With a Helium Filled Tube/MCO Gap and MCO and with Chemical Reactions Due to the Decomposition of the Reaction Product Hydrates. $A_{R}=80,000$ $\mathrm{cm}^{2} ; \mathrm{m}_{\mathrm{RP}}=16 \mathrm{Kg} ; \mathrm{Q}_{\mathrm{DH}}=750$ watts $\ldots \ldots \ldots 144$

$7.31 \mathrm{Fe}_{2} \mathrm{O}_{3} \cdot 3 \mathrm{H}_{2}$ Water Mass in the Rubble

Basket For Rubble Basket Heat Up During staging in the CSB With a Helium Filled Tube/MCO Gap and MCO and with Chemical Reactions Due to the Decomposition of the Reaction Product Hydrates. $A_{R}=80,000 \mathrm{~cm}^{2} ; m_{R P}=16 \mathrm{Kg} ; Q_{D H}=750$ watts. $\ldots \ldots \ldots 145$

$7.32 \mathrm{Al}_{2} \mathrm{O}_{3} \cdot 3 \mathrm{H}_{2}$ Water Mass in the Rubble

Basket For Rubble Basket Heat Up During staging in the CSB with a Helium Filled Tube/MCO Gap and MCO and with Chemical Reactions Due to the Decomposition of the Reaction Product Hydrates. $A_{R}=80,000 \mathrm{~cm}^{2} ; m_{\mathrm{RP}}=16 \mathrm{Kg} ; Q_{\mathrm{DH}}=750$ watts. $\ldots \ldots \ldots 146$

$7.33 \mathrm{UO}_{3} \cdot 2 \mathrm{H}_{2}$ Water Mass in the Rubble Basket

For Rubble Basket Heat Up During Staging in the CSB With a Helium Filled Tube/MCO Gap and MCO and with Chemical Reactions Due to the Decomposition of the Reaction Product Hydrates. $A_{R}=80,000$ $\mathrm{cm}^{2} ; \mathrm{m}_{\mathrm{RP}}=16 \mathrm{Kg} ; Q_{\mathrm{DH}}=750$ watts. ...........

7.34 MCO Pressure During Interim Storage Assuming $16 \mathrm{Kg}$ of Oxidation Products Containing $1 \%$ Residual

water.

7.35 MCO Hydrogen Concentration During Interim Storage Assuming $16 \mathrm{~kg}$ of Oxidation Products Containing 18

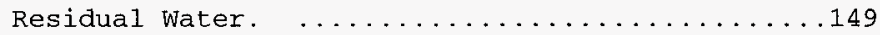

7.36 MCO Rod and Structure Temperatures For the Second Basket From the Bottom During Heat Up With Air Filled Gap for a High Powered MCO. ...........152 
7.37 MCO Pressurization for Nominal Transport From Basin to CVDF with $0.55 \mathrm{~m}^{3}$ gas space in $\mathrm{MCO}$ and

Oxygen Free water Reaction with $800,000 \mathrm{~cm}^{2}$

Rubble Basket Reaction Area and 5 inches of

Damaged Fuel on each Fuel Rod...............153

7.38 MCO Hydrogen Gas Space Concentration for Nominal

Transport From Basin to CVDF with $0.55 \mathrm{~m}^{3}$ gas

space in MCO and Oxygen Free water Reaction with

$800,000 \mathrm{~cm}^{2}$ Rubble Basket Reaction Area and 5

inches of Damaged Fuel on each Fuel Rod........154

7.39 MCO Rod and Structure Temperatures For the top

Rubble Basket During Heat Up With An Air Filled

Gap for a High Powered MCO During A 30 Minute

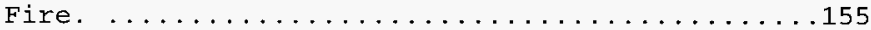

7.40 MCO Pressurization for a Design Basis Fire Fo $r$

Shipping From The Basin to CVDF with $0.55 \mathrm{~m}^{3}$

gas space in MCO and Oxygen Free water Reaction

with $800,000 \mathrm{~cm}^{2}$ Rubble Basket Reaction Area

and 5 inches of Damaged Fuel on each Fuel Rod...156

7.41 MCO Hydrogen Gas Space Concentration for a Design

Basis Fire For Shipping From the Basin to CVDF with $0.55 \mathrm{~m}^{3}$ gas space in $\mathrm{MCO}$ and Oxygen Free

Water Reaction with $800,000 \mathrm{~cm}^{2}$ Rubble Basket

Reaction Area and 5 inches of Damaged Fuel on each

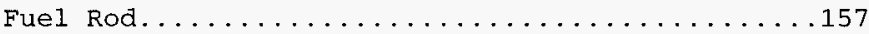

7.42 MCO Rod and structure Temperatures For the Rubble

Basket Heat Up During Transport From the CVDF to

the CSB With Helium Filled Cask/MCO Gap and MCO

and Without Any Chemical Reactions ...........160

7.43 MCO Pressurization Rates For the Rubble Basket

Heat Up During Transport From the CVDF to the CSB

With Helium Filled Cask/MCO Gap and MCO and

Without Any Chemical Reactions ..............161

7.44 MCO Rod and Structure Temperatures For the Rubble

Basket Heat Up During Transport From the CVDF to

the CSB With Helium Filled Cask/MCO Gap and MCO

and With Chemical Reactions Due to the

Decomposition of the Reaction Product Hydrates.

$A_{R}=800,000 \mathrm{~cm}^{2} ; m_{R P}=150 \mathrm{Kg} ; Q_{D H}=926$ watts $\ldots \ldots 163$ 


$$
\text { WHC-SD-SNF-ER-014, Rev. } 0 \text {. }
$$

7.45 MCO Rod and Structure Temperatures For the Rubble Basket Heat Up During Transport From the CVDF to the CSB With Helium Filled Cask/MCO Gap and MCO and with Chemical Reactions Due to the

Decomposition of the Reaction Product Hydrates.

$\mathrm{A}_{\mathrm{R}}=800,000 \mathrm{~cm}^{2} ; \mathrm{m}_{\mathrm{RP}}=150 \mathrm{Kg} ; \mathrm{Q}_{\mathrm{DH}}=929$ watts $\ldots \ldots \ldots 164$

7.46 MCO Pressurization Rates for the Rubble Basket Heat

Up During Transport From the CVDF to the CSB with

Helium Filled Cask/MCO Gap and MCO and with

Chemical Reactions Due to the Decomposition of the

Reaction Product Hydrates. $A_{R}=800,000 \mathrm{~cm}^{2}$;

$\mathrm{I}_{\mathrm{RP}}=150 \mathrm{Kg} ; \mathrm{Q}_{\mathrm{DH}}=929$ watts. . . . . . . . . . . .

7.47 Hydrogen Gas Volume Fractions in the Rubble Basket

For Rubble Basket Heat Up During Transport From

the CVDF to the CSB With a Helium Filled Cask/MCO

Gap and MCO and with Chemical Reactions Due to the

Decomposition of the Reaction Product Hydrates.

$A_{R}=800,000 \mathrm{~cm}^{2} ; m_{R P}=150 \mathrm{Kg} ; Q_{D H}=929$ watts. .....166

$7.48 \mathrm{Fe}_{2} \mathrm{O}_{3} \cdot 3 \mathrm{H}_{2}$ Water Mass in the Rubble

Basket For Rubble Basket Heat Up During Transport

From the CVDF to the CSB With a Helium Filled

Cask/MCO Gap and MCO and with Chemical Reactions

Due to the Decomposition of the Reaction Product

Hydrates. $\mathrm{A}_{\mathrm{R}}=800,000 \mathrm{~cm}^{2}$;

$\mathrm{m}_{\mathrm{RP}}=150 \mathrm{Kg} ; Q_{\mathrm{DH}}=929$ watts.

$7.49 \mathrm{Al}_{2} \mathrm{O}_{3} \cdot 3 \mathrm{H}_{2}$ Water Mass in the Rubble

Basket For Rubble Basket Heat Up During Transport

From the CVDF to the CSB With a Helium Filled

Cask/MCO Gap and MCO and with Chemical Reactions

Due to the Decomposition of the Reaction Product

Hydrates. $\mathrm{A}_{\mathrm{R}}=800,000 \mathrm{~cm}^{2}$;

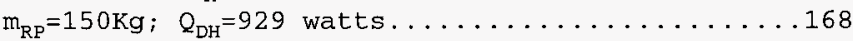

$7.50 \mathrm{UO}_{3} \cdot 2 \mathrm{H}_{2}$ water Mass in the Rubble Basket

For Rubble Basket Heat Up During Transport From

the CVDF to the CSB With a Helium Filled Cask/MCO

Gap and MCO and with Chemical Reactions Due to the

Decomposition of the Reaction Product Hydrates.

$A_{R}=800,000 \mathrm{~cm}^{2} 1 ; m_{R P}=150 \mathrm{Kg} ; Q_{D H}=929$ watts $\ldots \ldots 169$ 
7.52 MCO Rod and Structure Temperatures For the Rubble Basket Heat Up During Transport From the CVDF to the CSB With Helium Filled Cask/MCO Gap and MCO and with Chemical Reactions Due to the Decomposition of the Reaction Product Hydrates $A_{R}=800,000 \mathrm{~cm}^{2} ; m_{R P}=150 \mathrm{Kg} ; Q_{D H}=750$ watts $\ldots \ldots .171$

7.53 MCO Pressurization Rates for the Rubble Basket Heat

Up During Transport From the CVDF to the CSB With Helium Filled Cask/MCO Gap and MCO and with Chemical Reactions Due to the Decomposition of the Reaction Product Hydrates. $A_{R}=800,000 \mathrm{~cm}^{2}$; $m_{\mathrm{RP}}=150 \mathrm{Kg} ; \mathrm{Q}_{\mathrm{DH}}=750$ watts................

7.54 Hydrogen Gas Volume Fractions in the Rubble Basket For Rubble Basket Heat Up During Transport From the CVDF to the CSB With a Helium Filled Cask/MCO Gap and MCO and with Chemical Reactions Due to the Decomposition of the Reaction Product Hydrates. $\mathrm{A}_{\mathrm{R}}=800,000 \mathrm{~cm}^{2} ; \mathrm{m}_{\mathrm{RP}}=150 \mathrm{Kg} ; Q_{\mathrm{DH}}=750$ watts. . . . .

$7.55 \mathrm{Fe}_{2} \mathrm{O}_{3} \cdot 3 \mathrm{H}_{2}$ Water Mass in the Rubble

Basket For Rubble Basket Heat Up During Transport From the CVDF to the CSB With a Helium Filled Cask/MCO Gap and MCO and with Chemical Reactions Due to the Decomposition of the Reaction Product Hydrates. $A_{R}=800,000 \mathrm{~cm}^{2}$;

$\mathrm{m}_{\mathrm{RP}}=150 \mathrm{Kg} ; \mathrm{Q}_{\mathrm{DH}}=750$ watts.

$7.56 \mathrm{Al}_{2} \mathrm{O}_{3} \cdot 3 \mathrm{H}_{2}$ Water Mass in the Rubble

Basket For Rubble Basket Heat Up During Transport From the CVDF to the CSB With a Helium Filled Cask/MCO Gap and MCO and with Chemical Reactions Due to the Decomposition of the Reaction Product Hydrates. $\mathrm{A}_{\mathrm{R}}=800,000 \mathrm{~cm}^{2}$;

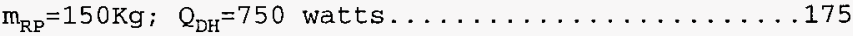

$7.57 \mathrm{UO}_{3} \cdot 2 \mathrm{H}_{2}$ Water Mass in the Rubble Basket

For Rubble Basket Heat Up During Transport From the CVDF to the CSB With a Helium Filled Cask/MCO Gap and MCO and with Chemical Reactions Due to the Decomposition of the Reaction Product Hydrates. $A_{\mathrm{R}}=800,000 \mathrm{~cm}^{2} ; \mathrm{m}_{\mathrm{RP}}=150 \mathrm{Kg} ; \mathrm{Q}_{\mathrm{DH}}=750$ watts $\ldots \ldots 176$ 


$$
\text { WHC-SD-SNF-ER-014, Rev. } 0 \text {. }
$$

7.59 MCO Pressurization Rates for the Rubble Basket Heat Up During Transport From the CVDF to the CSB with Helium Filled Cask/MCO Gap and MCO and with Chemical Reactions Due to the Decomposition of the Reaction Product Hydrates. $A_{R}=80,000 \mathrm{~cm}^{2}$;

$\mathrm{m}_{\mathrm{RP}}=150 \mathrm{Kg} ; \mathrm{Q}_{\mathrm{DH}}=750$ watts ...............

7.60 Hydrogen Gas Volume Fractions in the Rubble Basket

For Rubble Basket Heat Up During Transport From the CVDF to the CSB With a Helium Filled Cask/MCO Gap and MCO and with Chemical Reactions Due to the Decomposition of the Reaction Product Hydrates.

$A_{R}=80,000 \mathrm{~cm}^{2} ; m_{R P}=150 \mathrm{Kg} ; Q_{D H}=750$ watts. $\ldots \ldots 180$

$7.61 \mathrm{Fe}_{2} \mathrm{O}_{3} \cdot 3 \mathrm{H}_{2}$ water Mass in the Rubble

Basket For Rubble Basket Heat Up During Transport

From the CVDF to the CSB with a Helium Filled

Cask/MCO Gap and MCO and with Chemical Reactions Due to the Decomposition of the Reaction Product Hydrates. $A_{R}=80,000 \mathrm{~cm}^{2}$;

$\mathrm{m}_{\mathrm{RP}}=150 \mathrm{Kg} ; \mathrm{Q}_{\mathrm{DH}}=750$ watts $\ldots \ldots \ldots \ldots \ldots \ldots \ldots \ldots \ldots \ldots \ldots \ldots$

$7.62 \mathrm{Al}_{2} \mathrm{O}_{3} \cdot 3 \mathrm{H}_{2}$ Water Mass in the Rubble

Basket For Rubble Basket Heat Up During Transport

From the CVDF to the CSB with a Helium Filled

Cask/MCO Gap and MCO and with Chemical Reactions

Due to the Decomposition of the Reaction Product

Hydrates. $A_{R}=80,000 \mathrm{~cm}^{2}$;

$\mathrm{m}_{\mathrm{RP}}=150 \mathrm{Kg} ; \mathrm{Q}_{\mathrm{DH}}=750$ watts. . . . . . . . . . .

$7.63 \mathrm{UO}_{3} \cdot 2 \mathrm{H}_{2}$ Water Mass in the Rubble Basket

For Rubble Basket Heat Up During Transport From

the CVDF to the CSB With a Helium Filled Cask/MCO

Gap and MCO and with Chemical Reactions Due to the

Decomposition of the Reaction Product Hydrates.

$\mathrm{A}_{\mathrm{R}}=80,000 \mathrm{~cm}^{2} ; \mathrm{m}_{\mathrm{RP}}=150 \mathrm{Kg} ; \mathrm{Q}_{\mathrm{DH}}=750$ watts. . . . . .

7.64 MCO Rod and structure Temperatures For the Rubble

Basket Heat Up During Transport From the CVDF to

the CSB With Helium Filled Cask/MCO Gap and MCO

and With Chemical Reactions Due to the

Decomposition of the Reaction Product Hydrates.

$A_{R}=80,000 \mathrm{~cm}^{2} ; m_{R P}=16 \mathrm{Kg} ; Q_{D H}=750$ watts . . . . 


$$
\text { WHC-SD-SNF-ER-014, Rev. } 0 \text {. }
$$

7.66 Hydrogen Gas Volume Fractions in the Rubble Basket For Rubble Basket Heat Up During Transport From the CVDF to the CSB With a Helium Filled Cask/MCO Gap and MCO and with Chemical Reactions Due to the Decomposition of the Reaction Product Hydrates. $A_{R}=80,000 \mathrm{~cm}^{2} ; m_{R F}=16 \mathrm{Kg} ; Q_{D H}=750$ watts $\ldots \ldots \ldots 187$

$7.67 \mathrm{Fe}_{2} \mathrm{O}_{3} \cdot 3 \mathrm{H}_{2}$ Water Mass in the Rubble

Basket For Rubble Basket Heat Up During Transport From the CVDF to the CSB with a Helium Filled Cask/MCO Gap and MCO and with Chemical Reactions Due to the Decomposition of the Reaction Product Hydrates. $A_{R}=80,000 \mathrm{~cm}^{2}$;

$\mathrm{m}_{\mathrm{RP}}=16 \mathrm{Kg} ; \mathrm{Q}_{\mathrm{DH}}=750$ watts $\ldots \ldots \ldots \ldots \ldots \ldots \ldots \ldots \ldots \ldots \ldots$

$7.68 \mathrm{Al}_{2} \mathrm{O}_{3} \cdot 3 \mathrm{H}_{2}$ Water Mass in the Rubble

Basket For Rubble Basket Heat Up During Transport

From the CVDF to the CSB with a Helium Filled Cask/MCO Gap and MCO and with Chemical Reactions Due to the Decomposition of the Reaction Product Hydrates. $A_{R}=80,000 \mathrm{~cm}^{2}$;

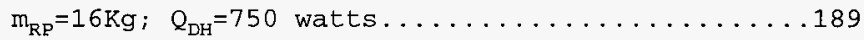

$7.69 \mathrm{UO}_{3} \cdot 2 \mathrm{H}_{2}$ Water Mass in the Rubble Basket

For Rubble Basket Heat Up During Transport From the CVDF to the CSB With a Helium Filled Cask/MCO Gap and MCO and with Chemical Reactions Due to the Decomposition of the Reaction Product Hydrates. $A_{R}=80,000 \mathrm{~cm}^{2} ; m_{R P}=16 \mathrm{Kg} ; Q_{D H}=750$ watts. . . . . . .

7.70 Case 2A - Failure to Drain - 55kg of Water - No Pressure Relief - Oxygen Free - Maximum Powered MCO - MCO Rod and Structure Temperatures for the Top Basket ......................... 192

7.71 Case $2 \mathrm{~A}$ - Failure to Drain - 55kg of Water - No Pressure Relief - Oxygen Free - Maximum Powered MCO - MCO Pressurization Rates. .............193

7.72 Case 2A - Failure To Drain - 55kg of Water - No Pressure Relief - Oxygen Free - Maximum Powered MCO - Hydrogen Gas Volume Fractions in the Top Fuel Basket. . . . . . . . . . . . . . . . . 194

7.73 Maximum MCO Pressure As a Function of Initial water Mass for Two MCO Temperatures..............196 
WHC-SD-SNF-ER-014, Rev . 0 .

7.74 Maximum MCO Pressure As a Function of Initial water

Mass for Two MCO Temperatures............. . 197

8.1 Hydrogen Mass Flow Rate Due To Pearce Oxygen Free

Uranium/Water Reaction Using the Hydrate

Equilibrium Pressures, $A_{R}=80,000 \mathrm{~cm}^{2} \ldots \ldots \ldots \ldots 8$

8.2 Hydrogen Volumetric Flow Rate at 150 psia Due to

Pearce Oxygen Free Uranium/Water Reaction Using

Hydrate Equilibrium Pressures. $A_{R}=80,000 \mathrm{~cm}^{2} \ldots \ldots 199$

8.3 Hydrogen velocity for 1 inch orifice at 150 psia Due

to Pearce Oxygen Free Uranium/Water Reaction Using

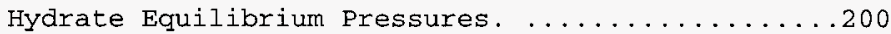

8.4 GOTH Model for MCO Pressure Relief. .............203

8.5 MCO and Tube Pressure with a $1 / 4$ inch Orifice in the

MCO Relief valve and a 1 inch Orifice in the Tube

Relief valve............................204

8.6 Vent Velocities with a $1 / 4$ inch Orifice in the MCO

Relief Valve and a 1 inch Orifice in the Tube

Relief valve............................205

8.7 Tube Pressure with a $1 / 4$ inch orifice in the MCO

Relief valve and a 1 inch Orifice in the Tube

Relief valve.........................206

8.8 Velocity in 1 inch Pipe Upstream of 1/4" MCO Relief

valve............................206

8.9 Helium (solid line) and Hydrogen (dashed line)

Concentrations Storage Tube................207

9.1 Comparison of Heat That Can be Removed Versus Heat

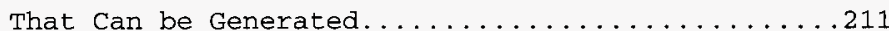

9.2 Maximum MCO Pressure As a Function of Initial Water

Mass for Two MCO Temperatures................213 


$$
\text { WHC-SD-SNF-ER-014, Rev, } 0 \text {. }
$$

\section{SUMMARY}

The purpose of the work presented in this report is to develop models capable of simulating the thermal and chemical processes that may result in the pressurization of the Multi-Canister-Overpack vessel (MCO) in which the spent nuclear fuel from the $K$ basins is to be stored.

Pressurization of the MCO may occur as the result of gases generated from various sources. The major sources of gas are:

1. Hydrogen generated from the reaction of residual bulk water or water vapor with uranium metal.

2. Hydrogen and oxygen generated from the radiolysis of surface bound water.

3. Fission product gases released from the metal as a result of corrosion.

4. Hydrogen generated as the result of hydride decomposition.

5. Hydrogen generated from the uranium reaction with water released from metal hydrates that may exist on the surface of the fuel.

All of these sources of gas have been considered in this evaluation with the exception of the fission gas release due to corrosion. This source of gas is considered to be small relative to the uncertainties in the other gas sources and can be ignored in the present analysis. Also, the gas generation rates from all sources are small compared to the gas generation rate due to the uranium/ 
WHC-SD-SNF-ER-014, Rev. 0 .

water reaction and can essentially be ignored for the MCO storage and transportation temperature ranges (assuming, of course, that a uranium/water reaction temperature excursion has not occured that will increase fuel temperatures to the point that hydride decomposition will be accelerated).

MCO pressurization is an issue during all stages of MCO processing and transport. These include transport from the basins to the Cold Vacuum Drying Facility (CVDF), cold vacuum drying, transport from the CVDF to the Canister storage Building (CSB), stageing in the CSB, hot conditioning and interim storage in the CSB. The cold and hot vacuum conditioning processes are assumed to be vented via the vacuum system or bounded by other cases in this evaluation and have not been explicitly treated in this study with the exception of the failure to drain transient during cold vacuum drying which has been considered.

Results of the evaluation show that, if the reaction area is sufficiently large and if there is sufficient water present, overpressurization of the MCO will occur within a few hours after a given process is started assuming limiting environmental temperatures and the amount of water that is postulated to be contained in the MCO or on the surface of the fuel in one form or another. The MCO will eventually over pressurize if there is more than 2.95 $\mathrm{kg}$ of water during shipping and more than $2.5 \mathrm{~kg}$ of water during storage in the CSB, based on the oxidation reaction of uranium metal with water and the ideal gas law, assuming that there are no reactions within the MCo that take up hydrogen. Overpressurization will occur with less water if uranium hydride is oxidized due to the additional hydrogen released from the hydride, $\mathrm{UH}_{3}$, during the reaction.

The issue is how long will it take for overpressurization to occur. This depends on the amount of fuel damage there is in the $\mathrm{MCO}$, what the reaction rate equation is and what the fuel temperatures are. Current bounding estimates 


$$
\text { WHC-SD-SNF-ER-014, Rev. } 0 \text {. }
$$

for the reaction area in the worst case MCO and the amount of water in the MCO result in the MCO pressure exceeding the MCO design pressure in as little as 15 hours during transport from the basin to the CVDF in the event of a design basis fire, in 30 hours for the failure to drain during cold vacuum drying, in 14 hours for shipping to the CSB, and in 5 hours for staging in the CSB. The pressurization of the $\mathrm{MCO}$ during shipping from the basins and in the event of a failure to drain the MCo during vacuum drying are driven by the large remaining volume of water and will require venting or some action to be taken to mitigate the conditions that lead to pressurization. Care must be taken to assure that sufficient gas volume is present in the MCO for shipping from the basins to assure even the short transportation times supported by the present analysis.

Temperature excursions can be eliminated during shipping from the CVDF to the CSB if it can be shown that the true reaction area within an $\mathrm{MCO}$ is less than $80,000 \mathrm{~cm} 2$ and that local hot spots do not develop in the fuel. Peak temperatures resulting from temperature excursions can be minimized if it can be shown that the amount of water that can react with the uranium is small. Temperature excursions will occur during staging in the CSB for all reaction areas considered in this study but can be limited if it is shown that the amount of water present in the MCO during staging is small. The peak temperature for all cases considered is not expected to be much over $1000^{\circ} \mathrm{F}$, although this will require additional analysis to assure that this is the case.

A summary of the key parameters and the results from the current evaluation are summarized in the following table.

There is an uncertainty in the application of the existing uranium/water reaction correlations to the decomposition rate of the metallic hydrates in addition to the rather wide scatter in the uranium/water reaction data 


$$
\text { WHC-SD-SNF-ER-014, Rev. } 0 \text {. }
$$

on which the existing correlations are based. It must be shown that the amount of uranium reactive surface area that is in an $\mathrm{MCO}$ is sufficiently low to assure that the fuel temperatures will be in the stable temperature range, effects of local reaction area concentrations and uncertainties included, if one wishes to avoid temperature excursions in the fuel. It is possible that temperature excursions are acceptable if it is shown that either 1) the amount of water in the MCO is not sufficient to cause the pressure or temperature limits of the MCO or fuel to be exceeded or 2) the MCO has a pressure relief device sized to handle the maximum flows expected during the water reaction history and it can be shown the fuel temperatures enter a stable region as the reaction rate levels off at higher temperatures and the radiant heat rejection rate increases. This second option is acceptable if temperature stability occurs at an acceptably low temperature. There are indications in the present analysis that this will be the case but additional analysis is required before this conclusion can be reached. 
WHC-SD-SNF-ER-014, Rev. 0 .

Table 1.1 Sumary of Key Parameters and Results for simulation Cases considered.

\begin{tabular}{|c|c|c|c|c|c|c|c|c|c|c|}
\hline $\begin{array}{l}\text { Case } \\
\text { No. }\end{array}$ & Transient Description & $\begin{array}{l}\text { Decay } \\
\text { Heat } \\
\text { (watts) }\end{array}$ & $\begin{array}{l}\text { Corrosion } \\
\text { Product } \\
\text { Mass (kg) }\end{array}$ & $\begin{array}{c}\text { Residual } \\
\text { Water Mass } \\
\text { Fraction } \\
\text { (8) }\end{array}$ & $\begin{array}{c}\text { Scrap } \\
\text { Basket } \\
\text { Reaction } \\
\text { Area, } \mathrm{cm}^{2}\end{array}$ & $\begin{array}{r}\text { Time } \\
(t)\end{array}$ & $\begin{array}{l}\text { Pressure } \\
\text { At time, t } \\
\text { (psia) }\end{array}$ & $\begin{array}{c}\text { Peak } \\
\text { Pressure } \\
\text { (psia) }\end{array}$ & $\begin{array}{c}\text { Peak } \\
\text { Temperature } \\
\left({ }^{\circ} \mathrm{F}\right)\end{array}$ & $\begin{array}{c}\text { Peak } \\
\mathrm{H}_{2} \text { Volume } \\
\text { Fraction } \\
\text { (z) }\end{array}$ \\
\hline $1 \mathrm{~A}$ & Interim storage (Bounding Case & 929 & 300 & 1.5 & 800,000 & & & & & \\
\hline $1 B$ & Interim storage (high nominal) & 929 & 16 & 1.0 & 800,000 & $75 \mathrm{yr}$ & 25 & 25 & $<300$ & 35 \\
\hline $2 \mathrm{~A}$ & Staging (Bounding case) & 929 & 150 & 6 & 800,000 & $5 \mathrm{hr}$ & 140 & 320 & $>950$ & $>91$ \\
\hline $2 \mathrm{~B}$ & staging (parametric case) & 750 & 150 & 6 & 80,000 & $18 \mathrm{hr}$ & 200 & 320 & $>1000$ & $>91$ \\
\hline $2 \mathrm{C}$ & Staging (High nominal case) & 750 & 70 & 6 & 80,000 & $18 \mathrm{hr}$ & 200 & 200 & $>850$ & $>91$ \\
\hline $2 \mathrm{D}$ & staging (parametric case) & 750 & 70 & 6 & 57,000 & $22 \mathrm{hr}$ & 165 & 200 & 800 & $>91$ \\
\hline $2 \mathrm{E}$ & Staging (parametric case) & 750 & 16 & 6 & 80,000 & $18 \mathrm{hr}$ & 70 & 70 & 480 & $<80$ \\
\hline $3 \mathrm{~A}$ & Shipping to CSB (Bounding case) & 929 & 150 & 6 & 800,000 & $14 \mathrm{hr}$ & 100 & 320 & $>850$ & $>91$ \\
\hline $3 \mathrm{~B}$ & Shipping to CSB (high nominal & 750 & 150 & 6 & 80.000 & $90 \mathrm{hr}$ & 55 & 320 & 210 & 75 \\
\hline $3 \mathrm{C}$ & Shipping to CSB (parametric) & 750 & 16 & 6 & 80,000 & $110 \mathrm{hr}$ & 60 & 60 & 210 & 75 \\
\hline $4 \mathrm{~A}$ & Failure to Drain water at CVDF & 929 & 150 & $55 \mathrm{~kg}$ & 800,000 & $30 \mathrm{hr}$ & 130 & $\gg 150$ & 320 & $>91$ \\
\hline $5 \mathrm{~A}$ & Transport from Basin to CVDF & 929 & 150 & flooded & 800,000 & $30 \mathrm{hr}$ & 85 & $>>150$ & NC & $>91$ \\
\hline $5 B$ & Transport Fire Basin to CVDF & 929 & 150 & flooded & 800,000 & $15 \mathrm{hr}$ & 100 & $\gg 150$ & NC & $>91$ \\
\hline
\end{tabular}


WHC-SD-SNF-ER-014, Rev. 0 .

The ability of the MCO to reject heat in the CSB storage tube is even poorer than in the transportation cask because 1) the CSB environment is at a higher temperature, 2) the tube surface area is smaller than the surface area of the cask and therefore has less ability to reject heat and 3 ) the storage tube is surrounded by other storage tubes that are at essentially the same temperature so heat rejection due to thermal radiation is minimized. Therefore, one can expect temperature excursions to occur for even lower reaction areas in the CSB. This means that the amount of water present the MCO when it reaches the CSB must be minimized to prevent temperature excursions in the fuel.

The stable operating range at low temperatures is shown in Figure 1.1. The chemical heat rejection capability of the $\mathrm{MCO} / \mathrm{cask}$ system for transportation is shown by the straight lines in the figure. There are two such lines shown, one for the conservative (minimum) estimate and one for the best estimate rate. The curved lines in the figure represent the chemical heat generation rates resulting from the water/uranium reaction for two different reaction areas, $80,000 \mathrm{~cm}^{2}$ and $800,000 \mathrm{~cm}^{2}$ for 1) the minimum steam partial pressure the Pearce rate equations are base on and 2) the $\mathrm{Al}_{2} \mathrm{O}_{3} \cdot 3 \mathrm{H}_{2} \mathrm{O}$ equilibrium pressure. The system is thermally stable in the region where the reaction heat generation curves (parabolic curves in the figure) intersect or fall below the heat rejection lines. A second stable region likely exists at higher temperatures. Data for this region is currently being generated. 
WHC-SD-SNF-ER-014， Rev. 0.

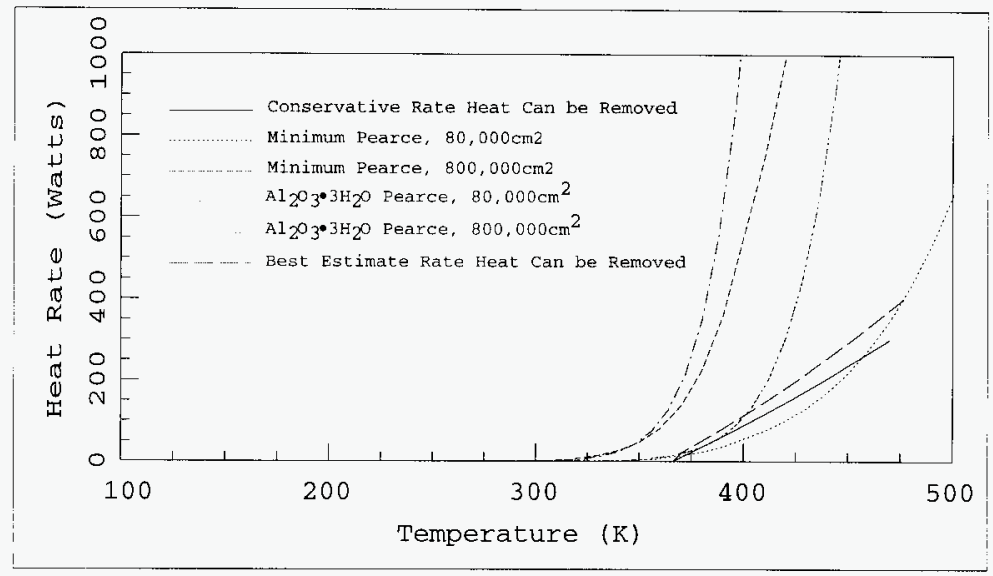

Figure 1.1 Comparison of Heat That Can be Removed Versus Heat That Can be Generated. 
WHC-SD-SNF-ER-014, Rev. 0 .

\section{INTRODUCTION.}

The MCO pressurization study has been undertaken to validate the assumption that the MCO can be sealed during shipping and to assess the feasibility of sealing the MCO's for long term storage and to determine the venting frequency necessary to assure that the MCO pressure limit will not be exceeded.

The pressurization of the MCO will depend on the amount of potentially gas generating material that is in the MCO during each stage of the process, the temperature history of the MCO internals and the reaction rates for the gas generating reactions.

The amount of potentially gas generating material contained within an MCO will depend on the fuel that is placed in the MCO and the amount of corrosion the fuel has undergone.

Some fuel is expected to be corroded and to contain water in the form of free water, weakly bound water in the form

of hydrates and tightly bound water in the form of hydroxides. Most of the eree water is expected to be removed during the cold vacuum drying process, although a design specification amount should be considered to remaing following vacuum drying. Some hydrates will decompose at cold vacuum drying temperatures and pressures. Those that do not completely decompose will continue to decompose during shipping and staging. The hydroxides are expected to decompose due to radiolysis during shipping, staging and interim storage. Hydroxides are not expected to thermally decompose at temperatures the MCO will be subjected to during any of the planned processing, shipping or storage conditions.

Corroded fuel is expected to contain uranium hydride which will decompose to form hydrogen gas. Most of the hydride will remain in the fuel until the fuel goes through 
hot conditioning. Therefore, it is likely that some hydride decomposition will occur during shipping and storage. Some hydride is likely to remain in the fuel during hot conditioning and this will slowly decompose during interim storage.

The evolution of hydrogen gas into the MCO environment as a result the decomposition of any of these sources will result in the build up of pressure inside of the MCO. Thermal transients will result in pressurization of the MCO by both increasing the amount of gas formation due to the release of the waters of corrosion and due to the thermal expansion of the gas within the MCO.

Several studies have been required to evaluate the pressurization of the MCO. These include

1. Operational Analysis: The purpose of this work has been to evaluate the operating, off-normal and low frequency events that the MCO will be subjected to from cold vacuum drying through interim storage to assure that all parameters, effects and conditions that may impact MCO pressurization have been addressed.

2. Environmental Temperature Analysis: The purpose of this work is to evaluate the MCO external environment pertinent to its thermal behavior including the effects of diurnal and seasonal temperature patterns in conjuction with loading and operating sequences.

3. MCO Temperature Modeling: The purpose of this work is to evaluate the internal MCo temperatures during shipping, vacuum drying, staging, hot conditioning and interim storage given externally imposed operational and environmental conditions. The thermal modeling of the MCO includes the effects of all pertinent chemical reactions occuring on the fuel or other material contained within the MCO. 


$$
\text { WHC-SD-SNF-ER-014, Rev . } 0 \text {. }
$$

4. Pressurization Modeling: The purpose of this work is to determine the sources of gas generation and to predict the MCO pressurization history for all phases of shipping, staging and interim storage. This model is implicitly coupled with the MCO temperature and environmental analyses.

5. Supporting Analyses: Several supporting analyses are required to achieve the overall objective encompassed by the above four tasks. These include:

a. Vacuum drying modeling.

b. Reaction rate models.

c. Drying curve analysis.

d. Radiolysis rate analysis.

e. Oxygen gettering and consumption.

f. Monitoring technology.

The results of the combined effort from all of these studies are provided in this report.

\section{OPERATIONAL ANALYSIS.}

Operation analysis has been conducted to determine the operating sequences that the MCO will undergo from cold vacuum drying through interim storage. This analysis includes the evaluation of normal operational events as well as off-normal, design basis accident events and extremely low frequency events. A description of transients pertinent to MCO pressurization is provided in [Ref. 8]. 


\section{SUPPORTING STUDIES.}

Several supporting studies provide input to the models that have been used to determine the MCO internal pressure during the various MCO process steps. Results of these supporting studies that have been used in the model are summarized in this section.

\subsection{CHEMICAL REACTION RATES.}

Chemical reactions for uranium with moist air (oxygenated water reactions), uranium with oxygen free water, uranium with dry air and inert gases with varying oxygen concentrations, dehydriding rates and hydride decomposition rates have been implemented into the MCO Pressurization Model. The relationships for the uranium/water and uranium/ oxygen reactions are based on the recommendations made by Cooper for corrosion of $N$ Reactor fuel, [Ref 4]. The decomposition rate for uranium hydride is based on a restricted document, although the relationship itself is not restricted. The relationships for the decomposition of hydrates is based on work presented in [Ref 1], [Ref 2] and [Ref. 3] and on a methodology developed in the present work.

\subsubsection{Moist Air Equations.}

The Pearce reaction rate equations for moist air are a function of temperature range and relative humidity, RH.

The molecular weight ratio for water and uranium is: 


$$
\text { mwruh2o }:=\frac{2 \cdot 18.016 \frac{1 \mathrm{bm}}{1 \mathrm{bm}-\mathrm{mole}}}{238.03 \frac{1 \mathrm{bm}}{1 \mathrm{bm}-\mathrm{mole}}}=0.1514
$$

The molecular weight ratio for oxygen and uranium is:

$$
\text { mwro2ur }:=\frac{32 \frac{1 \mathrm{bm}}{1 \mathrm{bm}-\mathrm{mole}}}{238.03 \frac{1 \mathrm{bm}}{1 \mathrm{bm}-\mathrm{mole}}}=0.1344
$$

The units for the rate equation are given in terms of $\mathrm{mg}$ of $\mathrm{O}_{2}$ taken up by the Uranium per square centimeter of fuel reaction area per second. This constant, given below, is converted into English units for use in the model.

$$
\mathrm{mlt}:=1 \frac{\mathrm{mg}}{\mathrm{cm}^{2}-\mathrm{hr}}=5.689 \times 10^{-07} \frac{\mathrm{lbm}}{\mathrm{ft}^{2}-\mathrm{s}}
$$

The molecular weight ratio for water and hydrogen is:

$$
\text { mwrh } 2 \mathrm{~h} 20:=\frac{18.016 \frac{1 \mathrm{bm}}{1 \mathrm{bm}-\mathrm{mole}}}{2.016 \frac{1 \mathrm{bm}}{1 \mathrm{bm}-\mathrm{mole}}}=8.937
$$

The molecular weight ratio for $\mathrm{O}_{2}$ and $\mathrm{H}_{2}$ is:

$$
\operatorname{mwrO}_{2} \mathrm{H}_{2}:=\frac{32 \frac{1 \mathrm{bm}}{1 \mathrm{bm}-\mathrm{mole}}}{2 \cdot 2.016 \frac{1 \mathrm{bm}}{1 \mathrm{bm}-\mathrm{mole}}}=7.937
$$

The rate equations for the various ranges of temperature and relative humidity are given by the expressions that follow.

\section{For $\mathrm{T}<373^{\circ} \mathrm{K}$ and $11 \%<\mathrm{RH}<75 \%$ :}

The common logarithm of Reaction rate in terms of $\mathrm{mg}-\mathrm{O}_{2} / \mathrm{cm}^{2}-\mathrm{hr}$ is given by: 
LK1 $(T)=13.6780-\frac{5290.9}{T}$

where the temperature, $\mathrm{T}$, is given in ${ }^{\circ} \mathrm{K}$.

The reaction rate in terms of $\mathrm{mg}-\mathrm{O}_{2} / \mathrm{cm}^{2}-\mathrm{hr}$ :

rratel $(\mathrm{T}):=\mathrm{mlt} \cdot 10^{\mathrm{LKI}}(373 \mathrm{~K})$

The heat of reaction per $\mathrm{kg}$ of uranium is given by:

$\Delta \mathrm{H}_{\mathrm{u}}:=\frac{259300 \frac{\mathrm{cal}}{\mathrm{gm}-\mathrm{mole}}}{238.03 \frac{\mathrm{gm}}{\mathrm{gm}-\mathrm{mole}}}=4.564 \times 10^{+06} \frac{\mathrm{J}}{\mathrm{kg}}$

The heat of reaction in terms of $\mathrm{kg}$ of $\mathrm{O}_{2}$ taken up is given by:

$\Delta \mathrm{H}_{\mathrm{O} 2}:=\Delta \mathrm{H}_{\mathrm{u}} \cdot \frac{238.03 \frac{1 \mathrm{bm}}{1 \mathrm{bm}-\mathrm{mole}}}{32 \frac{\mathrm{lbm}}{1 \mathrm{bm}-\mathrm{mole}}}=3.395 \times 10^{+07} \frac{\mathrm{J}}{\mathrm{kg}}$

The heat of reaction in terms of $1 \mathrm{bm}$ of $\mathrm{O}_{2}$ taken up is given by:

$\Delta \mathrm{H}_{\mathrm{O} 2}=1.46 \times 10^{+04} \frac{\mathrm{Btu}}{1 \mathrm{bm}}$

\section{For $\mathbf{T}<373^{\circ} \mathrm{K}$ and $\mathrm{RH}<100 \%$ :}

The common logarithm of the reaction rate in terms of $\mathrm{mg}-\mathrm{O}_{2} / \mathrm{cm}^{2}-\mathrm{hr}$ :

$\operatorname{LK} 2(T)=8.333-\frac{3730}{T}$

where the temperature, $\mathrm{T}$, is given in ${ }^{\circ} \mathrm{K}$. 


$$
\text { WHC-SD-SNF-ER-014, Rev. } 0 \text {. }
$$

The reaction rate in terms of $\mathrm{mg}-\mathrm{O}_{2} / \mathrm{cm}^{2}-\mathrm{hr}$ is given by:

$$
\text { rrate } 2(T)=\operatorname{mlt} 10^{\mathrm{LK} 2}(\mathrm{~T})
$$

\section{For $373^{\circ} \mathrm{K}<\mathrm{T}<463^{\circ} \mathrm{K}$ and $\mathrm{RH}<100 \%$ :}

The common logarithm of the reaction rate in terms of $\mathrm{mg}-\mathrm{O}_{2} / \mathrm{cm}^{2}-\mathrm{hr}$ is given by:

$\operatorname{LK} 3(T, P)=10.566-\frac{4990}{T}+0.3 \log _{10}(P)$

where the temperature, $\mathrm{T}$, is given in ${ }^{\circ} \mathrm{K}$ and the pressure, $\mathrm{P}$, is given in units of $\mathrm{kPa}$.

The reaction rate in terms of $\mathrm{mg}-\mathrm{O}_{2} / \mathrm{cm}^{2}-\mathrm{hr}$ is given by:

$$
\text { rrate } 3(T, P)=\operatorname{mlt} 10^{\operatorname{LK} 3}(\mathrm{~T}, \mathrm{P})
$$

For $\mathrm{T}>463^{\circ} \mathrm{K}$ and $\mathrm{RH}<100 \%$ :

The common logarithm of reaction rate in terms of $\mathrm{mg}-\mathrm{O}_{2} / \mathrm{cm}^{2}-\mathrm{hr}$ :

$\operatorname{LK} 4(T, P)=6.1931-\frac{2963}{T}+0.3 \log _{10}(P)$

where the temperature, $\mathrm{T}$, is given in ${ }^{\circ} \mathrm{K}$ and the pressure, $\mathrm{P}$, is given in $\mathrm{kPa}$.

The reaction rate in terms of $\mathrm{mg}-\mathrm{O}_{2} / \mathrm{cm}^{2}-\mathrm{hr}$ is given by:

rrate $4(\mathrm{~T}, \mathrm{P})=\operatorname{mlt} 10^{\mathrm{LK} 4}(\mathrm{~T}, \mathrm{P})$ 


$$
\text { WHC-SD-SNF-ER-014, Rev. } 0 .
$$

\subsubsection{Oxygen Free Water Vapor.}

The correlations for the reaction of uranium with oxygen free water vapor are given below for the various ranges of temperature and relative humidity.

For $\mathrm{T}<373^{\circ} \mathrm{K}$ RH $<=100 \%$

The common logarithm of reaction rate in terms of $\mathrm{mg}-\mathrm{O}_{2} / \mathrm{cm}^{2}-\mathrm{hr}$ is given by:

LK5 $(\mathrm{T})=7.364-\frac{3016}{\mathrm{~T}}$

where the temperture, $\mathrm{T}$, is given in ${ }^{\circ} \mathrm{K}$.

The reaction rate in terms of $\mathrm{mg}-\mathrm{O}_{2} / \mathrm{cm}^{2}-\mathrm{hr}$ is given by:

$$
\text { rrates }(\mathrm{T})=\mathrm{mlt} 10^{\mathrm{LK} 5}(\mathrm{~T})
$$

\section{For $\mathrm{T}<523^{\circ} \mathrm{K}$ and $\mathrm{RH}<100 \%$ :}

The common logarithm of reaction rate in terms of $\mathrm{mg}-\mathrm{O}_{2} / \mathrm{cm}^{2}-\mathrm{hr}$ is given by:

$\operatorname{LK} 6(T, P)=4.33-\frac{2144}{T}+0.5 \log _{10}(P)$

where the temerature, $\mathrm{T}$, is given in ${ }^{\circ} \mathrm{K}$ and the pressure, $\mathrm{P}$, is given in $\mathrm{kPa}$.

The reaction rate in terms of $\mathrm{mg}-\mathrm{O}_{2} / \mathrm{cm}^{2}-\mathrm{hr}$ is given by:

$\operatorname{rrate} 6(T, P)=\operatorname{mlt} 10^{\operatorname{LK} 6}(\mathrm{~T}, \mathrm{P})$

\section{For $523^{\circ} \mathrm{K}<\mathrm{T}<735^{\circ} \mathrm{K}$ and $43-93 \mathrm{kPa} \mathrm{H}_{2} \mathrm{O}$ :}

The common logarithm of reaction rate in terms of $\mathrm{mg}-\mathrm{O}_{2} / \mathrm{cm}^{2}-\mathrm{hr}$ is given by: 
$\operatorname{LK7}(T)=-22.915417+\frac{30066.5}{T}-\frac{9.119078 \times 10^{6}}{T^{2}}$

where the temperature, $\mathrm{T}$, is given in ${ }^{\circ} \mathrm{K}$.

The reaction rate in terms of $\mathrm{mg}-\mathrm{O}_{2} / \mathrm{cm}^{2}-\mathrm{hr}$ is given by:

rrate $(\mathrm{T})=\operatorname{mlt} 10^{\mathrm{LK} 7}(\mathrm{~T})$

\section{For $735^{\circ} \mathrm{K}<\mathrm{T}<923^{\circ} \mathrm{K}$ and $43-93 \mathrm{kPa} \mathrm{H}_{2} \mathrm{O}$ :}

The common logarithm of reaction rate in terms of $\mathrm{mg}-\mathrm{O}_{2} / \mathrm{cm}^{2}-\mathrm{hr}$ is given by:

$\operatorname{LK} 8(T)=-23.905197+\frac{42718.8}{T}-\frac{1.787581 \times 10^{7}}{T^{2}}$

The reaction rate in terms of $\mathrm{mg}-\mathrm{O}_{2} / \mathrm{cm}^{2}-\mathrm{hr}$ is given by:

$\operatorname{rrate} 8(\mathrm{~T})=\operatorname{mlt} 10^{\mathrm{LK} 8}(\mathrm{~T})$

\subsubsection{Uranium Oxidation (Oxygen in Dry Air).}

Several relationships for the reaction of uranium metal with the oxygen in dry air are available. However, no relationships have been found in the literature for the reaction of uranium with oxygen in inert gases for oxygen concentrations that are lower than the concentration of oxygen in air. The reaction rate at varying concentrations of oxygen is important for MCO pressurization and fuel conditioning as this determines the effectiveness of oxygen gettering that will take place within the MCo. This effects the MCO pressure, the flammable mixture of hydrogen and oxygen and the efficiency with which the fuel is passivated during hot conditioning. 


$$
\text { WHC-SD-SNF-ER-014, Rev . } 0 \text {. }
$$

While no reaction rate relationships for variable oxygen concentration have been found, Ritchie reports data for variable oxygen concentration [Ref 5]. This data has been fit by cooper. The current work has fit a modified form of Ritchie's equation for dry air to Cooper's fit of Ritchie's data for variable oxygen concentration to obtain a relationship for the oxidation reaction of uranium as a function of the oxygen concentration. This modified Ritchie equation is the equation that is actually used in the integrated Mco model.

\subsubsection{Ritchie Equation for Uranium In Dry Air.}

The rate equations for the reaction of uranium in ary air are reported in [Ref 5] and [Ref 6]. The rate equation and parameters that enter into the rate equation are provided below.

Density of Uranium:

$$
\rho_{\mathrm{u}}:=0.680 \frac{\mathrm{lbm}}{\mathrm{in}^{3}}=1.882 \times 10^{+04} \frac{\mathrm{kg}}{\mathrm{m}^{3}}
$$

Reaction rate in terms of $\mathrm{mg}$ of $\mathrm{U} / \mathrm{cm}^{2}-\mathrm{hr}$ :

$$
k=6.9 \times 10^{8} e^{\frac{-18300}{R T}}
$$

where the temperature, $\mathrm{T}$, is given in ${ }^{\circ} \mathrm{K}$ and

$$
\mathrm{R}=1.986 \frac{\mathrm{cal}}{\mathrm{gm}-\mathrm{mole}-\mathrm{K}}
$$

The activation energy for the reaction of uranium with oxygen is:

$$
E=\frac{-18300 \frac{\mathrm{cal}}{\mathrm{gm}-\mathrm{mole}}}{\mathrm{R}}=-9215 \mathrm{~K}
$$


where the negative sign indicates that the reaction is exothermic.

The reaction rate in terms of $\mathrm{mg}$ of $\mathrm{U} / \mathrm{cm}^{2}-\mathrm{hr}$ is given by:

$$
\begin{aligned}
& \text { A }:=6.9 \times 10^{8} \frac{\mathrm{mg}}{\mathrm{cm}^{2}-\mathrm{hr}}=1917 \frac{\mathrm{kg}}{\mathrm{m}^{2}-\mathrm{s}} \\
& \text { rdauq }_{\mathrm{r}}(\mathrm{T})=\mathrm{A} \mathrm{e}^{\frac{-9214.50}{\mathrm{~T}}} \\
& \text { where the temperture, } \mathrm{T} \text {, is given in }{ }^{\circ} \mathrm{K} .
\end{aligned}
$$

The heat of reaction per $\mathrm{kg}$ of uranium reacted is:

$$
\Delta \mathrm{H}_{\mathrm{u}}:=\frac{259300 \frac{\mathrm{cal}}{\mathrm{gm}-\mathrm{mole}}}{238.03 \frac{\mathrm{gm}}{\mathrm{gm}-\mathrm{mole}}}=4.564 \times 10^{+06} \frac{\mathrm{J}}{\mathrm{kg}}
$$

The reaction rate in terms of $\mathrm{kg}$ of $\mathrm{O}_{2} / \mathrm{m}^{2}-\mathrm{s}$ is given by:

$$
\begin{aligned}
& \mathrm{A}_{\mathrm{O}}:=6.9 \times 10^{8} \frac{\mathrm{mg}}{\mathrm{cm}^{2}-\mathrm{hr}} \cdot \frac{32 \frac{\mathrm{lbm}}{\mathrm{lbm}-\mathrm{mole}}}{238.03 \frac{1 \mathrm{bm}}{1 \mathrm{bm}-\mathrm{mole}}}=257.7 \frac{\mathrm{kg}}{\mathrm{m}^{2}-\mathrm{s}} \\
& \operatorname{rdaoq}_{r}(\mathrm{~T})=\mathrm{A}_{O} \mathrm{e} T \mathrm{~T}
\end{aligned}
$$

where the temperature, $\mathrm{T}$, is given in ${ }^{\circ} \mathrm{K}$ and the rate constant, $A_{O}$, in english units is.

$$
A_{O}=52.78 \frac{1 \mathrm{bm}}{\mathrm{ft}-\mathrm{s}}
$$

The heat of reaction in terms of $\mathrm{kg}$ of $\mathrm{O}_{2}$ consumed is: 
WHC-SD-SNF-ER-014, Rev. 0 .

$$
\Delta \mathrm{H}_{\mathrm{O}_{2}}:=\Delta \mathrm{H}_{\mathrm{u}} \cdot \frac{238.03 \frac{\mathrm{lbm}}{\frac{1 \mathrm{bm}-\mathrm{mole}}{1 \mathrm{lbm}}}}{32 \frac{\mathrm{bm}-\mathrm{mole}}{1 \mathrm{~b}}}=3.39510^{+07} \frac{\mathrm{J}}{\mathrm{kg}}
$$

4.1.3.2. Pearce Equation for Dry Air.

The rate equations for the reaction of uranium in dry air developed by Pearce are presented in [Ref 7].

The common logarithm of the reaction rate in terms of $\mathrm{mg}-\mathrm{O}_{2} / \mathrm{cm}^{2}-\mathrm{hr}$ is given by:

$$
\text { LKA }(T)=8.9464-\frac{4638.2}{T}
$$

for temperatures less than $597^{\circ} \mathrm{K}$, where the temperature, $\mathrm{T}$, is given in ${ }^{\circ} \mathrm{K}$. The reaction rate for temperatures greater than $597^{\circ} \mathrm{K}$ is given by:

$$
\operatorname{LKB}(T)=28.381-7 \log _{10}(T)-\frac{4638.2}{T}
$$

The rate equation for the reaction of uranium in dry air developed by Ritchie is:

$$
\operatorname{LKC}(T)=7.968-\frac{4000}{T}
$$

where the temperature, $\mathrm{T}$, is given in ${ }^{\circ} \mathrm{K}$.

The reaction rates for the two temperature ranges given by Pearce and that given by Ritchie in terms of the mass of oxygen reacted is given by the following expressions:

$$
\begin{aligned}
& \text { rratea }(\mathrm{T}):=1 \frac{\mathrm{mg}}{\mathrm{cm}^{2}-\mathrm{hr}} \cdot 10^{\mathrm{LKA}}(\mathrm{T}) \\
& \text { rrateb }(\mathrm{T}):=1 \frac{\mathrm{mg}}{\mathrm{cm}^{2}-\mathrm{hr}} \cdot 10^{\text {LKB }(\mathrm{T})}
\end{aligned}
$$




$$
\begin{aligned}
& \text { rrated }(\mathrm{T}):=\min (\text { rratea }(\mathrm{T}) \text {, rrateb }(\mathrm{T})) \\
& \operatorname{rratec}(\mathrm{T}):=1 \frac{\mathrm{mg}}{\mathrm{cm}^{2}-\mathrm{hr}} \cdot 10^{\mathrm{LKC}}(\mathrm{T})
\end{aligned}
$$

The Pearce and Ritchie rate equations for the reaction of uranium in dry air are presented, for reference in the following figure. The Ritchie equation is conservative from an energy generation view point in that it predicts a higher reaction rate at lower temperatures. However, it is non-conservative relative to the Pearce equation from an oxygen gettering view point in that it assumes that oxygen is consumed more easily at lower temperatures. Since only Richie provides data for the reaction of oxygen at different concentrations with uranium, the Ritchie equation is used as the basis for the oxygen reaction rate in the MCo pressurization model. Development of this model for varying concentrations of oxygen in the MCO atmosphere is presented in the following section.

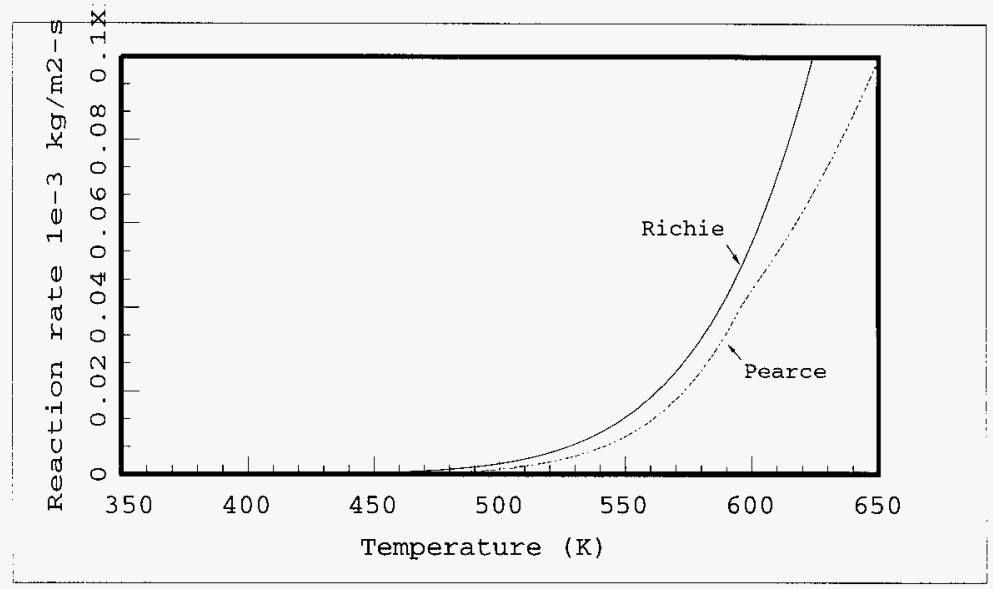

Figure 4.1 Reaction Rate in Dry Air versus Temperature. 
4.1.3.3. Ritchie Equation Modified for Variable Concentration of oxygen.

The reaction rate constant, $A_{0}$, in equation 4.33 has been derived for the oxygen concentration in air. The mass fraction of oxygen in air is:

$$
\mathrm{m}_{\mathrm{f}} \mathrm{O}_{2} \mathrm{AIR}:=0.23143
$$

This equation is not a function of oxygen concentration, so we assume that the equation is based on data taken from tests in which an unlimited supply of fresh air with the above oxygen concentration is available and the equation is not valid for a gas mixture with a changing concentration of oxygen or for other components of the gas mixture that are different than those for aix. However, since no other information is currently available, we make the assumption that the reaction rate is a function of the molar concentration of oxygen in the gas mixture and that this effect is contained in the reaction rate constant coefficient, $A_{0}$ which, based on reaction rate kinetics must be equal to the frequency factor A times the molar concentration of the reacting gases, $\mathrm{C}_{\mathrm{N}}{ }^{\mathrm{n}}$. The rate equation for a simple irreversible reaction is:

$$
-r_{A}=k C_{A}^{a} C_{B}^{b} \ldots C_{N}^{n}
$$

The proportionality constant $\mathrm{k}$ in Equation 4.45 is the specific reaction rate, or rate constant, which is markedly dependent upon temperature. The order of the reaction, in terms of the individual reacting components, is equal to the molecularity of the reaction only for elementary reactions. The temperature dependency of the rate expression, Equation 4.45, is usually represented by the rate constant through the Arrhenius equation:

$$
k=A e^{\frac{-E}{R T}}
$$

In this equation, $\mathrm{A}$ is called the frequency factor and has 
the same units as $\mathrm{k}$ in Equation 4.45. $\mathrm{E}$ is the activation energy and is considered by Arrhenius as the amount of energy in excess of the average energy level the reactants must have in order for the reaction to proceed. Combining equations 4.45 and 4.46 gives:

$$
-r_{A}=A e^{\frac{-E}{R T}} C_{A}{ }^{a} C_{B}{ }^{b} \ldots C_{N}{ }^{n}
$$

The Ritchie rate equation, Equation 4.33 , has a similar form to equation 4.47 if we assume that:

$$
\mathrm{A}_{\mathrm{O}}=\mathrm{A}^{-}{ }^{-} \mathrm{C}_{\mathrm{O} 2}{ }^{-} \mathrm{n}
$$

The molar concentration of $\mathrm{O}_{2}$ is equal to the partial density of $\mathrm{O}_{2}$ divided by the molecular weight of $\mathrm{O}_{2}$,

$$
[\mathrm{C}]=\frac{\rho_{\mathrm{O} 2}}{\mathrm{M}_{\mathrm{O} 2}}=\mathrm{mf}_{\mathrm{O} 2} \frac{\rho_{\mathrm{m}}}{\mathrm{M}_{\mathrm{O}} 2}
$$

where:

$$
\begin{aligned}
& \rho_{\mathrm{O} 2}=\text { partial density of oxygen } \\
& \mathrm{M}_{\mathrm{O} 2}=\text { molecular weight of oxygen } \\
& \mathrm{mf}_{\mathrm{O} 2}=\text { mass fraction of oxygen in mixture } \\
& \rho_{\mathrm{m}}=\text { density of gas mixture }
\end{aligned}
$$

Once the frequency factor is known, then the reaction rate constant for any concentration of oxygen in air or any other carrier gas can be determined if it is assumed that the carrier gas itself has no effect on the reaction rate and that the ideal chemical kinetics of reacting gases holds true. The new reaction rate constant coefficient is determined as follows. The frequency factor is: 


$$
A=\frac{A_{O}}{\left(\frac{m f_{O 2 A}}{M_{O} 2} \rho_{A}\right)^{n}}
$$

where,

$$
\begin{aligned}
& \mathrm{mf}_{\mathrm{O} 2 \mathrm{~A}}=\text { mass fraction of oxygen in air }=0.23143 . \\
& \rho_{\mathrm{A}}=\operatorname{air} \text { density }
\end{aligned}
$$

but

$$
\rho_{\mathrm{A}}=\frac{\mathrm{P}}{\mathrm{R}_{\mathrm{A}} \mathrm{T}}
$$

where:

$$
\begin{aligned}
& \mathrm{P}=\text { total pressure } \\
& \mathrm{T}=\text { gas temperature } \\
& \mathrm{R}_{\mathrm{A}}=\text { gas constant for air }
\end{aligned}
$$

so

$$
A=\frac{A_{O}}{\left(\frac{m f_{02 A} P}{M_{O 2} R_{A} T}\right)^{n}}
$$

The frequency factor is then multiplied by the oxygen concentration of $\mathrm{O}_{2}$ in the gas mixture of concern to obtain the new reaction rate constant for the gas mixture:

$$
A_{O m} f=A\left[C_{O 2}\right]=A_{O} \frac{\left(\frac{m_{O 2} P}{M_{O 2} R_{m} T}\right)^{n}}{\left(\frac{m f_{O 2 A} P}{M_{O 2} R_{A} T}\right)^{n}}=A_{O}\left(\frac{m f_{O 2} R_{A}}{m f_{O 2 A} R_{m}}\right)^{n}
$$


where:

$\mathrm{mf}_{\mathrm{O} 2}=$ mass fraction of $\mathrm{O}_{2}$ in the gas mixture of concern.

$\mathrm{R}_{\mathrm{M}}=$ gas constant for gas mixture of concern.

$\mathrm{n}=$ order of the reaction with respect to $\mathrm{O}_{2}$.

Comparison with available data from Ritchie for the reaction rate versus oxygen concentration suggests that the exponent, $\mathrm{n}$, should have a value of 0.77 , Figures 4.1 through 4.7 .

The new reaction rate for uranium in terms of $\mathrm{kg}$ of $\mathrm{O}_{2}$ reacted is then:

$$
A_{O m f}\left(R_{m}, m f_{O 2}\right):=A_{\circ} \cdot\left(\frac{m f_{O 2}}{m_{f} O_{2} A I R} \cdot \frac{53.34 \frac{f t-l b f}{1 b m-R}}{R_{m}}\right)^{.77}
$$

The reaction rate for any carrier gas is then given by:

$$
\operatorname{rdaomfq}_{r}\left(T, \mathrm{mf}_{\mathrm{O} 2}, \mathrm{R}_{\mathrm{m}}\right)=\mathrm{A}_{\mathrm{O} \mathrm{f}}\left(\mathrm{R}_{\mathrm{m}}, \mathrm{mf}_{\mathrm{O} 2}\right) \mathrm{e}^{\frac{-9214.50}{\mathrm{~T}}}
$$

where the temperature, $\mathrm{T}$, is in ${ }^{\circ} \mathrm{K}$.

The reaction rate of oxygen, in $\mathrm{kg}-\mathrm{O}_{2} / \mathrm{s}$, is:

$$
\text { rrate } \mathrm{O}_{2}\left(\mathrm{~T}, \mathrm{mf}_{\mathrm{O} 2}, \mathrm{R}_{\mathrm{m}} \text {, Area }, \mathrm{SAE}\right):=\text { rdaomfq }_{\mathrm{r}}\left(\mathrm{T}, \mathrm{mf}_{\mathrm{O} 2}, \mathrm{R}_{\mathrm{m}}\right) \cdot \text { Area } \cdot \mathrm{SAE}
$$

where Area is the geometric reaction surface area and SAE is the surface area enhancement factor that accounts for effects of corrosion, irradiation ect to give the true reactive surface area. 


$$
\text { WHC-SD-SNF-ER-014, Rev. } 0 \text {. }
$$

The heat generated by the reaction is:

$$
\mathrm{q}_{\circ 2}\left(\mathrm{~T}, \mathrm{mf}_{\mathrm{O} 2}, \mathrm{R}_{\mathrm{m}}, \text { Area }, \mathrm{SAE}\right):=\text { rrate }_{\mathrm{o} 2}\left(\mathrm{~T}, \mathrm{mf}_{\mathrm{O} 2}, \mathrm{R}_{\mathrm{m}}, \text { Area }, \mathrm{SAE}\right) \cdot \Delta \mathrm{H}_{\mathrm{O} 2}
$$

\subsubsection{Cooper's Equation for Dry Air with Oxygen.}

Thurman Cooper has performed a fit to the available Ritchie data for varying concentrations of oxygen in dry air. This data covers a temperature range of $150^{\circ} \mathrm{C}$ to $200^{\circ} \mathrm{C}$ and an oxygen pressure range of 6 to 240 Torr $(0.116$ to 4.641 psi). Cooper's fit to the data is given below. The reaction rate in terms of $\mathrm{mg}$ of $\mathrm{O}_{2}$ consumed per $\mathrm{cm}^{2}$ per hour is given by:

$$
\text { rratee }(T, P)=\frac{M_{O 2}}{M_{U}} \frac{P}{((A 3 T-A 2) T+A 1)+P((B 3 T-B 2) T+B 1)}
$$

where:

$$
\begin{aligned}
& \mathrm{A} 1:=1220.600867715301531 \\
& \mathrm{~A} 2:=5.043238477414361324 \frac{1}{\mathrm{~K}} \\
& \mathrm{~A} 3:=0.005225640143162579997 \frac{1}{\mathrm{~K}^{2}} \\
& \mathrm{~B} 1:=318.5838806616339302 \\
& \mathrm{~B} 2:=1.346635168586668193 \frac{1}{\mathrm{~K}} \\
& \mathrm{~B} 3:=0.001423997666666668257 \quad \frac{1}{\mathrm{~K}^{2}} \\
& \mathrm{~T} \text { is the temperature in }{ }^{\circ} \mathrm{K} . \\
& \mathrm{M}_{\mathrm{O} 2} \text { is the molecular weight of oxygen gas. } \\
& \mathrm{M}_{\mathrm{U}} \text { is the molecular weight of uranium. }
\end{aligned}
$$




$$
\text { WHC-SD-SNF-ER-014, Rev. } 0 .
$$

A comparison of the modified Ritchie equation, Equation 5.44 with Cooper's fit to the Ritchie data is shown in the following figures for various concentrations of $\mathrm{O}_{2}$. The reasonable comparison with the Cooper fit to Ritchie's data over the temperature range that Ritchie's data has been taken suggests that the model is approriate. The modified Ritchie equation is used in the MCO pressurization model as it can be used to extrapolate to higher temperatures than the limited range to which the cooper fit can be used.

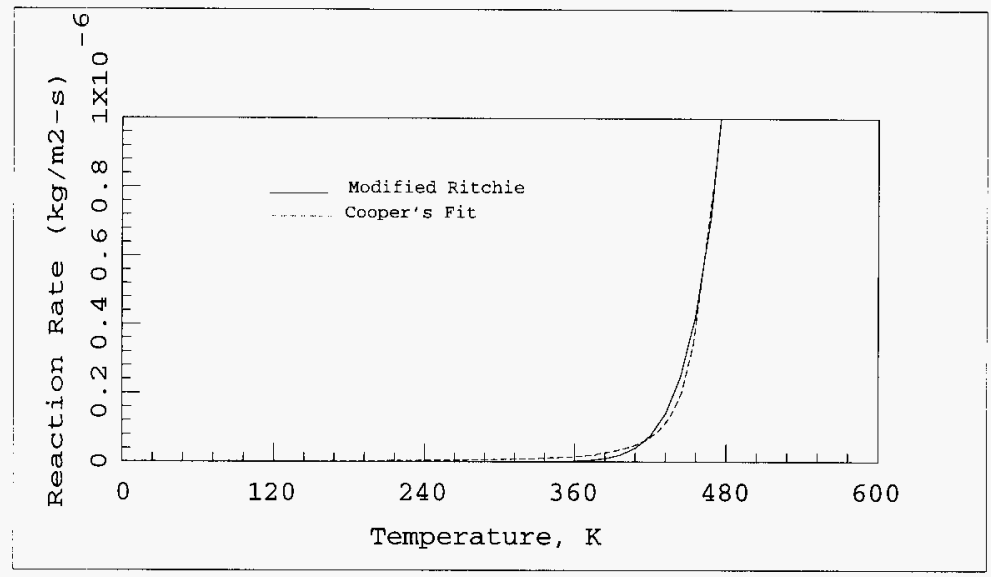

Figure 4.2 Comparison of Modified Ritchie Equation and Cooper's Equation for Dry Air, $\mathrm{mf}_{\mathrm{O} 2}=0.2323$, $\mathrm{vf}_{\mathrm{O} 2}=0.2095, \mathrm{P}_{\mathrm{O} 2}=3.0793 \mathrm{psi}$. 
WHC-SD-SNF-ER-014, Rev. 0 .

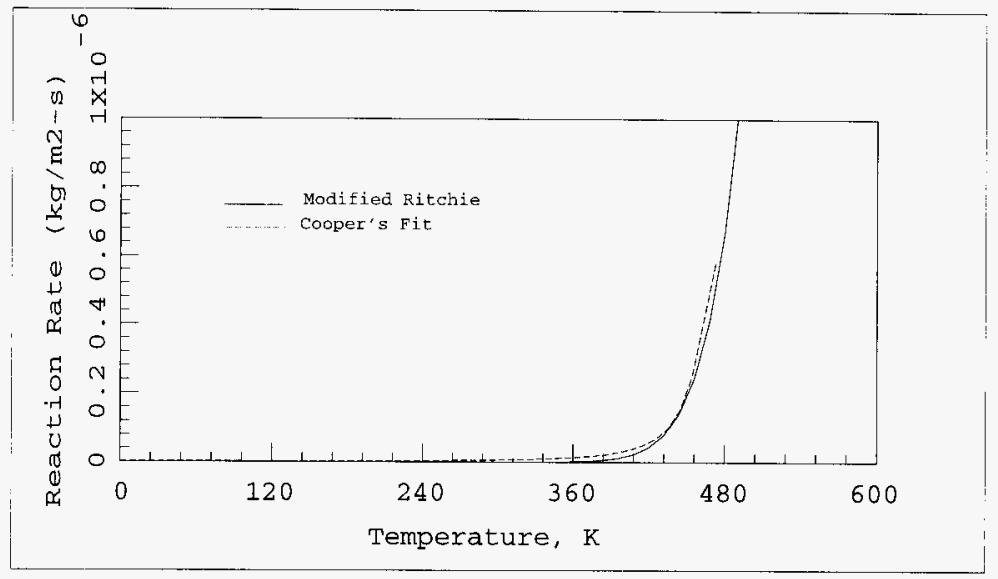

Figure 4.3 Comparison of Modified Ritchie Equation and Cooper's Equation, $\mathrm{mf}_{\mathrm{O} 2}=0.1126, \mathrm{vf}_{\mathrm{O} 2}=0.10$, $\mathrm{P}_{\mathrm{O} 2}=1.47 \mathrm{psi}$. 
WHC-SD-SNF-ER-014, Rev. 0 .

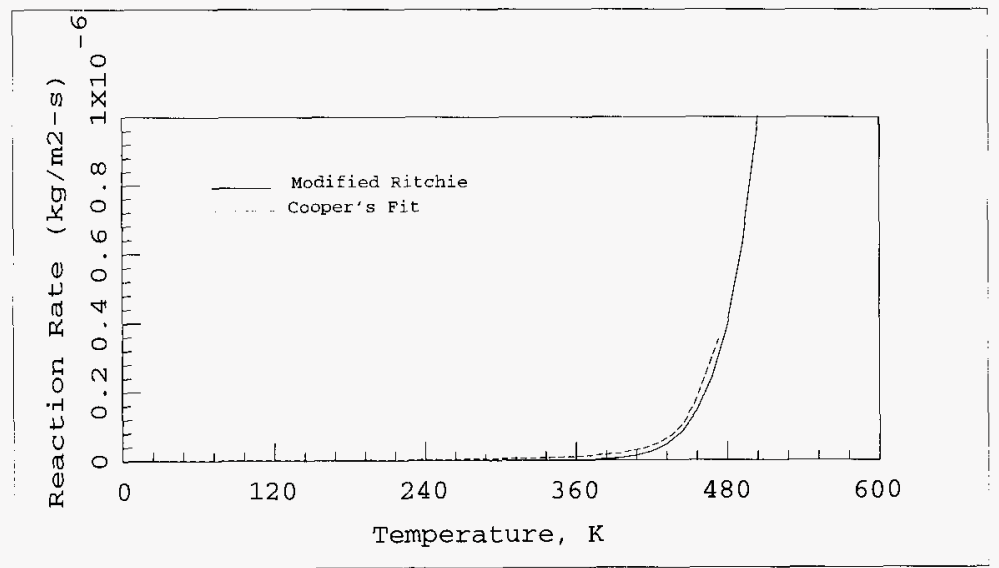

Figure 4.4 Comparison of Modified Ritchie Equation and Cooper's Equation, $\mathrm{mf}_{\mathrm{O} 2}=0.0567, \mathrm{vf}_{\mathrm{O} 2}=0.05$, $\mathrm{P}_{\mathrm{o} 2}=0.735 \mathrm{psi}$. 
WHC-SD-SNF-ER-014, Rev. 0 .

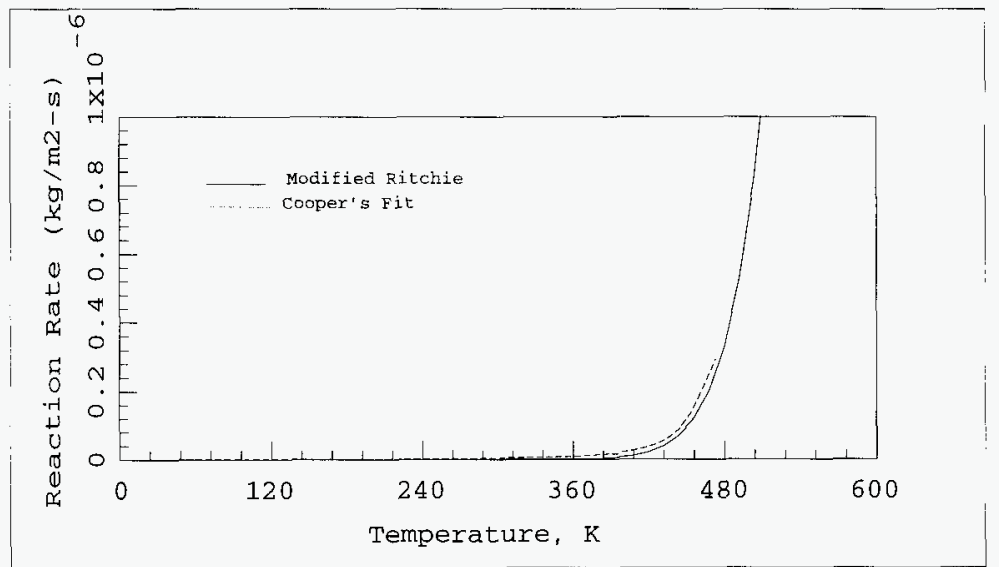

Figure 4.5 Comparison of Modified Ritchie Equation and Cooper's Equation, $\mathrm{mf}_{\mathrm{O} 2}=0.0454, \mathrm{vf}_{\mathrm{O} 2}=0.04$, $\mathrm{P}_{\mathrm{O} 2}=0.588 \mathrm{psi}$. 
WHC-SD-SNF-ER-014, Rev. 0 .

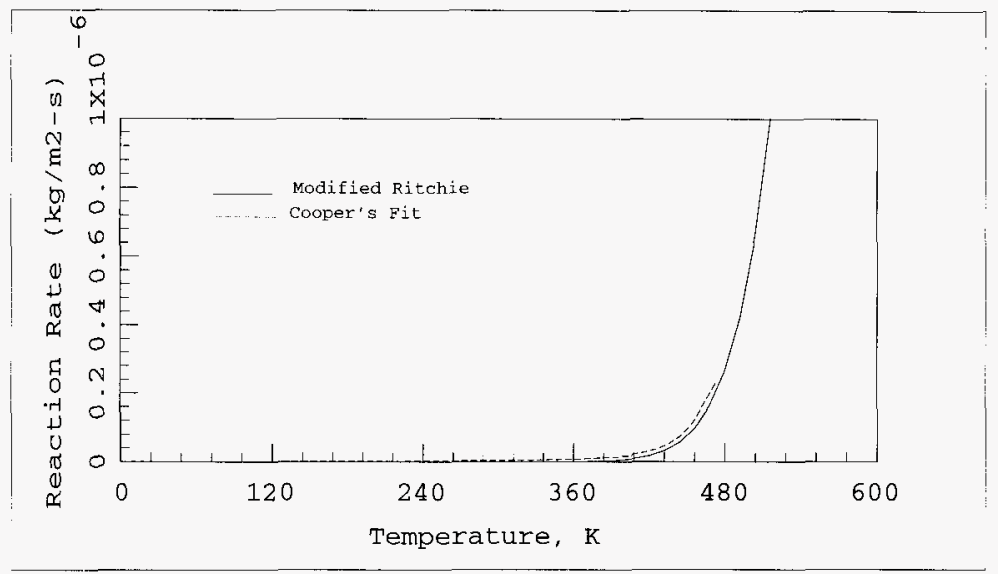

Figure 4.6 Comparison of Modified Ritchie Equation and Cooper's Equation, $\mathrm{mf}_{\mathrm{O} 2}=0.0341, \mathrm{vf}_{\mathrm{O} 2}=0.03$, $\mathrm{P}_{\mathrm{O} 2}=0.4410 \mathrm{psi}$. 
WHC-SD-SNF-ER-014, Rev. 0 .

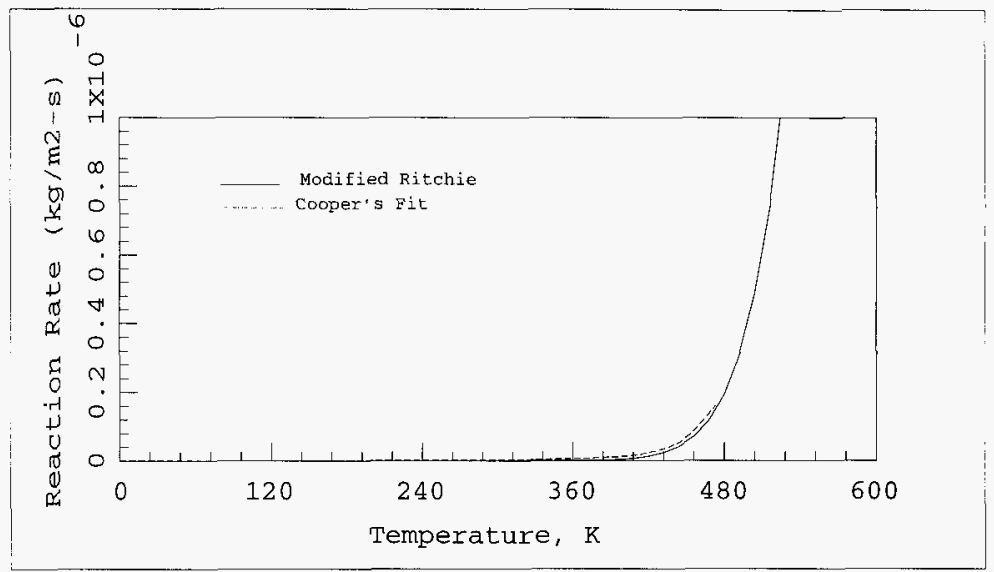

Figure 4.7 Comparison of Modified Ritchie Equation and Cooper's Equation, $\mathrm{mf}_{\mathrm{O} 2}=0.0228, \mathrm{vf}_{\mathrm{O} 2}=0.02$, $\mathrm{P}_{\mathrm{O} 2}=0.294 \mathrm{psi}$. 
WHC-SD-SNF-ER-014, Rev. 0.

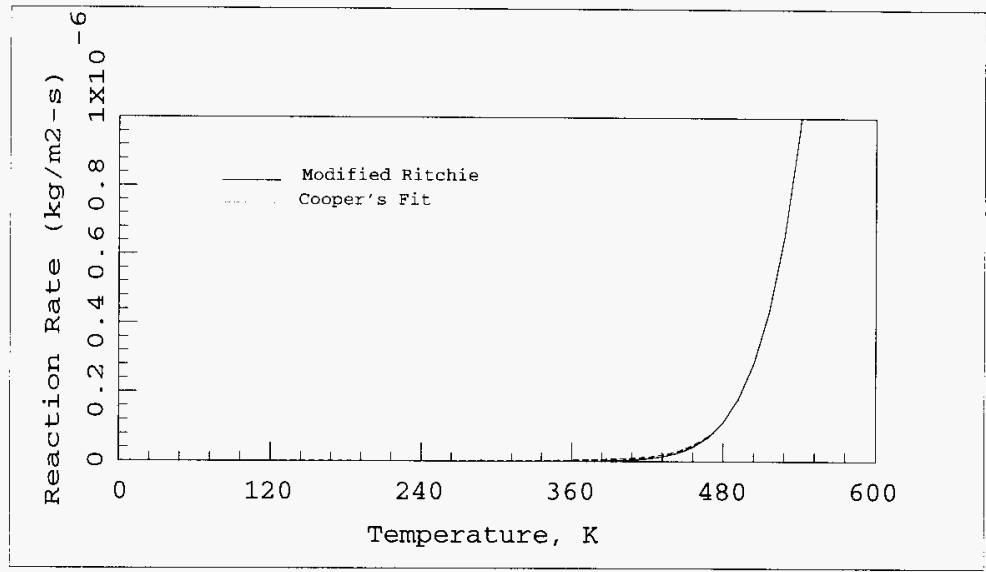

Figure 4.8 Comparison of Modified Ritchie Equation and Cooper's Equation, $\mathrm{mf}_{\mathrm{O} 2}=0.0114$, $\mathrm{vf}_{\mathrm{O} 2}=0.01$, $\mathrm{P}_{\mathrm{O} 2}=0.147 \mathrm{psi}$.

\subsubsection{Hydriding and Dehydriding.}

Uranium hydride is known to be present in the N-Reactor fuel. This hydride will decompose if fuel temperatures are sufficiently high. Uranium metal that is left after the hydride has decomposed can rehydride if the hydrogen concentration in gas surrounding the uranium becomes sufficiently high.

The correct model for calculating the rate of hydriding and dehydriding is given by Linder and is described below.

The equilibrium $\mathrm{H}_{2}$ pressure, $\mathrm{P}_{\mathrm{o}}$ (in Torrs or mm of mercury) at a given temperature $\mathrm{T}$ (where $\mathrm{T}$ is in Kelvin) is given by: 


$$
P_{0}(A, B, T)=10^{\frac{-A}{T}+B}
$$

where, for hydriding;

$$
\begin{aligned}
& A=3473 \\
& B=8.05
\end{aligned}
$$

and, for dehydriding:

$$
\begin{aligned}
& A=4717 \\
& B=9.46
\end{aligned}
$$

The extent of the reaction is given by the expression:

$$
\alpha_{h y}=92.833 \log _{e}\left(\frac{P_{0}(A, B, T)}{P}\right) e^{\frac{-9524.67}{T}} t
$$

where $\mathrm{P}$ is the partial pressure of hydrogen in the gas surrounding the fuel in Torr, $T$ is the fuel temperature in ${ }^{\circ} \mathrm{K}$ and $\mathrm{t}$ is the time from initiation of hydride decomposition.

The extent is equal to the fraction of hydride mass, $m$, present at time $t=t_{0}$, that is decomposed over the time period, $t$ for the dehydriding process and it is equal to the fraction of available previously hydrided uranium that can be rehydrided. It is assumed in the above equation that the hydrogen partial pressure, P, is constant. This will not be the case in a sealed MCO since, for the dehydriding process, the hydrogen concentration will continuously increase until it reaches the equilibrium concentration. The hydrogen concentration will decrease for the hydriding process until the equilibrium concentration is reached. The equilibrium concentration will be continually changing since it is a function of the fuel temperature which will be continuously changing during the various stages in which it is stored due to the 
changing ambient temperatures.

The time required to decompose all of the hydride at $\mathrm{T}=300^{\circ} \mathrm{C}$ and $\mathrm{P}=10$ Torr is 94.43 hours. Hydride decomposition will not occur at normal MCO temperatures during shipping, staging and interim storage.

The time required to rehydride all of the hydride at a temperature of $27^{\circ} \mathrm{C}$ and a hydrogen pressure of 760 Torr is 1500 years.

The time required to rehydride all for the original hydrided uranium at the MCO fuel storage temperature of $200^{\circ} \mathrm{C}$ and a hydrogen pressure of 760 Torr is 14 days.

This correlation has been incorporated into the MCO pressurization model but no hydride decomposition occurs unless temperature excursions occur in the fuel.

\subsubsection{Hydrate Decomposition.}

Hydrate decomposition relations for the three hydrates assumed to be present on the fuel in the MCO are provided in this section. The three hydrates are $\mathrm{Al}_{2} \mathrm{O}_{3} \bullet 3 \mathrm{H}_{2} \mathrm{O}$, $\mathrm{Fe}_{2} \mathrm{O}_{3} \cdot 3 \mathrm{H}_{2} \mathrm{O}$ and $\mathrm{UO}_{3} \cdot 2 \mathrm{H}_{2} \mathrm{O}$. The model is composed of two parts.

The first, based on the work reported in [Ref 1], [Ref 2] and [Ref. 3] is for the decomposition rate under vacuum conditions where only steam is present and the decomposition rate is governed by Darcy flow of steam through the decomposed layer of the oxide particle.

The second is for the decomposition of the hydrates in the presence of an inert gas in the MCO. The decomposition rate is governed by diffusion of water vapor from the decomposition surface, which is at the hydrate equilibrium pressure, through the decomposed layer of the 
oxide particle to the gas in the oxide layer, which contains water vapor at some partial pressure between that of the decomposing particle's water vapor pressure, the bulk MCO atmosphere water vapor pressure and the water vapor pressure at the reacting surface, which can be assumed to be zero. Diffusion of water vapor through the oxide layer is complicated since the location of hydrate particles on the layer is random and the direction that the vapor will diffuse depends on the hydrate particle's proximity to the reacting surface and the free surface of the oxide layer. A conservative approach is used for purposes of calculating the MCO pressurization. It is assumed that the steam pressure used in the Pearce uranium reaction equations is the hydrate equilibrium pressure and that the hydrates will decompose at the rate the water vapor can be reacted with the uranium. This will produce the maximum dehydration rate and the maximum reaction rate of water with uranium giving the maximum rate of hydrogen generation and MCO pressurization.

These two models are described briefly below.

\subsubsection{Dehyration Rate under Vacuum Conditions.}

A brief description of the porous media flow limited model, which is valid when only steam is present in the MCO, is provided below. The reader should refer to [Ref 1], [Ref 2] and [Ref. 3] for a more complete description of the derivation of the model. First, parametric fits to the Gibbs free energy for each of the hydrates, $\Delta \mathrm{G}(\mathrm{T})$, are given by:

For $\mathrm{AL}_{2} \mathrm{O}_{3} \cdot 3 \mathrm{H}_{2} \mathrm{O}$ :

$$
\Delta \text { GAL }(T):=534.97-0.38644 \cdot T-60.505 \cdot \log _{e}(T)-\frac{9702.8}{T}
$$

For $\mathrm{UO}_{3} \bullet 2 \mathrm{H}_{2} \mathrm{O}$ : 
$\Delta G U O(T):=253.23-0.26633 \cdot T-23.486 \cdot \log _{e}(T)-\frac{3412.2}{T}$

For $\mathrm{Fe}_{2} \mathrm{O}_{3} \cdot 3 \mathrm{H}_{2} \mathrm{O}$ :

$\Delta \mathrm{GFE}(\mathrm{T}):=51.046-0.1541 \cdot \mathrm{T}$

where the temperature, $T$, is given in ${ }^{\circ} \mathrm{K}$.

The hydrate equilibrium pressures, in atmospheres, are given by:

$$
\begin{aligned}
& \operatorname{PEAL}(\mathrm{T})=e^{\frac{-1000 \Delta \mathrm{GAL}(\mathrm{T})}{3(8.313) \mathrm{T}}} \\
& \text { PEUO }(\mathrm{T})=e^{\frac{-1000 \Delta \text { GUO }(\mathrm{T})}{2(8.313) \mathrm{T}}} \\
& \operatorname{PEFE}(\mathrm{T})=\mathrm{e}^{\frac{-1000 \Delta \mathrm{GFE}(\mathrm{T})}{3(8.313) \mathrm{T}}}
\end{aligned}
$$

The equilibrium pressures are plotted in the following figure. The equilibrium pressure for the iron tri-hydrate is based on the Gibbs free energy of the iron monohydrate. This is not correct and must be corrected in the future, however, the effect of this error on the current results is not significant. 
WHC-SD-SNF-ER-014, Rev. 0 .

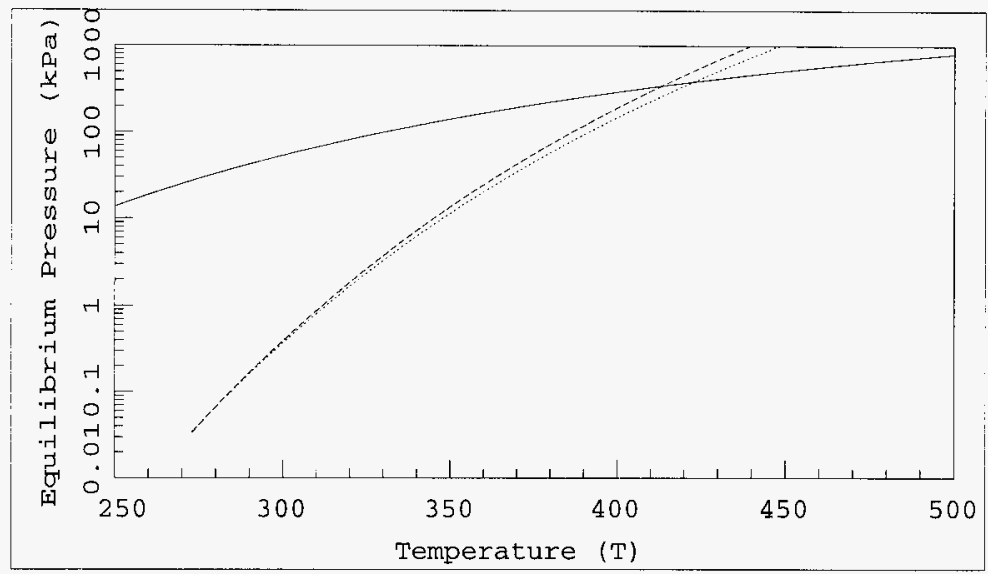

Figure 4.9 Hydrate Equilibrium Temperatures.

The diffusion parameter for diffusion through the particle decomposed layer is:

$D(z, t)=\frac{\rho_{p}(z) K_{p}}{\mu_{g} C_{o}}\left(P_{e q}(T)-P(z)\right)$

where:

$\mathrm{K}_{\mathrm{p}}=$ particle permeability .

$K_{p}\left(d, \varepsilon_{p}\right)=\frac{d^{2} \varepsilon_{p}^{3}}{180\left(1-\varepsilon_{p}\right)^{2}}$

$\varepsilon_{\mathrm{p}}=$ porosity of the particle decomposed layer $=0.2$.

$\mu_{g}=$ steam viscosity

$\mathrm{C}_{0}=$ density of water in Hydrate 
$\rho_{\mathrm{P}}=$ particle steam density $\left(P+P_{\text {eq }}\right) /\left(2{ }^{*} R_{s}{ }^{*} T\right)$

$\mathrm{R}_{\mathrm{s}}=$ Ideal gas constant for steam.

$P_{\text {eq }}(T)=$ Temperature dependant hydrate equilibrium pressure.

$P(z)=$ Steam pressure at location $z$ in the decomposed hydrate particle layer.

The rate of change of the decomposition layer depth, $\delta$, is given by:

For $\delta<<R$ :

$$
\frac{d \delta}{d t}=\frac{1}{2 \Delta t}\left(\sqrt{\delta_{\circ}{ }^{2}+\frac{4 D(z, t) R \Delta t}{R-\delta_{\circ}}}-\delta_{\circ}\right)
$$

For $\delta \approx R$ :

$$
\frac{d \delta}{d t}=\frac{1}{\Delta t}\left(\sqrt{\delta_{0}^{2}+\frac{2 \mathrm{D}(z, t) \Delta t}{1-\frac{2}{3} \frac{\delta_{0}}{R}}}\right)-\frac{\delta_{0}}{\Delta t}
$$

Limit :

$$
\frac{\mathrm{d} \delta}{\mathrm{dt}}=\frac{\mathrm{R}-\delta_{\mathrm{o}}}{\Delta \mathrm{t}}
$$

where:

$D(z, t)=$ diffusion parameter

$\Delta t=$ time increment

$\delta_{0}=$ location of decomposition front at beginning of time step.

$R_{b}=$ Bed Particle radius $=40 \mu \mathrm{m}$ 


$$
\mathrm{R}_{\mathrm{b}}:=40 \mu \mathrm{m}
$$

Assuming that flow through the particle's decomposed layer porous medium limits the decomposition rate, the steam mass flux from surface is given by:

$$
w^{\prime \prime}{ }_{s}=\frac{3\left(1-\varepsilon_{b}\right)}{R} C_{0} \Delta z\left(1-\frac{\delta_{0}}{R}\right)^{2} \frac{d \delta}{d t}
$$

where:

$\boldsymbol{\varepsilon}_{\mathrm{b}}=$ bed porosity $=0.4$

$\Delta \mathrm{z}=$ node length (bed thickness)

This flux is multiplied by the geometric surface area that is obtained by dividing the sludge volume by $\Delta z$.

and the decomposition energy is given by:

$$
q^{\prime \prime}=3 \frac{\left(1-\varepsilon_{b}\right)}{R} \rho_{f} \Delta h \Delta z\left(1-\frac{\delta_{o}}{R}\right)^{2} \frac{d \delta}{d t}
$$

where:

$\Delta \mathrm{h}=$ hydrate decomposition enthalpy

$\rho_{f}=$ hydrate particle density, $\mathrm{kg} / \mathrm{m} 3$.

This flux is multiplied by the geometric surface area that is obtained by dividing the sludge volume by $\Delta z$.

\subsubsection{Dehydration Rate In the Pressence of} Non-Condensable Gases.

If the decomposition rate is driven by the gradiant in steam pressure, and not the differential pressure across the porous medium, as would be the case at lower temperatures when the cask contains an inert gas at nearly atmospheric pressure (e. g. during transport from the CVDF to the CSB and during staging in the CSB), the 


$$
\text { WHC-SD-SNF-ER-014, Rev. } 0 \text {. }
$$

steam rate will be limited by gas diffusion through the porous media with the evaporation occuring at the Langmuir rate at the surface of the decomposing hydrate. The Langmuir rate for the total evaporation rate in the particle bed at the particle surface is:

$$
w^{\prime \prime}{ }_{L}=\left(\frac{P_{e}(T)-P_{S}}{\sqrt{2 \pi R_{S} T}}\right) 3 \frac{1-\varepsilon_{b}}{R} \Delta z\left(1-\frac{\delta_{0}}{R}\right)^{2}
$$

where:

The rate of change of the depth of the particle decomposition depth is given by:

$$
\begin{aligned}
& \frac{d \delta}{d t}=\frac{w^{\prime \prime}{ }_{L}}{C_{0}} \\
& P_{e}(T)=\text { particle equilibrium steam pressure. } \\
& P_{s}=\text { water vapor pressure in the particle bed. } \\
& R_{s}=\text { ideal gas constant for steam. } \\
& T=\text { particle temperature. } \\
& \varepsilon_{b}=\text { oxide particle bed porosity }=0.4 \\
& R=\text { particle radius } \\
& \Delta z=\text { particle bed thickness. } \\
& \delta_{0}=\text { particle decomposition depth at the beginning of } \\
& \quad \text { the time interval, } \delta_{0}{ }^{n+1}=\delta_{0}{ }^{+}+d \delta / d t * \Delta t .
\end{aligned}
$$

The water vapor mass flux given by this expression is very high for any significant difference between the hydrate's equilibrium pressure and the particle bed vapor pressure and clearly will be limited by the rate at which water vapor can diffuse through the particle's decomposed layer up to the temperature at which the particle equilibrium 
WHC-SD-SNF-ER-014, Rev. 0 .

pressure exceeds the total gas pressure in the particle bed at which point the decomposition rate will become limited by Darcy's law for the porous decomposed layer.

An additional limit that can be imposed on the decomposition rate is the rate at which water vapor is removed from the particle bed. The particle will stop decomposing when the particle bed vapor pressure reaches the hydrate's equilibrium pressure. This will occur quite rapidly if there is no means for removing the water vapor from the bed. In the absence of water/uranium reactions, removal is accomplished by diffusion and, possibly porous media flow from the bed to the MCO atmosphere. Removal will continue until the MCO total pressure and vapor partial pressure are in equilibrium with the hydrate's equilibrium pressure. However, when reactive uranium surfaces beneath the oxide layer are available in sufficient quantity to draw water vapor from the MCO atmosphere, through the oxide layer to the metal, water vapor from particle decomposition will likely flow towards the reactive surface where it is reacted. The maximum rate at which the reaction can occur when the hydrates are the only source of water is obtained by using the hydrate equilibrium pressure in the expressions for the water/ uranium reaction, since this is the maximum pressure that the steam can reach. This bounding, simple model for the dehydration rate is used in the MCO pressurization model. While the dehydration rate can be no faster than this bounding rate, further experimental data is needed to demonstrate that this model is not overly conservative for purposes of calculating the MCO pressurization rate.

The fraction of total oxidation product mass that is water in hydrated form for each of the three hydrates are given below:

$$
\begin{aligned}
& \mathrm{Al}_{2} \mathrm{O}_{3} \cdot 3 \mathrm{H}_{2} \mathrm{O}: \\
& \text { MEAL }:=0.005
\end{aligned}
$$


WHC-SD-SNF-ER-014， Rev. 0 .

$$
\begin{aligned}
& \mathrm{UO}_{3} \bullet 2 \mathrm{H}_{2} \mathrm{O}: \\
& \text { InfUO }:=0.033 \\
& \mathrm{Fe}_{2} \mathrm{O}_{3} \bullet 3 \mathrm{H}_{2} \mathrm{O}: \\
& \text { mfFE }:=0.005
\end{aligned}
$$

The mass of water in hydrated form used for the three oxidation product (sludge) masses used in the analysis are pressented in the following tables.

Total Oxidation Product Mass:

Mhydrate := $150 \mathrm{~kg}$

\begin{tabular}{|c|c|c|c|c|c|}
\hline $\begin{array}{c}\text { Surface } \\
\text { No. }\end{array}$ & $\begin{array}{c}\text { Reactive } \\
\text { Area }\end{array}$ & $\begin{array}{c}\text { Suface } \\
\text { Mass } \\
\text { Fraction }\end{array}$ & $\begin{array}{c}\mathrm{AL}_{2} \mathrm{O}_{3} \bullet 3 \mathrm{H}_{2} \mathrm{O} \\
\text { Mass }\end{array}$ & $\begin{array}{c}\mathrm{UO}_{3} \cdot 2 \mathrm{H}_{2} \mathrm{O} \\
\text { Mass }\end{array}$ & $\begin{array}{c}\mathrm{Fe}_{2} \mathrm{O}_{3} \cdot 3 \mathrm{H}_{2} \mathrm{O} \\
\text { Mass }\end{array}$ \\
\hline & & & $1 \mathrm{bm}$ & $1 \mathrm{bm}$ & $1 \mathrm{bm}$ \\
\hline 10 & 1.987 & 0.099 & 0.164 & 1.085 & 0.164 \\
\hline 2 & 2.673 & 0.134 & 0.221 & 1.460 & 0.221 \\
\hline 11 & 2.481 & 0.124 & 0.205 & 1.355 & 0.205 \\
\hline 3 & 2.742 & 0.137 & 0.227 & 1.498 & 0.227 \\
\hline 12 & 2.608 & 0.131 & 0.216 & 1.424 & 0.216 \\
\hline 4 & 2.763 & 0.138 & 0.229 & 1.509 & 0.229 \\
\hline 13 & 2.487 & 0.124 & 0.206 & 1.358 & 0.206 \\
\hline 5 & 2.239 & 0.112 & 0.185 & 1.223 & 0.185 \\
\hline & 19.980 & 1.000 & 1.653 & 10.913 & 1.653 \\
\hline
\end{tabular}

Table 4.1 Hydrate Water Mass on Each Fuel Surface for $150 \mathrm{~kg}$ of Oxidation Products.

Total Oxidation Product Mass:

$$
\text { Mhydrate := } 70 \mathrm{~kg}
$$


WHC-SD-SNF-ER-014， Rev. 0.

Table 4.2 Hydrate water Mass on Each Fuel surface for $70 \mathrm{~kg}$ of Oxidation Products.

\begin{tabular}{|c|c|c|c|c|c|}
\hline $\begin{array}{c}\text { Surface } \\
\text { No. }\end{array}$ & $\begin{array}{c}\text { Reactive } \\
\text { Area }\end{array}$ & $\begin{array}{c}\text { Suface } \\
\text { Mass } \\
\text { Fraction }\end{array}$ & $\begin{array}{c}\mathrm{AL}_{2} \mathrm{O}_{3} \bullet 3 \mathrm{H}_{2} \mathrm{O} \\
\text { Mass }\end{array}$ & $\begin{array}{l}\mathrm{UO}_{3} \cdot 2 \mathrm{H}_{2} \mathrm{O} \\
\text { Mass }\end{array}$ & $\begin{array}{c}\mathrm{Fe}_{2} \mathrm{O}_{3} \cdot 3 \mathrm{H}_{2} \mathrm{O} \\
\text { Mass }\end{array}$ \\
\hline & & & $1 \mathrm{bm}$ & $1 \mathrm{bm}$ & $1 \mathrm{bm}$ \\
\hline 10 & 1.987 & 0.099 & 0.077 & 0.506 & 0.077 \\
\hline 2 & 2.673 & 0.134 & 0.103 & 0.681 & 0.103 \\
\hline 11 & 2.481 & 0.124 & 0.096 & 0.632 & 0.096 \\
\hline 3 & 2.742 & 0.137 & 0.106 & 0.699 & 0.106 \\
\hline 12 & 2.608 & 0.131 & 0.101 & 0.665 & 0.101 \\
\hline 4 & 2.763 & 0.138 & 0.107 & 0.704 & 0.107 \\
\hline 13 & 2.487 & 0.124 & 0.096 & 0.634 & 0.096 \\
\hline \multirow[t]{2}{*}{5} & 2.239 & 0.112 & 0.086 & 0.571 & 0.086 \\
\hline & 19.980 & 1.000 & 0.772 & 5.093 & 0.772 \\
\hline
\end{tabular}

Total Oxidation Product Mass:

Mhydrate $:=16 \mathrm{~kg}$

(4.91) 
WHC-SD-SNF-ER-014， Rev . 0 .

Table 4.3 Hydrate water Mass on Each Fuel Surface for $16 \mathrm{~kg}$ of Oxidation Products.

\begin{tabular}{|c|c|c|c|c|c|}
\hline $\begin{array}{c}\text { Surface } \\
\text { No. }\end{array}$ & $\begin{array}{c}\text { Reactive } \\
\text { Area }\end{array}$ & $\begin{array}{c}\text { Suface } \\
\text { Mass } \\
\text { Fraction }\end{array}$ & $\begin{array}{c}\mathrm{AL}_{2} \mathrm{O}_{3} \cdot 3 \mathrm{H}_{2} \mathrm{O} \\
\text { Mass }\end{array}$ & $\begin{array}{l}\mathrm{UO}_{3} \cdot 2 \mathrm{H}_{2} \mathrm{O} \\
\text { Mass }\end{array}$ & $\begin{array}{c}\mathrm{Fe}_{2} \mathrm{O}_{3} \cdot 3 \mathrm{H}_{2} \mathrm{O} \\
\text { Mass }\end{array}$ \\
\hline & & & $1 \mathrm{bm}$ & $1 \mathrm{bm}$ & $1 \mathrm{bm}$ \\
\hline 10 & 1.987 & 0.099 & 0.018 & 0.116 & 0.018 \\
\hline 2 & 2.673 & 0.134 & 0.024 & 0.156 & 0.024 \\
\hline 11 & 2.481 & 0.124 & 0.022 & 0.145 & 0.022 \\
\hline 3 & 2.742 & 0.137 & 0.024 & 0.160 & 0.024 \\
\hline 12 & 2.608 & 0.131 & 0.023 & 0.152 & 0.023 \\
\hline 4 & 2.763 & 0.138 & 0.024 & 0.161 & 0.024 \\
\hline 13 & 2.487 & 0.124 & 0.022 & 0.145 & 0.022 \\
\hline \multirow[t]{2}{*}{5} & 2.239 & 0.112 & 0.020 & 0.130 & 0.020 \\
\hline & 19.980 & 1.000 & 0.176 & 1.164 & 0.176 \\
\hline
\end{tabular}

The energy of decomposition of each of the hydrates are as follows:

The energy of decomposition for $\mathrm{Al}_{2} \mathrm{O}_{3} \bullet 3 \mathrm{H}_{2} \mathrm{O}$ is:

$$
\text { rhodhr1 }:=\frac{2.52 \times 10^{9} \frac{\mathrm{J}}{\mathrm{m}^{3}}}{880 \frac{\mathrm{kg}}{\mathrm{m}^{3}}}=1231 \frac{\mathrm{Btu}}{1 \mathrm{bm}}
$$

The energy of decomposition for $\mathrm{UO}_{3} \bullet 2 \mathrm{H}_{2} \mathrm{O}$ is:

$$
\text { rhodhr2 }:=\frac{2.37 \times 10^{9} \frac{\mathrm{J}}{\mathrm{m}^{3}}}{750 \frac{\mathrm{kg}}{\mathrm{m}^{3}}}=1359 \frac{\mathrm{Btu}}{\mathrm{lbm}}
$$




$$
\text { WHC-SD-SNF-ER-014, Rev. } 0 \text {. }
$$

The energy of decomposition for $\mathrm{Fe}_{2} \mathrm{O}_{3} \cdot 3 \mathrm{H}_{2} \mathrm{O}$ is:

$$
\text { rhodhr2 }:=\frac{1.05 \times 10^{9} \frac{\mathrm{J}}{\mathrm{m}^{3}}}{370 \frac{\mathrm{kg}}{\mathrm{m}^{3}}}=1220 \frac{\mathrm{Btu}}{\mathrm{lbm}}
$$

The oxygen free uranium/water reactions recommended by Cooper and based on the Pearce correlations are plotted in the following figure. The vertical lines in the figure show the transition points between correlations. The solid line in the figure is the correlation that is used below $373^{\circ} \mathrm{K}$, Equation 4.18. The dashed line is used between $373^{\circ} \mathrm{K}$ and $523^{\circ} \mathrm{K}$, Equation 4.20 , and the maximum of the two remaining curves, Equations 4.22 and 4.24 , are used above $523^{\circ} \mathrm{K}$. 
WHC-SD-SNF-ER-014, Rev. 0 .

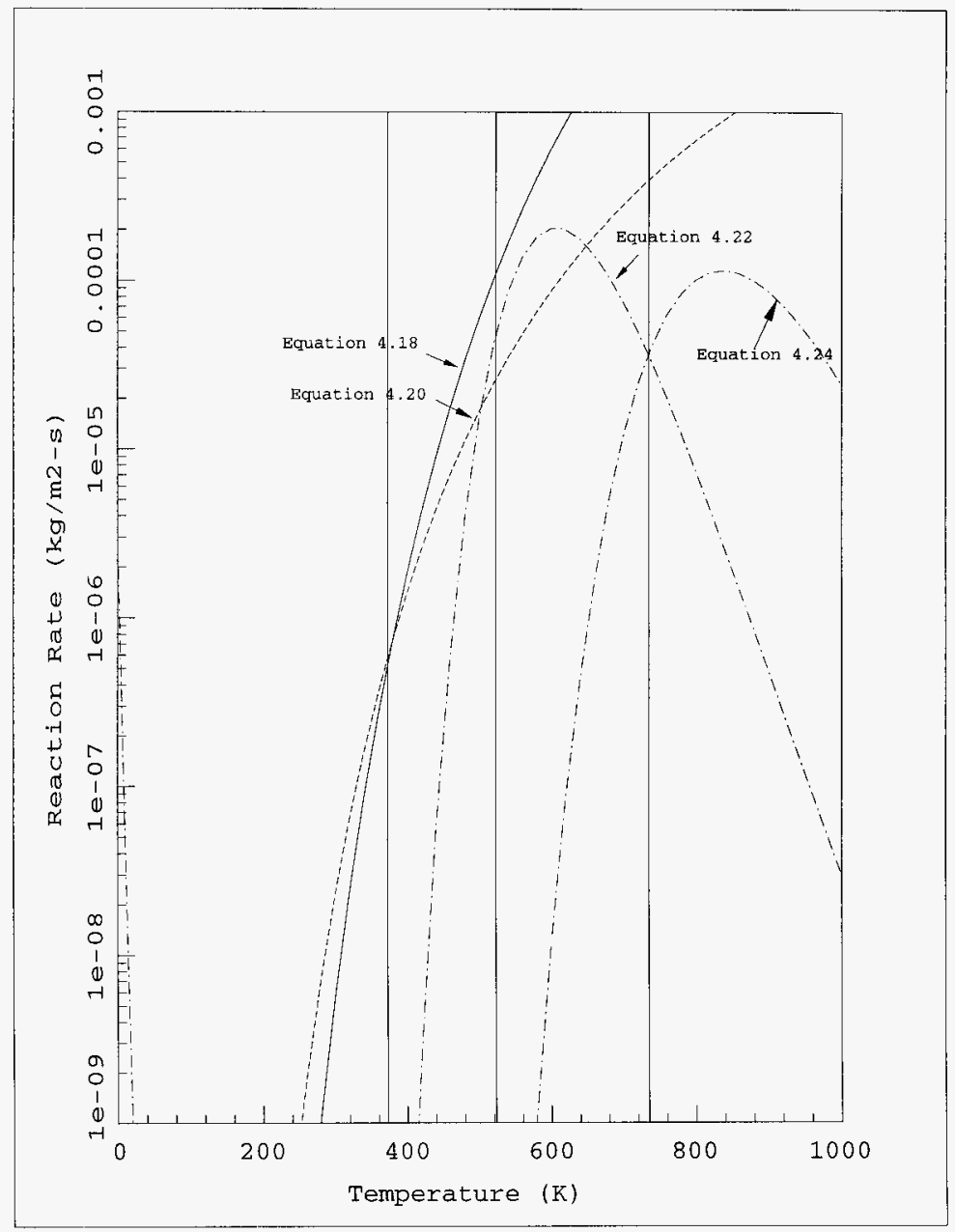

Figure 4.10 Reaction Rate In Oxygen Free water Vapor at a Pressure of $30 \mathrm{kPa}$. 
WHC-SD-SNF-ER-014, Rev . 0 .

The following expressions can be used to evaluate these correlations for the steam pressure range that they have been derived from and also to evaluate the reaction rate that would be obtained from these correlations if the hydrate equilibrium pressures are used in these correlations to obtain the uranium water reaction rates when the water coming off of the metal hydrates is the only water source in the MCO.

$$
\begin{aligned}
& \mathrm{T}:=\operatorname{tf}(400)=477.6 \mathrm{~K} \\
& \text { if }(\mathrm{T}-650 \mathrm{~K}) \\
& \text { rrateof (T) : max (xrate? (T), xates (T)) } \\
& \text { Ise- Block starting at Egn } 4.96
\end{aligned}
$$

rrateof $(T)=\max (\min (\operatorname{rrate} 5(\mathrm{~T}), \operatorname{rrate} 6(\mathrm{~T}, 50\{\mathrm{kPa}\})), \mathrm{rr}$ ate7 (T)) \#

end_if -- Block starting at Eqn 4.96

Applying these expressions to the temperature range of interest results in the set of reaction rate curves shown in Figure 4.11. The solid line and the small dashed line in the figure represent the reaction rate given by the correlations for the lower bound on the pressure range of the data fit by the correlation. The dotted line gives the fit to the upper water vapor pressure bound of the fit data. The remaining curves give the reaction rate that would result from using the hydrate equilibrium pressures in the temperature range where the correlations are water vapor pressure dependent. Clearly, use of the equilibrium pressures gives higher reaction rates. However, it is not known if these rates are conservative, overly conservative or non-conservative since the correlation is being used outside its range for water vapor pressure. Either a correlation for a wider range of water vapor pressure is required or a better model for the decomposition rate of 
WHC-SD-SNF-ER-014， Rev. 0 .

metal hydrates is required. However, since no better data is currently available, these curves will be used to estimate the water/uranium reaction rates when the only source of water in the MCO is that coming from the decomposition of hydrates. These rates are not the determining factor on whether a temperature excursion will occur or not as will be shown below. The chemical heat flux that will be generated using these correlations is shown in Figure 4.12. The chemical heat rate that will occur if there is a reaction area of $800,000 \mathrm{~cm}^{2}$ in the MCO is shown in Figure 4.13. The heat generated by the chemical reaction is over 1000 watts for this case before the lower bound of the pressure dependent correlation is reached. This is more than the decay heat for the maximum powered MCO and will result in a fuel temperature excursion before this temperature is reached. 
WHC-SD-SNF-ER-014, Rev. 0 .

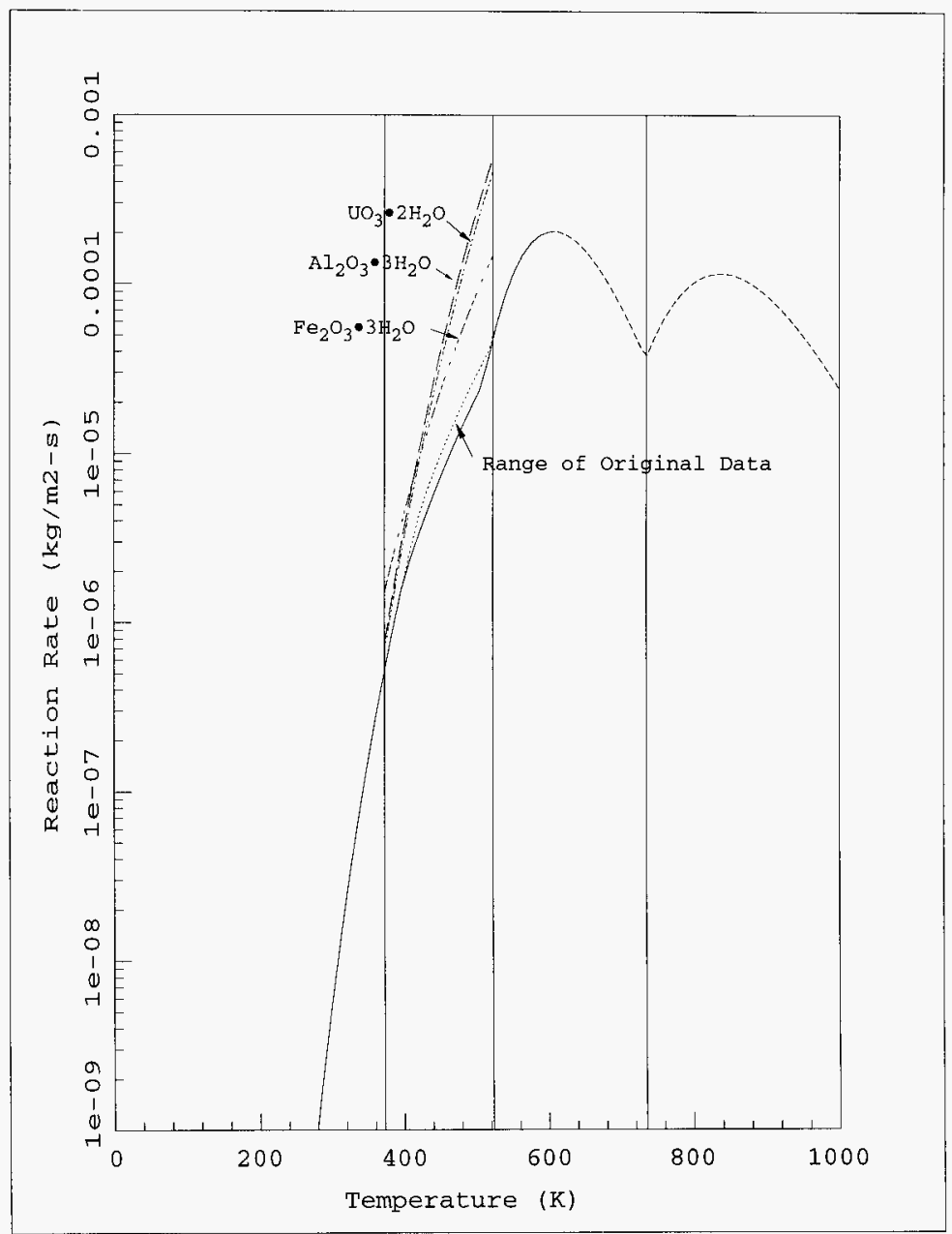

Figure 4.11 Reaction Rate In Oxygen Free water Vapor for the Pearce Equations and Using the Hydrate Equilibrium Pressures. 
WHC-SD-SNF-ER-014, Rev. 0 .

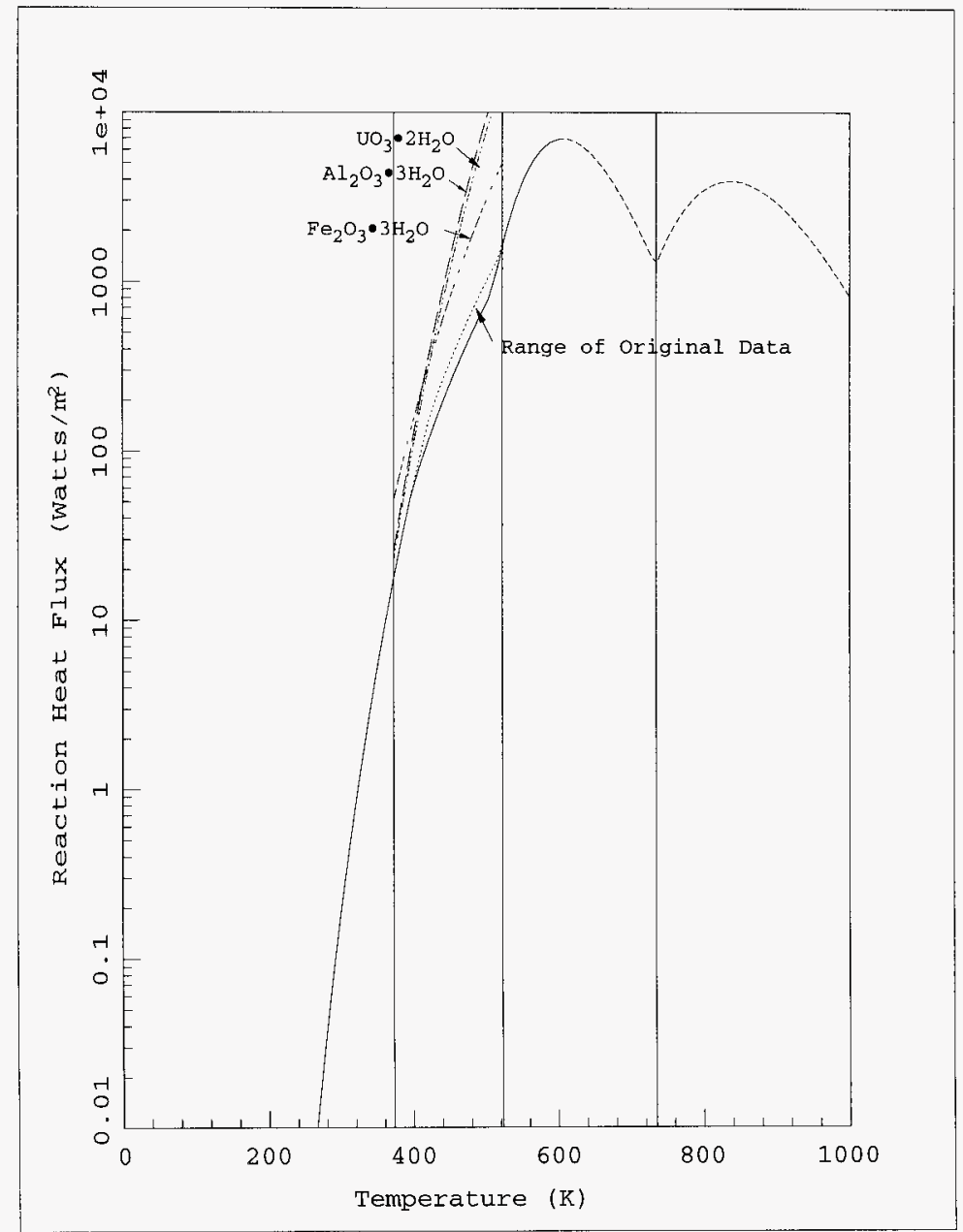

Figure 4.12 Reaction Heat Flux In Oxygen Free Water vapor for the Pearce Equations and Using the Hydrate Equilibrium Pressures. 
WHC-SD-SNF-ER-014, Rev. 0 .

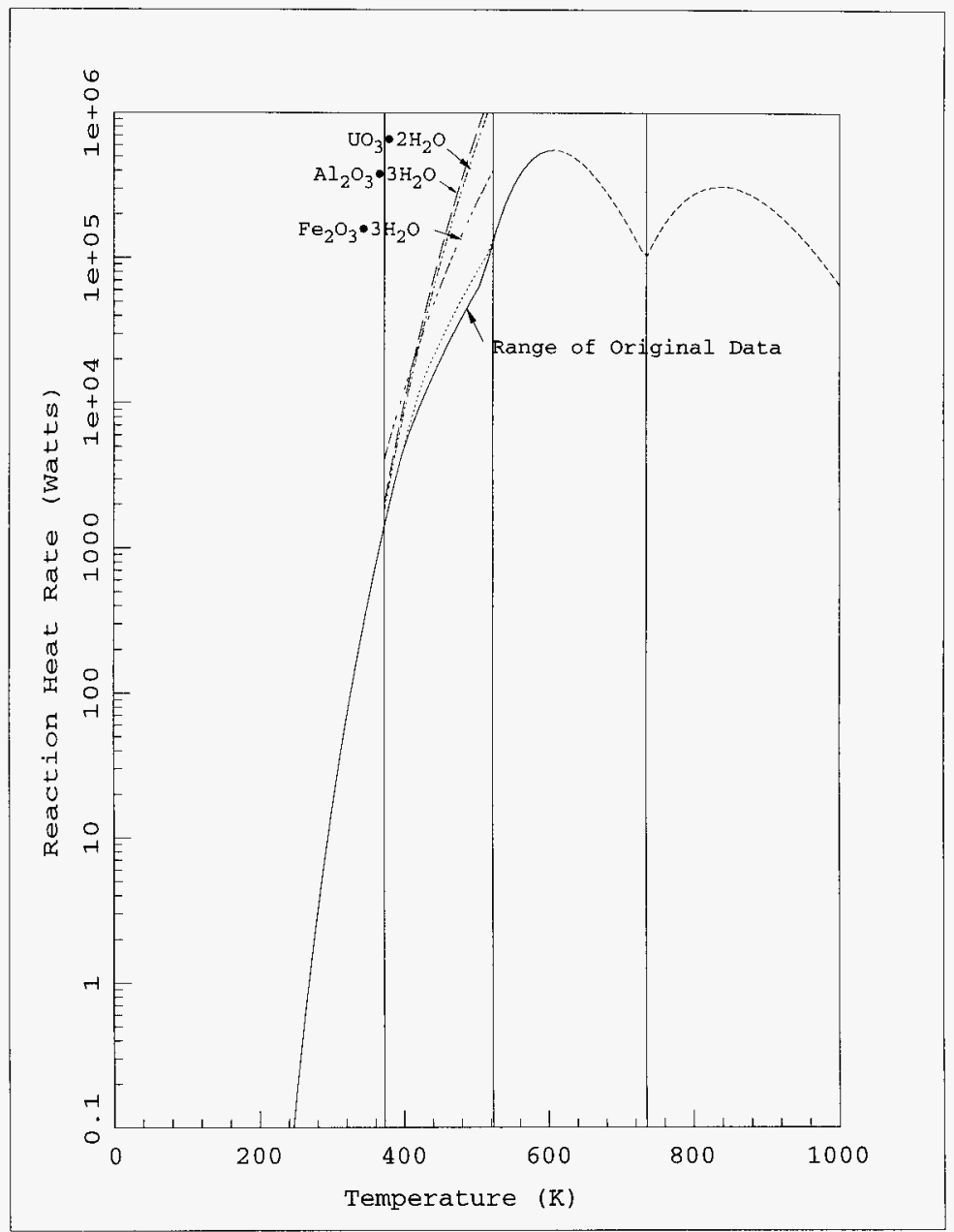

Figure 4.13 Reaction Heat Flux In Oxygen Free water vapor for the Pearce Equations and Using the Hydrate Equilibrium Pressures. 


$$
\text { WHC-SD-SNF-ER-014, Rev. } 0 \text {. }
$$

The thermal emissivities of the materials within the MCO, the $\mathrm{MCO}$, the CSB tube wall and the cask wall have a range that depends on the amount of oxidation that has occured on the surface or the treatment a surface has received. This has resulted in two set of emissivities that have been used in the MCO pressurization analysis. These are referred to as the conservative and the best estimate emissivity sets. These values are shown in the following table.

Table 4.4 Structure Thermal Emissivities.

\begin{tabular}{|l|r|r|}
\hline \multicolumn{1}{|c|}{ Structure } & \multicolumn{1}{c|}{ Conservative Best Estimate } \\
\hline Fuel & 0.40 & 0.70 \\
MCO/tube & 0.20 & 0.34 \\
Cask Inner Wall & 0.20 & 0.55 \\
Cask Outer Wall & 0.80 & 0.55 \\
\hline
\end{tabular}

The amount of chemical heat the system can reject, assuming that only the center ring of fuel is oxidizing is given as a function of temperature for the lower bound on material emissivities in Table 4.5 and for best estimate values of material emissivities in Table 4.6 . 


$$
\text { WHC-SD-SNF-ER-014, Rev. } 0 \text {. }
$$

Table 4.5 Lower Bound on Chemical Heat That Can be Transferred Out From Center Ring as a Function of Temperature for Transport In Cask.

\begin{tabular}{|c|c|}
\hline $\begin{array}{c}\text { Center } \\
\text { Rod } \\
\text { Temperature } \\
\text { (F) }\end{array}$ & $\begin{array}{c}\text { Center } \\
\text { Rod } \\
\text { Chemical } \\
\text { Heat } \\
\text { (watts }\end{array}$ \\
\hline 200.0 & 0.0 \\
\hline 213.7 & 20.0 \\
\hline 227.8 & 40.0 \\
\hline 251.7 & 75.0 \\
\hline 268.2 & 100.0 \\
\hline 299.9 & 150.0 \\
\hline 330.0 & 200.0 \\
\hline 386.2 & 300.0 \\
\hline
\end{tabular}




$$
\text { WHC-SD-SNF-ER-014, Rev. } 0 \text {. }
$$

Table 4.6 Best Estimate of Chemical Heat That Can be Transferred out From Center Ring as a Function of Temperature for Transport In Cask.

\begin{tabular}{|r|r|}
\hline $\begin{array}{c}\text { Center } \\
\text { Rod } \\
\text { Temperature } \\
\text { (F) }\end{array}$ & $\begin{array}{c}\text { Center } \\
\text { Rod } \\
\text { Chemical } \\
\text { Heat } \\
\text { (Watts }\end{array}$ \\
\hline 195.0 & 0.0 \\
206.2 & 20.0 \\
218.4 & 40.0 \\
239.2 & 75.0 \\
253.5 & 100.0 \\
280.7 & 150.0 \\
306.5 & 200.0 \\
354.2 & 300.0 \\
397.6 & 400.0 \\
600.2 & 1000.0 \\
826.8 & 2000.0 \\
\hline Array: heat2 & \\
\hline
\end{tabular}

The amount of chemical heat that can be generated on the center ring of rod's share of the total reaction area is given as a function of temperature for the minimum and maximum reaction areas assumed in this study using the minimum possible Pearce reaction rate, Table 4.7 , and the Reaction rate given by the aluminum equilibrium pressure, Table 4.8 . 


$$
\text { WHC-SD-SNF-ER-014, Rev. } 0 \text {. }
$$

Table 4.7 Chemical Heat Generated Based on Minimum Possible Pearce Equations.

\begin{tabular}{|c|c|c|}
\hline $\begin{array}{c}\text { Center } \\
\text { Rod } \\
\text { Temperature } \\
\text { (F) }\end{array}$ & $\begin{array}{l}\text { Chemical Heat } \\
\text { Generated On } \\
\text { Center Rod } \\
800,000 \mathrm{~cm}^{2} / 9 \\
\text { (watts) }\end{array}$ & $\begin{array}{c}\text { Chemical Heat } \\
\text { Generated On } \\
\text { Center Rod } \\
80,000 \mathrm{~cm}^{2} / 9 \\
\text { (watts) }\end{array}$ \\
\hline 100.0 & 3.867 & 0.387 \\
\hline 150.0 & 24.150 & 2.415 \\
\hline 200.0 & 114.200 & 11.420 \\
\hline 213.7 & 168.000 & 16.800 \\
\hline 225.0 & 228.200 & 22.820 \\
\hline 275.0 & 707.800 & 70.780 \\
\hline 300.0 & 1054.000 & 105.400 \\
\hline 325.0 & 1530.000 & 153.000 \\
\hline 350.0 & 2170.000 & 217.000 \\
\hline 375.0 & 3015.000 & 301.500 \\
\hline 400.0 & 4109.000 & 410.900 \\
\hline
\end{tabular}


WHC-SD-SNF-ER-014, Rev. 0 .

Table 4.8 Chemical Heat Generated Based on Maximum Possible Pearce Equations Using $\mathrm{Al}_{2} \mathrm{O}_{3} \cdot 3 \mathrm{H}_{2} \mathrm{O}$ Equilibrium Pressure.

\begin{tabular}{|c|c|c|}
\hline $\begin{array}{c}\text { Center } \\
\text { Rod } \\
\text { Temperature } \\
\text { (F) }\end{array}$ & $\begin{array}{l}\text { Chemical Heat } \\
\text { Generated on } \\
\text { Center Rod } \\
800,000 \mathrm{~cm}^{2} / 9 \\
\text { (watts) }\end{array}$ & $\begin{array}{l}\text { Chemical Heat } \\
\text { Generated on } \\
\text { Center Rod } \\
80,000 \mathrm{~cm}^{2} / 9 \\
\text { (watts) }\end{array}$ \\
\hline 100.0 & 2.204 & 0.220 \\
\hline 125.0 & 7.254 & 0.725 \\
\hline 150.0 & 21.650 & 2.165 \\
\hline 175.0 & 59.260 & 5.926 \\
\hline 200.0 & 150.200 & 15.020 \\
\hline 225.0 & 355.600 & 35.560 \\
\hline 250.0 & 791.700 & 79.170 \\
\hline 275.0 & 1668.000 & 166.800 \\
\hline 300.0 & 3344.000 & 334.400 \\
\hline 325.0 & 6408.000 & 640.800 \\
\hline 350.0 & 11790.000 & 1179.000 \\
\hline 375.0 & 20890.000 & 2089.000 \\
\hline 400.0 & 35790.000 & 3579.000 \\
\hline
\end{tabular}

The data given in the previous four tables is plotted in the Figure 4.14. The heat generated by either reaction rate expression for a reaction area of $800,000 \mathrm{~cm}^{2}$ will result in a temperature excursion since the heat generation rate exceeds the capacity of either the conservative or best estimate heat transfer model's ability to reject the heat. However, if the reaction area is reduced to 80,000 $\mathrm{cm}^{2}$ and the fuel temperature is maintained below $450^{\circ} \mathrm{K}$, both the conservative and the best estimate thermal models will reject all of the heat being generated by the chemical reaction. However, if the equilibrium pressure for aluminum hydrate is used in the correlation, then both thermal models are stable over a narrow temperature range 
below $400^{\circ} \mathrm{K}$. Therefore, while it is clear that a rubble basket reaction area of $800,000 \mathrm{~cm}^{2}$ is unstable if sufficient water is present, a better correlation for reaction rate is needed before it can be determined if a reaction area of $80,000 \mathrm{~cm}^{2}$ is stable or not. One must assume that a reaction area of at least half this amount would be required to provide sufficient margin to account for the uncertainty in the existing correlations. There is an unknown uncertainty in the application of the existing correlations to the decomposition rate of the metallic hydrates in addition to the rather wide scatter in the uranium/water reaction data on which the existing correlations are based. It must be shown that the amount of uranium reactive surface area that is in an MCO is sufficiently low to assure that the fuel temperatures will be in the stable temperature range, uncertainties included, if one wishes to avoid temperature excursions in the fuel. It is possible that temperature excursions are acceptable if it can be shown that either 1) the amount of water in the MCO will not cause the pressure or temperature limits of the MCO or fuel to be exceeded or 2) the MCO has a pressure relief device sized to handle the maximum flows expected during the water reaction history. In addition, it must also be shown the fuel temperatures enter a stable region as the reaction rate levels off at higher temperatures and the radiant heat rejection rate increases. This second option is acceptable if the peak temperature is acceptably low. There are indications in the present analysis that this will be the case but additional analysis is required before this conclusion can be reached.

The ability of the MCO to reject heat in the CSB storage tube is even poorer than in the transportation cask because 1) the CSB environment is at a higher temperature, 2) the tube surface area is smaller than the surface area of the cask and therefore has less ability to reject heat and 3 ) the storage tube is surrounded by other storage tubes that are at essentially the same temperature so heat rejection due to thermal radiation is minimized. Therefore, one 
would expect temperature excursions to occur for even lower reaction areas in the CSB. This means that the amount of water present the MCO when it reaches the CSB must be minimized to prevent temperature excursions in the fuel.

A second stable operating point may be reached due to the leveling off of the reaction rate at higher temperatures. This is illustrated in Figure 4.15 where the best estimate heat rejection rate is shown to again exceed the chemical heat generation rate at about $710^{\circ} \mathrm{K}$.

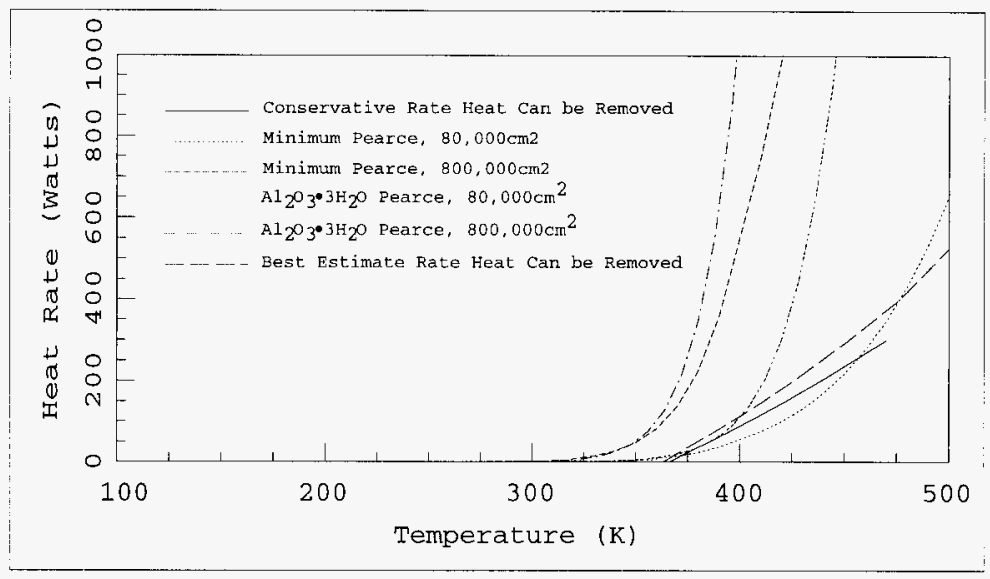

Figure 4.14 Comparison of Heat That Can be Removed Versus Heat That Can be Generated. 
WHC-SD-SNF-ER-014, Rev . 0 .

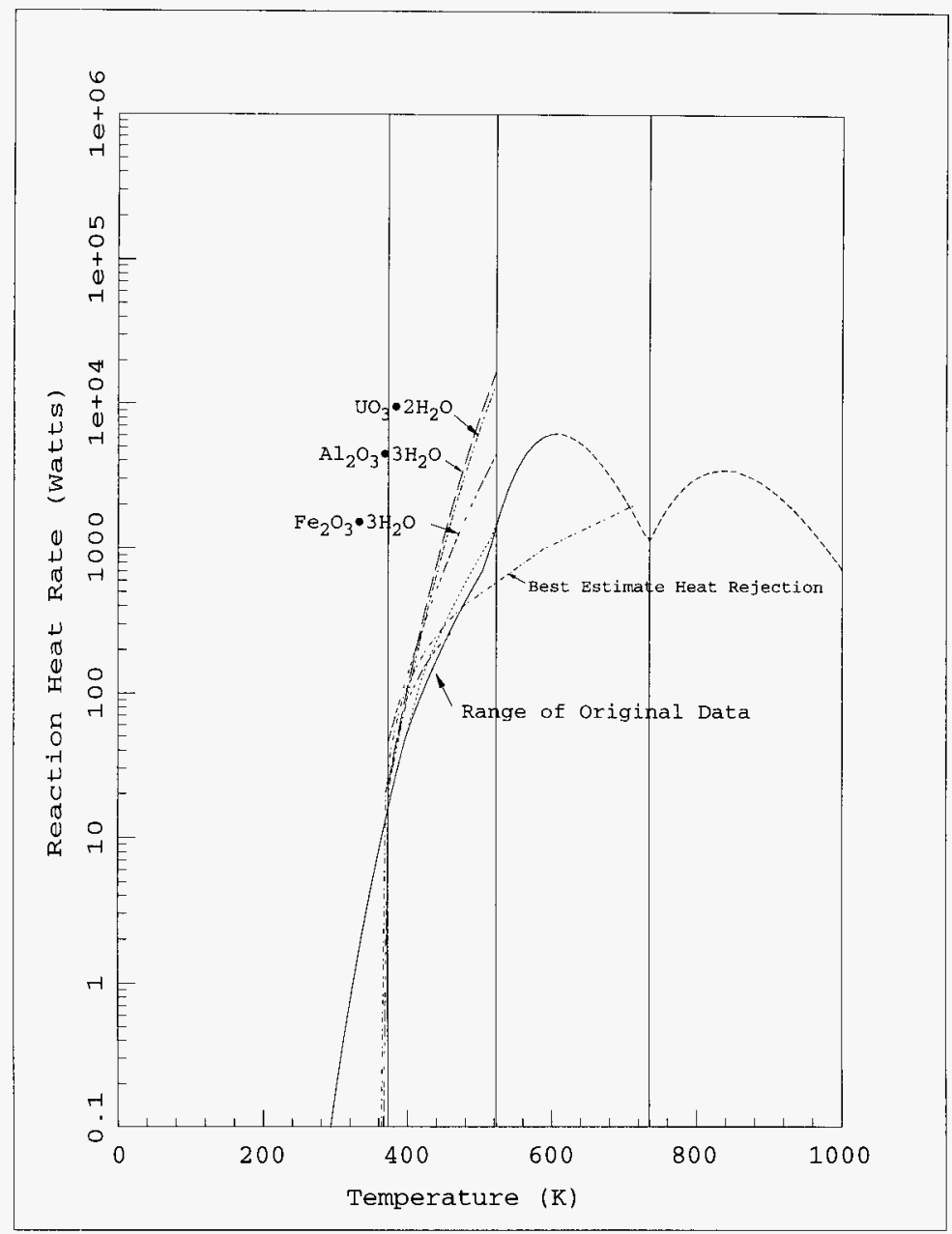

Figure 4.15 Reaction Heat Flux In Oxygen Free Water Vapor for the Pearce Equations and Using the Hydrate Equilibrium Pressures. 


\subsection{Radiolysis Rate Analysis.}

The maximum total hydrogen generation rates due to radiolysis for each of the stages is taken from [Ref 9] , and are,

1. For the flooded condition (assumes flooded with 135 gal of water $(511 \mathrm{~kg})$ and $16 \mathrm{~kg}$ of sludge that is $50 \%$ $\left.\mathrm{H}_{2} \mathrm{O} \mathrm{v} / \mathrm{v}(1.46 \mathrm{~kg})\right): 6.5133 \mathrm{e}-7 \mathrm{~mol} / \mathrm{s}$.

2. For the drained condition (assumes 14 liters of free water $(14 \mathrm{~kg})$ and $16 \mathrm{~kg}$ of sludge which is $50 \% \mathrm{H}_{2} \mathrm{O}$ $\mathrm{v} / \mathrm{v}(1.46 \mathrm{~kg}): 8.9272 \mathrm{e}-8 \mathrm{~mol} / \mathrm{s}$.

3. For the cold vacuum dried condition (assumes $16 \mathrm{~kg}$ of sludge which is $10 \% \mathrm{H}_{2} \mathrm{O} \mathrm{v} / \mathrm{V}\left(1.46 \mathrm{~kg} \mathrm{H} \mathrm{H}_{2} \mathrm{O}\right)$ and a thin molecular film of surface water $(2.83 \mathrm{e}-5 \mathrm{~kg})$ : $9.6876 \mathrm{e}-9$.

4. For the hot vacuum dried condition (assumes $16 \mathrm{~kg}$ of sludge that is $0.5 \%$ water $(8.04 \mathrm{e}-2 \mathrm{~kg})$ molecular film surface water $(2.83 \mathrm{e}-5 \mathrm{~kg})): 3.2764 \mathrm{e}-9 \mathrm{~mol} / \mathrm{s}$.

The hydrogen gas mass generation rates for each of the cases are:

$\mathrm{m} 1:=$

$6.5133 \times 10^{-7} \frac{\mathrm{gm}-\mathrm{moles}}{\mathrm{s}} \cdot 2.016 \frac{1 \mathrm{bm}}{1 \mathrm{bm}-\mathrm{mole}}=2.895 \times 10^{-09} \frac{1 \mathrm{bm}}{\mathrm{s}}$

(4.102)

$\mathrm{m} 2:=$

$8.9272 \times 10^{-8} \frac{\mathrm{gm}-\mathrm{moles}}{\mathrm{s}} .2 .016 \frac{1 \mathrm{bm}}{1 \mathrm{bm}-\mathrm{mole}}=3.968 \times 10^{-10} \frac{\mathrm{lbm}}{\mathrm{s}}$ 
m3 : =

$9.6876 \times 10^{-9} \frac{\mathrm{gm}-\mathrm{moles}}{\mathrm{s}} \cdot 2.016 \frac{1 \mathrm{bm}}{1 \mathrm{bm}-\mathrm{mole}}=4.306 \times 10^{-11} \frac{1 \mathrm{bm}}{\mathrm{s}}$

$(4.104)$

m4 :=

$3.2764 \times 10^{-9} \frac{\mathrm{gm}-\mathrm{moles}}{\mathrm{s}} \cdot 2.016 \frac{1 \mathrm{bm}}{1 \mathrm{bm}-\mathrm{mole}}=1.456 \times 10^{-11} \frac{1 \mathrm{bm}}{\mathrm{s}}$

The time required to decompose all of the surface bound water that is assumed to be on the surface of the fuel after the fuel has been hot conditioned assuming a total oxidation product mass of $16 \mathrm{~kg}$ having a water content mass fraction of $1 \%$ is:

$$
\frac{0.16 \mathrm{~kg}}{\mathrm{~m} 4 \cdot 8.93561}=85.9 \text { years }
$$

The gas generation rates due to radiolysis are at least three orders of magnitude smaller than the gas generation rates due to the uranium/water reaction and play no significant role in MCO pressurization when water is present in the $\mathrm{MCO}$ either in the form of free water or in the form of hydrated water, as is the case during shipping and staging of the MCO. Radiolysis is important during interim storage as the bound water will decompose over long periods of time. The total pressure that will develop in the MCO depends on the amount of surface bound water attached to the corrosion products within an MCO. MCO pressurization will not occur if the total corrosion product mass in the MCO is less than $80 \mathrm{~kg}$, the bound water content is less than $1 \%$ by mass and the oxygen is completely consumed by the uranium reaction or by a getter. However, if the water content is higher than this, the oxidation product mass is larger or the oxygen is not consumed, then the MCO will, in time, overpressurize due to the radiolytic decomposition of the bound water. 


$$
\text { WHC-SD-SNF-ER-014, Rev. } 0 \text {. }
$$

The radiolytic decomposition of water is included in all simulations of MCO pressurization but it plays a significant roll only during interim storage.

\subsection{Reaction Area.}

The true reaction area has been varied in this study between a value of $57,000 \mathrm{~cm}^{2}$ and $800,000 \mathrm{~cm}^{2}$ for the rubble basket. This value already includes the reaction rate multiplyer that accounts for the effects of corrosion on reaction area so no other factors are applied to this area, rather this area is used directly with the Pearce reaction rate equations to obtain the water/uranium reaction rate and the hydrogen generation rate due to the reaction. These values are within the range given by Cooper [Ref 10] for a reaction area multiplier of between 1 and 10 for the ratio between the true reaction area and the geometric reaction area. In addition, it has been assumed that the top five inches of each fuel element in each of the remaining four baskets is declad, corroded fuel having a geometric area multiplier of 10 . However, all of the hydrates are assumed to be in the rubble basket during dry transport and storage simulations and the water formed during the dehydration process is assumed to be completely reacted with the uranium in the rubble basket.

\subsection{Oxidation Product Inventory and Chemical Makeup.}

The oxidation product inventory is based on [Ref 11]. This parameter has been varied between a high value of $300 \mathrm{Kg}$ of oxidation products to a low value of $16 \mathrm{~kg}$. The chemical make up of the oxidation products assumed for this analysis are given in the following table. 


$$
\text { WHC-SD-SNF-ER-014, Rev. } 0 \text {. }
$$

Table 4.9 Oxidation Product Chemical Makeup.

\begin{tabular}{|l|r|r|r|r|}
\hline \multicolumn{1}{|c}{ Material } & \multicolumn{1}{c}{$\begin{array}{c}\text { Mole } \\
\text { Fraction }\end{array}$} & \multicolumn{1}{c}{$\begin{array}{c}\text { Initial } \\
\text { Hydrate } \\
\text { State }\end{array}$} & \multicolumn{2}{c|}{ Mass } \\
\multicolumn{2}{|c|}{$\begin{array}{c}\text { Water } \\
\text { Mass } \\
\text { Fraction }\end{array}$} \\
\hline $\mathrm{UO}_{2}$ & 0.700 & 0 & 0.744 & 0.000 \\
$\mathrm{UH}_{3}$ & 0.050 & 0 & 0.044 & 0.000 \\
$\mathrm{UO}_{3} \bullet 2 \mathrm{H}_{2} \mathrm{O}$ & 0.200 & 2 & 0.178 & 0.033 \\
$\mathrm{Al}_{2} \mathrm{O}_{3} \bullet 3 \mathrm{H}_{2} \mathrm{O}$ & 0.025 & 3 & 0.014 & 0.005 \\
$\mathrm{Fe}_{2} \mathrm{O}_{3} \bullet 3 \mathrm{H}_{2} \mathrm{O}$ & 0.025 & 3 & 0.020 & 0.005 \\
Surface water & 0.000 & & 0.000 & 0.010 \\
Totals & 1.000 & & 1.000 & 0.053 \\
\hline
\end{tabular}

\section{COMPUTER SIMULATION PROGRAMS.}

Two main computer programs are used in the analysis to obtain the thermal and pressure response of the MCO to various postulated operational and accident transients during various stages of the IPS process. These are the COBRA-TF code and the GOTH codes. COBRA-TF is a subchannel analysis code developed for the Nuclear Regulatory Commission by Battelle Northwest. Models for MCO internal convective, conductive and radiative heat transfer have been incorporated into this code as have been all of the chemical reaction rate equations, hydrate and hydride decomposition equations and radiolysis equations presented in previous sections of this report. The main use of COBRA-TF is to provide the overall thermal response of the fuel contained in the MCO due radiolytic decay heat, chemical reaction and decomposition heat and the thermal boundary condition imposed on the exterior of the MCO by the current process and/or accident that the MCO is being evaluated for. Since COBRA-TF also treats gas mixtures, it also provides a basis for an integrated MCO pressurization model. In this work it has been used to determine the MCO temperature and pressure response. 


$$
\text { WHC-SD-SNF-ER-014, Rev. } 0 \text {. }
$$

GOTH is a thermal hydraulic code based on GOTHIC, a thermal hydraulic code developed by EPRI for the analysis of nuclear power reactor containments. GOTH has be adapted to waste tank analysis by John Marvin, Inc. and is being applied in this study to the analysis of the CSB ventilation flow and heat transfer. GOTH has superior gas mixture modeling, open flow field modeling and component modeling to COBRA-TF and is the preferable basis for the integrated MCO model. The final objective of this work is to combine the fuel thermal and reaction modeling capabilities of COBRA-TF with the gas mixture, flow field and component modeling capabilities of GOTH to provide a best estimate integrated MCO modeling capability. This end

objective has not yet been fully achieved. GOTH has been used the work reported here mainly to obtain the MCO thermal boundary condition for the CSB staging and interim storage steps of the process. When the pressure response provided by COBRA-TF has been in question, the thermal solution from COBRA-TF has been input to the reaction rate equations to obtain a hydrogen gas mass rate which is then used in GOTH to obtain a the pressure response of the MCO.

\section{ENVIRONMENTAL TEMPERATURE HISTORY.}

The purpose of environmental temperature history evaluation is to evaluate the external boundary conditions that will imposed on the MCO during each stage of the process during which the MCO will be sealed. These boundary conditions are then applied to the external surface of the MCO to evaluate the internal temperature and pressure response within the MCO. During shipping, the external boundary conditions that are applied to the MCO include diurnal and seasonal temperature variations, solar incidence and external fire temperature transients applied to the exterior of the shipping cask. 
WHC-SD-SNF-ER-014, Rev . 0 .

External boundary conditions during cold vacuum drying include the effects imposed by the cooling/heating water jacket and the purge/vacuum drying systems, including the effects of off-normal and low frequency accident events such as failure to completely drain, incorrect gas species or temperature injection, water jacket temperature control failure and so forth.

External boundary conditions applied to the MCO during staging include diurnal and seasonal variation in the ambient atmospheric conditions, effects of tube loading sequence and Mco heat load, thermal inertia effects of fuel, MCO's, canister storage building structures and surrounding soil and natural convection flow through the CSB. The analysis also includes off normal and low frequency effects such as partial loss of natural convection flow.

Boundary conditions for interim storage are similar to those for staging except that effects of loading sequence do not apply. Long term effects of the decrease in decay heat are included.

\subsection{COMPUTATIONAL MODELS FOR ENVIRONMENTAL TEMPERATURE HISTORY .}

Three separate models for the CSB have been used in the study to determine the environmental temperature that the MCOs will be exposed to during staging and storage in the CSB. The models vary in the degree of complexity of the computational mesh. These models are a lumped parameter model of the CSB, a two-dimensional model of the CSB and a three-dimensional model of the CSB. The purpose of the two and three dimensional model is to evaluate the temperature variations within the CSB storage vault to determine the 


$$
\text { WHC-SD-SNF-ER-014, Rev . } 0 \text {. }
$$

peak temperatures that an MCO can be exposed to within the CSB. The deviation of the peak CSB temperature from the average CSB outlet temperature is then used as a temperature adder on the outlet temperature from the lumped parameter model to obtain the temperature boundary for the MCO for pressurization evaluations. The lumped parameter model is used to evaluate the thermal response of the MCO in the CSB for long term transients occuring over a period of several weeks to several years.

Three models of increasing complexity for the MCo have also been used in the study. These include the simple MCO model, the two dimensional FIDAP Model and the threedimensional COBRA-TF subchannel model. The primary purpose of the complex models is to demonstrate that the simple model is sufficiently accurate to capture the important phenomena. A secondary purpose of these models is to look at the detailed flow and temperature distributions within the MCO to evaluate local temperature peaks and effects of local fuel damage reaction effects.

Each of these three models is described in the following sections.

\subsubsection{CSB Computational Models.}

\subsubsection{Lumped Parameter Model.}

The lumped parameter model consists of four lumped parameter control volumes, Figure 6.1. The first volume represents the CSB storage vault which contain the storage tubes into which the MCos will be placed. This volume in connected thermally to conductors representing the concrete and soil at the bottom of the CSB and on the walls of the CSB, a conductor representing the roof of the CSB and a 
WHC-SD-SNF-ER-014, Rev. 0 .

simple MCO model representing the storage tubes, MCOs and fuel. The second volume represents the inlet structure and CSB inlet plenum. This volume, volume 2 , is connected to the vault volume, volume 1, via a junction representing the inlet openings, Junction 3. The third volume represents the vault outlet plenum, Volume 3 . The fourth, Volume 4, represents the 164 foot high ventilation stack. The outlet plenum is connected to the vault volume via Junction 4 , which represents the CSB vault outlet openings. Junction 5 represents the connection between the outlet plenum and the stack. Junctions 1 and 2 connect the inlet structure and the stack to the atmospheric pressure, temperature and relative humidity boundary condition. Hourly data for calendar year 1994 are currently being used as the atmospheric conditions for the analysis. The number of MCOs represented by the simple MCO model depends on the number of MCOs assumed to be loaded in the CSB for a given analysis. The time dependent decay heat load is specified to represent the reduction of decay heat over time. 
WHC-SD-SNF-ER-014, Rev. 0 .

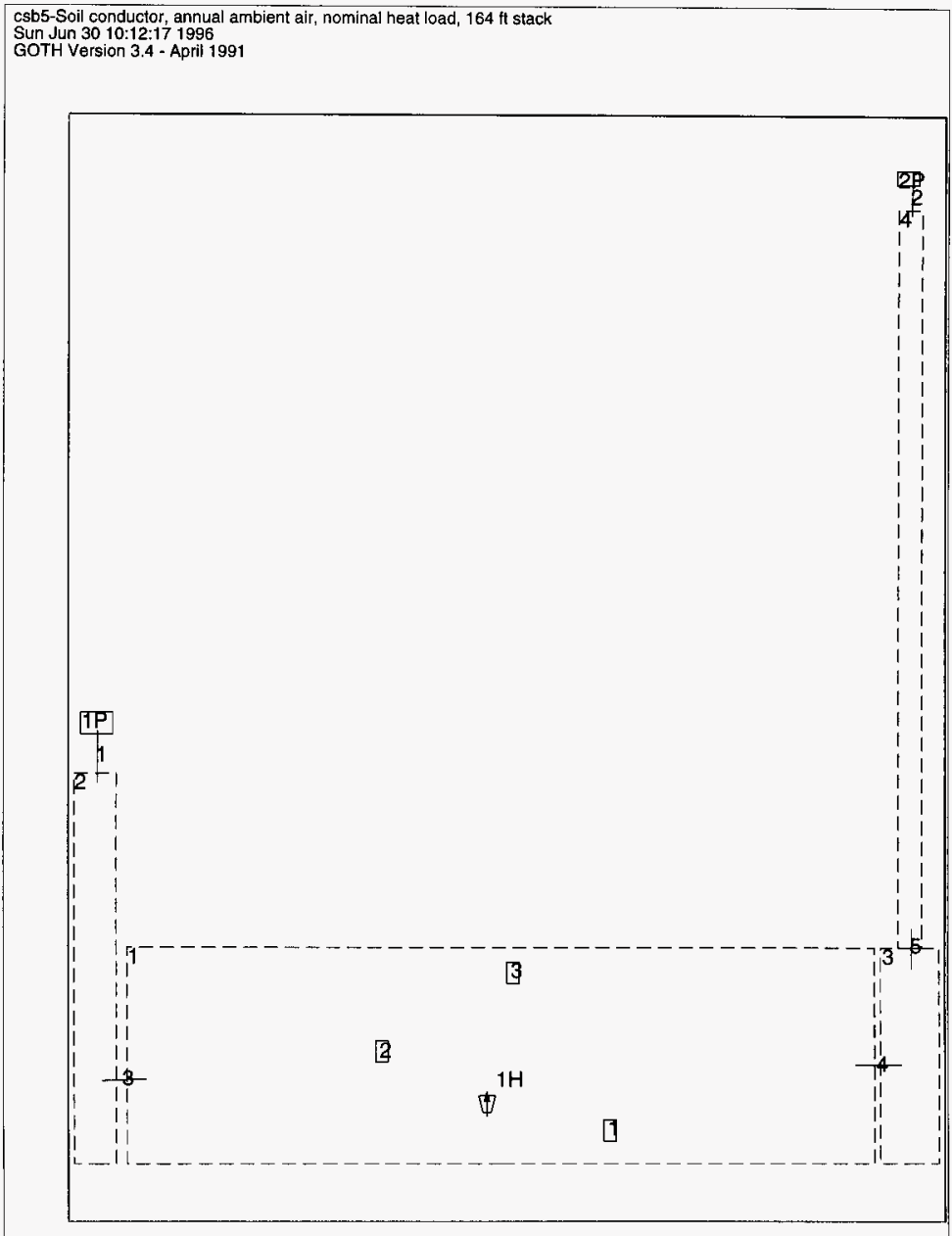

Figure 6.1 Lumped Parameter CSB Model. 


\subsubsection{Two-Dimensional Model.}

The two-dimensional model is identical to the three dimensional model except that the mesh lines in transverse dimension of the CSB are removed.

\subsubsection{Three-Dimensional Mode1.}

The three-dimensional CSB model is the same as the lumped parameter model of the CSB except that the inlet plenum, vault and outlet plenums are subdivided into a threedimensional mesh. This mesh is shown in Figure 6.2 with enlargements of the inlet and outlet plenums shown in Figures 6.3 and 6.4 . The mesh consists of 34 mesh cells along the length of the CSB, 22 mesh cells across the width and 7 mesh cells across the height. The tubes, Mcos and fuel are represented with 220 simple MCO models (this feature has not yet been implemented). 
WHC-SD-SNF-ER-014, Rev. 0 .

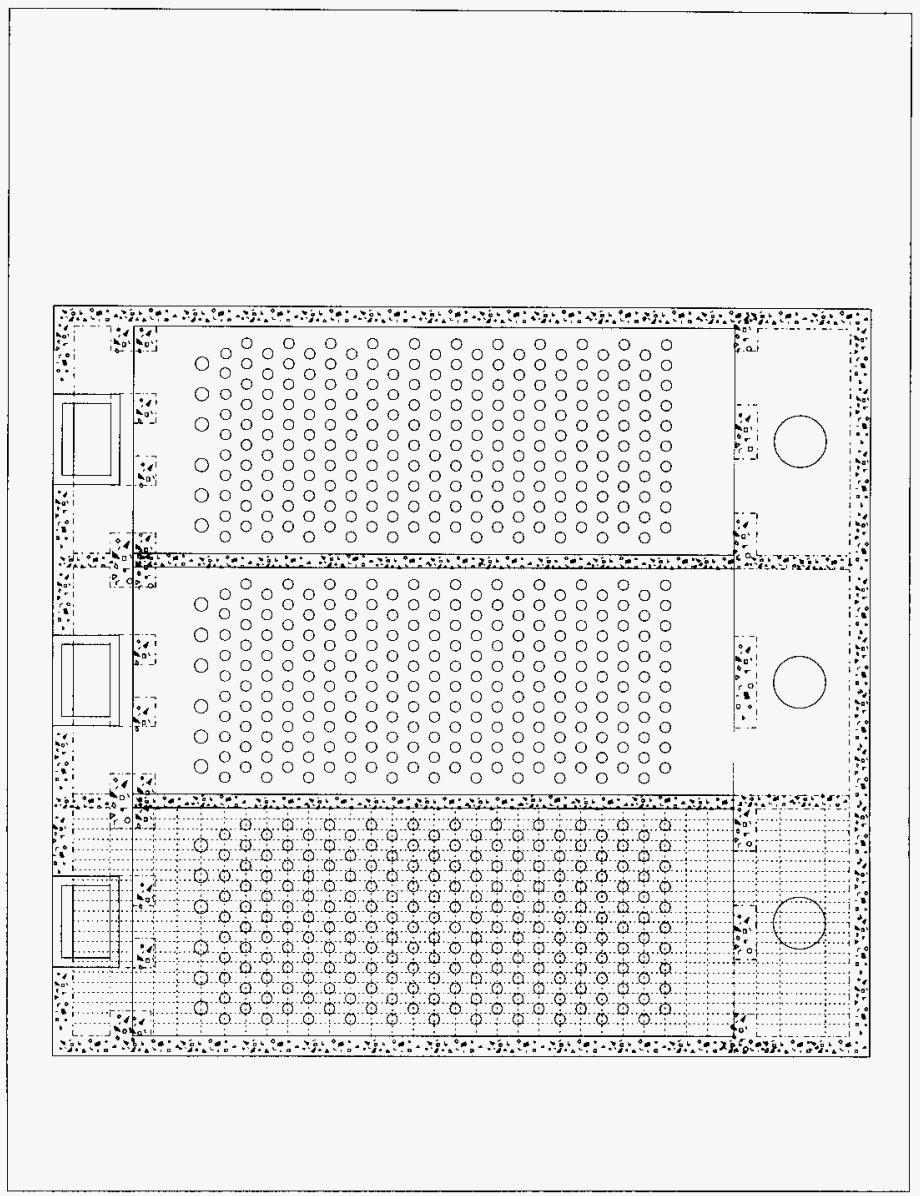

Figure 6.2 CSB Plan View. 
WHC-SD-SNF-ER-014, Rev. 0 .

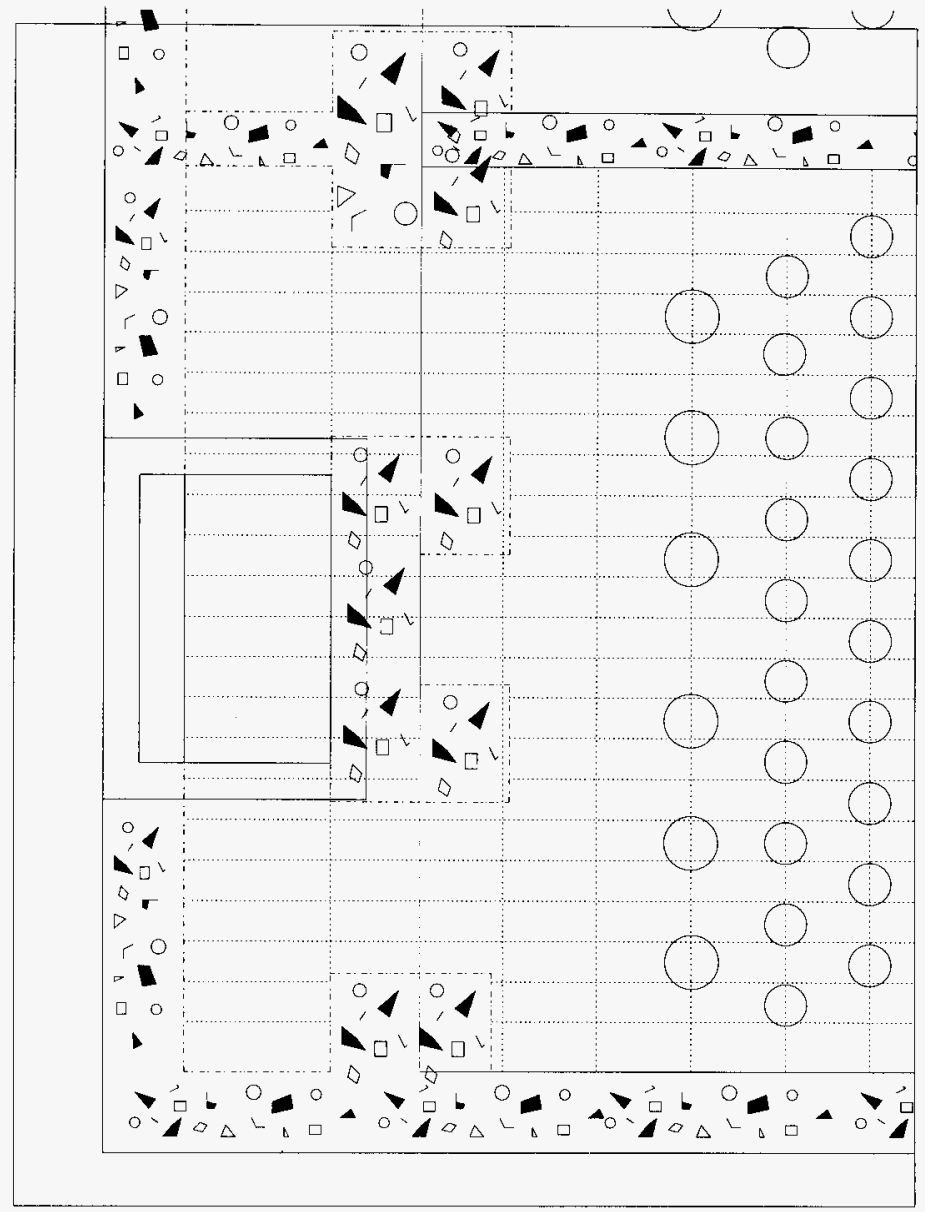

Figure 6.3 CSB Nodalization Detail - Inlet End. 
WHC-SD-SNF-ER-014, Rev. 0 .

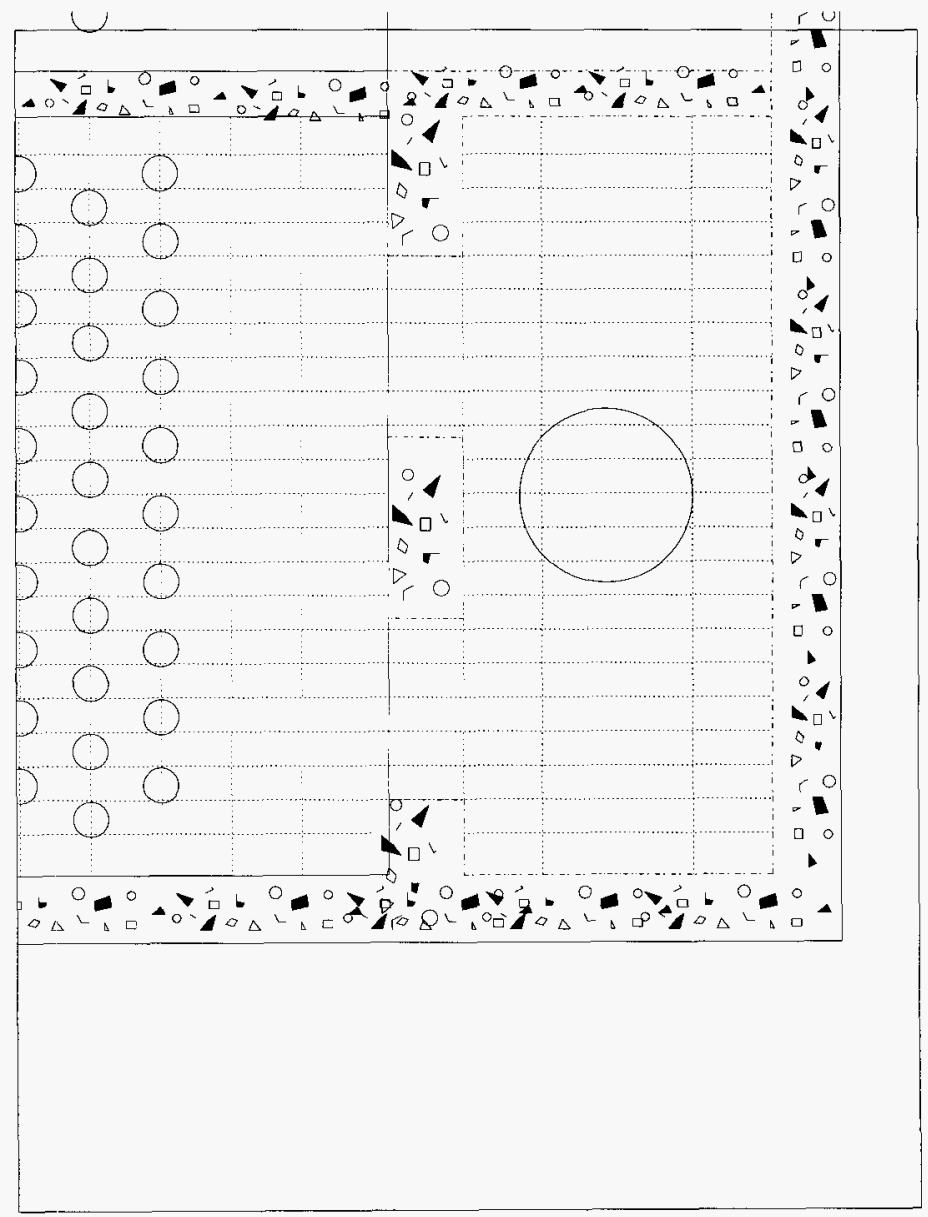

Figure 6.4 CSB Nodalization Detail - Outlet End. 
WHC-SD-SNF-ER-014, Rev . 0 .

\subsubsection{MCO Computational Models.}

6.1.2.1. TWo-DimensionaI FIDAP Model.

The two-dimensional FIDAP model is described in [Ref 12].

6.1.2.2. Detailed COBRA-TF Model.

The COBRA-TF subchannel model of an MCO within the CSB storage tube is developed by representing each space between three fuel assemblies in the triangular arrangement as a subchannel, the gas gap between each inner and outer fuel element as a subchannel, the hollow center of each inner fuel element as a subchannel, the space between the outer fuel elements and the MCO wall as a subchannel, the center tube as a subchannel and the gap between the MCO and tube walls as a subchannel. Solid structures such as fuel elements, MCO wall, tube wall and baskets are model using thermal conductors. The conductors are connected thermally to the gas in the flow channels through conduction, convection and radiation heat transfer. The conductors and flow channels are divided vertically into 5 sections, each section representing a fuel basket. Flow resistances at the bottom of each subchannel in each fuel basket are modeled using appropriate form loss coefficients. The bottom and top baskets are assumed to be filled with rubblized fuel. Damaged fuel reaction surface areas are specified for each fuel element in each basket. The fuel in the rubblized fuel baskets is assumed to have a true reaction area of $800,000 \mathrm{~cm} 2$. The top five inches of fuel in each of the intact fuel baskets is assumed to be damaged and an reaction surface area multiplier of 10 is applied to the fuel geometric surface area in this region to account for effects of corrosion on the true reaction surface area. Details of this model are presented in [Ref 12]. The primary purpose of this model in the MCO pressurization study has been to benchmark the simpler, 
WHC-SD-SNF-ER-014, Rev. 0.

faster running COBRA-TF MCO model.

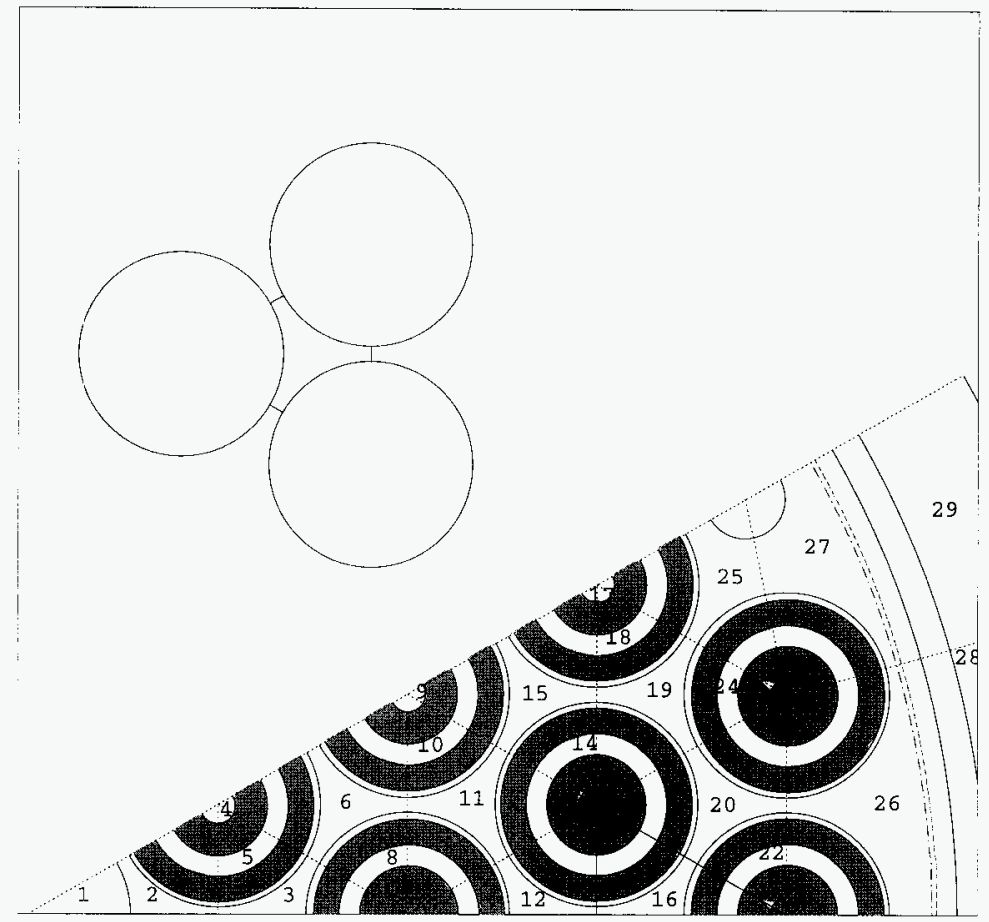

Figure 6.5 New Subchannel Numbers for 30 Degree Sector of 
WHC-SD-SNF-ER-014, Rev . 0 .

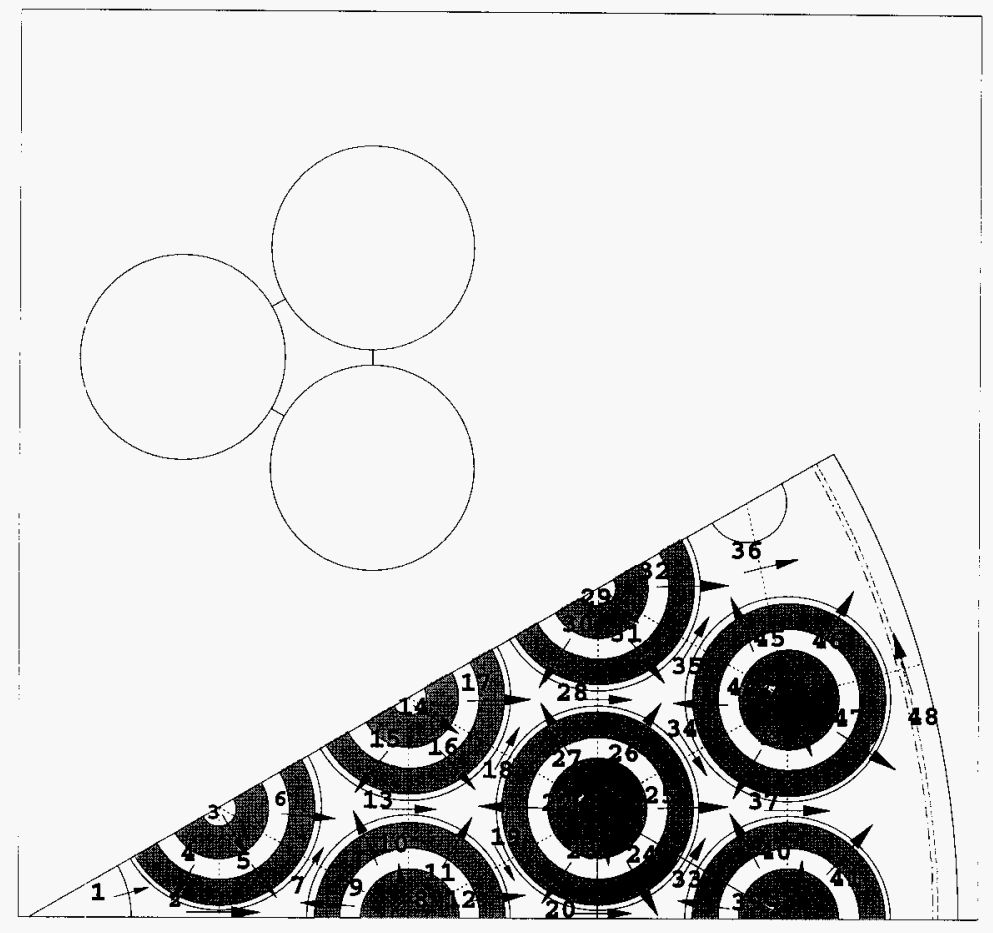

Figure 6.6 Gap numbers. 
WHC-SD-SNF-ER-014, Rev. 0 .

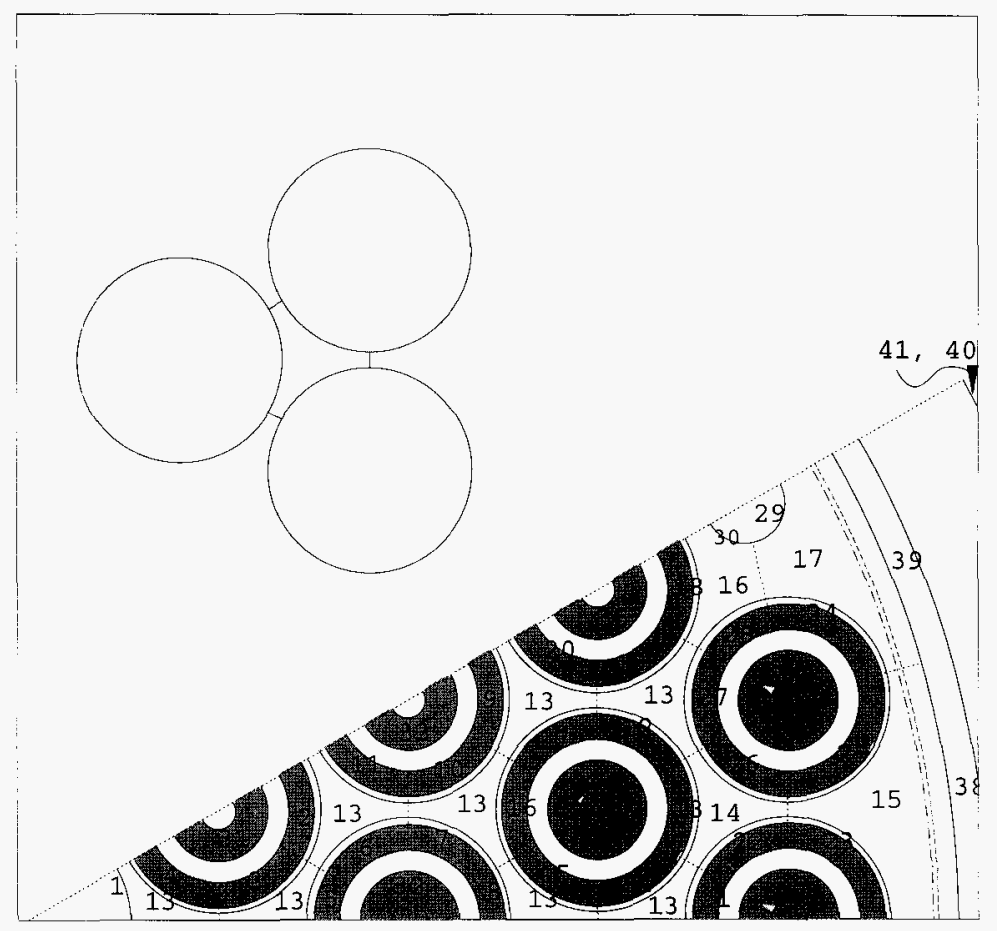

Figure 6.7 Radiation Channel Numbers.

\subsubsection{Simple MCO Model.}

Analysis conducted with the more detailed FIDAP and COBRA-TF models has provided valuable insight into the thermal response to be expected during the processing and transport of $\mathrm{K}$-basin spent fuel, and it has provided insight for improved design and operations specifications. It has also resulted in the following conclusions which relate to the adequacy of existing simulation capability. 
WHC-SD-SNF-ER-014, Rev . 0 .

1. The thermal response times which must be simulated are on the order of up to several days.

2. Complex 3-D modeling, or even 2-D modeling of al1 thermal transport mechanisms is not necessary for many of the normal process, or accident scenarios, that must be simulated.

3. Simple analytical models can be used for scoping analysis, but cannot adequately describe those multi-dimensional thermal transport phenomena which must be simulated to provide an accurate picture of thermal response.

4. Complex 3-D modeling, or even 2-D modeling of all thermal transport mechanisms requires long computer run times and considerable man hours to develop the input for these models and to interpret the output.

5. Most of the important thermal and pressure response characteristics of the Cask/MCO/basket/fuel system or the Tube/MCO/basket/fuel system can be adequately described with a computer model capable of the following: (a) simulation of radial thermal radiation between metal structures, (b) radial conduction within the gas gaps, (c) axial conduction within metal structures, (d) convection of gas and liquids radially and axially, (e) evaporation or phase change of water to steam, and (f) heat and gas generation due to chemical and radiolytic reactions which have been described in the previous sections.

As an option, the detailed COBRA-TF thermal radiation capability has recently been modified so that a simpler cylindrical representation of radiation and conduction between rings of fuel, between the outer ring of fuel and the fuel basket shroud, between the shroud and the MCo wall and between the MCO wall and the tube of cask inside wall can be used. 
WHC-SD-SNF-ER-014, Rev , 0 .

6.1.2.3.1. COBRA-TF Simple MCO Radiation Plus Radial Conduction Simulation Model.

The COBRA-TF radial radiation plus radial conduction model used to demonstrate and validate this fast running simulation capability and which is used in the MCO pressurization study is illustrated in Figure 6.8 and zoomed up in Figure 6.9.

The validation simulation considers the MCO to be surrounded by a $50^{\circ} \mathrm{C}$ water bath, with the MCO filled with the inert gas, Argon. The simulation is initiated with the MCO and contents at $50^{\circ} \mathrm{C}$ at atmospheric pressure and sealed. A transient is simulated for several days to arrive at a steady state condition. The steady state results are compared to a steady state analytical solution for radial thermal radiation combined with radial conduction between the MCO water bath and the fuel and other internal metal components. 


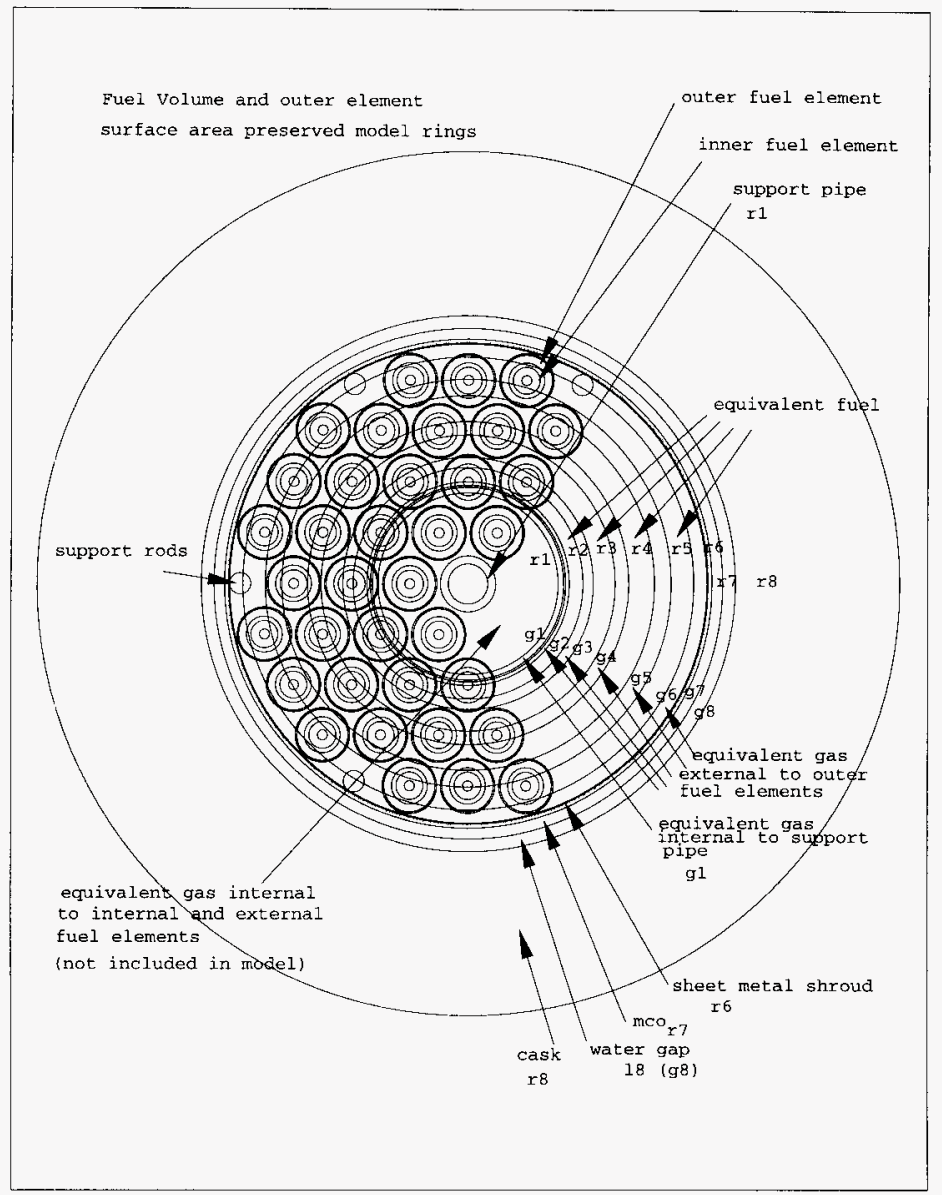

Figure 6.8 Mark IV Basket Bottom Plate with Fuel Socket Holes, Support Pipe, Support Rods, Sheet Metal Shroud, Mark IV Inner and outer Fuel Elements, MCO, and Cask 
WHC-SD-SNF-ER-014, Rev. 0 .

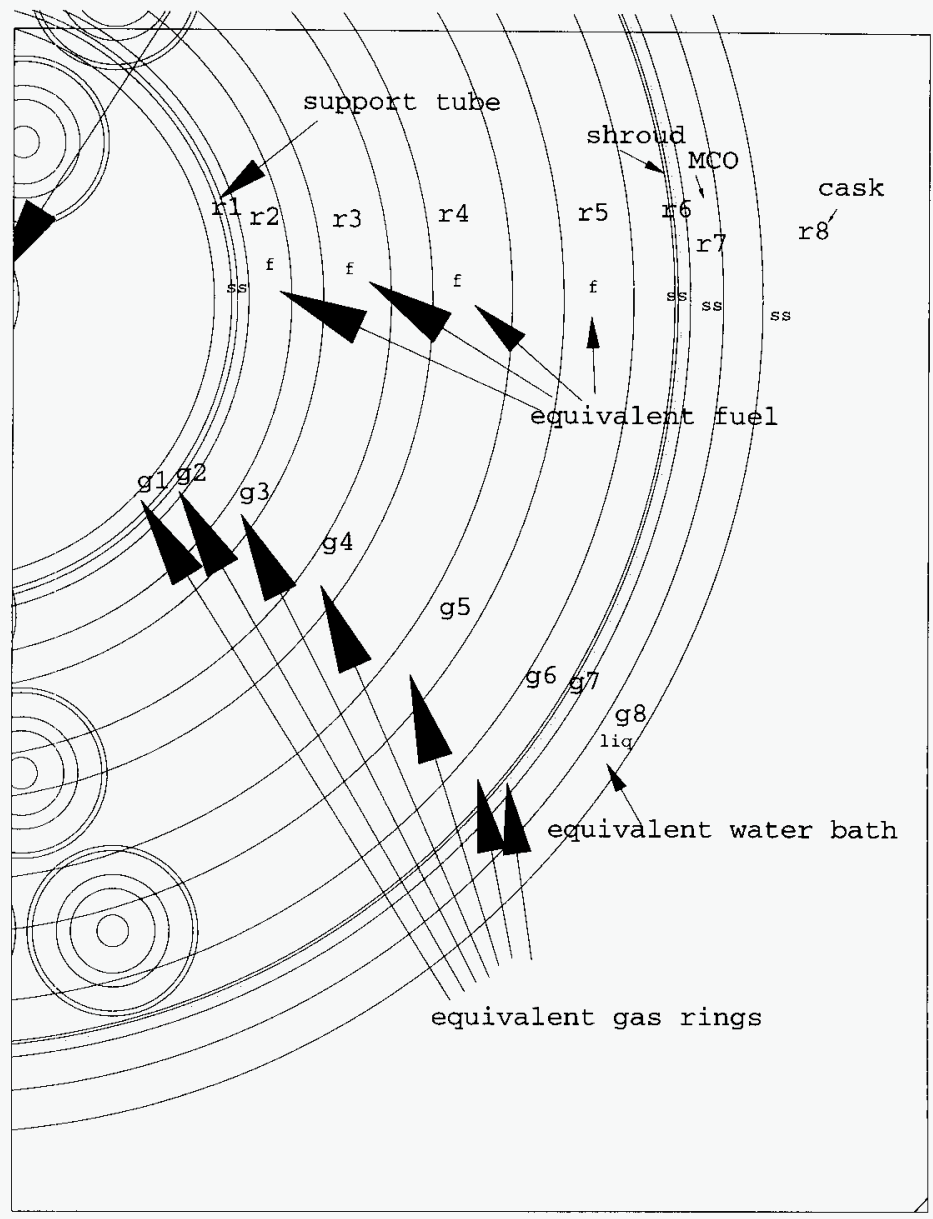

Figure 6.9 Mark IV Basket Bottom Plate with Fuel Socket Holes, Support Pipe, Support Rods, Sheet Metal Shroud, Mark IV Inner and outer Fuel Elements, MCO, and Cask--Zoomed Up 


$$
\text { WHC-SD-SNF-ER-014, Rev. } 0 \text {. }
$$

The model consists of 7 equivalent volume preserving metal rings. Metal ring 1 is the inner support tube, rings 2-5 are the fuel, ring 6 is the basket shroud, and ring 7 is the MCO. Although the cask, ring 8 is shown here, for this simulation it is not included since a water bath at constant temperature is assumed, which would keep the cask at constant temperature so it is not necessary that the cask be modeled in this case. The cask (or tube wall) is included in the simple model used for the MCO pressurization study. The model also includes 7 equivalent volume preserving gas rings, gas rings 1-7. Ring 8, shown in the figures is not included explicitly in the validation model, but is treated as a constant temperature boundary condition. This ring is included in the MCO pressurization study model. Five vertical baskets of fuel are included in both the MCO pressurization model and in this validaton simulation, however, since all are treated uniformly in the validation simulation, there are no axial temperature gradients computed. Axial temperature gradients are calculated in the MCO pressurization model due to the axial variation in reaction area and due to the natural convection of gas within the MCO caused by the density gradients due to gas and heat generation within the $\mathrm{MCO}$.

The inner support tube, basket shroud and MCO are stainless steel with an emissivity of 0.2 . The fuel is treated as being all uranium, but with an exterior surface emissivity of 0.4. The equivalent rings of fuel preserve the volume of the outer and inner fuel elements combined, and the exterior surface of the outer fuel element, but do not include the interior surfaces. Other analysis has shown that the interior element is generally only a few degrees different in temperature than the exterior element and therefore thermal transport between the exterior and interior element does not need to be simulated. Both volume and interior and exterior surface areas of the support tube, basket shroud, and MCO are preserved. In 


$$
\text { WHC-SD-SNF-ER-014, Rev. } 0 \text {. }
$$

this simulation the basket shroud is assumed to be without perforation holes and to extend the full length of the fuel. The radiation view factors across each gas gap in this simulation from the interior surface to the exterior surface are assumed to be 1.0 .

The gas volume external to the fuel elements is preserved, as is the gas volume internal to the fuel elements.

The water bath boundary condition of $50^{\circ} \mathrm{C}$ is assumed for this simulation at the exterior of the MCO ring.

Once drained of liquid, the MCO will contain only residual water, inert gas, or steam during normal process and storage operations. The residual water may exist in the form of bulk water or it may chemically bound water in the form of hydrates or hydroxides. During accident conditions it could contain air. The inert fill gas for the verification simulation is assumed to be argon. Its thermal conductivity compared to those for air and steam is illustrated in Figure 6.10.

The results of the analytical solution and the COBRA-TF solution at near steady state are presented in Figure 6.11. 
WHC-SD-SNF-ER-014, Rev. 0 .

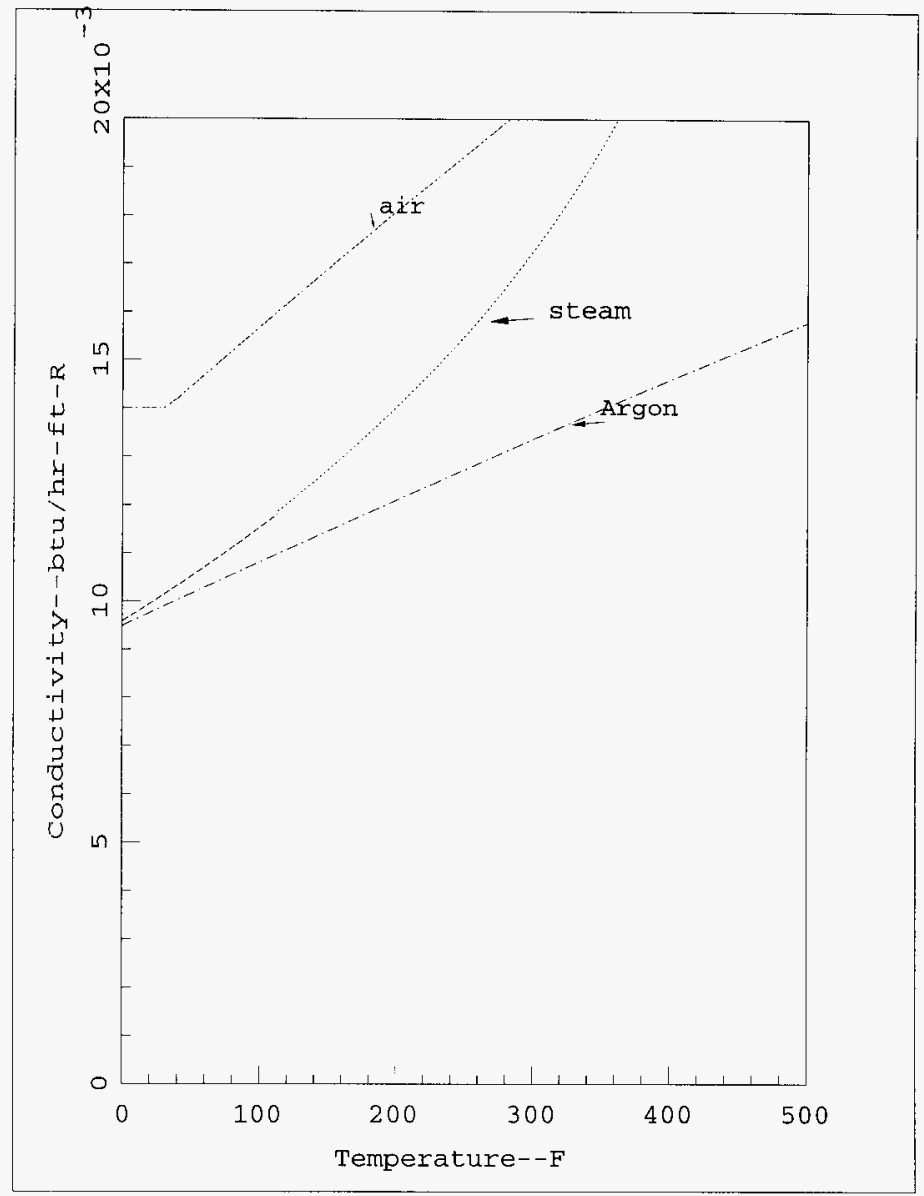

Figure 6.10 Thermal Conductivity of air, argon, steam versus Temperature 
WHC-SD-SNF-ER-014, Rev. 0.

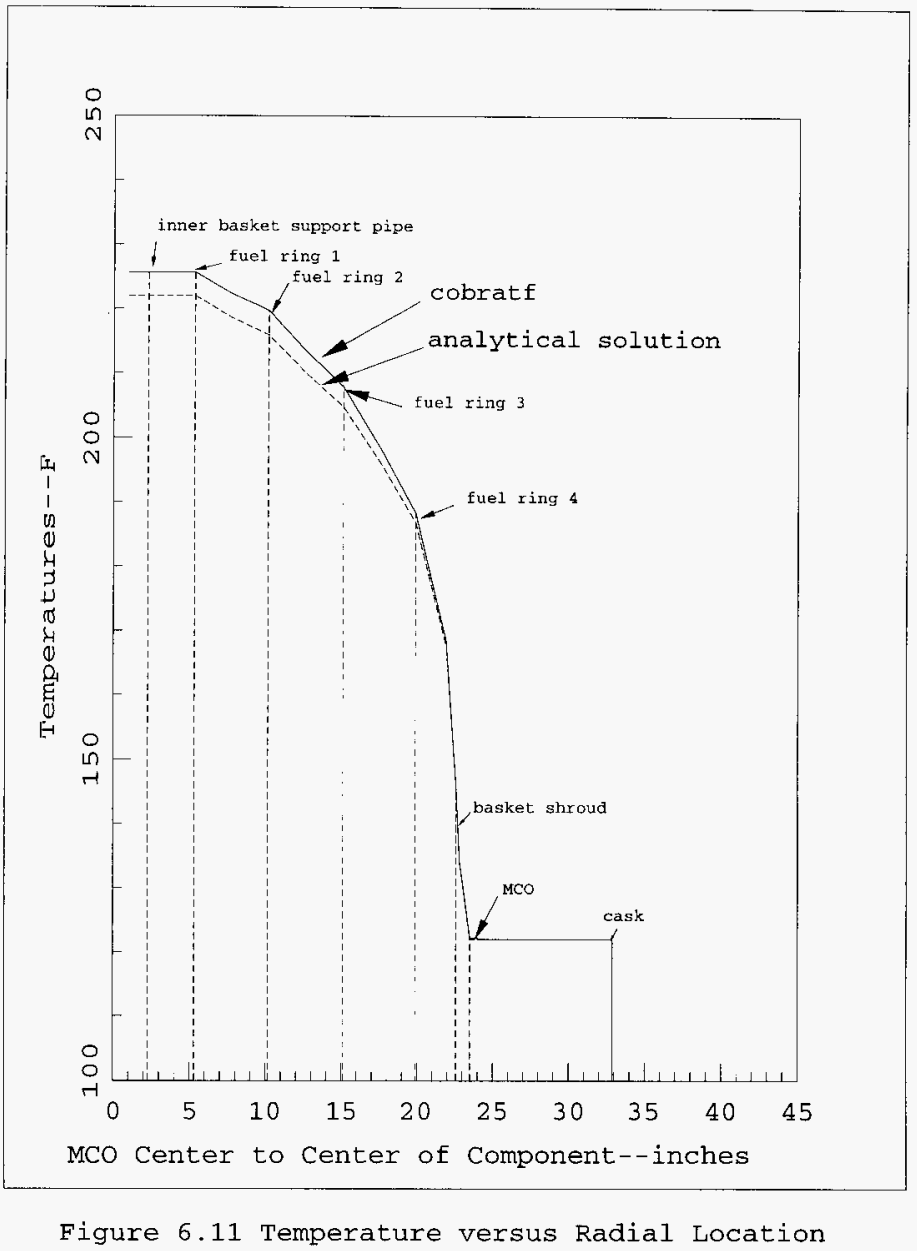




$$
\text { WHC-SD-SNF-ER-014, Rev. } 0 \text {. }
$$

6.1.2.3.2. Application of the Simple MCO Model to MCO Pressurization.

The simple MCO model has been applied in this study to obtain the thermal and pressure response of the MCO to various operational and transient conditions. The model used in this study uses the radial noding described above, including the cask (or tube) and the cask (tube)/MCo gap. The model is divided axially into one vertical node per basket. The chemical reaction area and hydrate mass associated with each ring of fuel in each fuel basket are specified from input and is proportionately split among the fuel elements by surface area. The upper basket is assigned the larger reaction areas and hydrate mass associated with rubble. The heat transport in the rubble basket is based on the fuel rod geometry to provide a conservative lower bound on heat transfer rates in the rubble for pressurization studies. Rubble bed porosity and thermal conductivities can be specified if desired but these have not been used in the MCO pressurization study.

The MCO and cask (tube)/gap are filled with helium gas for drained MCO simulations and with water and air for undrained simulations. External boundary conditions are applied to the cask and tube surfaces as appropriate for each of the conditions analyzed.

The decay heat is specified as a heat source uniformly distributed through the uranium portion of the fuel elements. Heat due to chemical reactions is applied to the surface node of the fuel. 


\subsection{CSB VAULT TEMPERATURE HISTORY.}

\subsubsection{Staging.}

6.2.1.1. Nominal Fully Loaded CSB.

CSB vault inlet and outlet flows and temperatures are shown in Figures 6.12 and 6.13 for nearly three fourths of a year for a fully loaded CSB vault. The air flow through the CSB is nearly constant throughout the year, at about 22,000 CFM. The vault outlet temperature follows the inlet temperature with an average temperature difference of about $30^{\circ} \mathrm{F}$. The difference between the vault outlet and inlet temperatures is shown in Figure 6.16. The temperature gradually increases during the first year as the surrounding soil heats up. The lowest vault outlet temperature is about $50^{\circ} \mathrm{F}$ and the peak vault outlet temperature is about $120^{\circ} \mathrm{F}$. The temperature of the soil to the sides and on the bottom of the CSB at various times during the year are shown in Figures 6.14 and 6.15 .

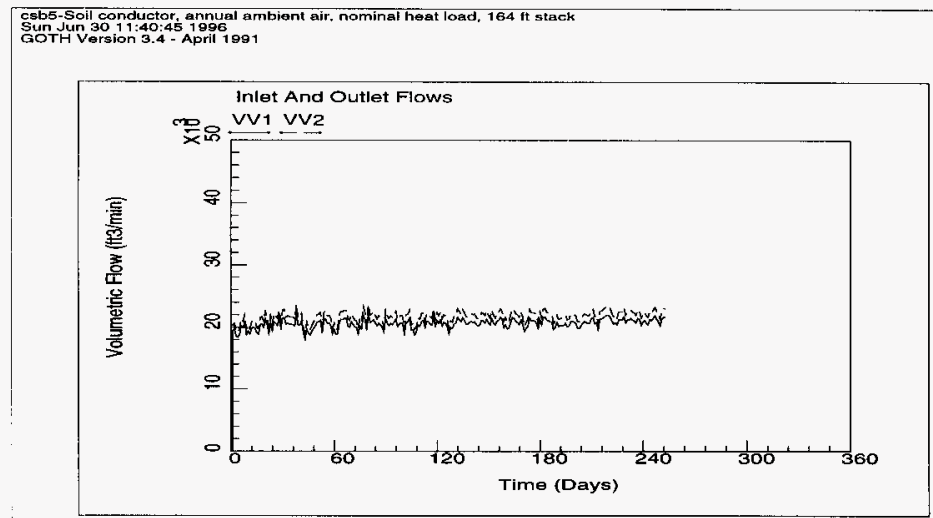

Figure 6.12 Vault Inlet and Outlet Volumetric Flows. 


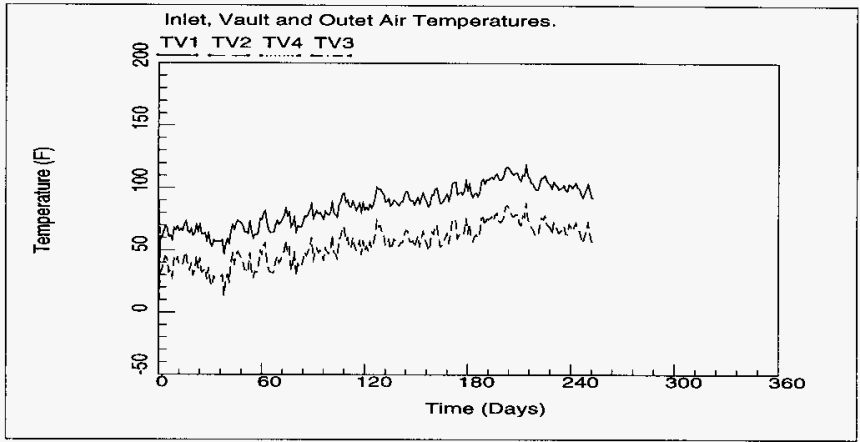

Figure 6.13 Inlet, Vault and Outlet Air Temperatures.

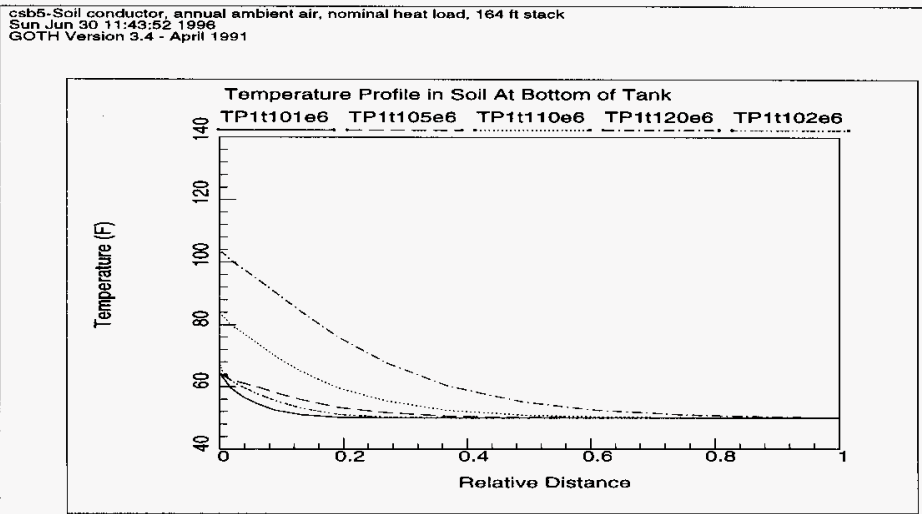

Figure 6.14 Temperature Profile in Soil At Bottom of CSB at Different Times During the Year. 
WHC-SD-SNF-ER-014, Rev . 0.

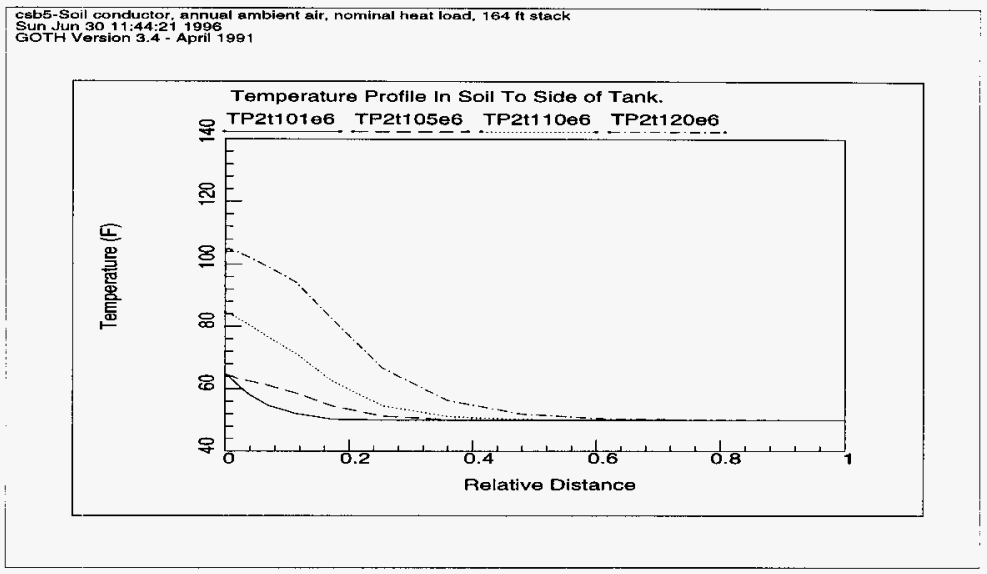

Figure 6.15 Temperature Profile in Soil To Side of CSB at Different Times During the Year.

csb5-Soli conductor, annual ambient air, nominal heat load, $164 \mathrm{ft}$ stack Gun Jun 301 1 $1: 44: 39$ 9 1996 691

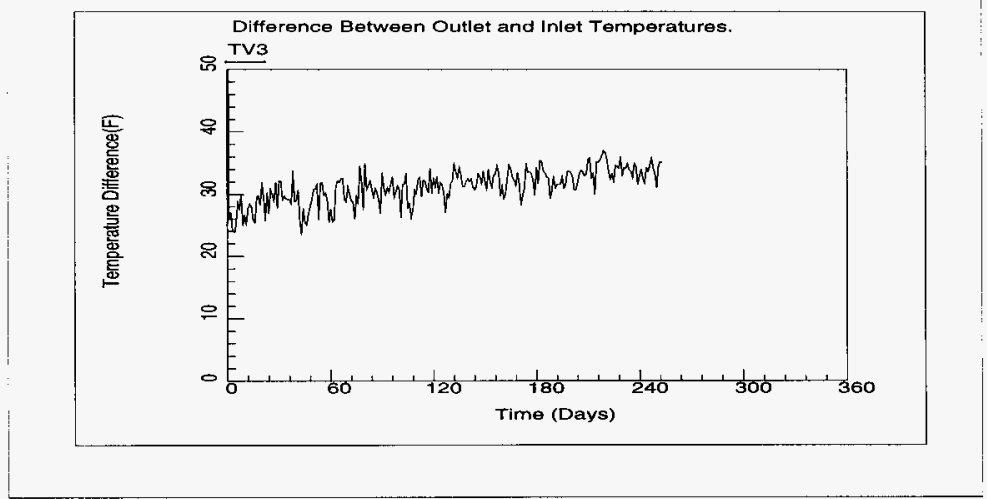

Figure 6.16 Difference Between Inlet and Outlet Air Temperatures. 
6.2.1.1.1. Flow and Temperature Distribution Using TwoDimensional Model.

The results for a two-dimensional simulation of the CSB using nominal heat loading for a fully loaded CSB are presented in Figures 6.17 through 6.19. Figure 6.17 shows the steady state two-dimensional velocity vectors in the CSB inlet structure and plenum, vault, outlet plenum and stack. The velocity vector plot shows that a strong recirculation develops in the vault due to the effects of the down draft created by the incoming cool air and the heating of the air by the MCOs. Air on the down stream side of the MCO tubes rises to the ceiling where the flow splits, some of it recirculating along the upper part of the vault towards the inlet and some flowing along the ceiling towards the outlet where it rises into the stack. The peak temperature in the CSB is not at the exit because of this recirculation, rather, the peak temperature is along the ceiling towards the inlet. This is illustrated by the gas temperature contour plot shown in Figure 6.18. The vault inlet, outlet and peak gas temperatures versus time with steady atmospheric conditions is shown in Figure 6.19. The difference between the peak gas temperature and the outlet temperature is not large $\left(3^{\circ} \mathrm{F}\right)$, suggesting that the simple lumped parameter model is adequate for obtaining MCO temperature boundary conditions for long term transients to evaluate MCO pressurization. This temperature delta will be applied to the CSB storage tube wall to obtain the MCO pressure response. 
WHC-SD-SNF-ER-014, Rev. 0 .

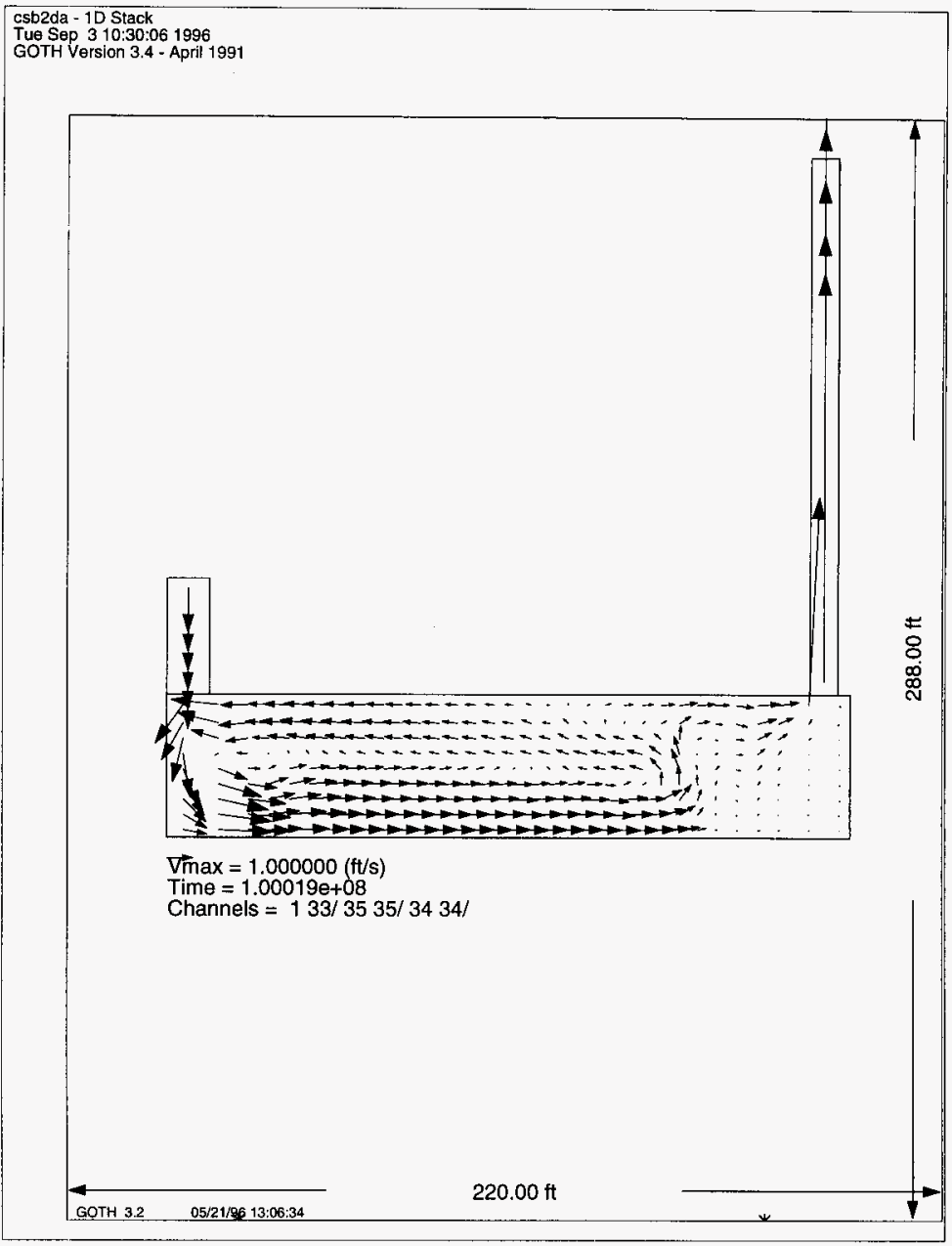

Figure 6.17 Velocity Vectors In CSB. 
WHC-SD-SNF-ER-014, Rev. 0 .

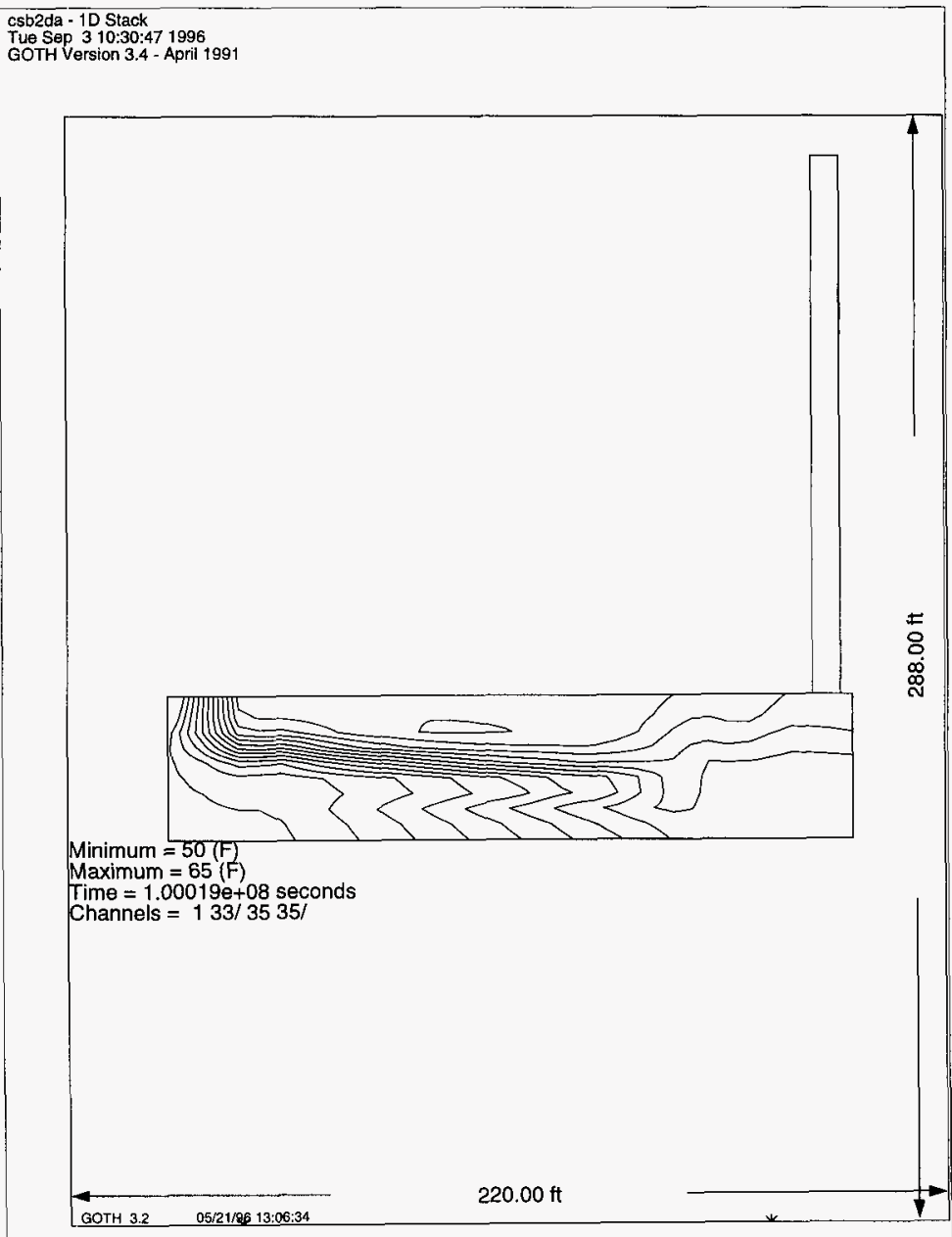

Figure 6.18 Temperature Profile in CSB. 


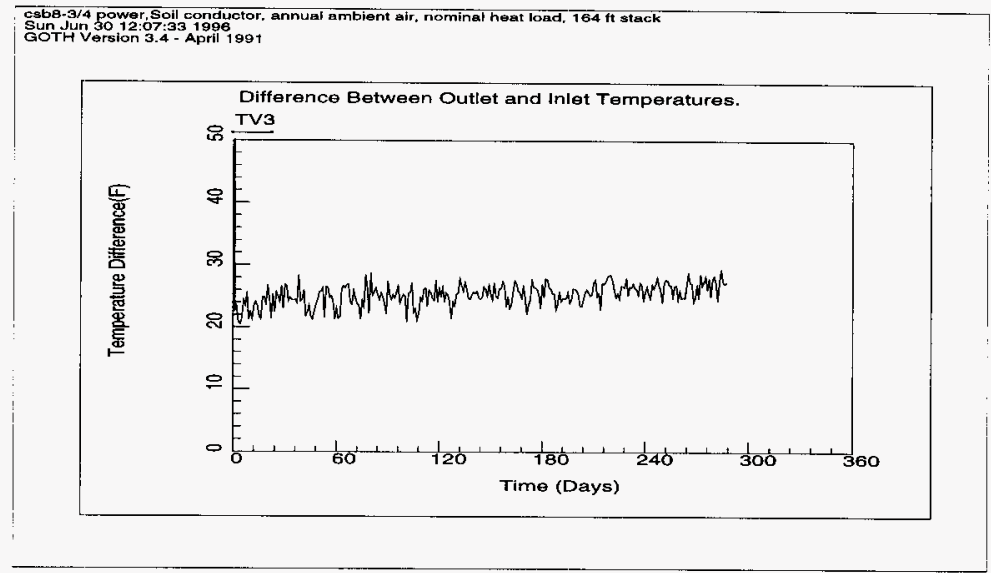

Figure 6.19 Difference Between Vault Inlet and Vault outlet Temperatures.

6.2.1.1.2. Flow and Temperature Distribution Using ThreeDimensional Model.

Time limitations and other project priorities did not permit the completion of a three-dimensional simulation of the CSB. The small temperature gradients obtained from the two-dimensional simulation provide a strong justification for not needing to perform a 3-D simulation.

\subsubsection{Loading Sequence Evaluation.}

Several cases have been run with different heat loads in the CSB to simulate various stages of loading the CSB with MCOs. These cases are described in this section.

6.2.1.2.1. CSB with one Fourth of the Tubes Filled.

The CSB inlet and outlet volumetric flows, inlet and outlet temperatures and difference between the inlet and outlet 
temperatures for a $1 / 4$ loaded CSB vault are shown in the following three figures. The vault volumetric flows are reduced from the fully loaded value to about 15,000 CFM. The minimum vault outlet temperature is about $10^{\circ} \mathrm{F}$ and the peak vault outlet temperature is about $85^{\circ} \mathrm{F}$. The difference between the vault inlet and outlet temperatures is about $17^{\circ} \mathrm{F}$.

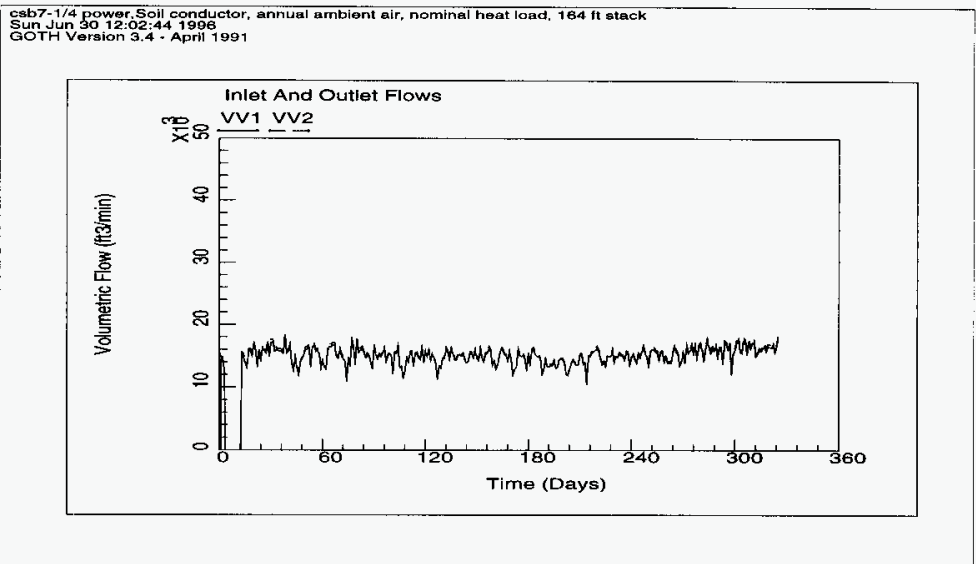

Figure 6.20 Vault Inlet and Outlet Volumetric Flows. 
WHC-SD-SNF-ER-014, Rev . 0 .

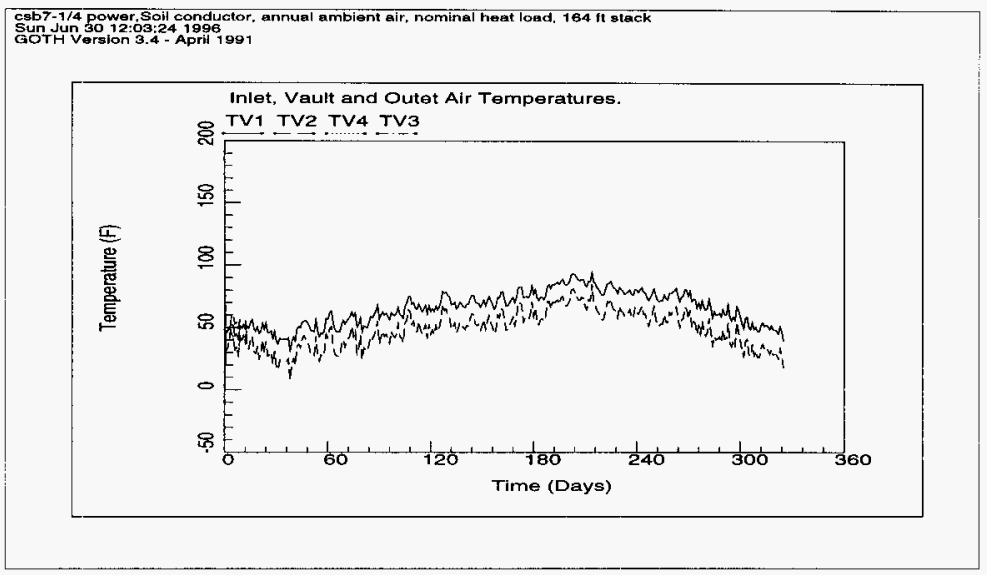

Figure 6.21 Vault Inlet and outlet Air Temperatures.

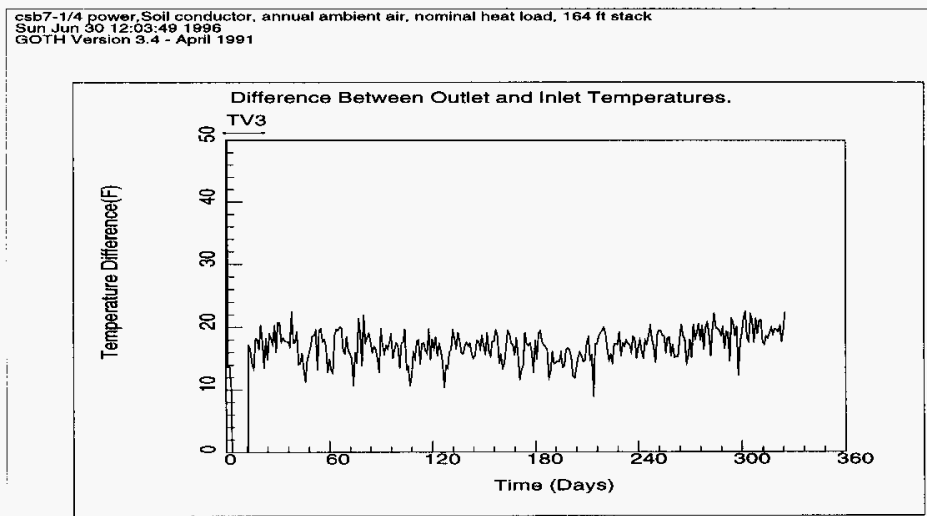

Figure 6.22 Difference Between Inlet and Outlet Air Temperatures. 


\subsection{CSB with one Half of the Tubes Filled.}

The CSB inlet and outlet volumetric flows, inlet and outlet temperatures and difference between the inlet and outlet temperatures for a $1 / 2$ loaded CSB vault are shown in the following three figures. The vault volumetric flows are reduced from the fully loaded value to about 17,000 CFM. The minimum vault outlet temperature is about $15^{\circ} \mathrm{F}$ and the peak vault outlet temperature is about $35^{\circ} \mathrm{F}$. The difference between the vault inlet and outlet temperatures is about $20^{\circ} \mathrm{F}$.

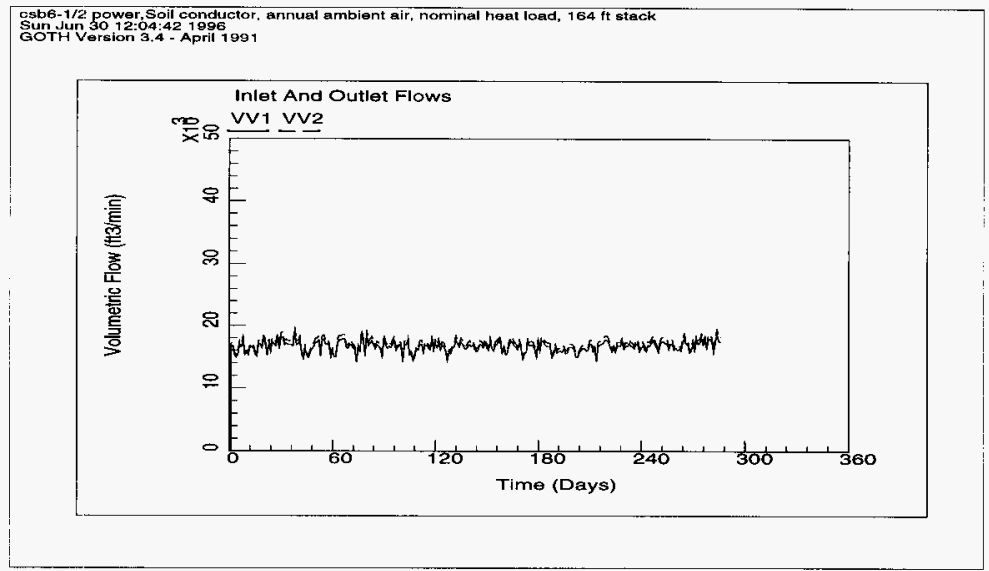

Figure 6.23 Vault Inlet and Outlet Volumetric Flow. 
WHC-SD-SNF-ER-014, Rev. 0 .

csb6-1/2 power, Soll conductor, annual ambient air, nominal heat load, $164 \mathrm{ft}$ stack Sun jữ 30 12:05:01 1996

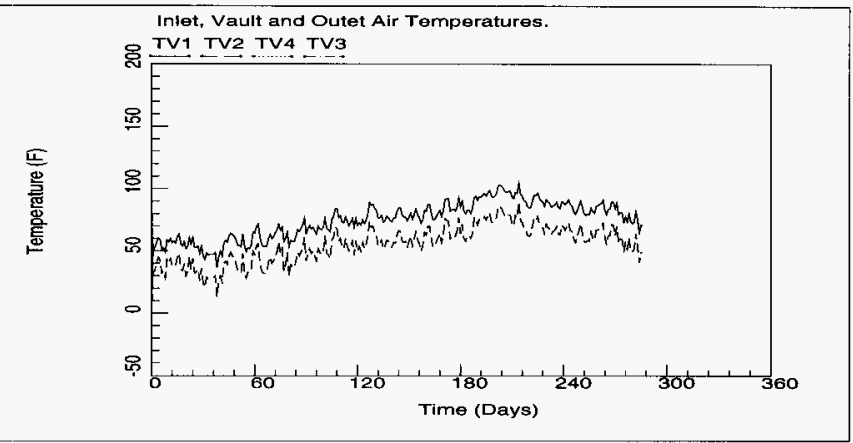

Figure 6.24 Vault Inlet and Outlet Air Temperatures.

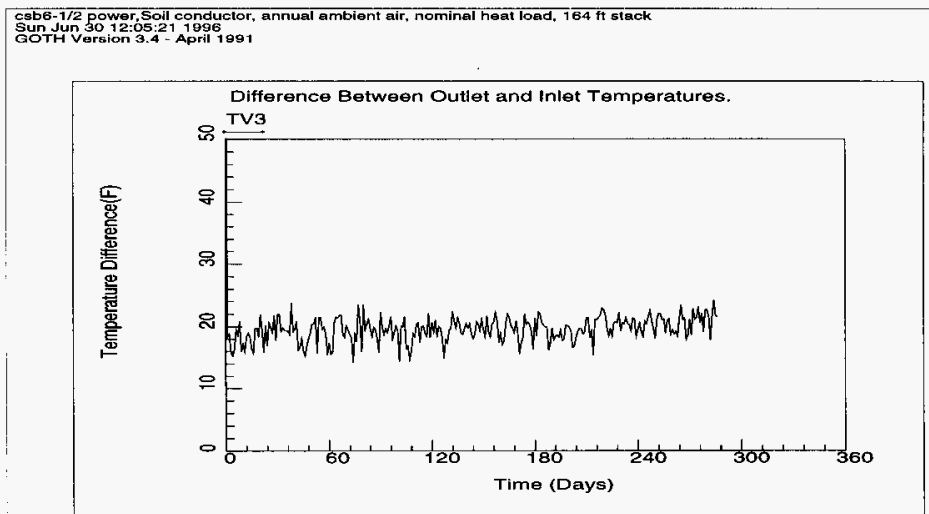

Figure 6.25 Difference Between Inlet and outlet Air Temperatures. 


$$
\text { WHC-SD-SNF-ER-014, Rev. } 0 \text {. }
$$

6.2.1.2.3. CSB with Three Fourths of the Tubes Filled.

The CSB inlet and outlet volumetric flows, inlet and outlet temperatures and difference between the inlet and outlet temperatures for a $3 / 4$ loaded CSB vault are shown in the following three figures. The vault volumetric flows are reduced from the fully loaded value to about 19,000 CFM. The minimum vault outlet temperature is about $15^{\circ} \mathrm{F}$ and the peak vault outlet temperature is about $115^{\circ} \mathrm{F}$. The difference between the vault inlet and outlet temperatures is about $26^{\circ} \mathrm{F}$.

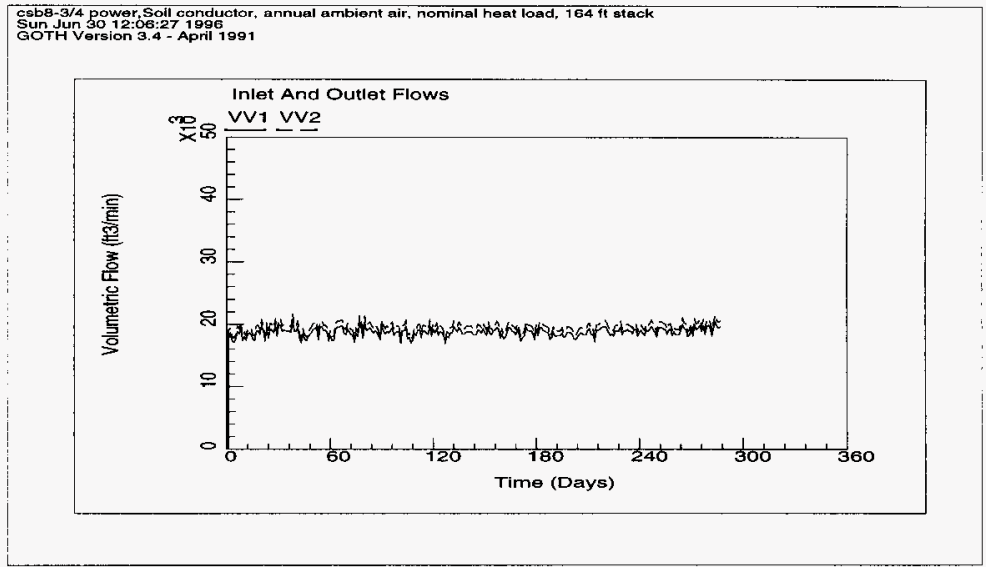

Figure 6.26 Inlet and outlet Volumetric Flow. 
WHC-SD-SNF-ER-014, ReV. 0 .

osb8-3/4 power. Soil conductor, annual ambient air. nominal hoat load, 164 ft stack

Sortun Version 3.4 - April 1991

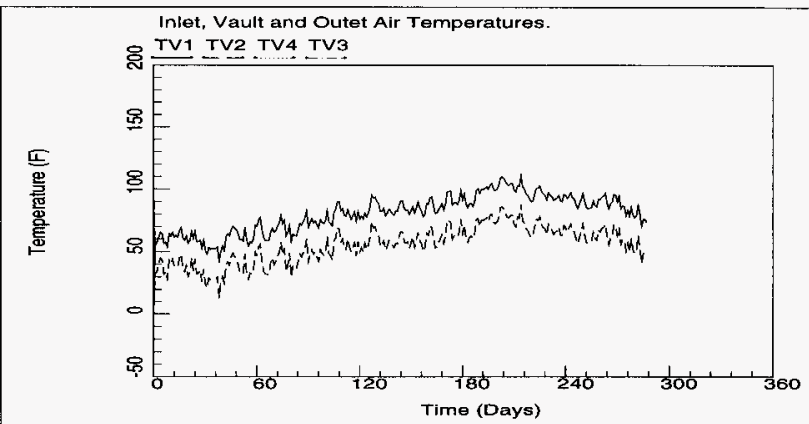

Figure 6.27 Inlet, Vault and Outlet Air Temperatures.

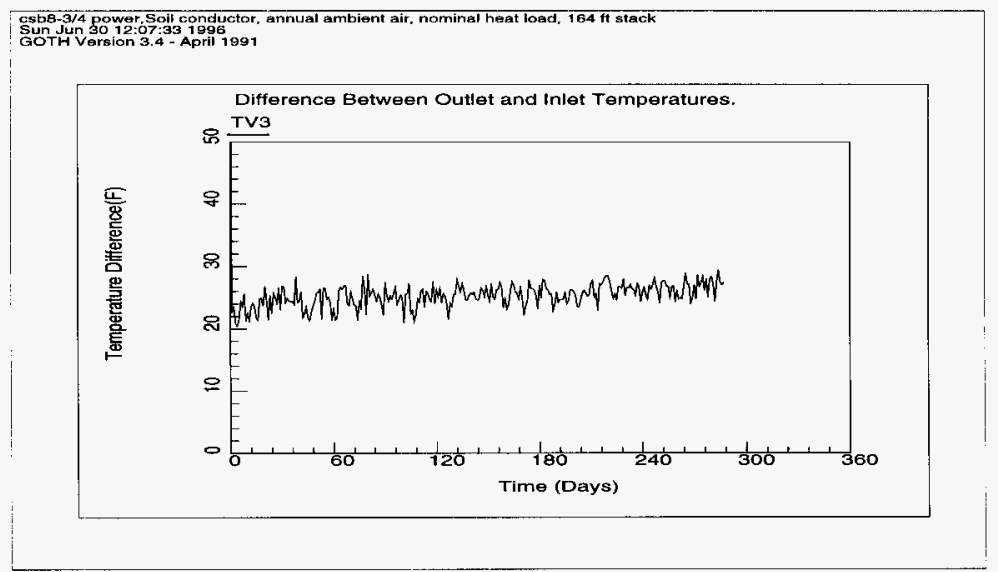

Figure 6.28 Difference Between Inlet and outlet Air Temperatures. 


$$
\text { WHC-SD-SNF-ER-014, Rev. } 0 \text {. }
$$

\subsubsection{Interim storage.}

The temperature history for the $\mathrm{MCO}^{\prime} \mathrm{s}$ stored in the CSB during interim storage is similar to the temperature history for staging, except that, over the 70 year period for interim storage, the decay heat will decrease due the continuing decay of the fission products such that the total heat load in the CSB at the end of interim storage will be about one fourth of what it is at the beginning of interim storage. The complete thermal history for interim storage has not been calculated because of time constraints for completing the analysis and since it has been shown that the rate of oxygen consumption during interim storage is adequate to maintain oxygen generated due to radiolysis at low levels even at the lowest CSB temperatures.

\subsection{MCO SHIPPING TEMPERATURE HISTORY.}

Ambient temperature conditions to which the MCO is exposed to during shipping are those due to the atmospheric temperature conditions imposed on the cask boundary, the incidence of solar radiation on the cask surface and the heat balance between these boundary conditions and the heat generated within the MCO due to radiolytic decay heat and chemical reactions. The atmospheric boundary conditions on the cask and the thermal response of the MCO structures including the effect of decay heat are presented in this section. Results including the effect of chemical heating are presented in the section on MCO pressurization.

\subsubsection{Results for Shipping From Basin to CVDF.}

Two thermal boundary conditions are postulated as bounding for the MCO during shipping from the basin to the cold vacuum drying facility. These two conditions are 1) ambient temperatures for the hottest part of the year and 
WHC-SD-SNF-ER-014, Rev. 0 .

2) ambient temperatures for exposure to a 30 minute fire having a flame temperature of $1475^{\circ} \mathrm{F}$. Each of these conditions are described below.

6.3.1.1. Nominal Shipping Conditions and Shipping Delay.

Thermal boundary conditions for nominal shipping and shipping delay are identical. The difference between the two conditions is the time over which the cask is exposed to these conditions. Nominal shipping is expect to take place within the time of one shift while shipping delay caused by mechanical breakdowns has been postulated to take as much as seven days. Assuming that the cask is loaded at the same time of day and year for both cases, the thermal response for the two cases will be the same for the first eight hours. After this time, the nominal case will be placed in the cold vacuum drying facility, connected to the MCO cooling system and the ambient temperature will be reduced to $10^{\circ} \mathrm{C}$.

The shipping delay case, on the other hand, will not arrive at the CVDF at this time but will continue to be exposed to the atmospheric conditions for a total of seven days. This will result in the continued heat up of the fuel in the MCO due to the poor heat transfer conditions during shipping.

The following conditions are assumed for both conditions in the analysis:

1. Maximum estimates for the diurnal temperature conditions are assumed for the hottest part of the year.

2. The cask is assumed to be exposed to direct sunlight over one half of its entire radial surface area at all times. The solar incidence is based on best estimate values for the longest day of the year. 
WHC-SD-SNF-ER-014, Rev. 0 .

3. The gap between the MCO and Cask is assumed to be filled with air, resulting in the poorest possible heat transfer in the gap.

4. The $\mathrm{MCO}$ is assumed to be filled with water to a level above the fuel in the top basket.

5. The initial temperature of the fuel, water, MCO and Cask is assumed to be $10^{\circ} \mathrm{C}$.

6. The convective heat transfer coefficient between the cask and the ambient conditions is assume to be 1.0 Btu/hr-ft2-F.

7. Radiant heat transfer between the cask surface and the atmospheric temperature condition is assumed to occur.

8. The emissivity of the cask outer surface is assumed to be 0.8 .

9. The emissivity of the case inner surface and the MCO wall is assumed to be 0.2 .

10. The temperature dependent thermal conductivity of air is assumed for the cask/MCO gap.

11. The temperature dependent thermal conductivity of water is assumed of the space between the solid fuel elements and the fuel and the inner MCO wall.

12. The maximum possible decay heat of 929 watts per MCO is assumed.

The diurnal temperatures for the hottest days during calendar year 1994 have been assumed as the basis for the analysis. Hourly temperature data taken at the Hanford weather station during this period for 8.5 days are shown as the solid line in Figure 6.29. The summer of 1994 was 
WHC-SD-SNF-ER-014, Rev . 0 .

an unusually warm year, and on this basis, provides a conservative estimate of the temperatures that the cask will be exposed to when actual shipping begins. However, to assure the analysis is conservative, these measured temperatures have been increased by 15 percent to provide the atmospheric temperatures to be used in the analysis. This temperature history is shown in as the dashed line in Figure 6.29. This produces peak daytime temperatures that are in the range of 115 to $120^{\circ} \mathrm{F}$.

Coincident with the above atmospheric temperatures, it is assumed that the cask surface is exposed to the daily incidence of solar radiation on its surface. The total solar heat flux assumed at the cask surface is shown in Figure 6.30 (solid line) along with the assumed atmospheric temperature condition (dashed line). The solar heat flux ranges between a value of about 150 Joules/m2-s during the peak of the day to zero during the night. The increase in solar radiation from zero is set to coincide with beginning of the increase in atmospheric temperature at the beginning of each day which is assumed to occur at sunrise. 
WHC-SD-SNF-ER-014, Rev. 0.

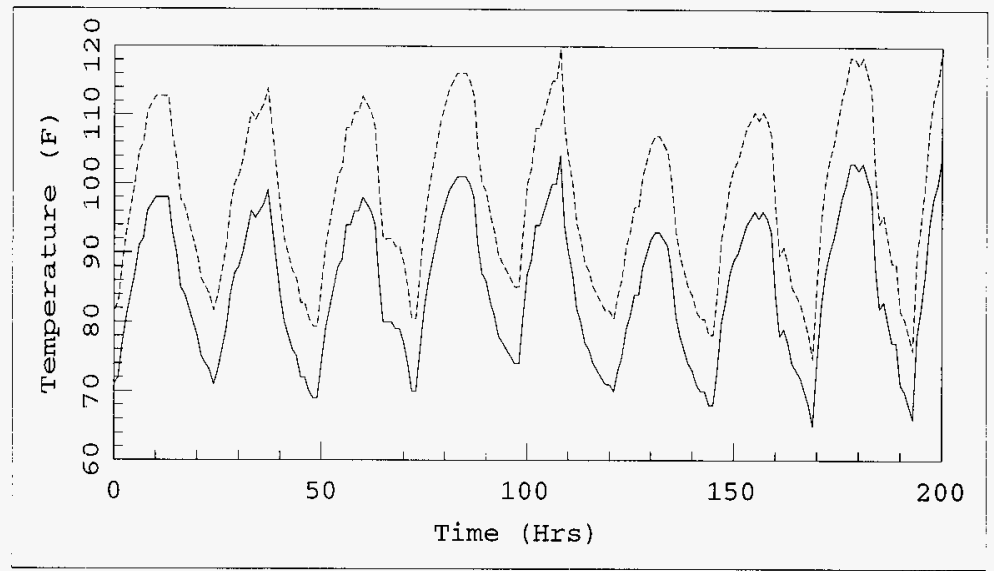

Figure 6.29 Diurnal Temperature Variations - Summer of 1994.

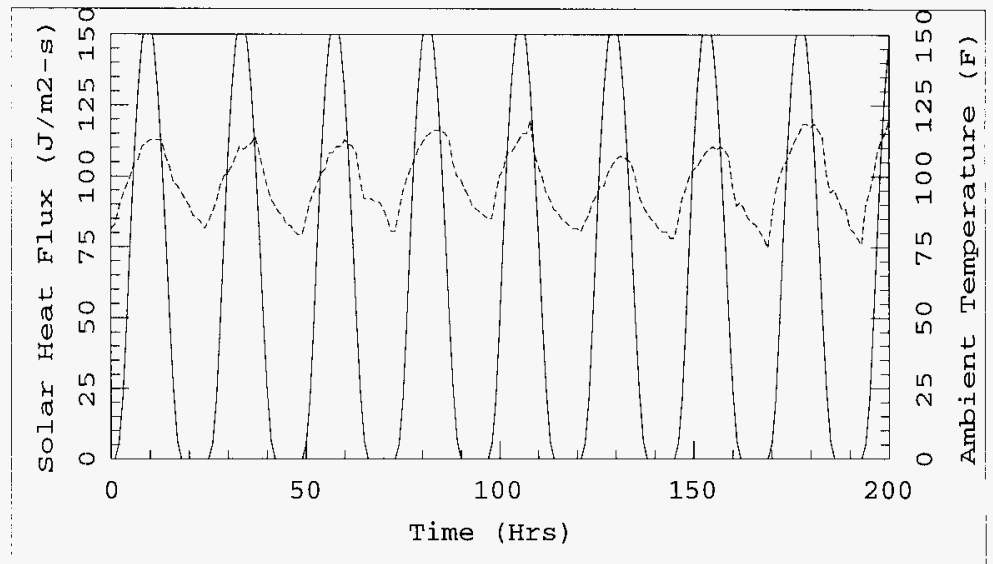

Figure 6.30 Solar Heat Flux on Cask Surface. 
WHC-SD-SNF-ER-014, Rev . 0 .

The thermal response of the inner cask wall, the MCO and the MCO internal structures to the above conditions without chemical reaction heat are shown in Figure 6.31 for a three day period beginning from the initial basin temperature of $10^{\circ} \mathrm{C}\left(50^{\circ} \mathrm{F}\right)$. The effect of the daily variation of the atmospheric temperature and solar incidence on the inner cask wall are clearly evident. This diurnal effects are washed out in the thermal response of the MCO and its internals because of their high thermal mass and the high thermal conductivity of water inside of the MCO and the low thermal conductivity of the air gap between the MCo and the cask inner wall surface. The MCO internals have not reached an equilibrium temperature in this time period but the temperatures have exceeded levels at which significant oxidation reactions between exposed uranium and the fuel will occur. The temperature increase of the Mco internals is maximized in this case by the air filled gap between the MCO and cask inner wall. The MCO internal temperatures would be lower if the gap where to be filled with water. 


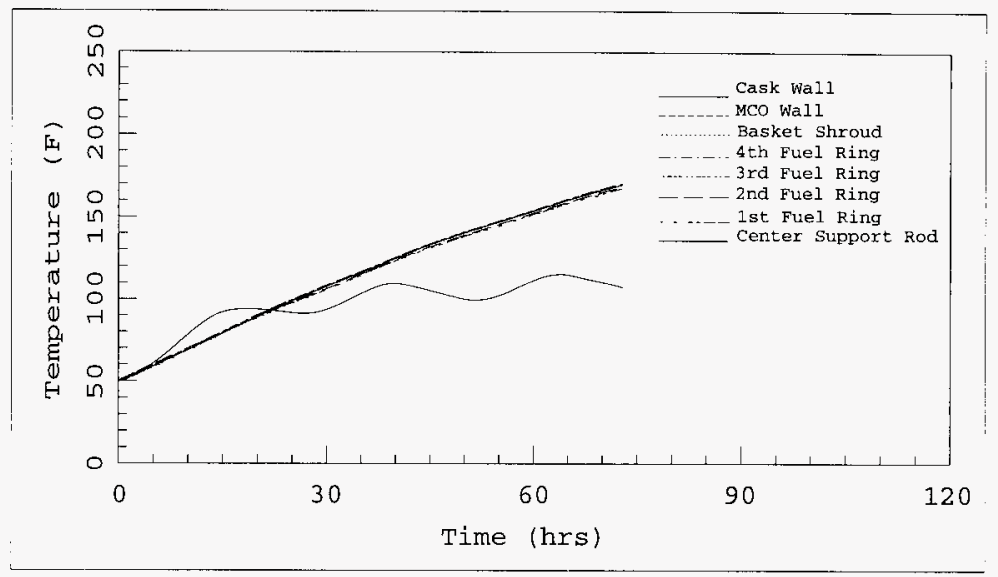

Figure 6.31 MCO Rod and structure Temperatures For the Top Rubble Basket During Heat Up With An Air Filled Gap for a High Powered MCO - No Reactions.

6.3.1.2. Design Basis Fire.

The assumptions for this case are identical to the case above except that the ambient temperature is assumed to be equal to that of the 30 minute design basis fire during the first 30 minutes following the removal of the cask from the basin. The flame temperature of the fire is assumed to be $1475^{\circ} \mathrm{F}$. It is assumed, during this period, that the cask receives heat from the fire through radiant and convective heat transfer due to the difference between the flame temperature and the cask wall temperature. A cask wall emissivity of 0.8 and a convective heat transfer coefficient of $1.0 \mathrm{Btu} / \mathrm{hr}-\mathrm{ft} 2-\mathrm{F}$ are assumed. It is assumed that the cask is exposed to the normal, dry ambient conditions after the fire is extinguished. The thermal response of the inner cask wall, the MCO and its internals are shown in Figure 6.32. The rapid thermal response of 


$$
\text { WHC-SD-SNF-ER-014, Rev. } 0 \text {. }
$$

the cask to the fire is evident in the rapid temperature rise of the inner cask wall. The MCO wall and internal also heat up more rapidly than in the nominal case and some radial temperature distribution is evident in the MCO internals. The temperature rise of the cask wall is reversed with the extinguishing of the fire and the exponential decay of the cask temperature with time occurs as heat is transferred from the cask wall to the MCO and form the cask to the cask surroundings. This condition is more severe than the nominal transportation case and results in higher temperatures in a shorter period of time. This will cause higher water reaction rates in the MCO within a shorter period of time. The temperature rise of the MCO contents is limited, in this case, due to the poor heat transfer characteristics of the air filled gap between the MCO and Cask inner wall. The thermal response of the MCO contents to the fire will be much more rapid if this gap is filled with water. This case has not been considered in this analysis. 
WHC-SD-SNF-ER-014, Rev . 0 .

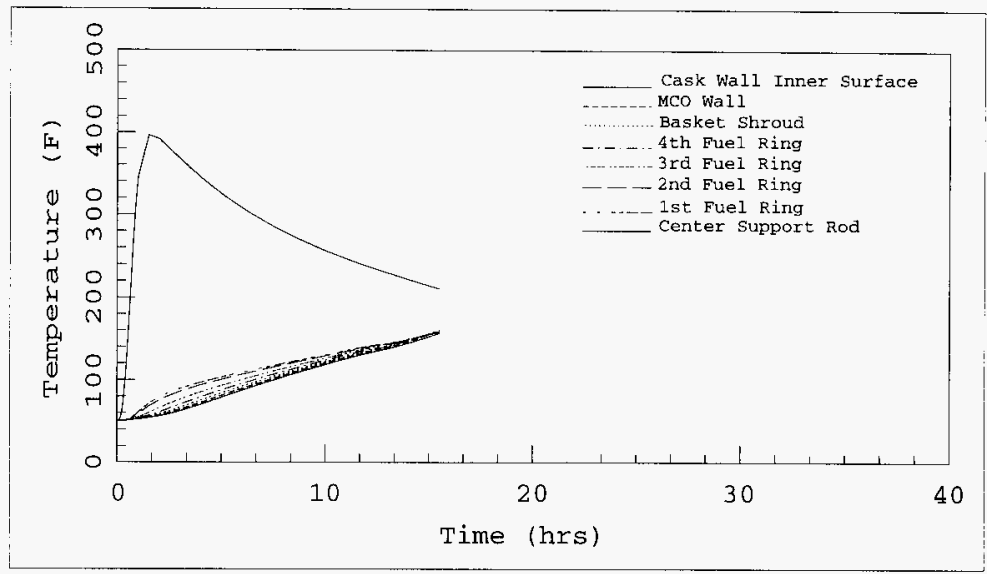

Figure 6.32 MCO Rod and Structure Temperatures For the top Rubble Basket During Heat up with An Air Filled Gap for a High Powered MCO During A 30 Minute Fire.

\subsubsection{Results for Shipping From CVDF to CSB.}

The thermal conditions for shipping from the CVDF to the CSB are different than those for shipping from the Basin to the CVDF in that the MCO is assumed to be filled with helium rather than water and the gap between the cask and the MCO is assumed to be filled with helium rather than air. This will result in improved heat transfer between the MCO and cask inner wall but degraded heat transfer between the fuel and the MCO wall as compared to shipping from the basin to the CVDF. Also, the initial temperature for the cask and $\mathrm{MCO}$ is $25^{\circ} \mathrm{C}\left(77^{\circ} \mathrm{F}\right)$ for this case. The result will be that the fuel heating rate will be higher during shipping from the CVDF to the CSB than it is for shipping from the basin to the CFDF. However, all of the free water will have been removed from the MCO in the CVDF 


$$
\text { WHC-SD-SNF-ER-014, Rev. } 0 \text {. }
$$

so the chemical reaction rates will be significantly reduced for this case with the main source of gas generation coming from the decomposition of the hydrates remaining in the MCO. Other than these two conditions (initial temperature and helium gas fill) all other assumptions for this condition are the same as for the basin to CVFD shipping case. The temperature response of the MCO structures for this condition without chemical reactions are shown in Figure 7.42 .

\section{MCO PRESSURIZATION.}

The following table summarizes the key transients that have been analyzed for MCO pressurization and the important input parameters for these calculations. 
WHC-SD-SNF-ER-014, Rev. 0

Table 7.1 Key Transients and Important Parameters.

\begin{tabular}{|c|c|c|c|c|c|c|c|c|c|c|}
\hline \multicolumn{2}{|c|}{$\begin{array}{l}\text { Case } \\
\text { Case } \\
\text { No. }\end{array}$} & \multirow{2}{*}{ 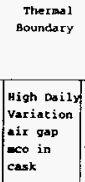 } & \multicolumn{2}{|l|}{$\begin{array}{l}\text { Stean/vate } \\
\text { Reaction } \\
\text { Ared }\end{array}$} & $\begin{array}{l}\text { Pree } \\
\text { rater }\end{array}$ & $\begin{array}{l}\text { Free chs } \\
\text { Volume }\end{array}$ & $\begin{array}{l}\text { Surface } \\
\text { water }\end{array}$ & $\begin{array}{l}\text { Rubble } \\
\text { Bosket } \\
\text { Location }\end{array}$ & \multicolumn{2}{|c|}{$\begin{array}{l}\text { Decay Heat Initial } \\
\text { Temperatu }\end{array}$} \\
\hline 1A & $\begin{array}{l}\text { Iranspoax delay from Basin to } \\
\text { cro }\end{array}$ & & $\begin{array}{l}\text { rubble: } \\
\text { 8000000 } \\
\text { Fuel: } \\
\text { Top } 5 \text { inch }\end{array}$ & 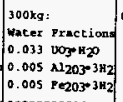 & $0.5=^{3}$ & $0.05 m^{3}$ & $300 \mathrm{~kg} * 0.0$ & rop & 929 watts & $5100 \mathrm{c}$ \\
\hline 18 & Transport Pire & $\begin{array}{l}2475^{\circ} \text { f for } \\
30 \text { ain } \\
\text { air gas } \\
\text { wco in } \\
\text { cask }\end{array}$ & as above & as above & as above & as above & as above & Top & as above : & as above \\
\hline $2 \lambda$ & Draining Pailure & $\begin{array}{l}50^{\circ} \mathrm{c} \\
\text { water gap }\end{array}$ & as above & $\begin{array}{l}1.5 \mathrm{~kg} \\
\text { fraction above }\end{array}$ & $0.055 \mathrm{~m}^{3}$ & $0.5 \mathrm{~m}^{3}$ & as above & Top & as above & $50^{\circ} \mathrm{C}$ \\
\hline 2B & Draining Pailure & as above & as above & as above & $0.46 \mathrm{~s}^{3}$ & $0.11 \mathrm{~m}^{3}$ & as above & Tos & as above & as above \\
\hline $2 c$ & Water Jacket over heat & $\left|\begin{array}{l}150^{\circ} \mathrm{c} \\
\text { ater gap }\end{array}\right|$ & as above & as above & ? & $?$ & as above & rop & as above & as above \\
\hline 32 & Transporte delay ca csB & $\begin{array}{l}\text { hot aver ag } \\
\text { daily } \\
\text { heli gatie gad } \\
\text { hel iun aco }\end{array}$ & of above & $\begin{array}{l}155 \mathrm{~kg} \\
\text { fractions above }\end{array}$ & $\{0.0$ & 0.55 & as above & Tos & as above 2 & $25^{\circ} \mathrm{C}$ \\
\hline 36 & Tramport to cse tire & 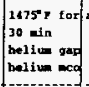 & as above & $\begin{array}{l}155 \mathrm{~kg} \\
\text { fractions above }\end{array}$ & 0.0 & 0.55 & as above & TOP & as above & $25 \mathrm{C}^{\circ}$ \\
\hline 4s & Staging at CSE & 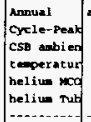 & As above & $\begin{array}{l}160 \mathrm{~kg} \\
\text { tractions abord }\end{array}$ & 0.0 & 0.55 & as above & Top & as above & $500 \mathrm{C}$ \\
\hline sos & Interin storage & $\begin{array}{l}\text { Annual } \\
\text { cycle-Peak } \\
\text { csb ambien } \\
\text { teaperatur } \\
\text { Helium rco } \\
\text { Helium tub }\end{array}$ & 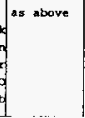 & $\begin{array}{l}300 \mathrm{~kg} \\
\text { fractions above }\end{array}$ & 0.0 & 0.55 & as above & Top & as above & $50^{\circ} \mathrm{C}$ \\
\hline
\end{tabular}




\subsection{PRESSURIZATION DURING STORAGE.}

\subsubsection{Staging.}

Five cases have been evaluated for MCO pressurization during staging in the CSB. The first case is the bounding case which assumes a maximum MCO decay heat of 929 watts, a rubble basket reaction area of $800,000 \mathrm{~cm}^{2}$ and $150 \mathrm{Kg}$ of oxidation products in the rubble basket. The second case is the same as the first except that the decay heat is reduced to 750 watts and the reaction area is reduced to $80,000 \mathrm{~cm}^{2}$. The third case is the same as the second except the oxidation product mass is reduced to $70 \mathrm{~kg}$. The fourth case differs from the third in that the reaction area is reduced to $57,000 \mathrm{~cm}^{2}$. The fifth case differs from the third case in that an oxidation product mass of 16 $\mathrm{Kg}$ is assumed.

The CSB temperature used in the analysis uses the hottest 8.5 days of summer temperature for the CSB with $15 \%$ added for uncertainty in the summer temperature and $5^{\circ} \mathrm{F}$ added for 2-dimensional temperature variations in the CSB. This temperature is shown in Figure 7.1 as the dashed line. The corresponding atmospheric temperature is shown as the solid line in the same figure. 
WHC-SD-SNF-ER-014, Rev. 0 .

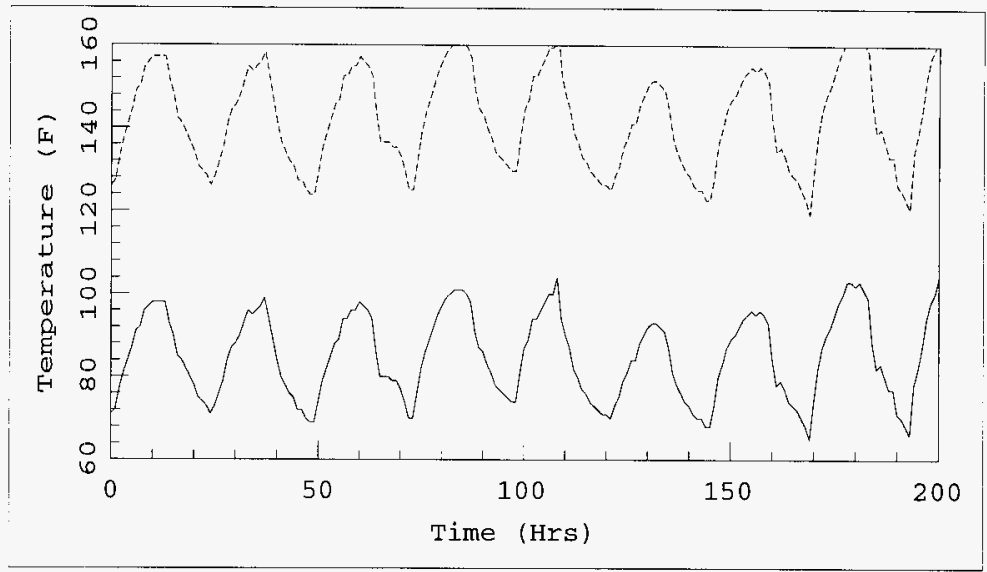

Figure 7.1 CSB Diurnal Temperature Variations - Summer of 1994 .

The thermal and pressure transients for the staging of the highest powered MCO in the CSB during the hottest part of summer are presented below.

7.1.1.1. MCO Thermal Solution Without Chemical Reactions.

The thermal transient for the fuel without any chemical reactions occuring is shown in Figure 7.2 and the pressure transient for this case is shown in Figure 7.3. The thermal transient begins from an initial uniform temperature of $50^{\circ} \mathrm{C}\left(122^{\circ} \mathrm{F}\right)$. There is no solar heating assumed since the MCO is inside of the cask which is inside of the CSB. The diurnal variation in the CSB vault temperature due to diurnal variations in the atmospheric temperature are clearly evident in the storage tube wall temperature. This diurnal fluctuation is severly damped out in the MCO internal temperatures which show little variation in temperature on a daily basis. The peak fuel 


$$
\text { WHC-SD-SNF-ER-014, Rev. } 0 \text {. }
$$

temperature is approaching $300^{\circ} \mathrm{F}$ for the steady state temperature. Storage of the MCO in the CSB storage tube is a much worse thermal condition than storage of the MCO in the transportation cask because 1) the environment temperature is higher for the CSB $\left(150^{\circ} \mathrm{F}\right.$ versus $\left.-100^{\circ} \mathrm{F}\right)$ 2) the heat transfer area of the storage tube is much less than that of the cask and 3) the storage tube is surrounded by other storage tubes at essentially the same temperature so there is no radiant heat loss. One would, therefore, expect higher fuel temperatures in the CSB and, if water is present, higher water/uranium reaction rates. Temperature excursions will be more likely to occur in the CSB than during transportation if water is present and if the reaction surface area is large enough.

The MCO pressurizes due to the thermal expansion of the fill gas, in this case helium. The pressure in the sealed MCO and the sealed MCO/cask gap are shown in Figure 7.3. 
WHC-SD-SNF-ER-014, Rev. 0 .

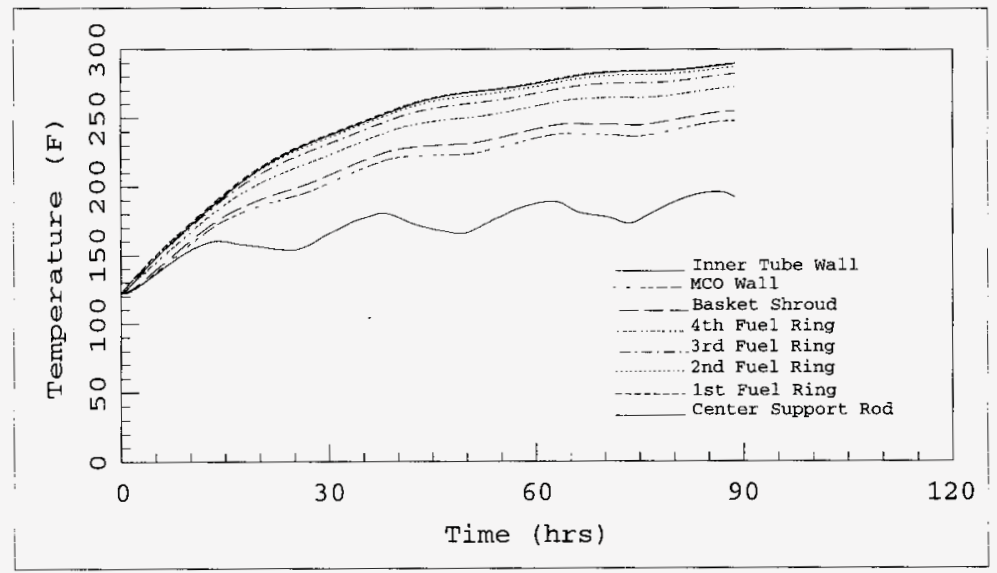

Figure 7.2 MCO Rod and Structure Temperatures For the Rubble Basket Heat Up During staging in the CSB With Helium Filled Tube/MCO Gap and MCO and Without Any Chemical Reactions for a High Powered MCO (929 watts). 


$$
\text { WHC-SD-SNF-ER-014, Rev. } 0 \text {. }
$$

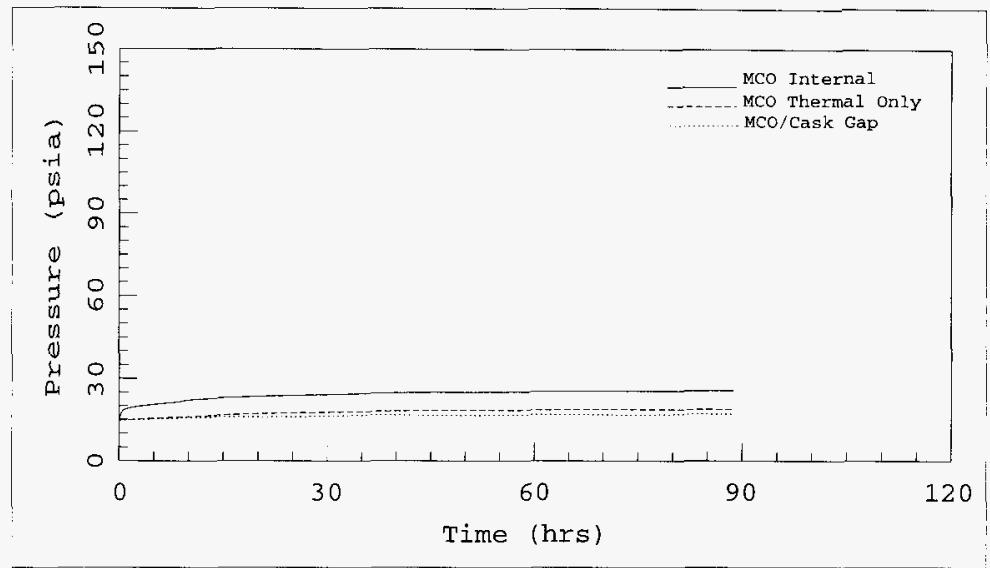

Figure 7.3 MCO Pressurization Rates For the Rubble Basket Heat Up During staging with Helium Filled Tube/MCO Gap and MCO and Without Any Chemical Reactions for a High Powered MCO (929 watts).

7.1.1.2. Bounding Case.

The thermal and pressure transient of the maximum powered MCO (929 watts of decay heat) containing $150 \mathrm{Kg}$ of corrosion products in the top rubble basket that has a reaction surface area of $800,000 \mathrm{~cm}^{2}$ stored in the peak temperature location of the CSB vault on a hot summer day with the $\mathrm{MCO}$ and fuel starting from a temperature of $50^{\circ} \mathrm{C}$ $\left(122^{\circ} \mathrm{F}\right)$ is shown below. The MCO and tube are assumed to be inerted with Helium gas.

The fuel temperatures increase at a much faster rate than the case without chemical heating due to the rapid increase in heat released by the uranium/water reaction CSB storage temperatures. This is shown in Figure 7.4, which shows the Tube, MCO and fuel temperatures plotted on the same time scale as has been used for the case without chemical 


$$
\text { WHC-SD-SNF-ER-014, Rev. } 0 \text {. }
$$

reactions. The same temperatures are plotted on a smaller time scale and a larger temperature scale in Figure 7.5 so that the thermal response and time can be more easily seen for this case. The rate at which heat is being generated significantly exceeds the rate at which heat can be removed for this configuration and a temperature excursion occurs at about 4.5 hours after the initiation of the transient. The exact timing of the excursion will depend on the time of year the MCO is placed into the CSB, the arrival temperature of the MCO, the loading time and on how full the CSB is. This analysis assumes that the high powered MCO is loaded into the last tube of a fully loaded CSB on the hottest day of the year.

The peak temperature of the fuel is expected to reach about $1000^{\circ} \mathrm{F}$ for this case. The case has not been run further because the rapid increase in temperature, MCO pressure and hydrogen generation cause the code to reduce the time step to such a small value that running the problem out further is impractical with the current code. Coupling the thermal solution of COBRA-TF with the hydrodynamic solution of GOTH would resolve this problem.

The pressurization of the MCO for this case is shown in Figure 7.6. There is sufficient water in the amount of hydrate assumed for this case to increase the MCo pressure to $320 \mathrm{psi}$ so venting of the MCO would be required. The MCO pressure has not yet reached this pressure because the less than half of the $\mathrm{UO}_{3} \cdot 2 \mathrm{H}_{2} \mathrm{O}$ hydrate has been decomposed at the end of the calculation and this hydrate contains most of the water mass. The hydrogen gas content of the MCO at the elevation of the rubble basket is shown in Figure 7.7 and the hydrate water mass inventory for each of the three hydrates are shown in Figures $7.8,7.9$ and 7.10 . All of the aluminum and iron hydrate and over half of the uranium hydrate in the center of the rubble basket have been decomposed by the end of the simulation while not quite all of the iron hydrate and none of the other hydrates have been decomposed on the cooler outer perimeter 
of the rubble basket. All of the hydrates will completely decompose within minutes due to the temperature excursion created the high uranium/water reaction rate at these temperatures.

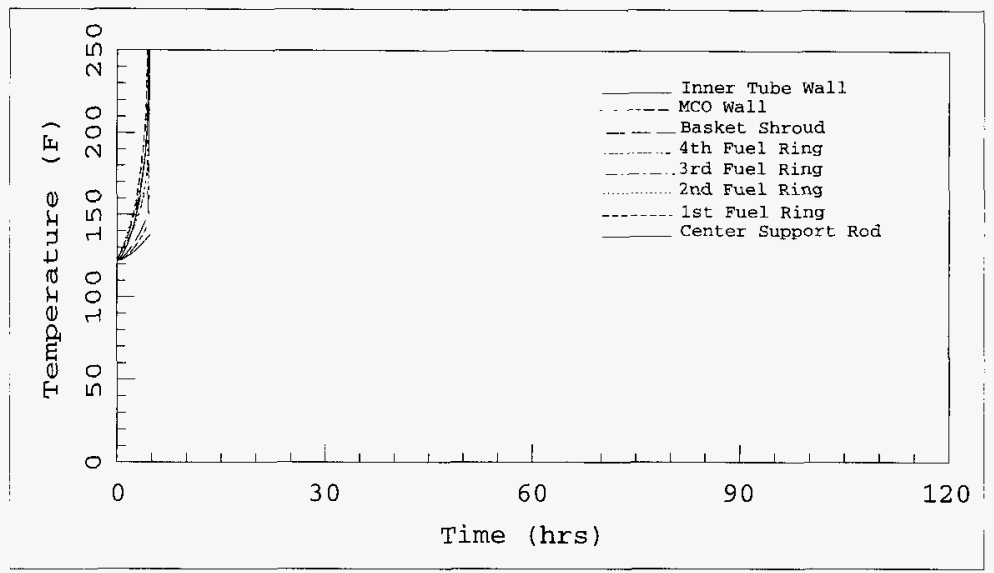

Figure 7.4 MCO Rod and structure Temperatures For the Rubble Basket Heat Up During staging in the CSB With Helium Filled Tube/MCO Gap and MCO and with Chemical Reactions Due to the Decomposition of the Reaction Product Hydrates. $A_{R}=800,000 \mathrm{~cm}^{2}$; $\mathrm{m}_{\mathrm{RP}}=150 \mathrm{Kg} ; Q_{\mathrm{DH}}=929$ watts. 
WHC-SD-SNF-ER-014, Rev. 0 .

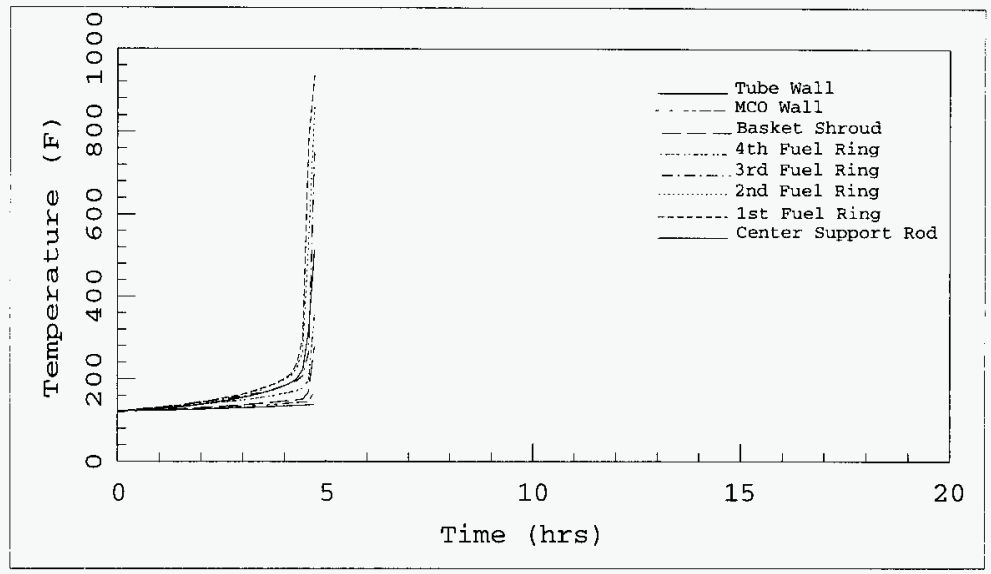

Figure 7.5 MCO Rod and Structure Temperatures For the Rubble Basket Heat Up During Staging in the CSB with Helium Filled Tube/MCO Gap and MCO and With Chemical Reactions Due to the Decomposition of the Reaction Product Hydrates. $A_{R}=800,000 \mathrm{~cm}^{2}$;

$m_{\mathrm{RP}}=150 \mathrm{Kg} ; \mathrm{Q}_{\mathrm{DH}}=929$ watts. 
WHC-SD-SNF-ER-014, Rev. 0 .

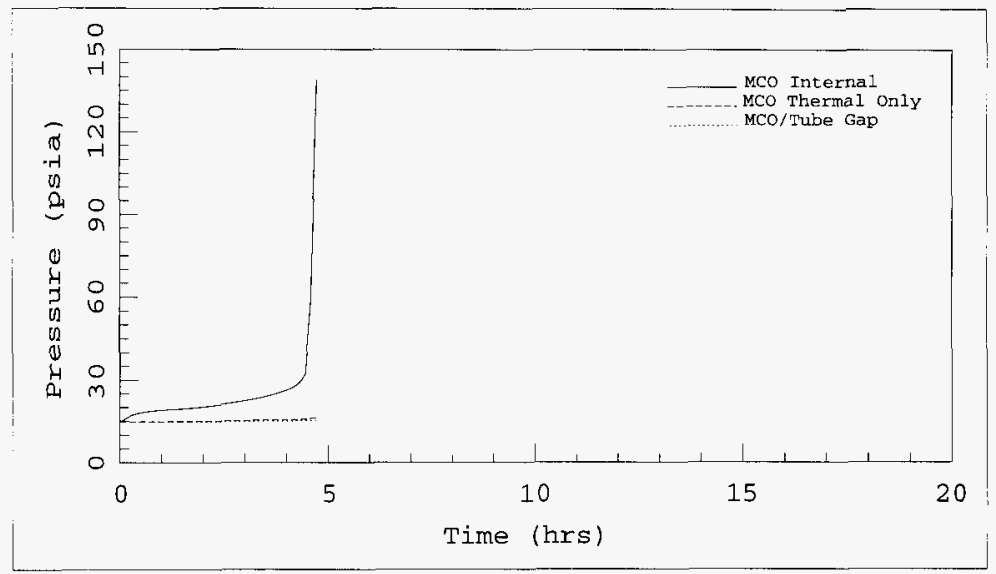

Figure 7.6 MCO Pressurization Rates for the Rubble Basket Heat Up During staging in the CSB With Helium Filled Tube/MCO Gap and MCO and with Chemical Reactions Due to the Decomposition of the Reaction Product Hydrates. $A_{R}=800,000 \mathrm{~cm}^{2} ; m_{R P}=150 \mathrm{Kg} ; Q_{D H}=$ 929 watts. 
WHC-SD-SNF-ER-014, Rev , 0 .

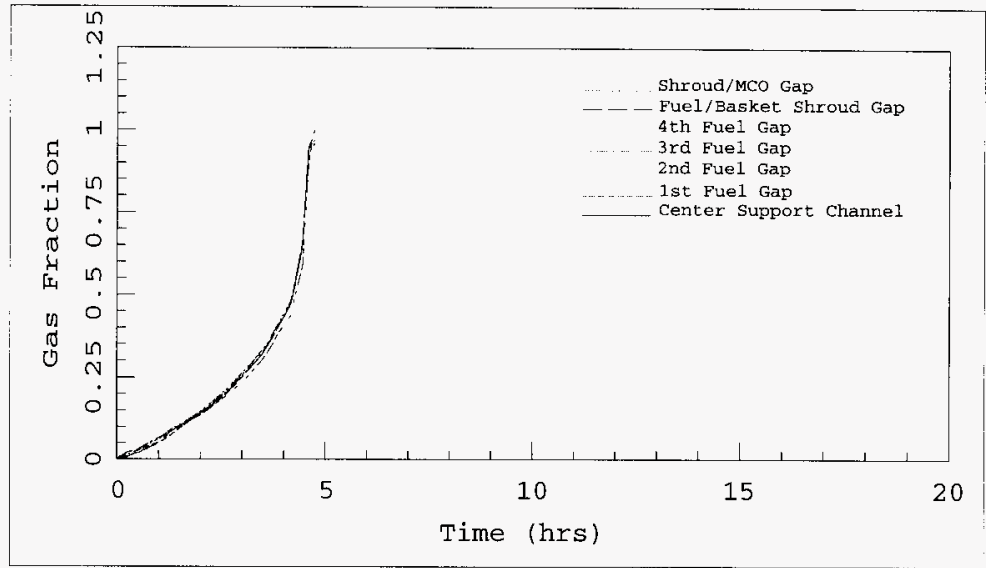

Figure 7.7 Hydrogen Gas Volume Fractions in the Rubble Basket For Rubble Basket Heat Up During staging in the CSB with a Helium Filled Tube/MCO Gap and MCO and with Chemical Reactions Due to the Decomposition of the Reaction Product Hydrates. $A_{R}=800,000 \mathrm{~cm}^{2} ; m_{R P}=150 \mathrm{Kg} ; Q_{D H}=929$ watts. 
WHC-SD-SNF-ER-014, Rev. 0 .

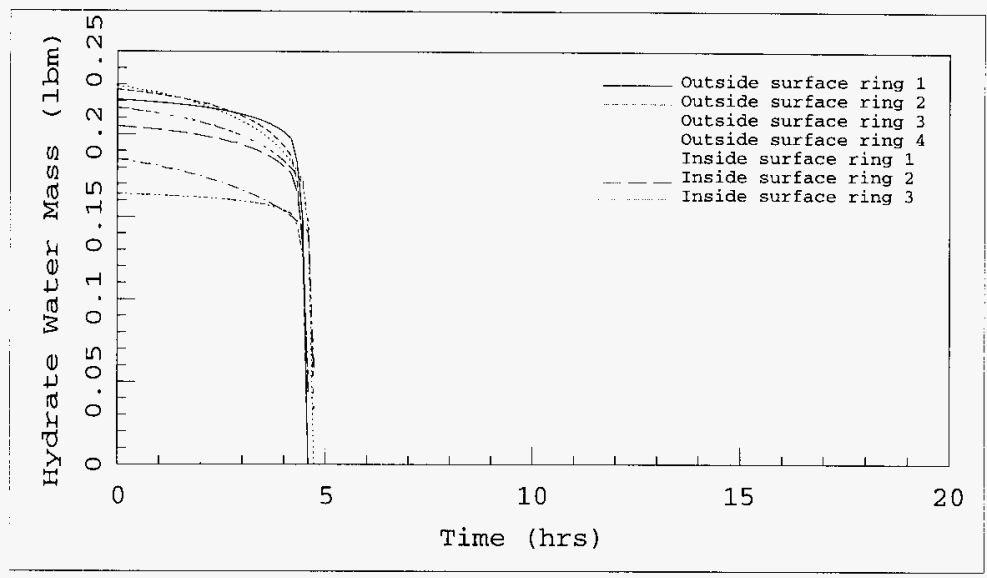

Figure $7.8 \mathrm{Fe}_{2} \mathrm{O}_{3} \cdot 3 \mathrm{H}_{2}$ Water Mass in the Rubble Basket For Rubble Basket Heat Up During staging in the CSB With a Helium Filled Tube/MCO Gap and MCO and with Chemical Reactions Due to the Decomposition of the Reaction Product Hydrates.

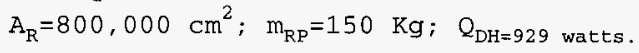




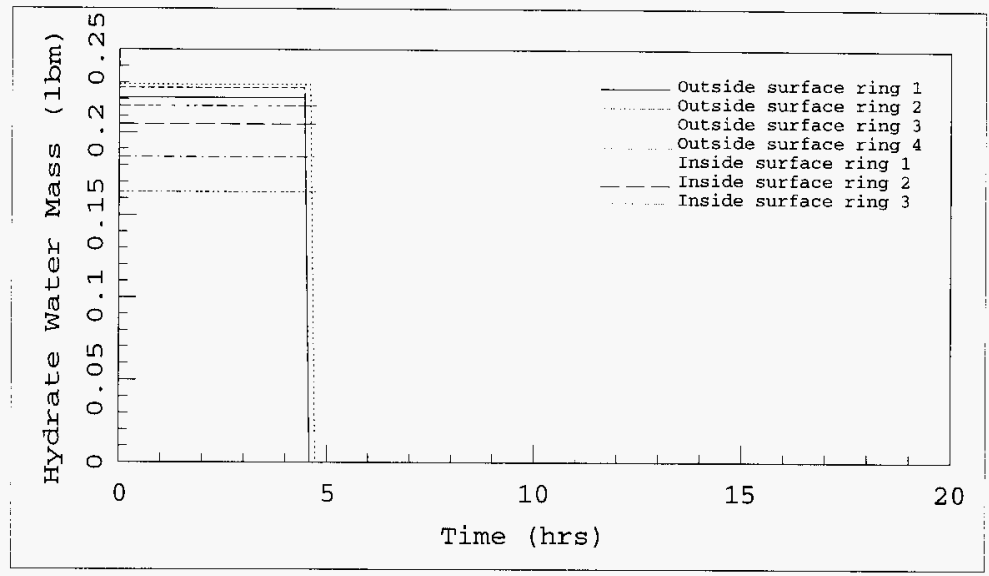

Figure $7.9 \mathrm{Al}_{2} \mathrm{O}_{3} \cdot 3 \mathrm{H}_{2}$ Water Mass in the Rubble Basket For Rubble Basket Heat Up During staging in the CSB With a Helium Filled Tube/MCO Gap and MCO and with Chemical Reactions Due to the Decomposition of the Reaction Product Hydrates. $\mathrm{A}_{\mathrm{R}}=800,000 \mathrm{~cm}^{2} ; \mathrm{m}_{\mathrm{RP}}=150 \mathrm{Kg} ; \mathrm{Q}_{\mathrm{DH}}=929$ watts. 


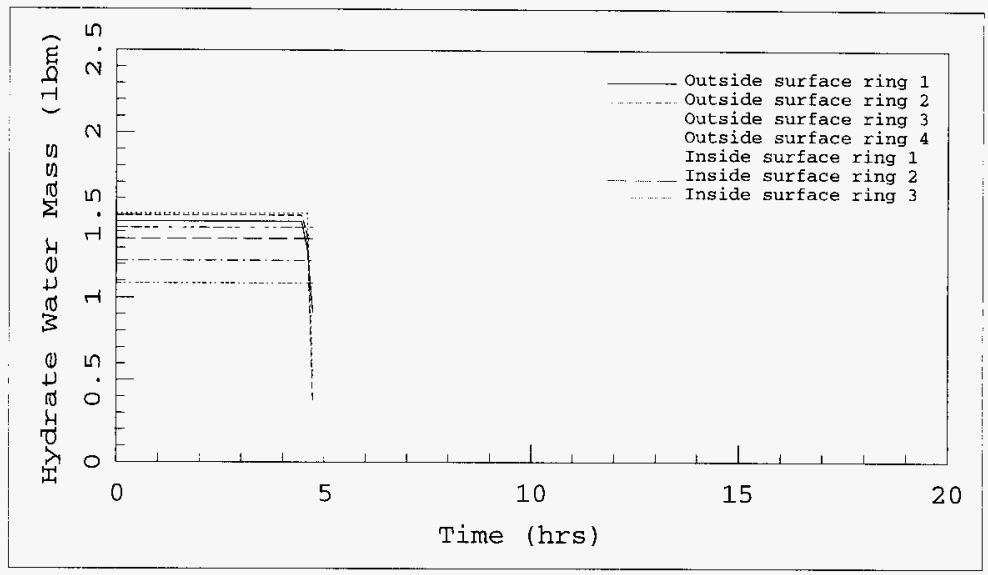

Figure $7.10 \mathrm{UO}_{3} \cdot 2 \mathrm{H}_{2}$ Water Mass in the Rubble Basket For Rubble Basket Heat Up During staging in the CSB With a Helium Filled Tube/MCO Gap and MCO and with Chemical Reactions Due to the Decomposition of the Reaction Product Hydrates. $\mathrm{A}_{\mathrm{R}}=800,000 \mathrm{~cm}^{2} ; \mathrm{m}_{\mathrm{RP}}=150 \mathrm{Kg} ; \mathrm{Q}_{\mathrm{DH}}=929$ watts.

\subsubsection{Case 2.}

The thermal and pressure transient of a high nominal powered MCO (750 watts of decay heat) containing $150 \mathrm{Kg}$ of corrosion product in the top rubble basket which has a reaction surface area of $80,000 \mathrm{~cm}^{2}$ for staging in the CSB during the hottest time of summer in the peak temperature location of a fully loaded CSB is shown below, Figures 7.11 through 7.13. The initial temperature of the MCO and fuel is assumed to be $50^{\circ} \mathrm{C}\left(122^{\circ} \mathrm{F}\right)$. The temperature rises more slowly for this case than for the previous case because of the combined effects of the reduced decay heat and the reduced reaction area, although, as expected, the fuel undergoes a temperature excursion due to the heat 
WHC-SD-SNF-ER-014, Rev. 0 .

generated by the chemical reaction. The tube, MCo and fuel temperatures are plotted on the same time and temperature scale as the previous cases for comparison purposes in Figure 7.11 and on expanded temperature and time scales in Figure 7.12. The temperature excursion occurs at about 18 hours for this case with the peak fuel temperature exceeding $1000^{\circ} \mathrm{F}$.

The MCO pressure, Figure 7.13, has exceeded the MCO design pressure and is approaching 300 psia at the end of the simulation so MCO venting would be required for this case. The hydrogen concentration in the rubble basket is shown in Figure 7.14. All of the iron and aluminum hydrates and over half of the uranium hydrate has decomposed, Figures $7.15,7.16$ and 7.17 . 
WHC-SD-SNF-ER-014, Rev. 0 .

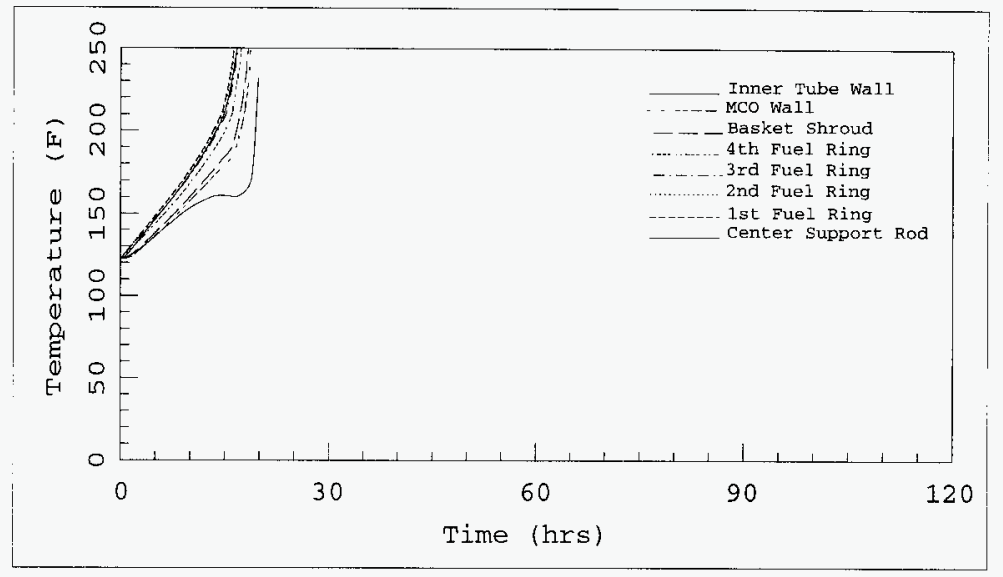

Figure 7.11 MCO Rod and Structure Temperatures For the Rubble Basket Heat Up During staging in the CSB With Helium Filled Tube/MCO Gap and MCO and With Chemical Reactions Due to the Decomposition of the Reaction Product Hydrates. $A_{R}=80,000 \mathrm{~cm}^{2}$;

$\mathrm{m}_{\mathrm{RP}}=150 \mathrm{Kg} ; \mathrm{Q}_{\mathrm{DH}}=750$ watts. 
WHC-SD-SNF-ER-014， Rev. 0 .

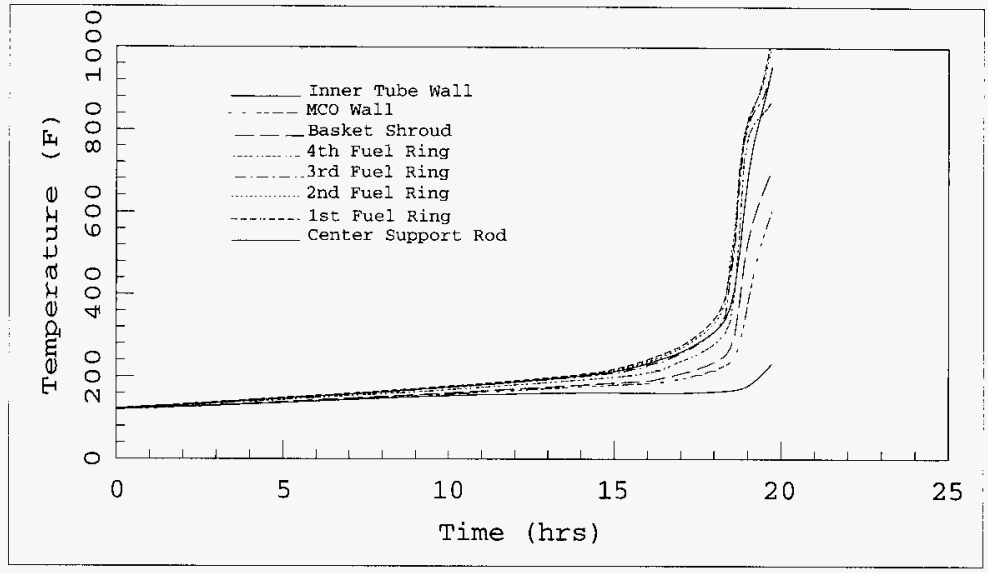

Figure 7.12 MCO Rod and Structure Temperatures For the Rubble Basket Heat Up During Staging in the CSB With Helium Filled Tube/MCO Gap and MCO and with Chemical Reactions Due to the Decomposition of the Reaction Product Hydrates. $A_{R}=80,000 \mathrm{~cm}^{2} ; m_{R P}=150$ $\mathrm{Kg} ; \mathrm{Q}_{\mathrm{DH}}=750$ watts. 
WHC-SD-SNF-ER-014, Rev. 0 .

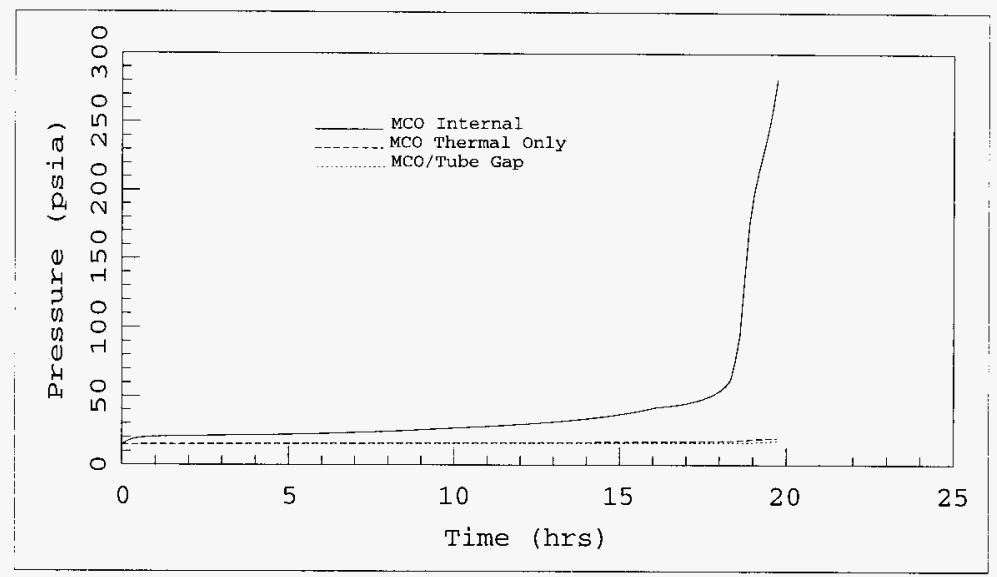

Figure 7.13 MCO Pressurization Rates for the Rubble Basket Heat Up During staging in the CSB With Helium Filled Tube/MCO Gap and MCO and with Chemical Reactions Due to the Decomposition of the Reaction Product Hydrates. $A_{R}=80,000 \mathrm{~cm}^{2} ; m_{R F}=150 \mathrm{Kg} ; Q_{D H}=$ 750 Watts. 
WHC-SD-SNF-ER-014, Rev. 0 .

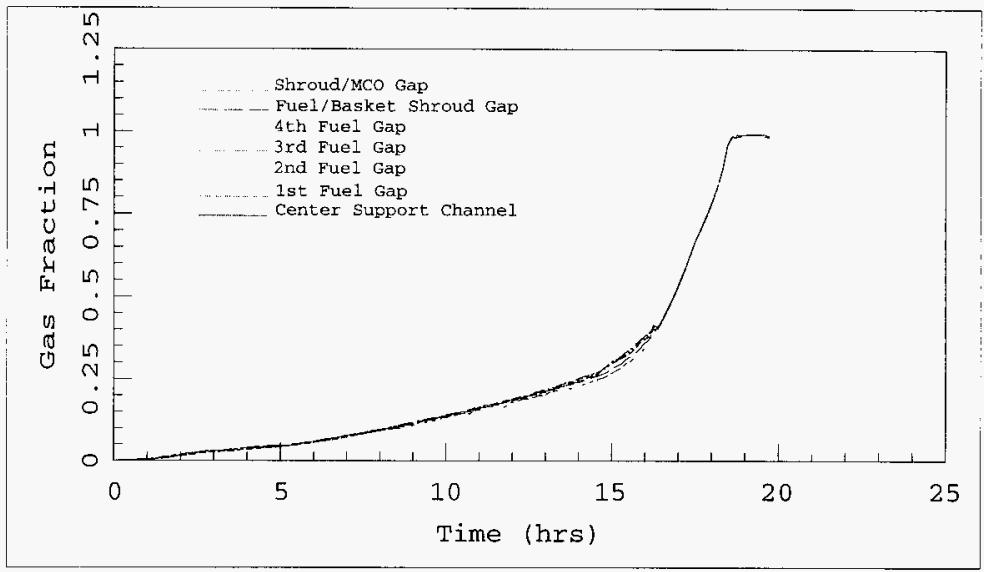

Figure 7.14 Hydrogen Gas Volume Fractions in the Rubble Basket For Rubble Basket Heat Up During staging in the CSB With a Helium Filled Tube/MCO Gap and MCO and with Chemical Reactions Due to the Decomposition of the Reaction Product Hydrates. $\mathrm{A}_{\mathrm{R}}=80,000 \mathrm{~cm}^{2} ; \mathrm{m}_{\mathrm{RP}}=150 \mathrm{Kg} ; \mathrm{Q}_{\mathrm{DH}}=750$ watts. 
WHC-SD-SNF-ER-014, Rev. 0.

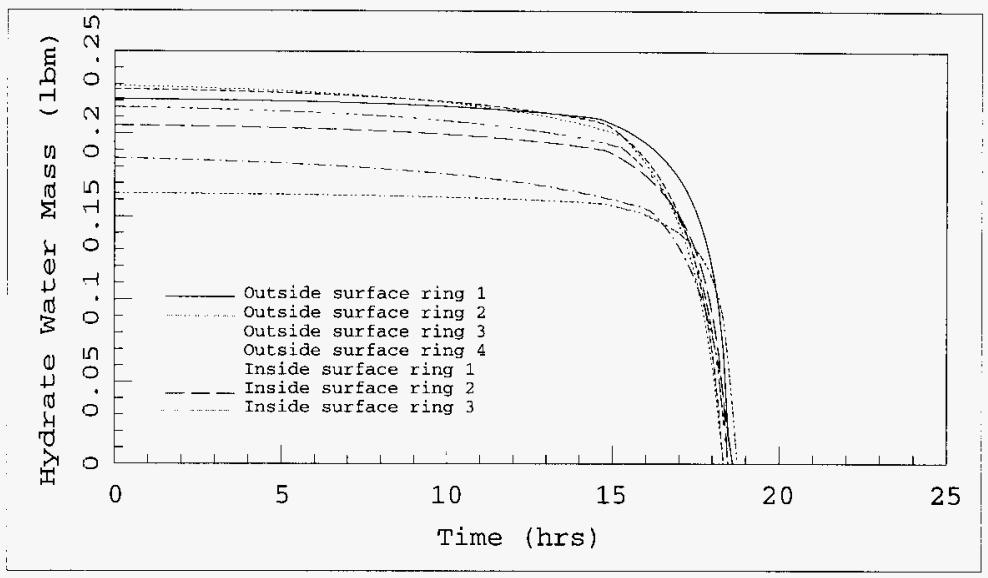

Figure $7.15 \mathrm{Fe}_{2} \mathrm{O}_{3} \cdot 3 \mathrm{H}_{2}$ Water Mass in the Rubble Basket For Rubble Basket Heat Up During staging in the CSB With a Helium Filled Tube/MCO Gap and MCO and with Chemical Reactions Due to the Decomposition of the Reaction Product Hydrates. $\mathrm{A}_{\mathrm{R}}=80,000 \mathrm{~cm}^{2} ; \mathrm{m}_{\mathrm{RP}}=150 \mathrm{Kg} ; \mathrm{Q}_{\mathrm{DH}}=750$ watts. 
WHC-SD-SNF-ER-014, Rev . 0 .

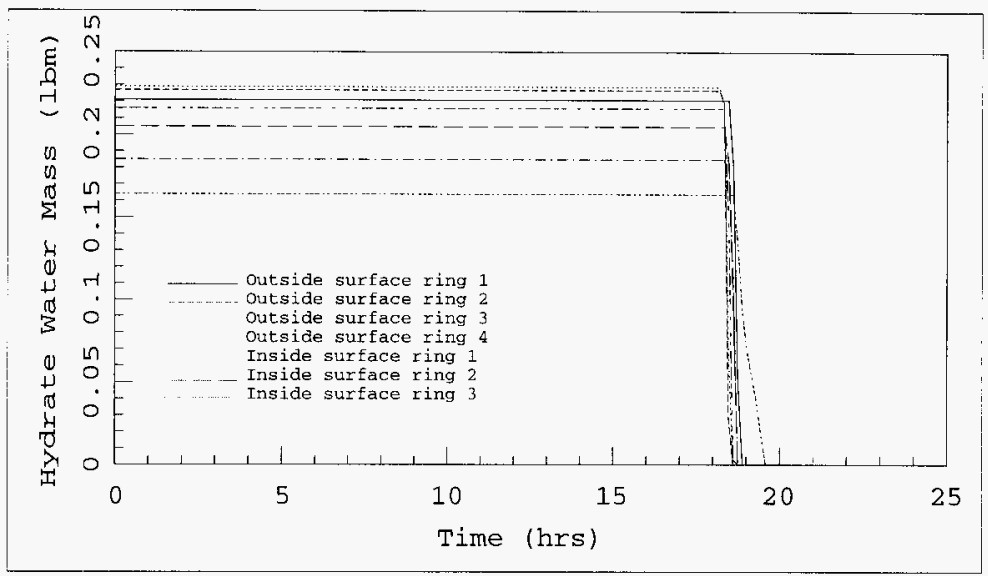

Figure $7.16 \mathrm{Al}_{2} \mathrm{O}_{3} \cdot 3 \mathrm{H}_{2}$ Water Mass in the Rubble Basket For Rubble Basket Heat Up During staging in the CSB With a Helium Filled Tube/MCO Gap and MCO and with Chemical Reactions Due to the Decomposition of the Reaction Product Hydrates. $\mathrm{A}_{\mathrm{R}}=80,000 \mathrm{~cm}^{2} ; \mathrm{m}_{\mathrm{RP}}=150 \mathrm{Kg} ; Q_{\mathrm{DH}}=750$ watts. 


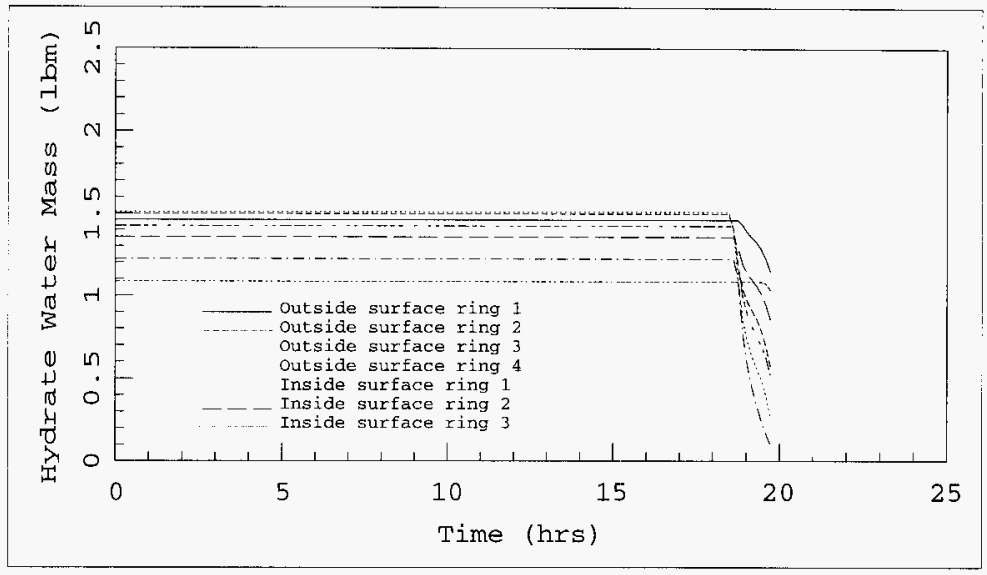

Figure $7.17 \mathrm{UO}_{3} \cdot 2 \mathrm{H}_{2}$ water Mass in the Rubble Basket For Rubble Basket Heat Up During Staging in the CSB With a Helium Filled Tube/MCO Gap and MCO and with Chemical Reactions Due to the Decomposition of the Reaction Product Hydrates.

\subsubsection{Case 3.}

This case is similar to the previous case except that the amount of oxidation products has been decreased to $70 \mathrm{Kg}$. The mass fraction of water in the iron and aluminum hydrates remains at 0.005 for each and the mass fraction of water in the uranium hydrate remains at 0.033 . This transient should behave exactly the same as the previous case except the waters of hydration should be consumed sooner and the peak MCO pressure and fuel temperature should be lower. The tube, MCO and fuel temperatures in the rubble basket are shown in Figure 7.18 using the same time scale as the base case for comparison and in Figure 7.19 using expanded time and temperature scales. The 
WHC-SD-SNF-ER-014, Rev. 0 .

temperature excursion occurs at the same time as in the $150 \mathrm{~kg}$ case but the peak fuel temperature rises to just over $800^{\circ} \mathrm{F}$, which is lower than the peak temperature in the previous case. The temperature turns around as all of the waters of hydration in the center of the rubble basket are consumed by the uranium/water of reaction. The temperatures continue to drop as the waters of hydration in each ring of fuel are depleted until all of the water is gone, then the temperature goes through an exponential decay back down to the temperatures corresponding to the decay heat and the surrounding ambient temperature.

The pressure peaks at about 200 psia, as would be expected for the amount of water in the hydrates for $70 \mathrm{Kg}$ of oxidation products, Figure 7.20, so venting would be required for this case. The hydrogen concentration in the rubble basket is shown in Figure 7.21. The axial hydrogen distribution at the end of the simulation is shown in Figure 7.22 .

The hydrate water mass consumption rates are shown in Figures $7.23,7.24$ and 7.25 . All of the waters of hydration are consumed within 21 hours for this case. 
WHC-SD-SNF-ER-014, Rev . 0 .

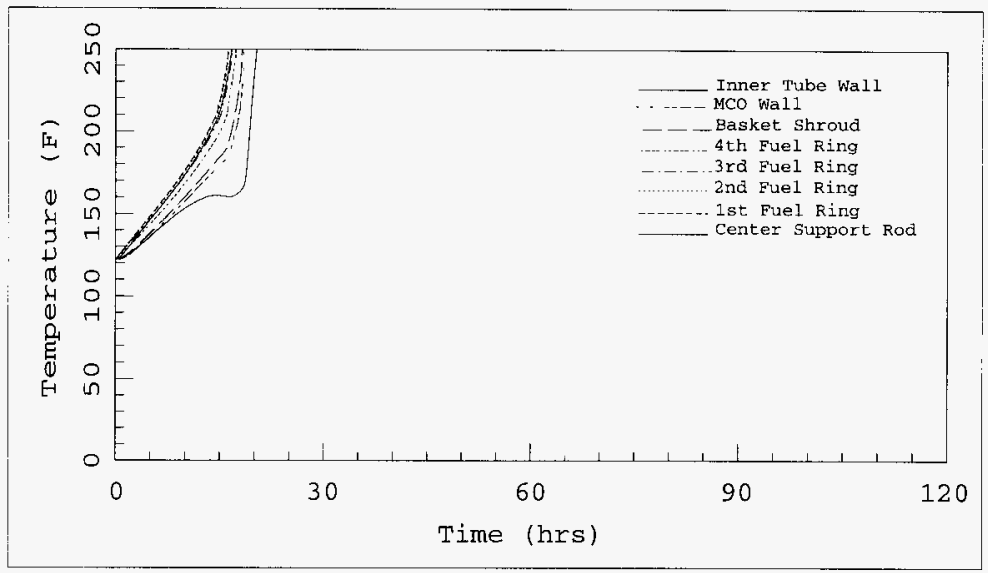

Figure 7.18 MCO Rod and Structure Temperatures For the Rubble Basket Heat Up During staging in the CSB with Helium Filled Tube/MCO Gap and MCO and with Chemical Reactions Due to the Decomposition of the Reaction Product Hydrates. $A_{R}=80,000 \mathrm{~cm}^{2}$; $\mathrm{m}_{\mathrm{RP}}=70 \mathrm{Kg} ; Q_{\mathrm{DH}}=750$ watts. 
WHC-SD-SNF-ER-014, Rev. 0.

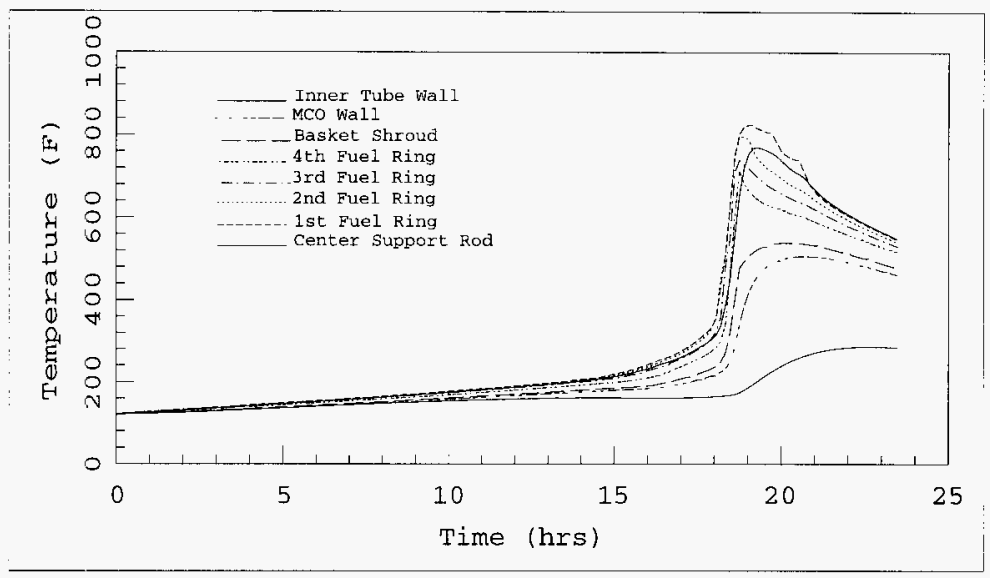

Figure 7.19 MCO Rod and Structure Temperatures For the Rubble Basket Heat Up During staging in the CSB with Helium Filled Tube/MCO Gap and MCO and With Chemical Reactions Due to the Decomposition of the Reaction Product Hydrates. $A_{R}=80,000 \mathrm{~cm}^{2}$; $\mathrm{m}_{\mathrm{RP}}=70 \mathrm{Kg} ; \mathrm{Q}_{\mathrm{DH}}=750$ watts. 
WHC-SD-SNF-ER-014, Rev. 0 .

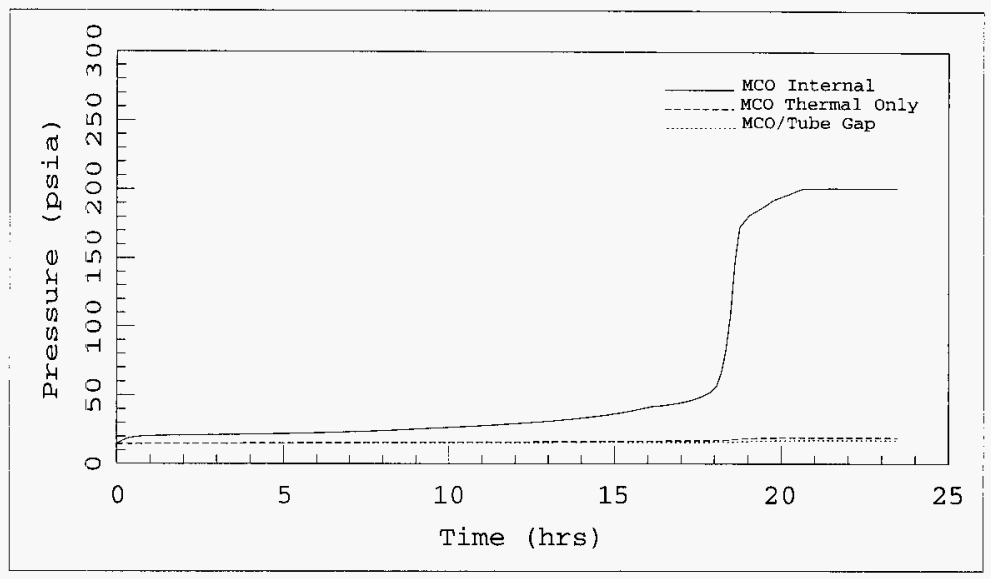

Figure 7.20 MCO Pressurization Rates for the Rubble Basket Heat Up During staging in the CSB With Helium Filled Tube/MCO Gap and MCO and with Chemical Reactions Due to the Decomposition of the Reaction Product Hydrates. $A_{R}=80,000 \mathrm{~cm}^{2} ; m_{R P}=70 \mathrm{Kg}$; $\mathrm{Q}_{\mathrm{DH}}=750$ watts. 
WHC-SD-SNF-ER-014, Rev. 0 .

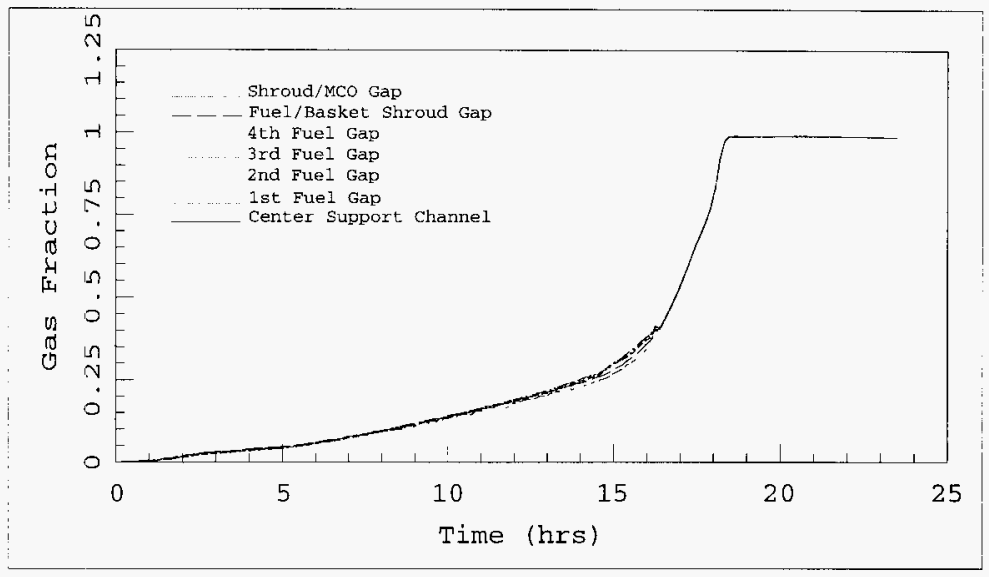

Figure 7.21 Hydrogen Gas Volume Fractions in the Rubble Basket For Rubble Basket Heat Up During Staging in the CSB with a Helium Filled Tube/MCO Gap and MCO and with Chemical Reactions Due to the Decomposition of the Reaction Product Hydrates. $A_{R}=80,000 \mathrm{~cm}^{2} ; m_{R P}=70 \mathrm{Kg} ; Q_{D H}=750$ wats. 
WHC-SD-SNF-ER-014, ReV. 0.

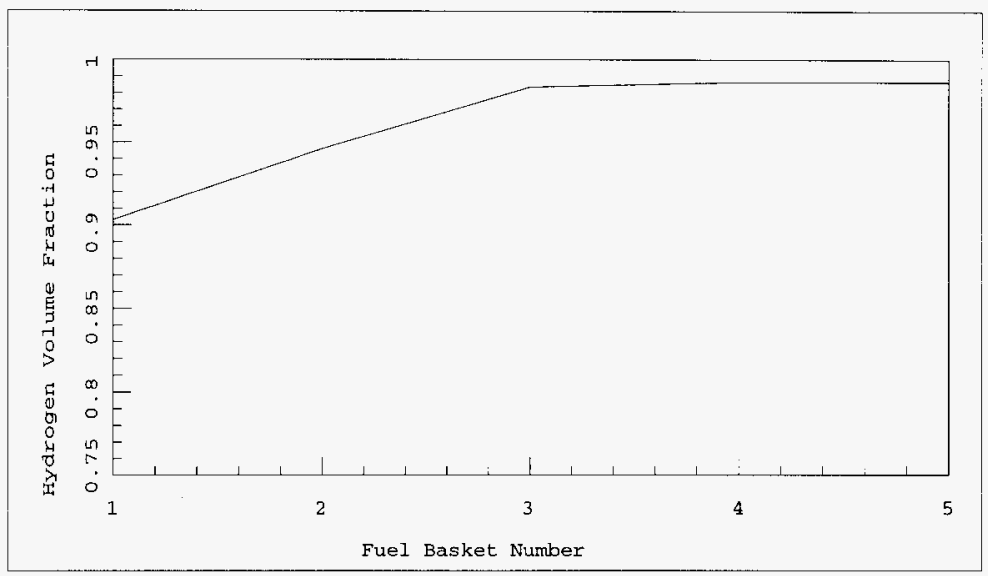

Figure 7.22 Axial Hydrogen Volume Fraction Distribution at the End of the Simulation. 


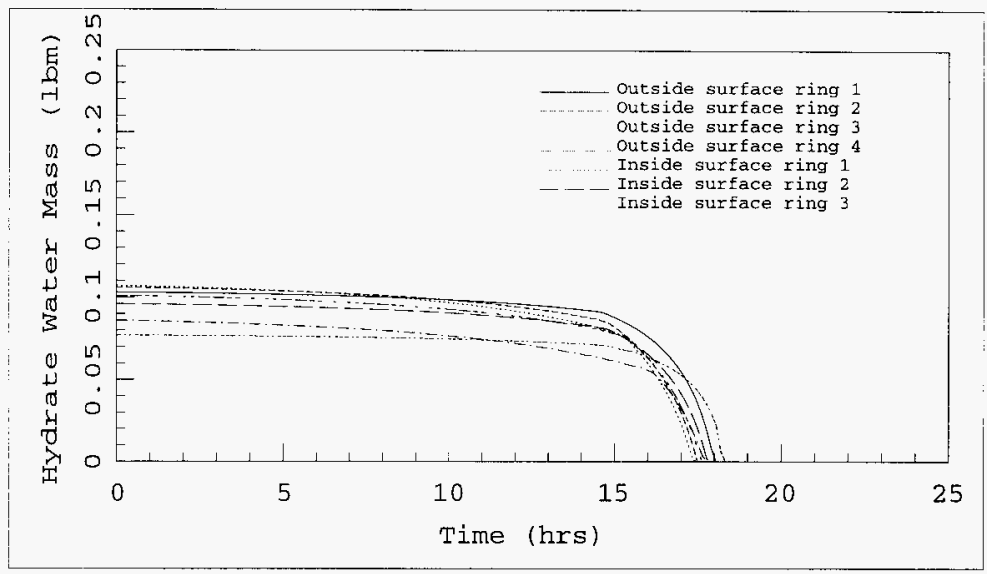

Figure $7.23 \mathrm{Fe}_{2} \mathrm{O}_{3} \cdot 3 \mathrm{H}_{2}$ Water Mass in the Rubble Basket For Rubble Basket Heat Up During Staging in the CSB With a Helium Filled Tube/MCO Gap and MCO and with Chemical Reactions Due to the Decomposition of the Reaction Product Hydrates. $A_{R}=80,000 \mathrm{~cm}^{2} ; m_{R P}=70 \mathrm{Kg} ; Q_{D H}=750$ watts. 
WHC-SD-SNF-ER-014, Rev. 0 .

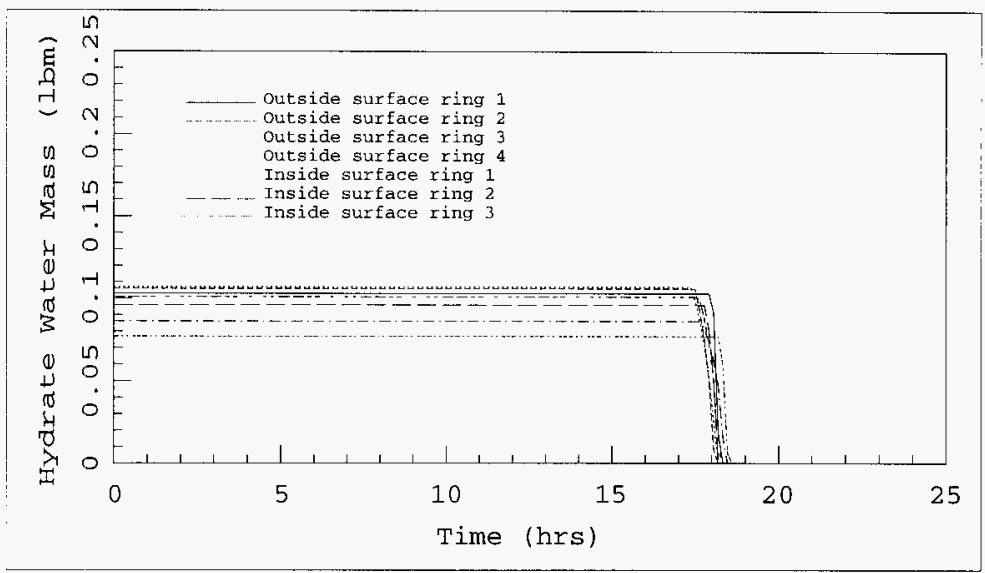

Figure $7.24 \mathrm{Al}_{2} \mathrm{O}_{3} \cdot 3 \mathrm{H}_{2}$ water Mass in the Rubble Basket For Rubble Basket Heat Up During staging in the CSB With a Helium Filled Tube/MCO Gap and MCO and with Chemical Reactions Due to the Decomposition of the Reaction Product Hydrates. $\mathrm{A}_{\mathrm{R}}=80,000 \mathrm{~cm}^{2} ; \mathrm{m}_{\mathrm{RP}}=70 \mathrm{Kg} ; \mathrm{Q}_{\mathrm{DH}}=750$ watts. 


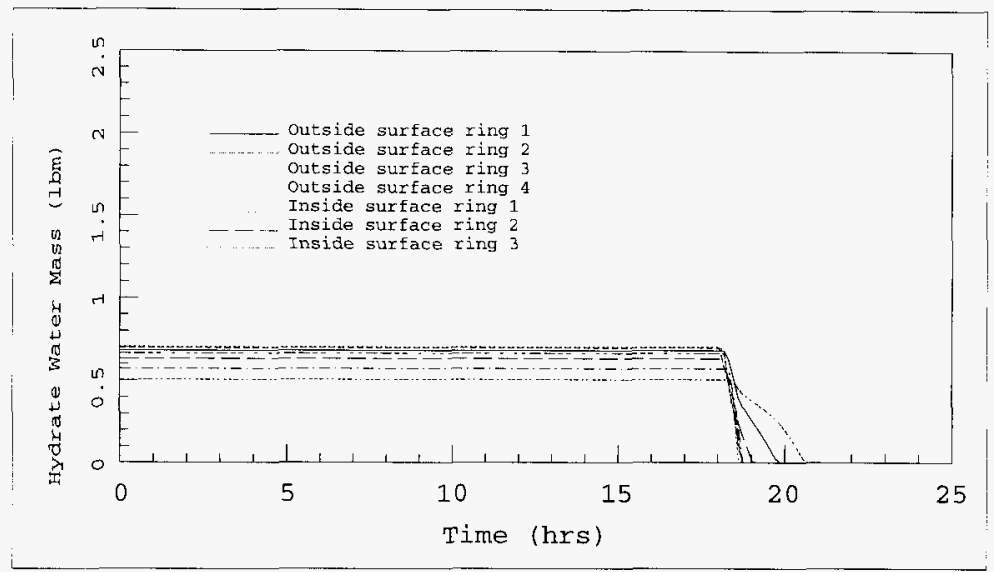

Figure $7.25 \mathrm{UO}_{3} \bullet 2 \mathrm{H}_{2}$ Water Mass in the Rubble Basket For Rubble Basket Heat Up During Staging in the CSB With a Helium Filled Tube/MCO Gap and MCO and with Chemical Reactions Due to the Decomposition of the Reaction Product Hydrates. $\mathrm{A}_{\mathrm{R}}=80,000 \mathrm{~cm}^{2} ; \mathrm{m}_{\mathrm{RP}}=70 \mathrm{Kg} ; \mathrm{Q}_{\mathrm{DH}}=750$ watts.

\subsubsection{Case 4}

This case is identical to the previous case except that the reaction area is decreased to $57,000 \mathrm{~cm}^{2}$. This case corresponds to the geometric surface area suggested by Cooper for the rubble basket. The effect of this reduction in reaction area is to delay the temperature excursion by about four hours and reduce the peak fuel temperature by about $40^{\circ} \mathrm{F}$, Figure 7.26 . 


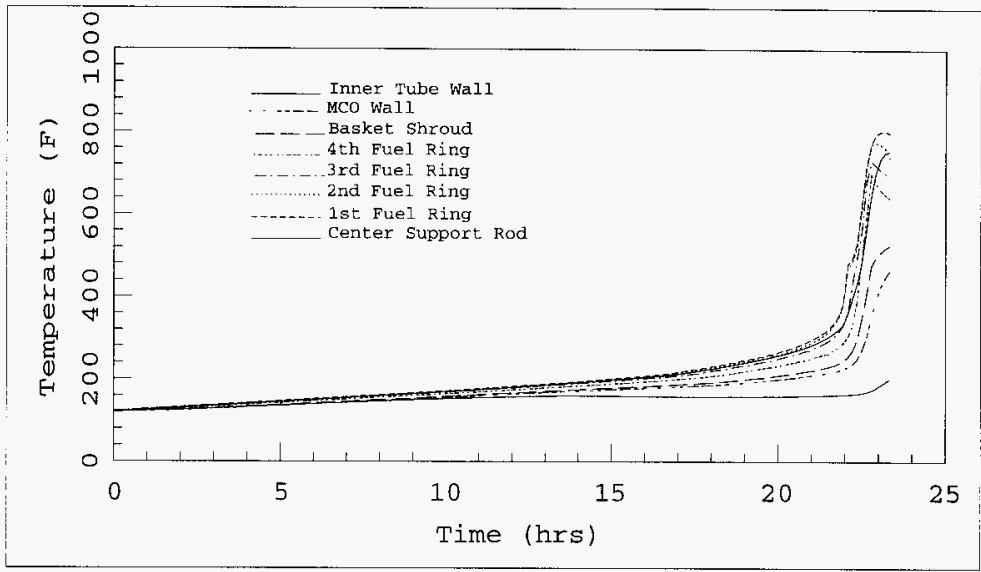

Figure 7.26 MCO Rod and Structure Temperatures For the Rubble Basket Heat Up During staging in the CSB with Helium Filled Tube/MCO Gap and MCO and With Chemical Reactions Due to the Decomposition of the Reaction Product Hydrates. $A_{r}=57,000 \mathrm{~cm}^{2} ; m_{R P}=70$ Kg; $Q_{\mathrm{DH}}=750$ watts.

\subsubsection{Case 5.}

This case assumes a MCO decay heat of 750 watts, a reaction area of $80,000 \mathrm{~cm}^{2}$ and an oxidation product inventory of 16 $\mathrm{Kg}$. The temperature history for this case is shown in Figure 7.27 on a scale that is the same as the base case and in Figure 7.28 on using an expanded time and temperature scale. A temperature excursion occurs for this case at the same time that it occurs for the previous cases using a reaction area of $80,000 \mathrm{~cm}^{2}$. However, the peak fuel temperature is significantly reduced because of the limited amount of water available in the oxidation products. The peak temperature in this case is about 


$$
\text { WHC-SD-SNF-ER-014, Rev. } 0 .
$$

$475^{\circ} \mathrm{F}$. The MCO pressure increases to 65 psia for this case, Figure 7.29 , so venting would not be required. The rubble basket hydrogen concentration is shown in Figure 7.30. The hydrogen concentration reaches a peak and then drops back down as hydrogen in the rubble basket mixes with the gas in the baskets lower in the MCO and the concentration levels out at the average MCo hydrogen concentration. Plots of the water inventory of each of the hydrates are shown in Figures 7.31, 7.32 and 7.33. The water is completely consumed within 20 hours for this case.

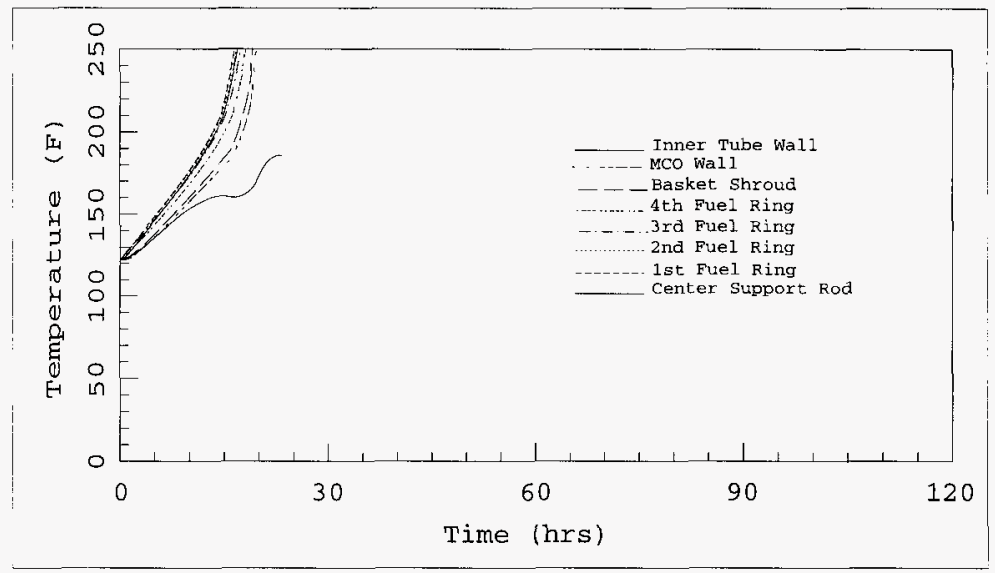

Figure 7.27 MCO Rod and Structure Temperatures For the Rubble Basket Heat Up During staging in the CSB with Helium Filled Tube/MCO Gap and MCO and With Chemical Reactions Due to the Decomposition of the Reaction Product Hydrates. $A_{R}=80,000 \mathrm{~cm}^{2} ; m_{R P}=16$

$\mathrm{Kg} ; \mathrm{Q}_{\mathrm{DH}}=750$ watts. 
WHC-SD-SNF-ER-014, Rev. 0 .

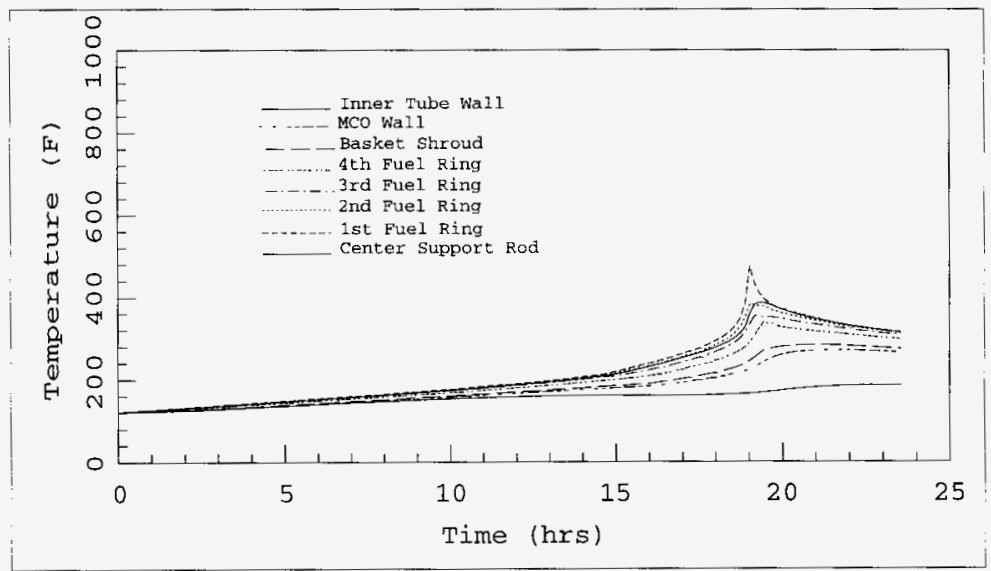

Figure 7.28 MCO Rod and Structure Temperatures For the Rubble Basket Heat Up During Staging in the CSB with Helium Filled Tube/MCO Gap and MCO and With Chemical Reactions Due to the Decomposition of the Reaction Product Hydrates. $A_{R}=80,000 \mathrm{~cm}^{2} ; m_{R P}=16$ $\mathrm{Kg} ; \mathrm{Q}_{\mathrm{DH}}=750$ watts. 


$$
\text { WHC-SD-SNF-ER-014, Rev. } 0 \text {. }
$$

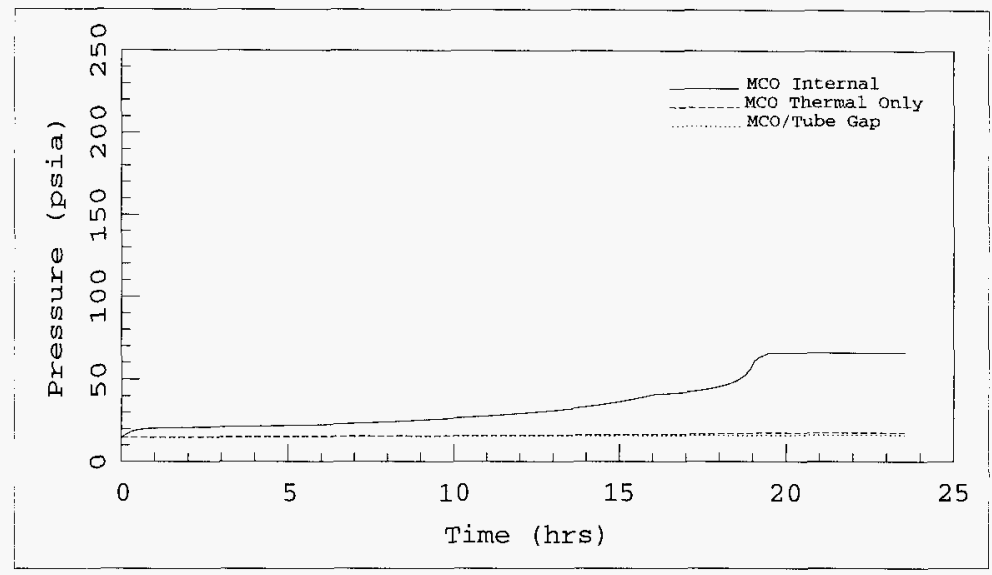

Figure 7.29 MCO Pressurization Rates for the Rubble Basket Heat Up During staging in the CSB With Helium Filled Tube/MCO Gap and MCO and with Chemical Reactions Due to the Decomposition of the Reaction Product Hydrates. $A_{\mathrm{R}}=80,000 \mathrm{~cm}^{2} ; \mathrm{m}_{\mathrm{RP}}=16 \mathrm{Kg} ; \mathrm{Q}_{\mathrm{DH}}=$ 750 watts. 
WHC-SD-SNF-ER-014, Rev. 0 .

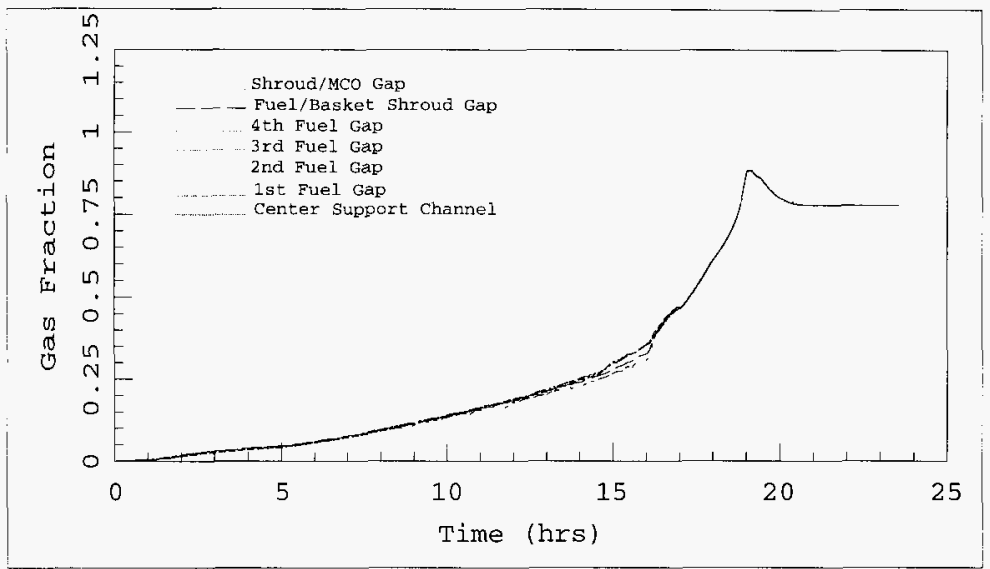

Figure 7.30 Hydrogen Gas Volume Fractions in the Rubble Basket For Rubble Basket Heat Up During staging in the CSB with a Helium Filled Tube/MCO Gap and MCO and with Chemical Reactions Due to the Decomposition of the Reaction Product Hydrates. $A_{R}=80,000 \mathrm{~cm}^{2} ; m_{R P}=16 \mathrm{Kg} ; Q_{D H}=750$ watts. 
WHC-SD-SNF-ER-014, Rev . 0 .

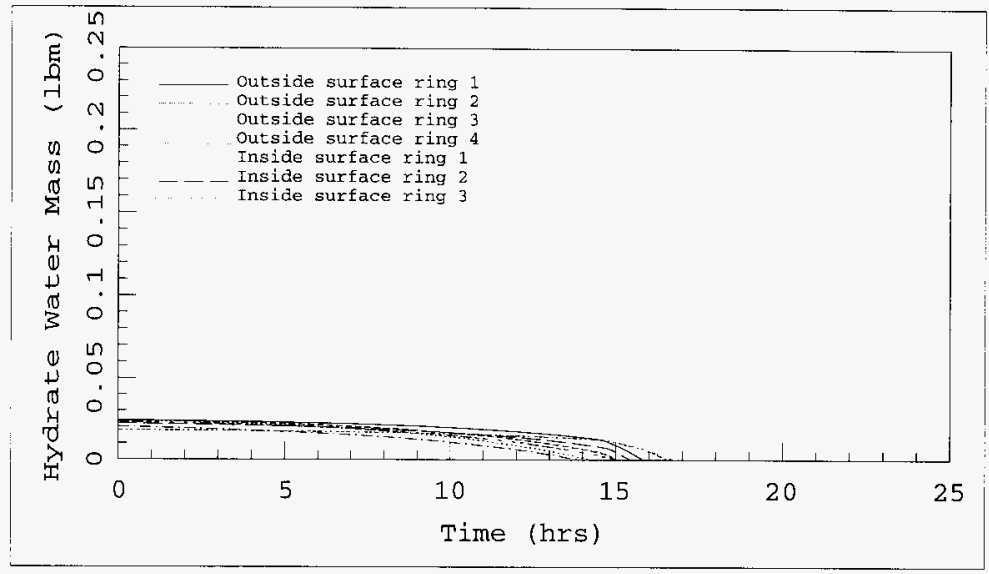

Figure $7.31 \mathrm{Fe}_{2} \mathrm{O}_{3} \cdot 3 \mathrm{H}_{2}$ Water Mass in the Rubble Basket For Rubble Basket Heat Up During staging in the CSB With a Helium Filled Tube/MCO Gap and MCO and with Chemical Reactions Due to the Decomposition of the Reaction Product Hyarates. $\mathrm{A}_{\mathrm{R}}=80,000 \mathrm{~cm}^{2} ; \mathrm{m}_{\mathrm{RP}}=16 \mathrm{Kg} ; \mathrm{Q}_{\mathrm{DH}}=750$ watts. 
WHC-SD-SNF-ER-014, Rev. 0 .

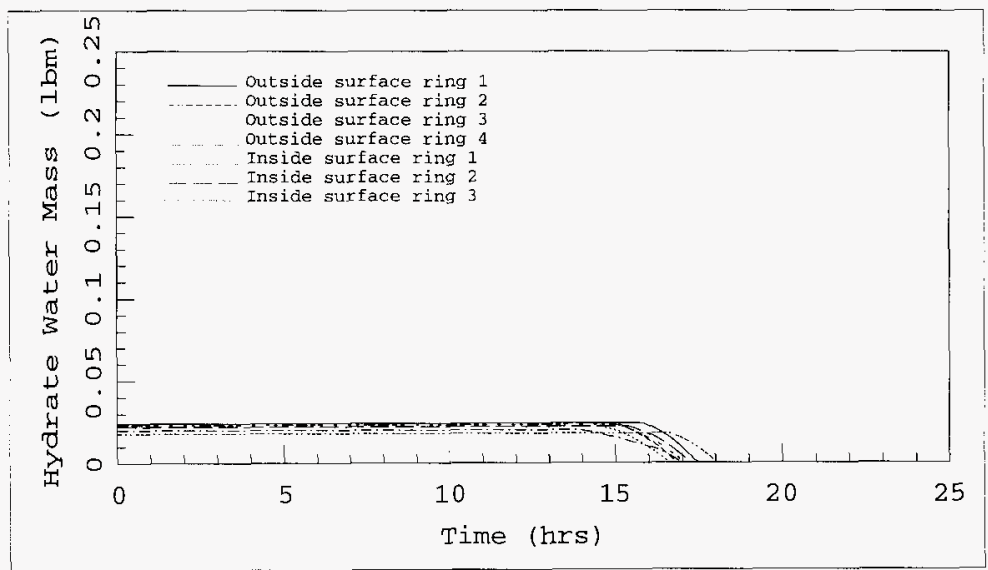

Figure $7.32 \mathrm{Al}_{2} \mathrm{O}_{3} \bullet 3 \mathrm{H}_{2}$ Water Mass in the Rubble Basket For Rubble Basket Heat Up During Staging in the CSB With a Helium Filled Tube/MCO Gap and MCO and with Chemical Reactions Due to the Decomposition of the Reaction Product Hydrates. $A_{R}=80,000 \mathrm{~cm}^{2} ; m_{R P}=16 \mathrm{Kg} ; Q_{D H}=750$ watts. 


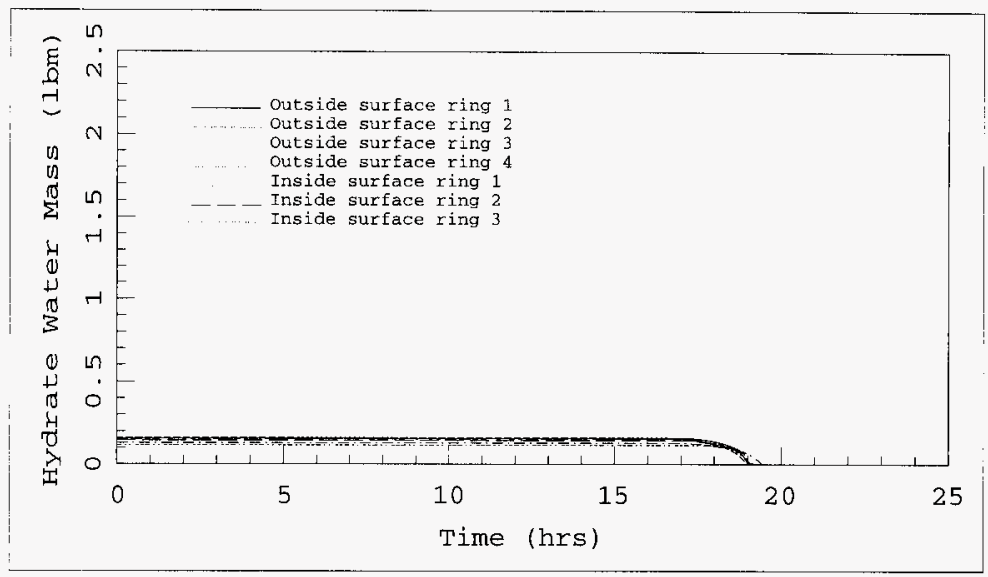

Figure $7.33 \mathrm{UO}_{3} \bullet 2 \mathrm{H}_{2}$ Water Mass in the Rubble Basket For Rubble Basket Heat Up During staging in the CSB With a Helium Filled Tube/MCO Gap and MCO and with Chemical Reactions Due to the Decomposition of the Reaction Product Hydrates. $A_{\mathrm{R}}=80,000 \mathrm{~cm}^{2} ; \mathrm{m}_{\mathrm{RP}}=16 \mathrm{Kg} ; Q_{\mathrm{DH}}=750$ watts.

\subsubsection{Interim storage.}

It is assumed, for interim storage that $16 \mathrm{~kg}$ of reaction products containing surface bound water are remaining in an MCO and that this water is decomposed by radiolysis into hydrogen and oxygen. It is further assumed that the oxygen is consumed and that only hydrogen is left to pressurize the MCO. The MCO pressure history for this case is shown in Figure 7.34 and the hydrogen concentration history is shown in Figure 7.35. The MCO pressure reaches a peak of less than 25 psia in 70 years for this case and the hydrogen concentration reaches a peak of $35 \%$ in this same time. Since upper bound estimates for the amount of 


$$
\text { WHC-SD-SNF-ER-014, Rev, } 0 \text {. }
$$

oxidation products retained in the MCO are on the order of $300 \mathrm{Kg}$ at a maximum water concentration of $1.5 \%$, additional analysis must be done to determine the peak pressure that can occur without venting during interim storage, although rough estimates indicate that the pressure will easily exceed 150 psia. Further studies are also required to determine if the oxygen will be consumed by the uranium or other getters placed into the MCO.

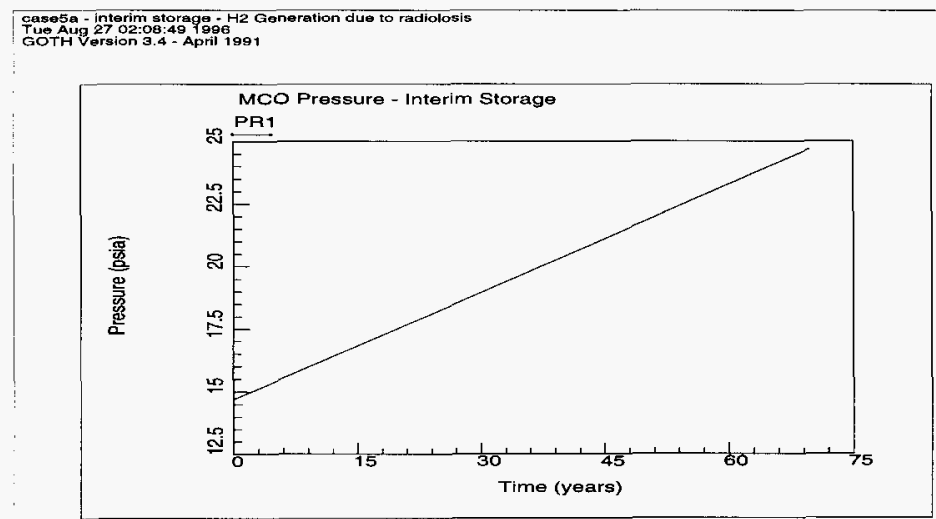

Figure 7.34 MCO Pressure During Interim Storage Assuming 16 $\mathrm{kg}$ of Oxidation Products Containing $1 \%$ Residual water. 
WHC-SD-SNF-ER-014, Rev. 0 .

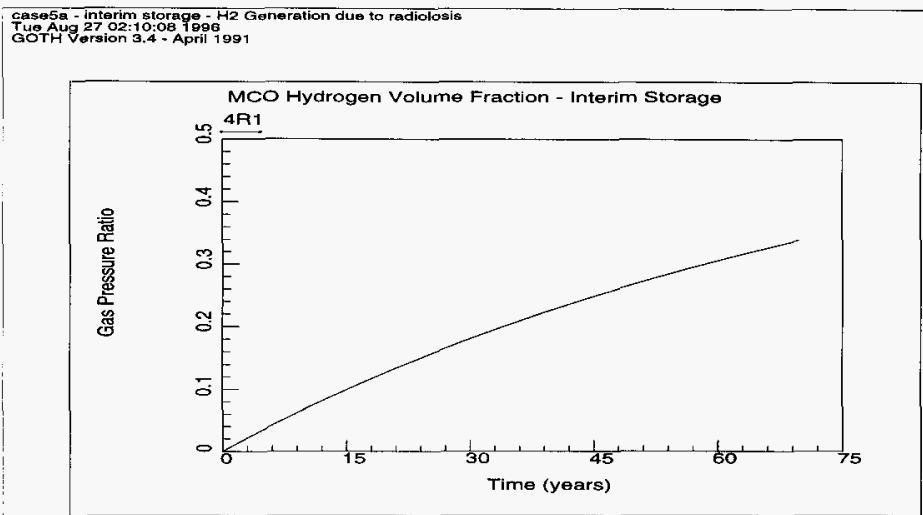

Figure 7.35 MCO Hydrogen Concentration During Interim Storage Assuming $16 \mathrm{Kg}$ of oxidation Products Containing 18 Residual Water.

\subsection{MCO PRESSURIZATION DURTNG SHIPPING.}

\subsubsection{Results for Shipping From Basin to CVDF.}

The pressure response due to shipping from the basin to the CVDF are presented in this section. The thermal boundary conditions for this stage of the process are as described in the previous section on environmental temperature history for this condition. In addition, the following assumptions are made in the analysis.

1. The MCO contains $0.5 \mathrm{~m}^{3}$ of free water.

2. The MCO contains an air volume above the fuel of $0.55 \mathrm{~m}^{3}$ (55 liters). This assumption is important as it determines the rate of pressure rise due given a gas generation rate. 


$$
\text { WHC-SD-SNF-ER-014, Rev. } 0 \text {. }
$$

3. It assumes that the fuel is covered with oxygen free water and that the reaction rate proceeds according to the oxygen free water reaction rate given in section 3 .

4. The rubble basket is assumed to be located at the top basket location in the MCO and the rubble is assumed to have a true reaction area of $800,000 \mathrm{~cm}^{2}$. This number is conservative relative to the number given by cooper in his reaction area study. This number was arrived at early in the pressurization rate study as an upper bound estimate of the maximum amount of damaged fuel that could be physically placed in an MCO rubble basket.

5. The remaining four fuel baskets are assumed to be filled with fuel having the upper 5 inches of the fuel damaged. The reaction area of this 5 inches of damaged fuel is assumed to be equal to 10 times the geometric surface area of completely declad fuel.

6. The decay heat is equal to the upper bound estimate for the maximum powered MCO of 929 watts.

7. No decomposition of hydrates of hydrides are assumed to occur during this stage of the process.

8. Hydrogen generation due to radiolysis is included but is insignificant compared to hydrogen generation due to the water reaction.

9. The MCO is not vented nor does it have a pressure relief device to limit the MCO internal pressure. 
7.2.1.1. Nominal Shipping and Shipping Delay Conditions, Case $1 A$.

The thermal response of the MCO internals to the nominal atmospheric shipping conditions including the effect of heat generation due to uranium reactions with de-oxygenated water are shown in Figure 6.1. Comparison with Figure 5.27 shows the impact of the chemical reaction heating. The temperature rise in the fuel keeps pace with the temperature rise of the inner cask wall indicating that the fuel is not receiving heat from the environment in this case but is heating itself due to the combined effects of decay heat and water reaction heating. The fuel is rejecting heat to the cask after about 15 hours of transient time while, without chemical heating, the fuel is receiving heat from the inner cask wall from 5 to 22 hours of transient time and did not beginning rejecting heat to the cask wall until the following night after the initiation of shipping. The fuel temperature exceeds $100^{\circ} \mathrm{F}$ after about 17 hours with chemical heating while about 26 hours are required to exceed this temperature without chemical heating. The fuel continues to heat and reject heat to the cask wall during the following night. The MCO pressure response due the production of hydrogen from the water reaction is shown in Figure 6.2. The pressure increases exponentially as the water reaction with uranium increases with increasing fuel temperature. The pressure increase is minimal during the first 12 hours indicating that the MCO can likely be transported from the basin to the CVDF if the transport is completed within a shift and the cask is connected to the CVDF cooling system and the mco is cooled back down to $10^{\circ} \mathrm{C}$. Longer transport times will allow the reaction rate to increase to the point that the MCO pressure will exceed the MCO pressure limit of 10 atmospheres within 36 hours if the MCO is not pressure relieved with a relief valve or rupture disk or vented. Attempts to cool the MCO down after the first 12 to 16 hours may not prevent over-pressurization if the cask/mco gap is filled with air because of the thermal time constant 


$$
\text { WHC-SD-SNF-ER-014, Rev. } 0 \text {. }
$$

of the water filled cask with the air gap.

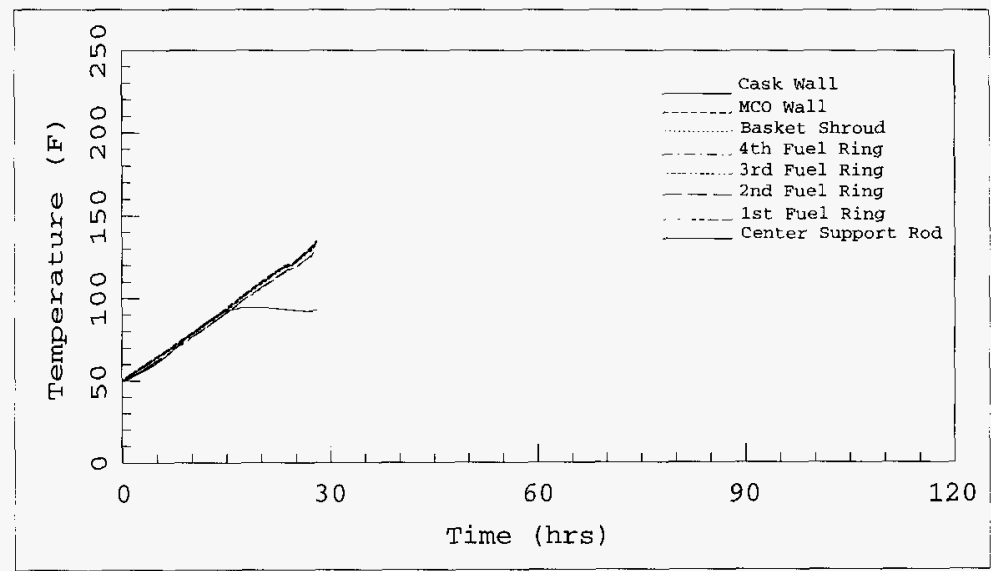

Figure 7.36 MCO Rod and Structure Temperatures For the Second Basket From the Bottom During Heat Up With Air Filled Gap for a High Powered MCO. 
WHC-SD-SNF-ER-014, ReV. 0 .

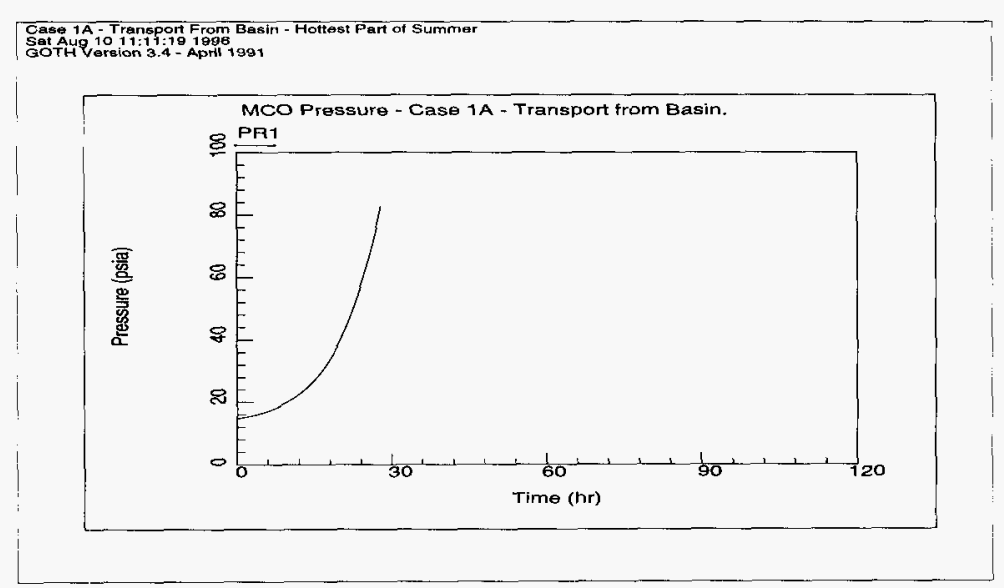

Figure 7.37 MCO Pressurization for Nominal Transport From Basin to CVDF with $0.55 \mathrm{~m}^{3}$ gas space in MCO and oxygen Free water Reaction with $800,000 \mathrm{~cm}^{2}$ Rubble Basket Reaction Area and 5 inches of Damaged Fuel on each Fuel Rod. 


$$
\text { WHC-SD-SNF-ER-014, Rev. } 0 \text {. }
$$

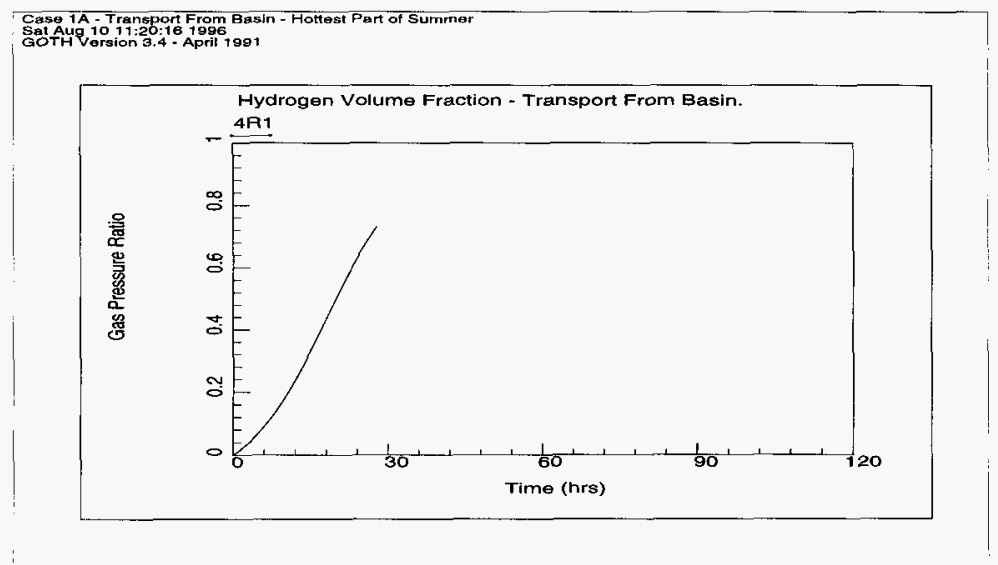

Figure 7.38 MCO Hydrogen Gas Space Concentration for Nominal Transport From Basin to CVDF with $0.55 \mathrm{~m}^{3}$ gas space in MCO and Oxygen Free water Reaction with $800,000 \mathrm{~cm}^{2}$ Rubble Basket Reaction Area and 5 inches of Damaged Fuel on each Fuel Rod.

\subsubsection{Design Basis Fire, Case 1B.}

The thermal response of the MCO internals to the Design Basis Fire shipping condition including the effect of heat generation due to uranium reactions with de-oxygenated water are shown in Figure 6.4. This plot is shown on the same scale as for the previous case so that cross comparisons can easily be made. Fuel temperatures reach $100^{\circ} \mathrm{F}$ within 6 hours of initiation of the fire in this case. The rapid increase in fuel temperature results in higher oxidation reaction heat release rates which further accelerates fuel heat up. The pressure response of the MCO to this condition is shown in Figure 6.5. The mco pressure reaches $100 \mathrm{psi}$ within 16 hours of initiation of the fire and will exceed the MCO pressure limit within an hour or 


$$
\text { WHC-SD-SNF-ER-014, Rev. } 0 \text {. }
$$

two after that. It is unlikely that mco over pressurization for this case can be prevented unless the cask is quenched with water following the fire to cool it below ambient conditions unless it can be delivered to the CVDF and connected to the cooling system within 6 hours of the initiation of the fire. The cask/mco air gap will not allow the fuel to cool sufficiently if cask quenching does not occur sufficiently soon. The hydrogen concentration in the mco gas space versus time is shown in Figure 6.6. Hydrogen concentrations have nearly reached $80 \%$ by 16 hours into the transient.

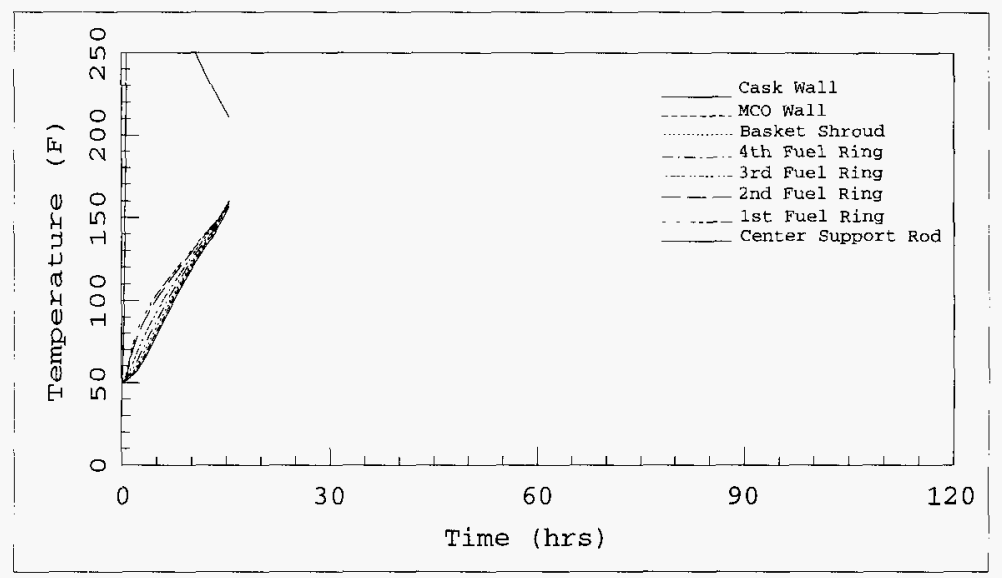

Figure 7.39 MCO Rod and Structure Temperatures For the top Rubble Basket During Heat Up with An Air Filled Gap for a High Powered MCO During A 30 Minute Fire. 
WHC-SD-SNF-ER-014, Rev. 0 .

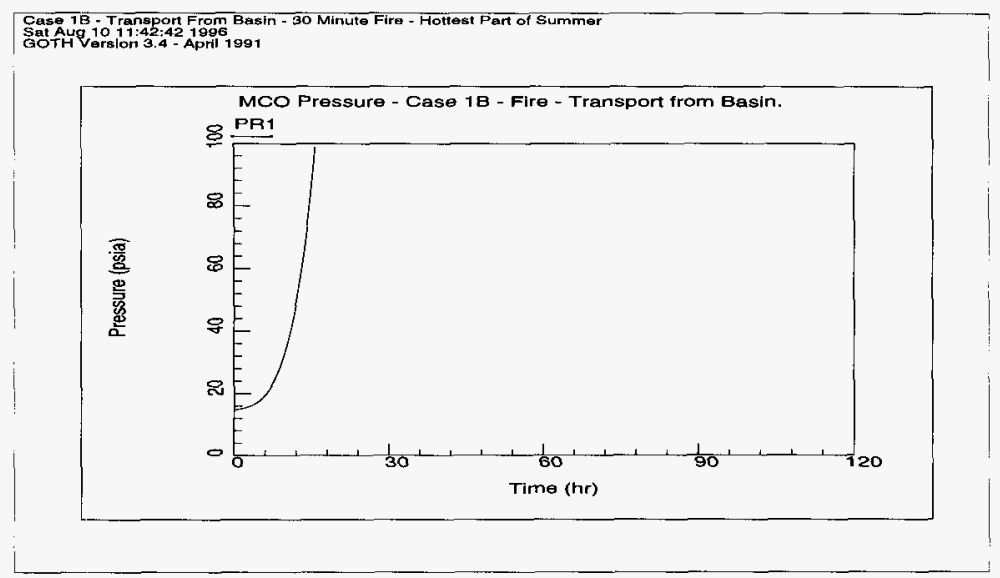

Figure 7.40 MCO Pressurization for a Design Basis Fire Fo r Shipping From The Basin to CVDF with $0.55 \mathrm{~m}^{3}$ gas space in MCO and Oxygen Free water Reaction with $800,000 \mathrm{~cm}^{2}$ Rubble Basket Reaction Area and 5 inches of Damaged Fuel on each Fuel Rod. 
WHC-SD-SNF-ER-014, Rev. 0 .

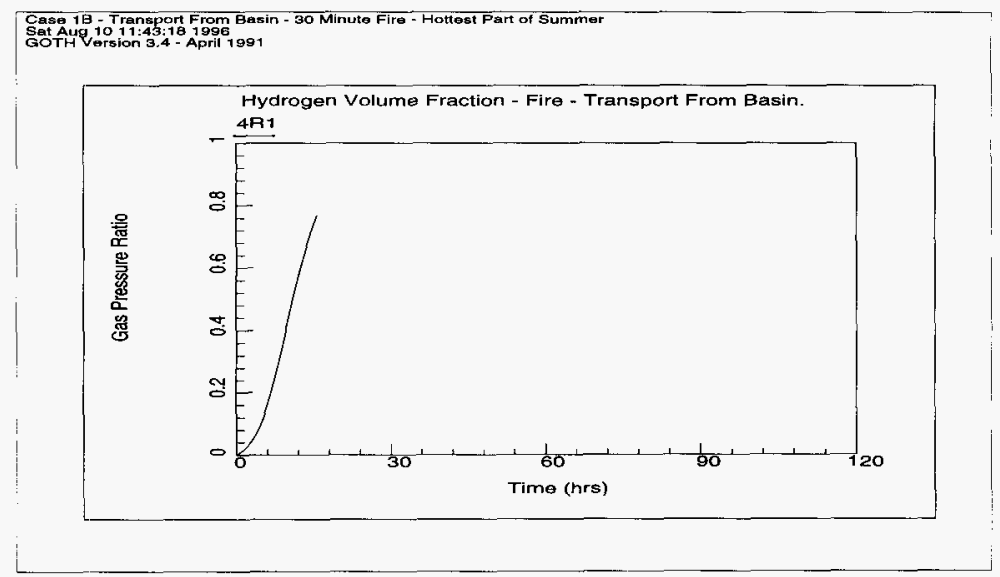

Figure 7.41 MCO Hydrogen Gas Space Concentration for a Design Basis Fire For Shipping From the Basin to CVDF with $0.55 \mathrm{~m}^{3}$ gas space in MCO and Oxygen Free Water Reaction with $800,000 \mathrm{~cm}^{2}$ Rubble Basket Reaction Area and 5 inches of Damaged Fuel on each Fuel Rod.

\subsubsection{Conclusions and Recommendations for Shipping From Basin to CVDF.}

The following conclusions can be reached for shipping the maximum powered mco from the basin to the CVDF with an air gap between the cask and the mco wall during the hottest part of the year assuming that the mco contains a rubble basket with a uranium reaction surface area of $800,000 \mathrm{~cm}^{2}$ and 5 inches of declad, damaged fuel on the top end of each fuel rod in the remaining baskets and assuming the oxygen free water reaction with uranium.

The mco can be shipped under normal conditions if:

1. Shipment is completed within a single shift. 


$$
\text { WHC-SD-SNF-ER-014, Rev. } 0 \text {. }
$$

2. The cask is connected to the CVDF cooling system with in that shift and the MCo cooled down to $10^{\circ} \mathrm{C}$.

The shipping time can be prolonged to allow for breakdowns and delays in shipping if:

1. The reaction surface area is shown to be lower than those used in this analysis.

2. Or, the cask is maintained in a quenched condition using water from a water truck.

3. Or, the cask/mco gap is filled with water.

4. Or, shipment is conducted during a cooler time of the year.

5. Or, a larger mco gas volume is assured.

The additional shipping time that can be gained through any one or a combination of the above conditions should be demonstrated with further analysis.

The mco can be shipped under design basis accident conditions if:

1. Shipment is completed and the cask is connected to the MCO cooling system within 5 hours of initiation of the fire.

2. The cask is quenched following the fire with water.

\subsubsection{Results for shipping From CVDF to CSB.}

The thermal and pressure transients for the transport of the highest powered MCO from the CVDF to the CSB during the hottest part of summer are presented below. 


$$
\text { WHC-SD-SNF-ER-014, Rev. } 0 \text {. }
$$

7.2.2.1. Thermal and Pressure Transient without Chemical Reactions.

The thermal transient for the fuel without any chemical reactions occuring is shown in Figure 7.42 and the pressure transient for this case is shown in Figure 7.43. The thermal transient begins from the condition that it will be released from the CVDF, i.e., $25^{\circ} \mathrm{C}\left(77^{\circ} \mathrm{F}\right)$. The effect of the diurnal temperature variation and solar heating of the cask is clearly evident in the plot of the cask inner wall temperature. This effect is damped as the thermal wave moves into the MCO and fuel and is barely noticeable on the center fuel elements. The peak fuel temperature reaches a steady value of about $99^{\circ} \mathrm{C}\left(210^{\circ} \mathrm{F}\right)$.

The MCO pressurizes due to the thermal expansion of the gas in the MCO only in this case. The pressure in the sealed $\mathrm{MCO}$ and the sealed MCO/cask gap are shown in Figure 7.43. 
WHC-SD-SNF-ER-014, Rev. 0.

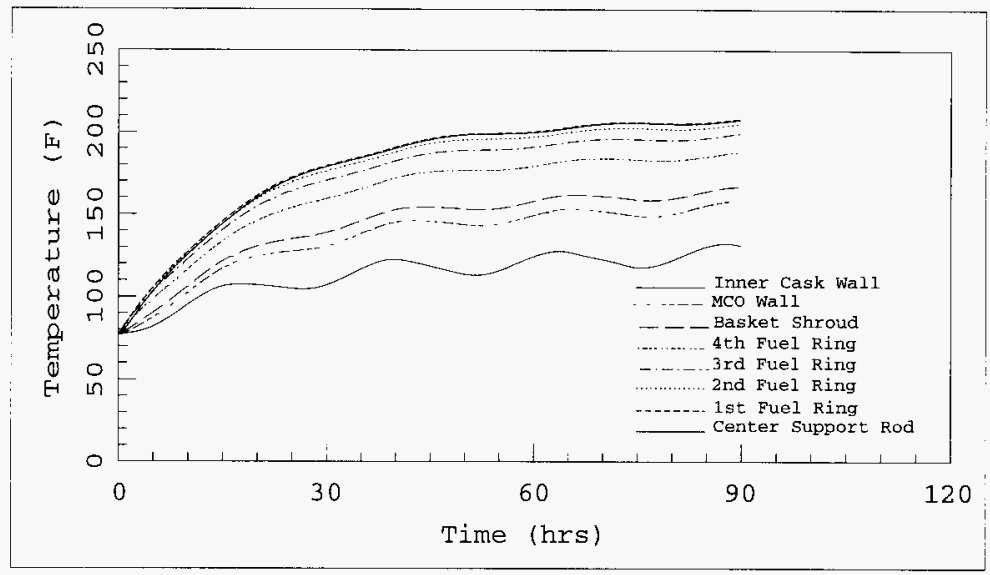

Figure 7.42 MCO Rod and Structure Temperatures For the Rubble Basket Heat Up During Transport From the CVDF to the CSB With Helium Filled Cask/MCO Gap and $\mathrm{MCO}$ and Without AnY Chemical Reactions for a High Powered MCO (929 watts). 


$$
\text { WHC-SD-SNF-ER-014, Rev. } 0 \text {. }
$$

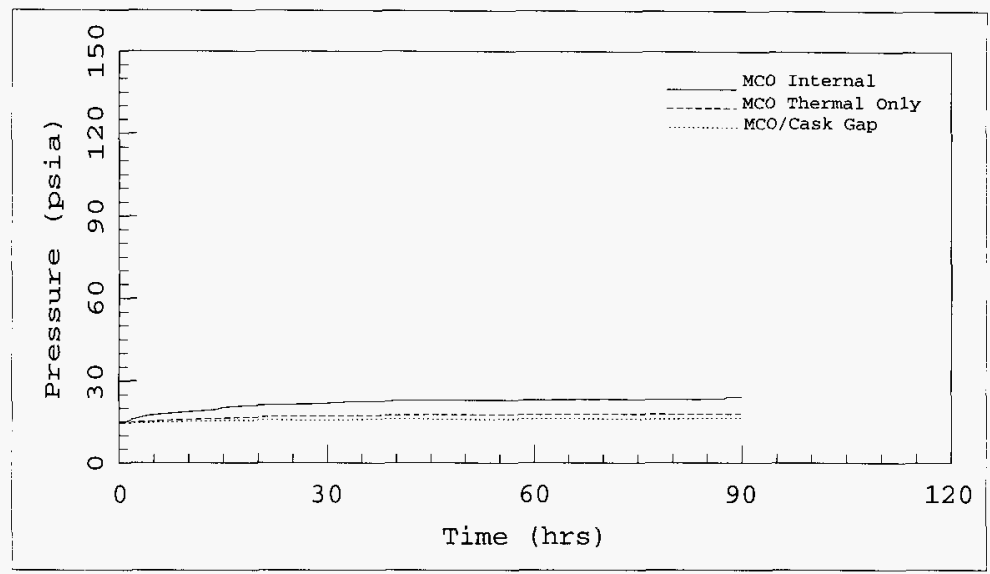

Figure 7.43 MCO Pressurization Rates For the Rubble Basket Heat Up During Transport From the CVDF to the CSB With Helium Filled Cask/MCO Gap and MCO and Without Any Chemical Reactions for a High Powered MCO (929 watts).

\subsubsection{Bounding Case.}

The thermal and pressure transient of a maximum powered MCO (929 watts of decay heat) containing $150 \mathrm{~kg}$ of corrosion product in the top rubble basket that has a reaction surface area of $800,000 \mathrm{~cm}^{2}$ for transport from the CVDF to the CSB on a hot summer day with shipping starting just before dawn with the cask, MCO and fuel at the CVDF release temperature of $25^{\circ} \mathrm{C}\left(77^{\circ} \mathrm{F}\right)$ is shown below. The MCO and the MCO/Cask gap are assumed to be inerted with Helium gas.

The fuel temperatures increase at a faster rate than for the case without chemical reactions due to the heat released by the chemical reactions. This is shown in 


$$
\text { WHC-SD-SNF-ER-014, Rev. } 0 \text {. }
$$

Figure 7.44 which shows the Cask, MCO and fuel temperatures plotted on the same scale as has been used for the case without chemical reactions. The same temperatures are plotted on a smaller time scale and a larger temperature scale in Figure 7.45 so that the thermal response and time can be more easily seen for this case. The rate at which heat is being generated exceeds the rate at which heat can be removed for this configuration and a temperature excursion occurs at between 14 and 15 hours after the initiation of transport. The exact timing of the excursion will depend on the time of day shipping actually begins, the actual ambient temperature on that day and the degree to which a uniform temperature of $25^{\circ} \mathrm{C}\left(77^{\circ} \mathrm{F}\right)$ has been achieved in the fuel before commencement of shipping.

The peak temperature of the fuel is expected to reach about $1000^{\circ} \mathrm{F}$ for this case. The case has not been run further because the rapid increase in temperature, MCO pressure and hydrogen generation cause the code to reduce the time step to such a small value that running the problem out further is impractical with the current code. Coupling the thermal solution of COBRA-TF with the hydrodynamic solution of GOTH would resolve this problem.

The pressurization of the MCO is shown in Figure 7.46. There is sufficient water in the hydrates for this case to increase the MCO pressure to $320 \mathrm{psi}$ so venting of the MCO would be required in this case. The MCO pressure has not yet reached this pressure because less than half of the $\mathrm{UO}_{3} \cdot 2 \mathrm{H}_{2} \mathrm{O}$ has been consumed at the end of the calculation and this hydrate contains most of the water mass. The hydrogen gas content of the MCO is shown in Figure 7.47 and the hydrate water mass history for each of the three hydrates are shown in Figures 7.48, 7.49 and 7.50. Al1 of the aluminum and iron hydrate and over half of the uranium hydrate in the center of the rubble basket have been decomposed by the end of the simulation while not quite all of the iron hydrate and none of the other hydrates have been decomposed on the cooler outer perimeter of the rubble 
basket. All of the hydrates will completely decompose within minutes due to the temperature excursion created by the uranium/water reaction.

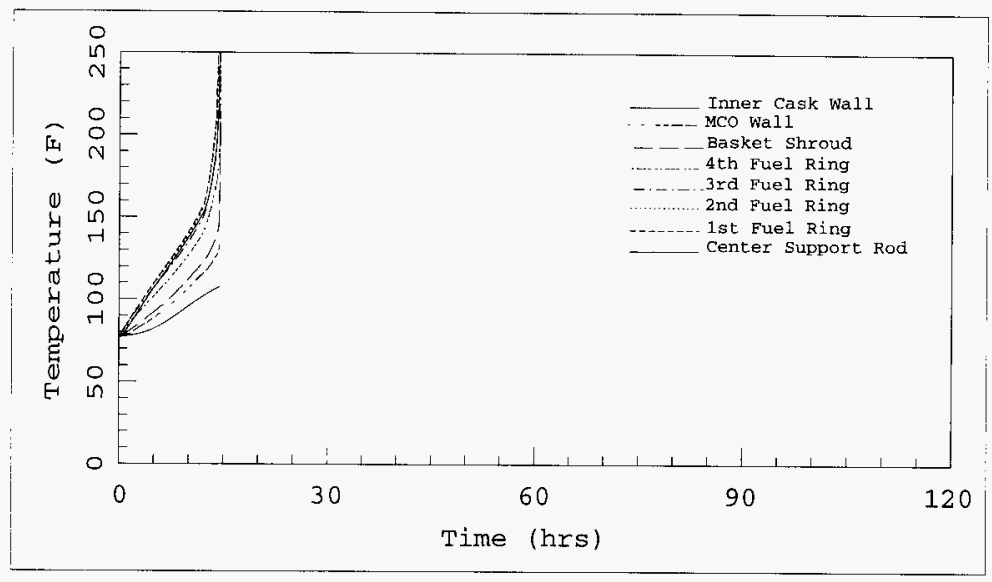

Figure 7.44 MCO Rod and Structure Temperatures For the Rubble Basket Heat Up During Transport From the CVDF to the CSB With Helium Filled Cask/MCO Gap and MCO and with Chemical Reactions Due to the Decomposition of the Reaction Product Hydrates. $A_{R}=800,000 \mathrm{~cm}^{2} ; m_{R P}=150 \mathrm{Kg} ; Q_{D H}=926$ watts. 
WHC-SD-SNF-ER-014, Rev. 0 .

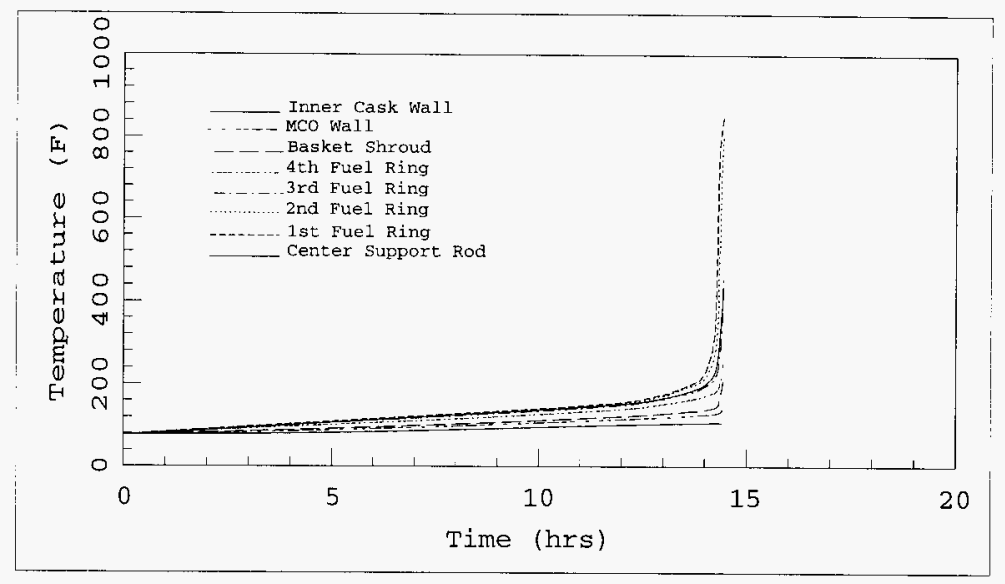

Figure 7.45 MCO Rod and structure Temperatures For the Rubble Basket Heat Up During Transport From the CVDF to the CSB With Helium Filled Cask/MCO Gap and MCO and With Chemical Reactions Due to the Decomposition of the Reaction Product Hydrates. $A_{R}=800,000 \mathrm{~cm}^{2} ; m_{R P}=150 \mathrm{Kg} ; Q_{D H}=929$ watts. 
WHC-SD-SNF-ER-014, Rev. 0 .

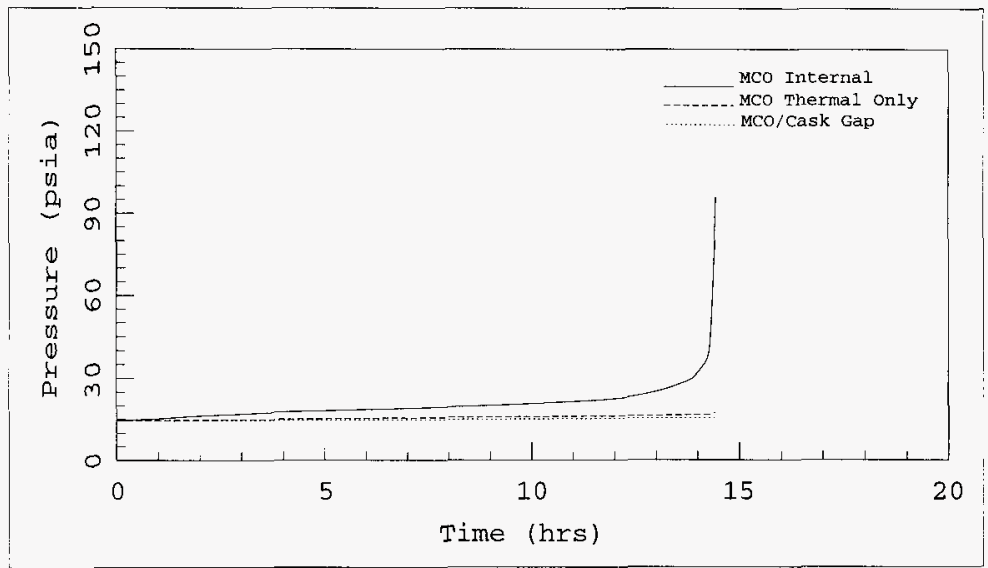

Figure 7.46 MCO Pressurization Rates for the Rubble Basket Heat Up During Transport From the CVDF to the CSB With Helium Filled Cask/MCO Gap and MCO and with Chemical Reactions Due to the Decomposition of the Reaction Product Hydrates. $A_{R}=800,000 \mathrm{~cm}^{2} ; m_{R P}=$ $150 \mathrm{Kg} ; Q_{\mathrm{DH}}=929$ watts. 
WHC-SD-SNF-ER-014, Rev . 0.

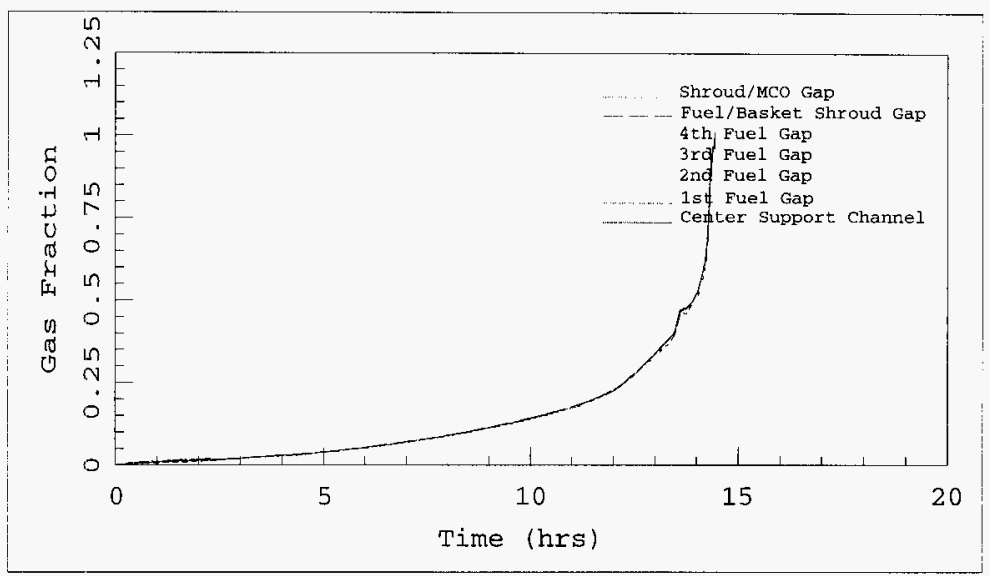

Figure 7.47 Hydrogen Gas Volume Fractions in the Rubble Basket For Rubble Basket Heat Up During Transport From the CVDF to the CSB with a Helium Filled Cask/MCO Gap and MCO and with Chemical Reactions Due to the Decomposition of the Reaction Product Hydrates. $A_{R}=800,000 \mathrm{~cm}^{2} ; m_{\mathrm{RP}}=150 \mathrm{Kg} ; Q_{\mathrm{DH}}=929$ watts. 
WHC-SD-SNF-ER-014, Rev. 0 .

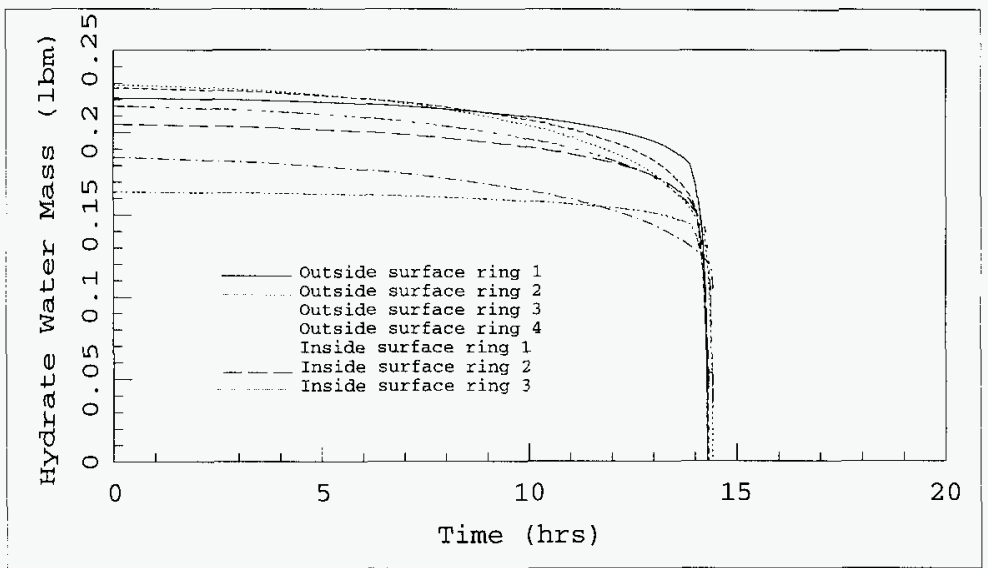

Figure $7.48 \mathrm{Fe}_{2} \mathrm{O}_{3} \bullet 3 \mathrm{H}_{2}$ water Mass in the Rubble Basket For Rubble Basket Heat Up During Transport From the CVDF to the CSB With a Helium Filled Cask/MCO Gap and MCO and with Chemical Reactions Due to the Decomposition of the Reaction Product Hydrates. $A_{\mathrm{R}}=800,000 \mathrm{~cm}^{2} ; \mathrm{m}_{\mathrm{RP}}=150 \mathrm{Kg} ; \mathrm{Q}_{\mathrm{DH}}=929$ watts. 
WHC-SD-SNF-ER-014, Rev. 0 .

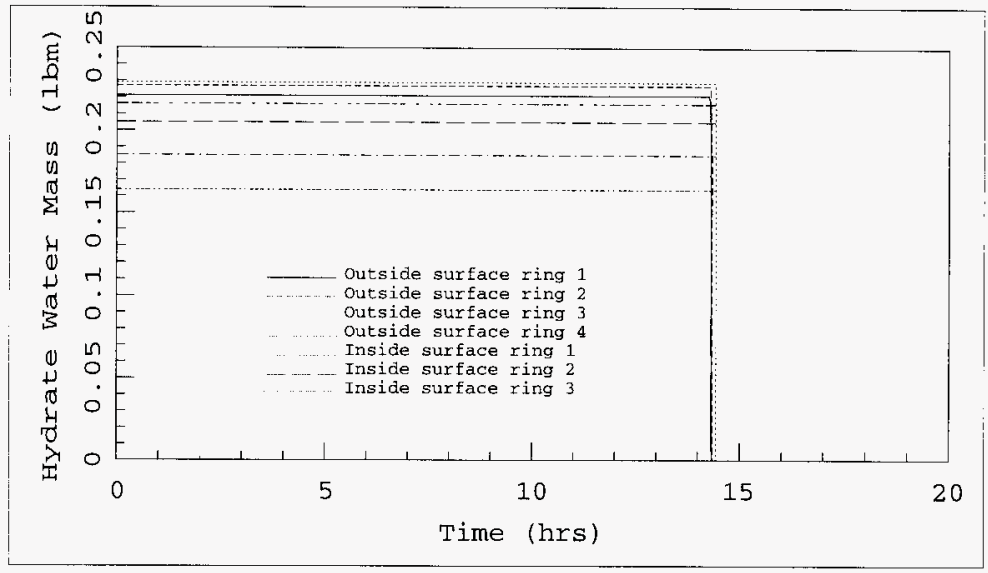

Figure $7.49 \mathrm{Al}_{2} \mathrm{O}_{3} \cdot 3 \mathrm{H}_{2}$ Water Mass in the Rubble Basket For Rubble Basket Heat Up During Transport From the CVDF to the CSB With a Helium Filled Cask/MCO Gap and MCO and with Chemical Reactions Due to the Decomposition of the Reaction Product Hydrates. $\mathrm{A}_{\mathrm{R}}=800,000 \mathrm{~cm}^{2} ; \mathrm{m}_{\mathrm{RP}}=150 \mathrm{Kg} ; \mathrm{Q}_{\mathrm{DH}}=929$ watts. 


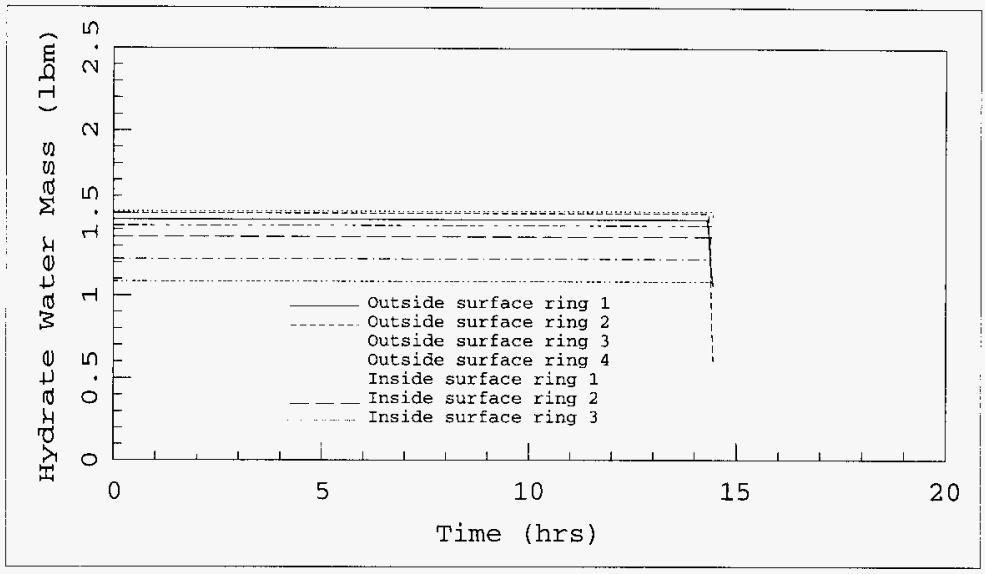

Figure $7.50 \quad \mathrm{UO}_{3} \cdot 2 \mathrm{H}_{2}$ Water Mass in the Rubble Basket For Rubble Basket Heat Up During Transport From the CVDF to the CSB With a Helium Filled Cask/MCO Gap and MCO and with Chemical Reactions Due to the Decomposition of the Reaction Product Hydrates. $A_{\mathrm{R}}=800,000 \mathrm{~cm}^{2} 1 ; \mathrm{m}_{\mathrm{RP}}=150 \mathrm{Kg} ; Q_{\mathrm{DH}}=929$ watts.

\subsubsection{Bounding Case With Reduced Decay Heat.}

The thermal and pressure transient of a high nominal powered MCO (750 watts of decay heat) containing $150 \mathrm{~kg}$ of corrosion product in the top rubble basket that has a reaction surface area of $800,000 \mathrm{~cm}^{2}$ for transport from the CVDF to the CSB on a hot summer day with shipping starting just before dawn with the cask, MCO and fuel at the CVDF release temperature of $25^{\circ} \mathrm{C}\left(77^{\circ} \mathrm{F}\right)$ is shown below. The MCO and the MCO/cask gap are assumed to be inerted with Helium gas. The only difference between this case and the case discussed in the previous section is that the decay heat has bee decreased to 750 watts. The temperature response 
for the fuel, MCO and Cask are shown in Figures 7.51 and 7.52. It is evident from these Figures that the net effect of decreasing the MCO decay heat by $20 \%$ has the net effect of increasing the time to the temperature excursion by about 2 hours due to the slightly slower heat up caused by the lower decay heat.

The MCO pressure, fuel basket hydrogen concentration and hydrate water mass histories are shown in Figures 7.53 through 7.57. The response of these parameters is similar to those for the case in the previous section except that they are delayed in time by about 2 hours.

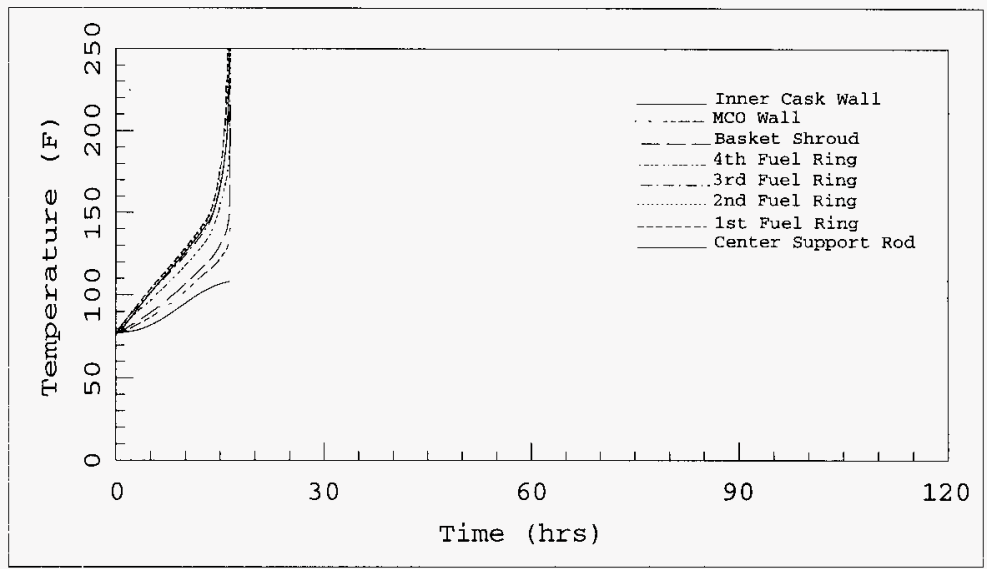

Figure 7.51 MCO Rod and Structure Temperatures For the Rubble Basket Heat Up During Transport From the CVDF to the CSB With Helium Filled Cask/MCO Gap and MCO and with Chemical Reactions Due to the Decomposition of the Reaction Product Hydrates; $\mathrm{A}_{\mathrm{R}}=800,000 \mathrm{~cm}^{2} ; \mathrm{m}_{\mathrm{RP}}=150 \mathrm{Kg} ; \mathrm{Q}_{\mathrm{DH}}=750$ watts. 
WHC-SD-SNF-ER-014, Rev. 0 .

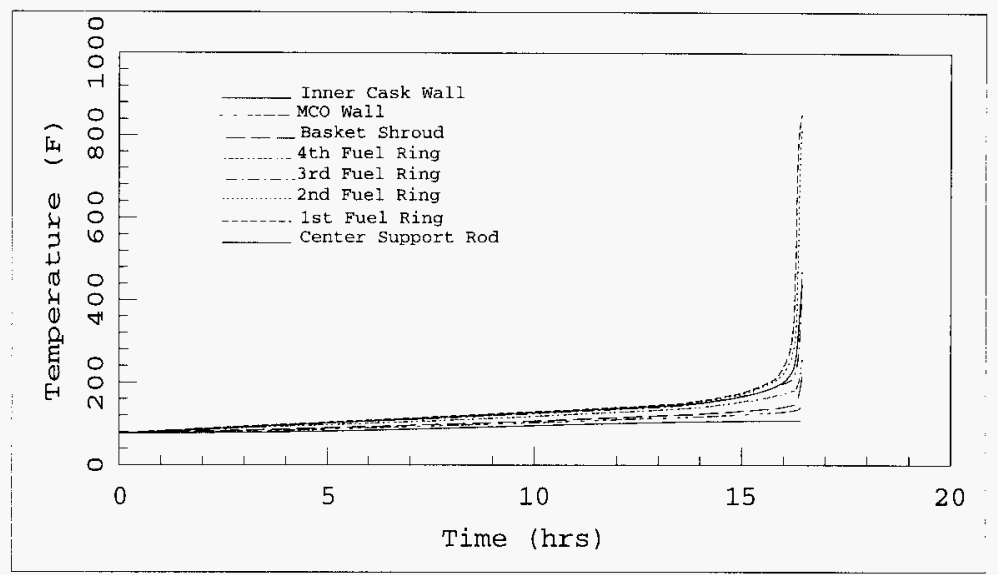

Figure 7.52 MCO Rod and Structure Temperatures For the Rubble Basket Heat Up During Transport From the CVDF to the CSB With Helium Filled Cask/MCO Gap and MCO and with Chemical Reactions Due to the Decomposition of the Reaction Product Hydrates $A_{R}=800,000 \mathrm{~cm}^{2} ; m_{R P}=150 \mathrm{Kg} ; Q_{D H}=750$ watts. 
WHC-SD-SNF-ER-014, Rev. 0 .

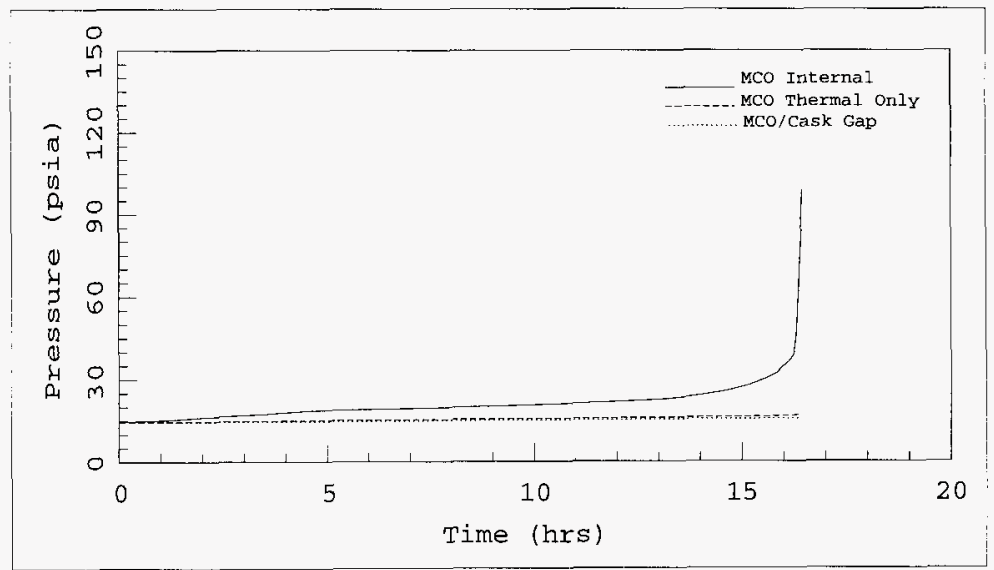

Figure 7.53 MCO Pressurization Rates for the Rubble Basket Heat Up During Transport From the CVDF to the CSB With Helium Filled Cask/MCO Gap and MCO and with Chemical Reactions Due to the Decomposition of the Reaction Product Hydrates. $A_{R}=800,000 \mathrm{~cm}^{2} ; \mathrm{m}_{\mathrm{RP}}=$ $150 \mathrm{Kg} ; \mathrm{Q}_{\mathrm{DH}}=750$ watts. 
WHC-SD-SNF-ER-014, Rev. 0 .

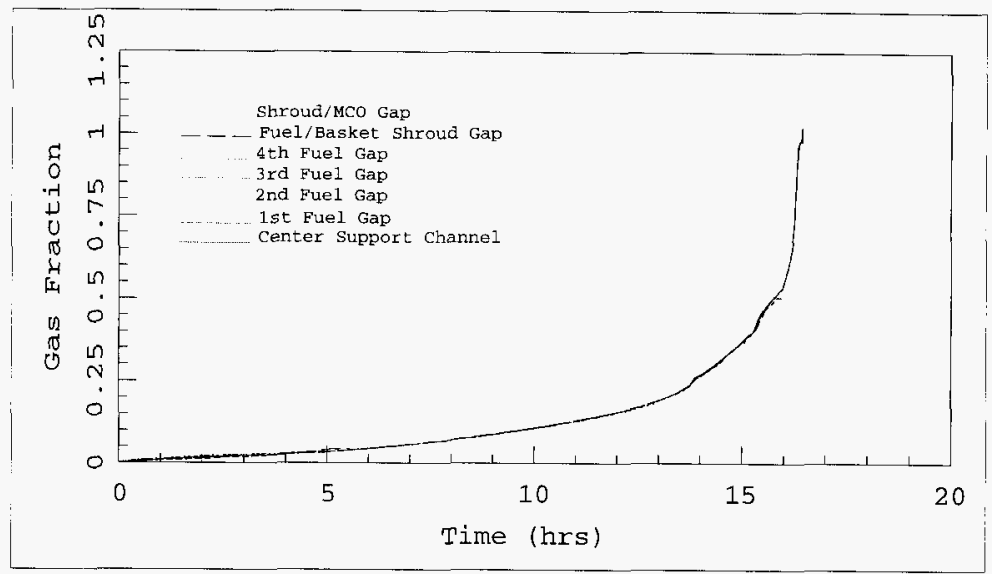

Figure 7.54 Hydrogen Gas Volume Fractions in the Rubble Basket For Rubble Basket Heat Up During Transport From the CVDF to the CSB With a Helium Filled Cask/MCO Gap and MCO and with Chemical Reactions Due to the Decomposition of the Reaction Product Hydrates. $\mathrm{A}_{\mathrm{R}}=800,000 \mathrm{~cm}^{2} ; \mathrm{m}_{\mathrm{RP}}=150 \mathrm{Kg} ; \mathrm{Q}_{\mathrm{DH}}=750$ watts. 
WHC-SD-SNF-ER-014, Rev. 0.

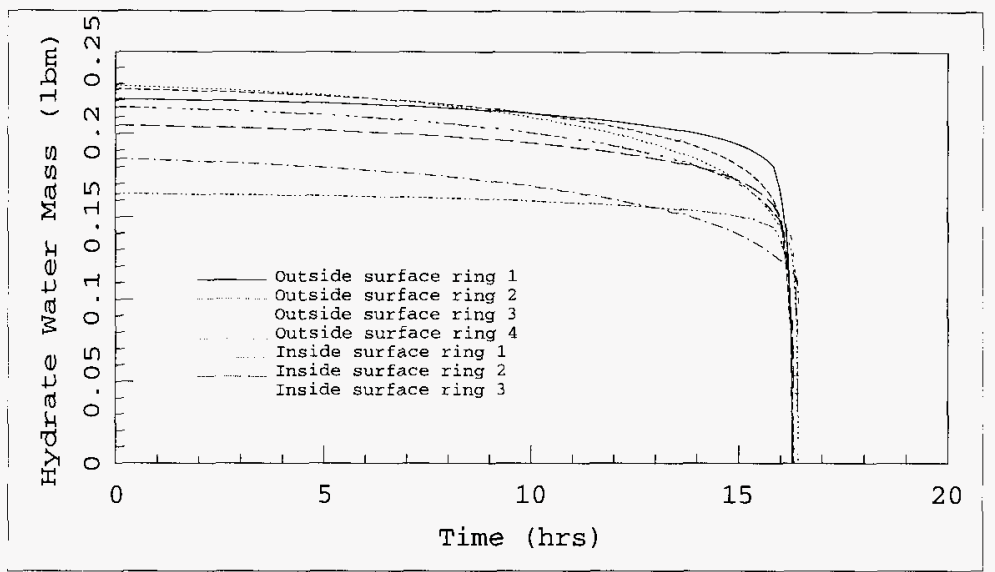

Figure $7.55 \mathrm{Fe}_{2} \mathrm{O}_{3} \bullet 3 \mathrm{H}_{2}$ Water Mass in the Rubble Basket For Rubble Basket Heat Up During Transport From the CVDF to the CSB With a Helium Filled Cask/MCO Gap and MCO and with Chemical Reactions Due to the Decomposition of the Reaction Product Hydrates. $A_{R}=800,000 \mathrm{~cm}^{2} ; m_{R P}=150 \mathrm{Kg} ; Q_{D H}=750$ watts. 
WHC-SD-SNF-ER-014, Rev. 0 .

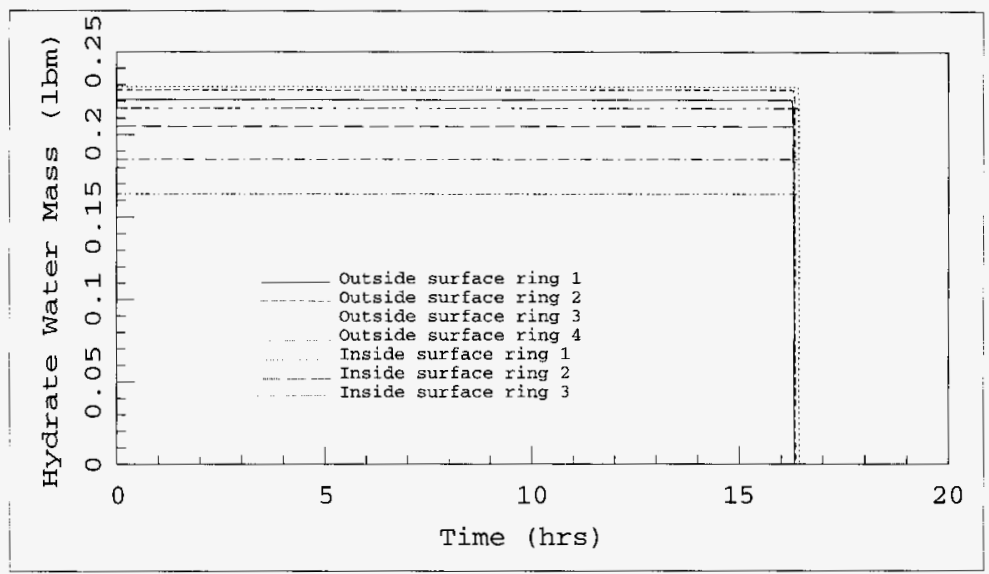

Figure $7.56 \mathrm{Al}_{2} \mathrm{O}_{3} \cdot 3 \mathrm{H}_{2}$ water Mass in the Rubble Basket For Rubble Basket Heat Up During Transport From the CVDF to the CSB With a Helium Filled Cask/MCO Gap and MCO and with Chemical Reactions Due to the Decomposition of the Reaction Product Hydrates. $\mathrm{A}_{\mathrm{R}}=800,000 \mathrm{~cm}^{2} ; \mathrm{m}_{\mathrm{RP}}=150 \mathrm{Kg} ; \mathrm{Q}_{\mathrm{DH}}=750$ watts. 


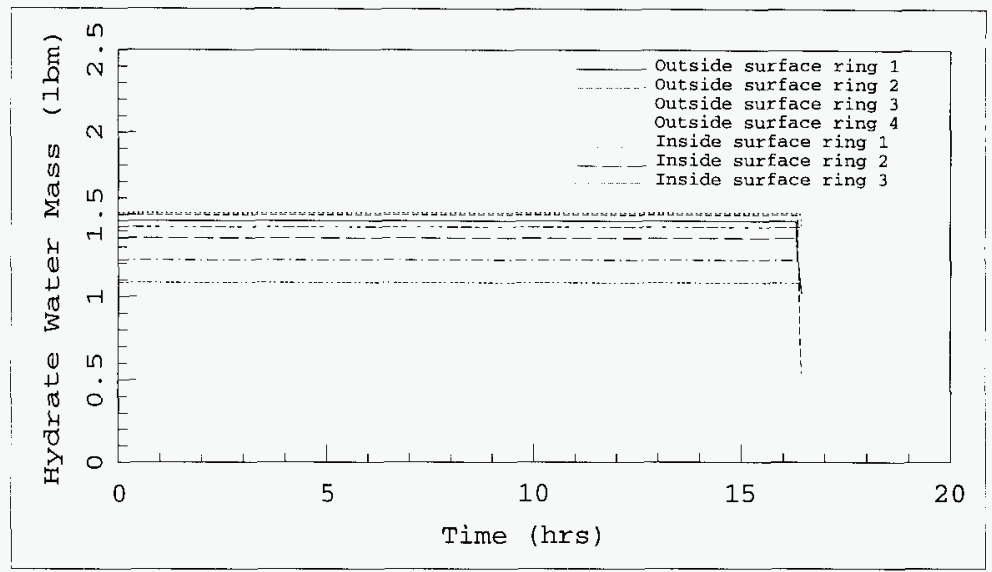

Figure $7.57 \mathrm{UO}_{3} \cdot 2 \mathrm{H}_{2}$ Water Mass in the Rubble Basket For Rubble Basket Heat Up During Transport From the CVDF to the CSB With a Helium Filled Cask/MCO Gap and $\mathrm{MCO}$ and with Chemical Reactions Due to the Decomposition of the Reaction Product Hydrates. $A_{\mathrm{R}}=800,000 \mathrm{~cm}^{2} ; \mathrm{m}_{\mathrm{RP}}=150 \mathrm{Kg} ; \mathrm{Q}_{\mathrm{DH}}=750$ watts.

7.2.2.4. High Nominal Case with 750 Watts of Decay Heat and $80,000 \mathrm{~cm}^{2}$ Reaction Area in the Rubble Basket.

This case is identical to the case presented in the previous section except that the reaction area in the rubble basket has been decreased from $800,000 \mathrm{~cm}^{2}$ to 80,000 $\mathrm{cm}^{2}$. The conditions for this case are, therefore, a decay heat of 750 watts, a reaction area of $80,000 \mathrm{~cm}^{2}$ in the rubble basket and a reaction product mass of $150 \mathrm{Kg}$ which contains $6.45 \mathrm{~kg}$ of water in hydrate form. The reduction in reaction area reduces the amount of heat generated by the chemical reaction to a level that can be rejected by 
WHC-SD-SNF-ER-014, Rev. 0 .

the MCO to the surroundings so a temperature excursion is not experienced for this case, Figure 7.58. Rather, the temperatures look similar to the temperature response without chemical heating except the temperatures rise more rapidly initially and they steady out at a slightly higher value.

The MCO pressure response for this case is shown in Figure 7.59. The pressure rises initially due to both the thermal expansion of the gas and due to hydrogen being generated by the uranium water reactions. The temperature then starts to rise exponentially for a short period of time. This exponential rise is caused by the period of time at lower temperatures where the chemical heating is higher than the system can reject as discussed in the introduction for this section. However, as the system heats up further, its ability to reject heat exceeds the rate at which the chemical reaction is generating heat so the temperatures level out and the pressure increases at a much slower rate. The temperatures do not exceed the upper bound where the system cannot reject the chemical heat as fast as it is being generated in the 3.5 day period covered by this simulation. It does not appear that this limit will be exceeded, however, a slow upward creep in the fuel temperatures could allow the limit to be exceeded after several days. The MCO pressure will eventually exceed the MCO design limit of 150 psia since there is enough water in the hydrate for this case to raise the MCO pressure to over 300 psia. This will take several days at these conditions.

The iron hydrate has nearly been consumed during the period covered by this simulation (it is all consumed in the center most region of the rubble basket and about half consumed in the outer regions), Figures 7.61 through 7.63 . The iron hydrate contains about 128 of the total hydrate water mass. The hydrogen fraction is over $75 \%$ at the end of the simulation which is consistent with the MCO pressure, Figure 7.60. 
WHC-SD-SNF-ER-014, Rev. 0 .

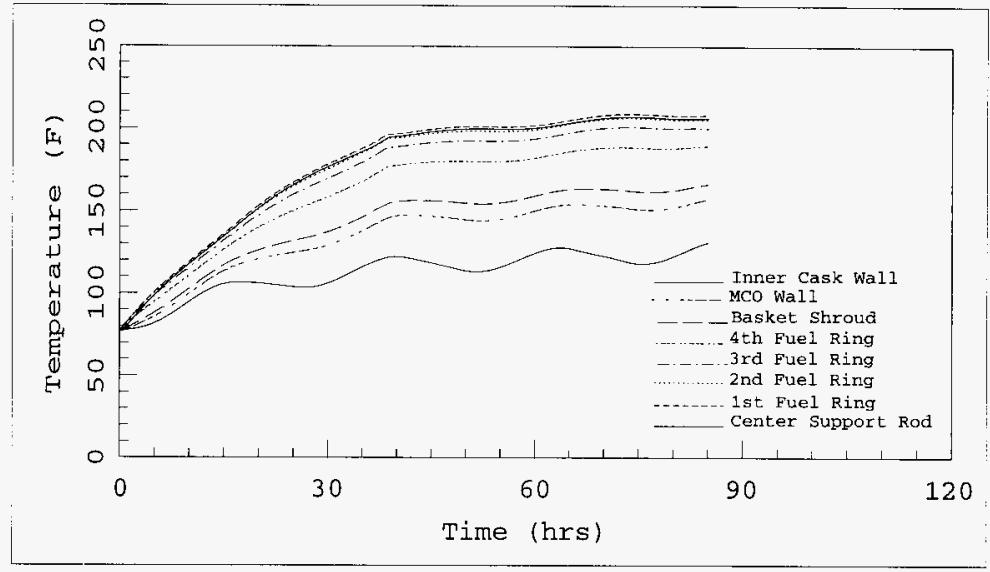

Figure $7.58 \mathrm{MCO}$ Rod and Structure Temperatures For the Rubble Basket Heat Up During Transport From the CVDF to the CSB With Helium Filled Cask/MCO Gap and MCO and with Chemical Reactions Due to the Decomposition of the Reaction Product Hydrates. $\mathrm{A}_{\mathrm{R}}=80,000 \mathrm{~cm}^{2} ; \mathrm{m}_{\mathrm{RP}}=150 \mathrm{Kg} ; \mathrm{Q}_{\mathrm{DH}}=750$ watts . 


$$
\text { WHC-SD-SNF-ER-014, Rev. } 0 \text {. }
$$

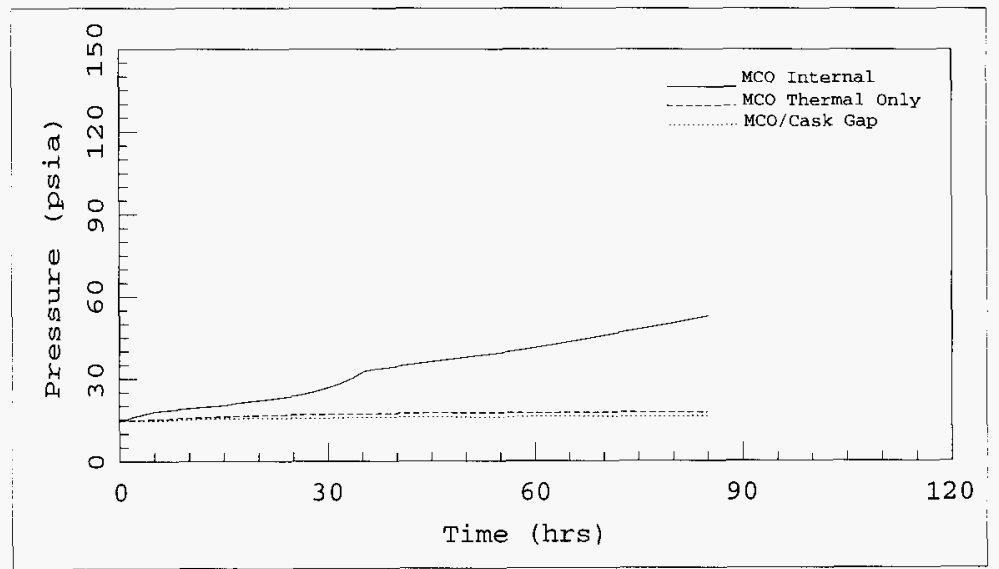

Figure 7.59 MCO Pressurization Rates for the Rubble Basket Heat Up During Transport From the CVDF to the CSB With Helium Filled Cask/MCO Gap and MCO and with Chemical Reactions Due to the Decomposition of the Reaction Product Hydrates. $A_{R}=80,000 \mathrm{~cm}^{2}$; $\mathrm{m}_{\mathrm{RP}}=150 \mathrm{Kg} ; \mathrm{Q}_{\mathrm{DH}}=750$ watts. 
WHC-SD-SNF-ER-014, Rev . 0 .

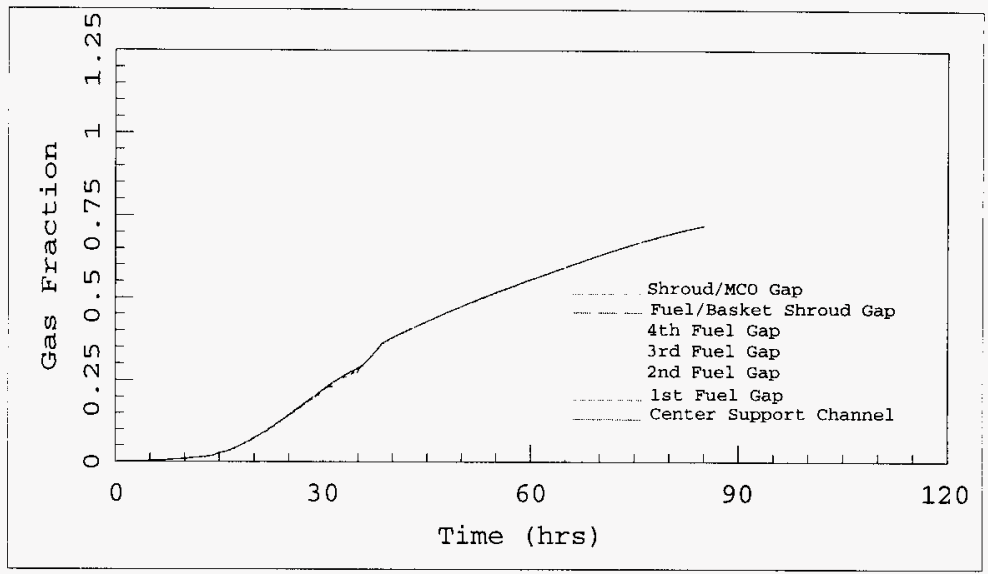

Figure 7.60 Hydrogen Gas Volume Fractions in the Rubble Basket For Rubble Basket Heat Up During Transport From the CVDF to the CSB With a Helium Filled Cask/MCO Gap and MCO and with Chemical Reactions Due to the Decomposition of the Reaction Product Hydrates. $A_{R}=80,000 \mathrm{~cm}^{2} ; m_{R P}=150 \mathrm{Kg} ; Q_{D H}=750$ watts. 
WHC-SD-SNF-ER-014, Rev. 0 .

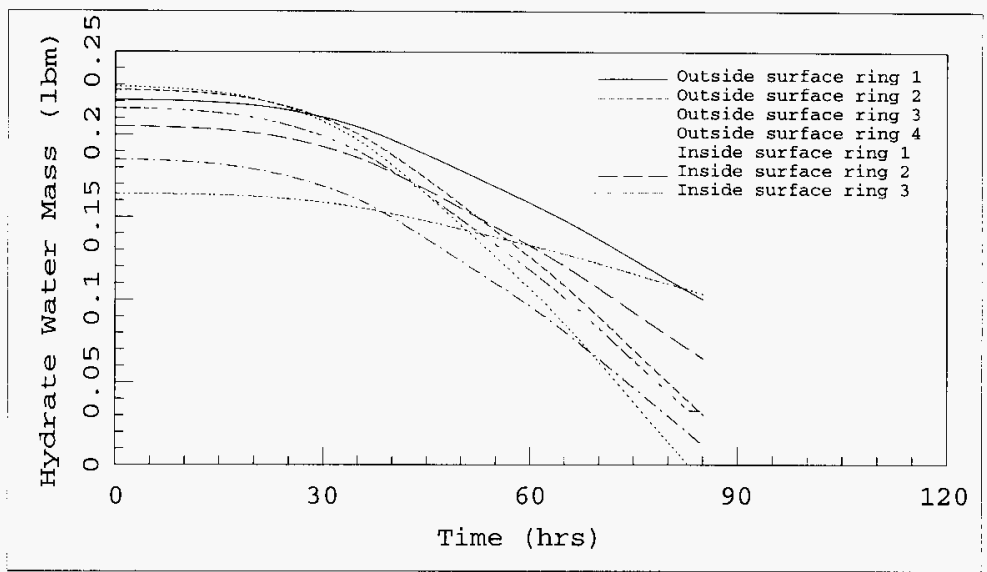

Figure $7.61 \mathrm{Fe}_{2} \mathrm{O}_{3} \cdot 3 \mathrm{H}_{2}$ Water Mass in the Rubble Basket For Rubble Basket Heat Up During Transport From the CVDF to the CSB With a Helium Filled Cask/MCO Gap and MCO and with Chemical Reactions Due to the Decomposition of the Reaction Product Hydrates. $A_{R}=80,000 \mathrm{~cm}^{2} ; m_{R P}=150 \mathrm{Kg} ; Q_{D H}=750$ watts. 
WHC-SD-SNF-ER-014, Rev. 0 .

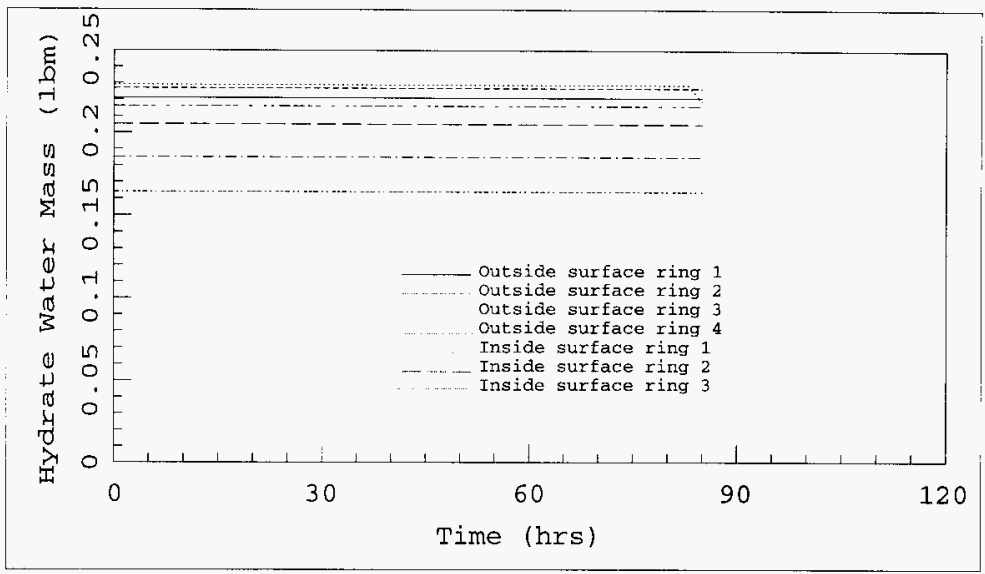

Figure $7.62 \mathrm{Al}_{2} \mathrm{O}_{3} \cdot 3 \mathrm{H}_{2}$ water Mass in the Rubble Basket For Rubble Basket Heat Up During Transport From the CVDF to the CSB With a Helium Filled Cask/MCO Gap and MCO and with Chemical Reactions Due to the Decomposition of the Reaction Product Hydrates. $\mathrm{A}_{\mathrm{R}}=80,000 \mathrm{~cm}^{2} ; \mathrm{m}_{\mathrm{RP}}=150 \mathrm{Kg} ; \mathrm{Q}_{\mathrm{DH}}=750$ watts . 
WHC-SD-SNF-ER-014, Rev. 0 .

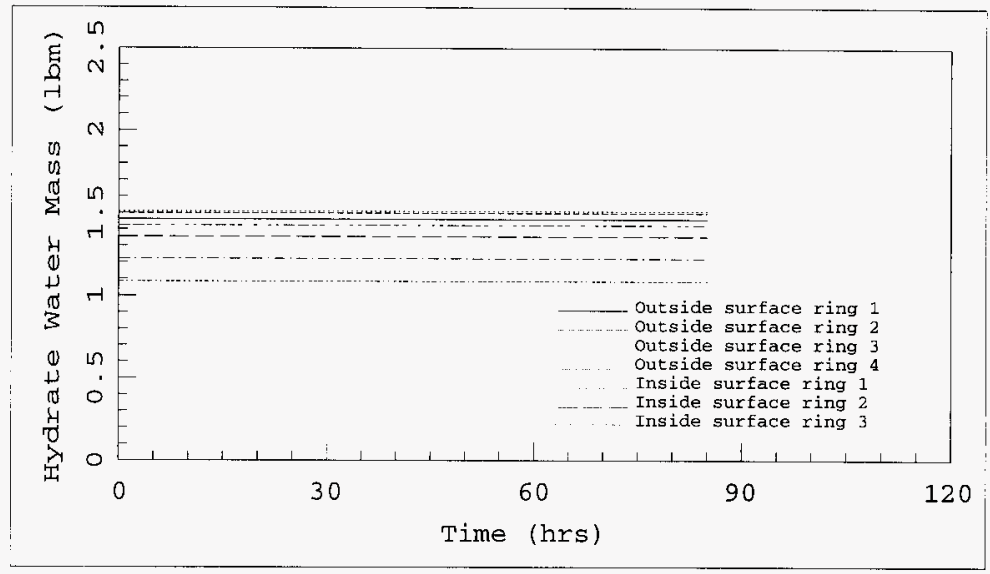

Figure $7.63 \mathrm{UO}_{3} \cdot 2 \mathrm{H}_{2}$ Water Mass in the Rubble Basket For Rubble Basket Heat Up During Transport From the CVDF to the CSB With a Helium Filled Cask/MCO Gap and MCO and with Chemical Reactions Due to the Decomposition of the Reaction Product Hydrates. $\mathrm{A}_{\mathrm{R}}=80,000 \mathrm{~cm}^{2} ; \mathrm{m}_{\mathrm{RP}}=150 \mathrm{Kg} ; Q_{\mathrm{DH}}=750$ watts.

\subsubsection{Minimum Sludge Case.}

This case is identical to the previous case except that the amount of reaction product assumed to be available in the rubble basket is $16 \mathrm{Kg}$. Therefore, one would expect the behavior of this simulation to be similar to the previous case except that the waters of hydration will be consumed sooner. There may also be a slight difference in the temperature response and hydrogen generation rates since the equilibrium pressures for the three hydrates are different and this will result in different water/uranium reaction rates. 
The temperature response of the fuel, MCO and cask at the top rubble basket location are shown in Figure 7.64. The temperature rises rapidly at first, as before, until it reaches a value where the heat generated by the reaction can be rejected by system. The temperatures begin noticeably drop after 90 hours because all of the water in the center region of the rubble basket has been consumed.

The MCO pressure and hydrogen concentrations also level out as the water is depleted, Figures 7.65 through 7.69. The pressure levels out at about 60 psi which is the correct value for $16 \mathrm{~kg}$ of reaction products. There is still an upward creep in pressure and hydrogen concentration as the last of the water is depleted from the uranium hydrate, Figure 7.69. The MCO would not require venting given this amount of reaction product. 
WHC-SD-SNF-ER-014, Rev . 0 .

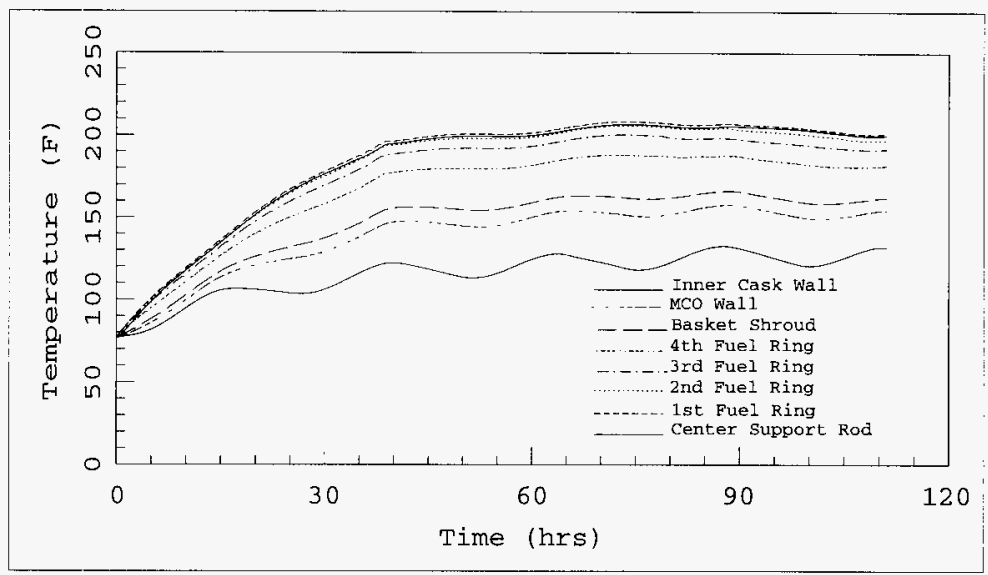

Figure 7.64 MCO Rod and Structure Temperatures For the Rubble Basket Heat Up During Transport From the CVDF to the CSB With Helium Filled Cask/MCO Gap and MCO and with Chemical Reactions Due to the Decomposition of the Reaction Product Hydrates. $A_{R}=80,000 \mathrm{~cm}^{2} ; m_{R P}=16 \mathrm{Kg} ; Q_{D H}=750$ watts. 
WHC-SD-SNF-ER-014, Rev. 0 .

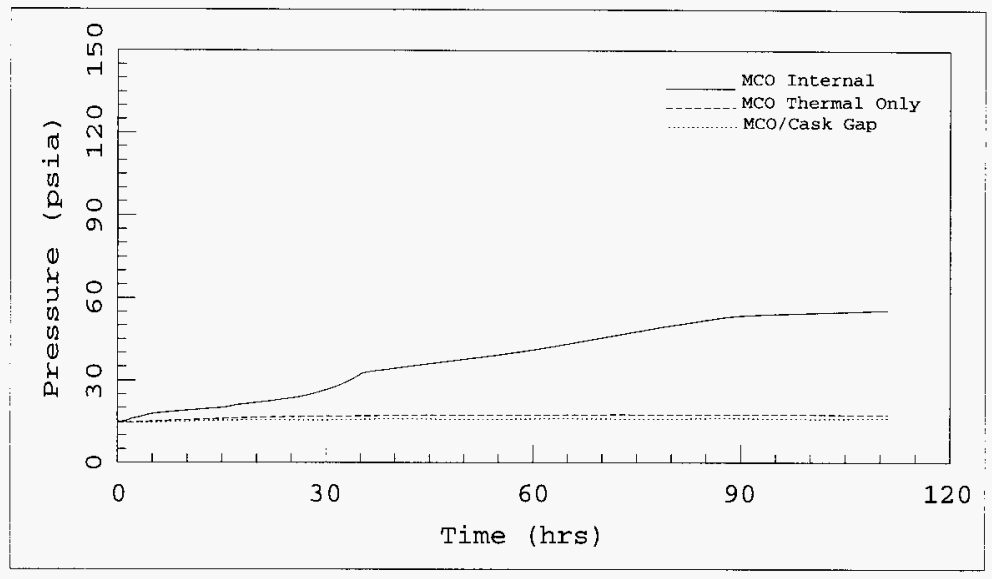

Figure 7.65 MCO Pressurization Rates for the Rubble Basket Heat Up During Transport From the CVDF to the CSB With Helium Filled Cask/MCO Gap and MCO and with Chemical Reactions Due to the Decomposition of the Reaction Product Hydrates. $A_{R}=80,000 \mathrm{~cm}^{2}$; $\mathrm{m}_{\mathrm{RP}}=16 \mathrm{Kg} ; Q_{\mathrm{DH}}=750$ watts. 
WHC-SD-SNF-ER-014, Rev. 0 .

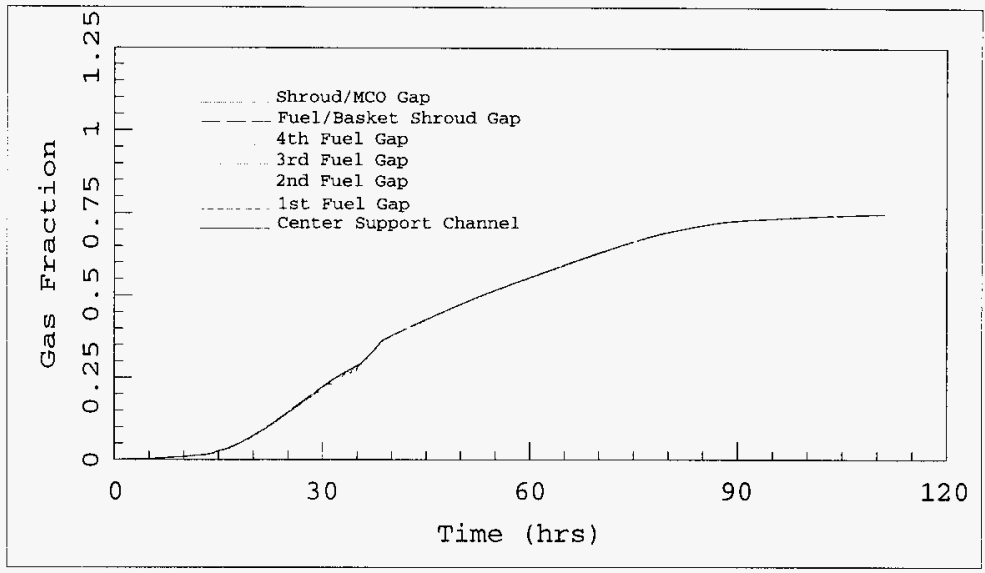

Figure 7.66 Hydrogen Gas Volume Fractions in the Rubble Basket For Rubble Basket Heat Up During Transport From the CVDF to the CSB with a Helium Filled Cask/MCO Gap and MCO and with Chemical Reactions Due to the Decomposition of the Reaction Product Hydrates. $A_{R}=80,000 \mathrm{~cm}^{2} ; m_{R P}=16 \mathrm{Kg} ; Q_{D H}=750$ watts 
WHC-SD-SNF-ER-014, Rev. 0 .

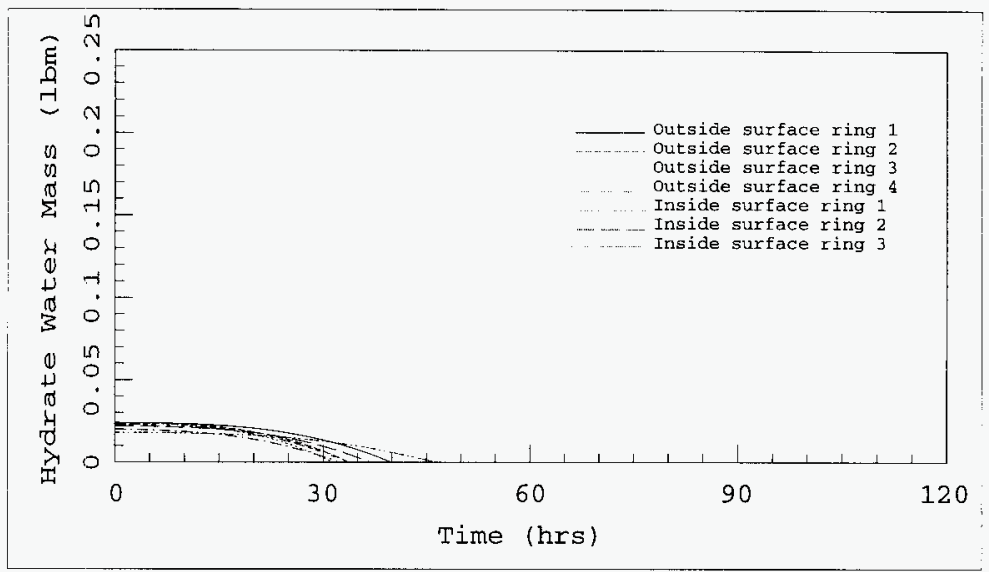

Figure $7.67 \mathrm{Fe}_{2} \mathrm{O}_{3} \bullet 3 \mathrm{H}_{2}$ water Mass in the Rubble Basket For Rubble Basket Heat Up During Transport From the CVDF to the CSB With a Helium Filled Cask/MCO Gap and MCO and with Chemical Reactions Due to the Decomposition of the Reaction Product Hydrates. $\mathrm{A}_{\mathrm{R}}=80,000 \mathrm{~cm}^{2} ; \mathrm{m}_{\mathrm{RP}}=16 \mathrm{Kg} ; \mathrm{Q}_{\mathrm{DH}}=750$ watts. 
WHC-SD-SNF-ER-014, Rev. 0 .

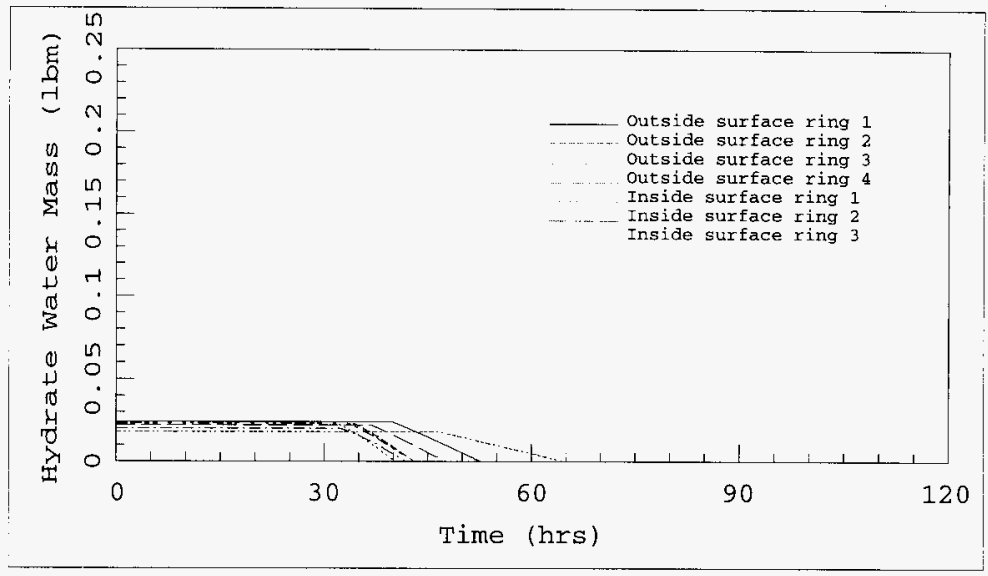

Figure $7.68 \mathrm{Al}_{2} \mathrm{O}_{3} \cdot 3 \mathrm{H}_{2}$ Water Mass in the Rubble Basket For Rubble Basket Heat Up During Transport From the CVDF to the CSB With a Helium Filled Cask/MCO Gap and MCO and with Chemical Reactions Due to the Decomposition of the Reaction Product Hydrates. $A_{R}=80,000 \mathrm{~cm}^{2} ; m_{R P}=16 \mathrm{Kg} ; Q_{D H}=750$ wats. 


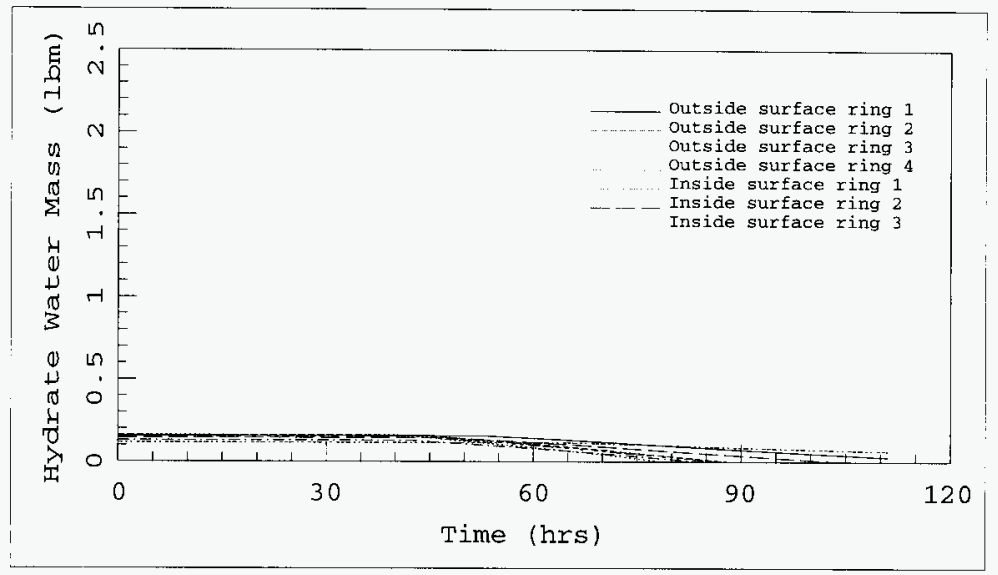

Figure $7.69 \mathrm{UO}_{3} \bullet 2 \mathrm{H}_{2}$ Water Mass in the Rubble Basket For Rubble Basket Heat Up During Transport From the CVDF to the CSB With a Helium Filled Cask/MCO Gap and MCO and with Chemical Reactions Due to the Decomposition of the Reaction Product Hydrates. $\mathrm{A}_{\mathrm{R}}=80,000 \mathrm{~cm}^{2} ; \mathrm{m}_{\mathrm{RP}}=16 \mathrm{Kg} ; Q_{\mathrm{DH}}=750$ watts.

\subsection{MCO PRESSURIZATION DURING COLD VACUUM DRYING DRAINING FAILURE.}

This case assumes that the maximum powered MCO (929 watts) contains $55 \mathrm{~kg}$ of water due to a failure to completely drain the $\mathrm{MCO}$ of water during cold vacuum drying. The rubble basket is in the top of the MCO and has a reaction area of $800,000 \mathrm{~cm}^{2}$. In addition, each fuel basket is assumed to be loaded with fuel elements that are completed declad and corroded on the top 5 inches of both the inner and outer elements. These elements are assumed to have a true reaction area that is 10 times the geometric surface area of the declad fuel. This results in an additional 


$$
\text { WHC-SD-SNF-ER-014, Rev. } 0 \text {. }
$$

$560,000 \mathrm{~cm}^{2}$ of reaction area in the MCO. The cask/mco gap is assumed to be filled with water which is at $50^{\circ} \mathrm{C}$ $\left(122^{\circ} \mathrm{F}\right)$ and the MCO and fuel are assumed to initially be at this temperature.

The fuel which is not covered by water begins to heat up due to the decay heat in the fuel. Water vapor in the atmosphere surrounding the fuel is consumed by the uranium water reaction. This water is replaced by water evaporating from the water remaining in the bottom of the mco. Heat from the upper regions of the MCO is transferred from the fuel to the MCO wall. Axial conduction in the MCO wall conducts the heat down to the water in the bottom of the MCO increasing the temperature of the water and enhancing the evaporation rate which supplies more water vapor to the upper fuel and rubble baskets. The resultant water/uranium reaction generates more heat in the fuel causing the fuel to heat more and causing the MCo pressure to rise due to the generation of hydrogen gas from the uranium/water reaction. The fuel and MCO temperature histories in the upper rubble basket are shown in Figure 7.70. The center fuel temperatures reach a peak temperature of $330^{\circ} \mathrm{F}$. The fuel nearer the MCO wall is cooler. The MCO wall reaches a peak temperature of $170^{\circ} \mathrm{F}$ at this time.

The MCO pressure has reached $130 \mathrm{psi}$ and is still rising due to the continued reaction of steam with the uranium, Figure 7.71. This reaction will continue until all of the water is consumed or until all of the uranium is oxidized so the pressure will continue to rise and exceed the MCO design pressure. The MCO will need to be vented for this case. The MCO hydrogen volume fraction is shown in Figure 7.72. The hydrogen volume fraction is approaching $85 \%$ at the end of the simulation. 
WHC-SD-SNF-ER-014, Rev. 0.

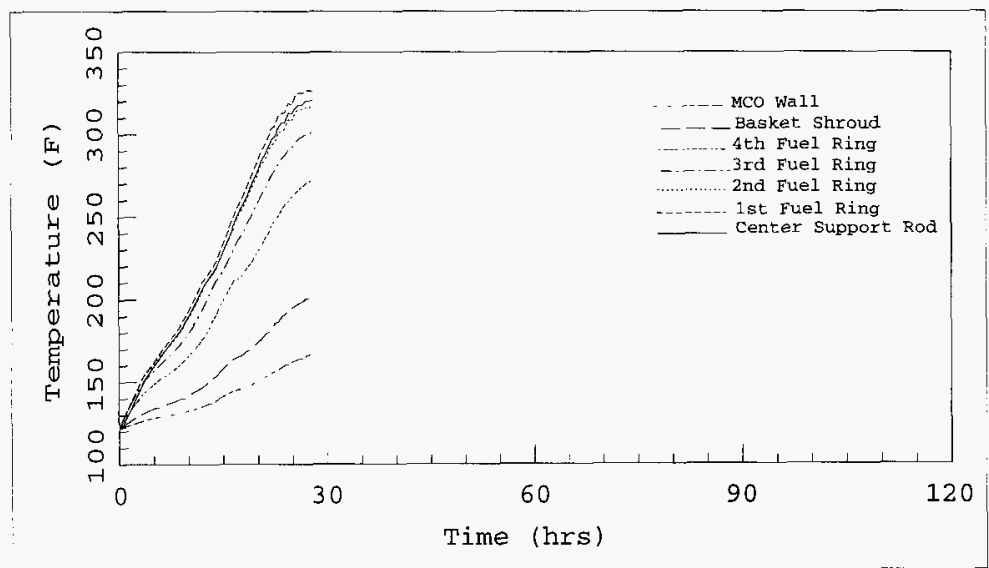

Figure 7.70 Case 2A - Failure to Drain - $55 \mathrm{~kg}$ of Water No Pressure Relief - Oxygen Free - Maximum Powered MCO - MCO Rod and structure Temperatures for the Top Basket 
WHC-SD-SNF-ER-014, Rev. 0 .

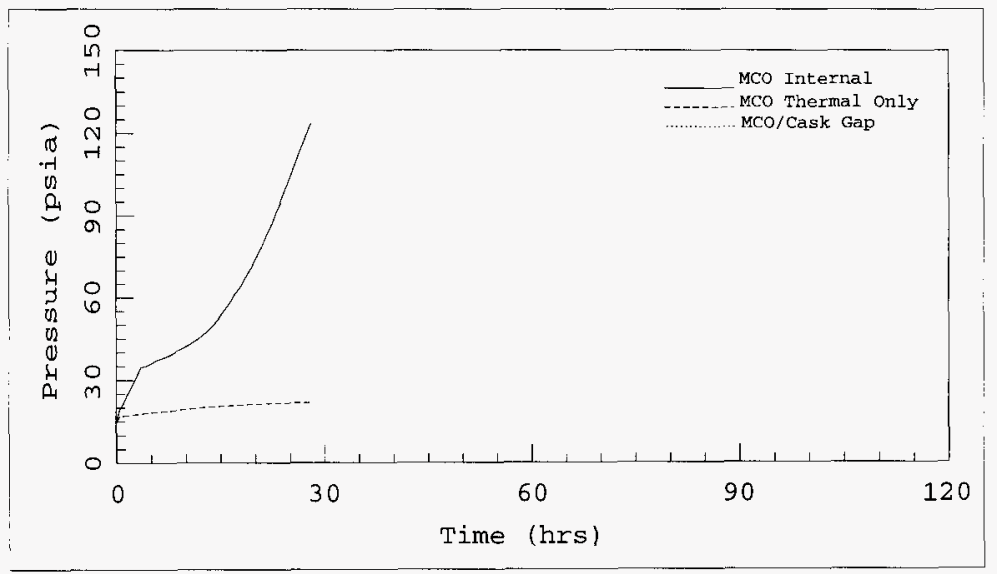

Figure 7.71 Case 2A - Failure to Drain - 55kg of Water No Pressure Relief - oxygen Free - Maximum Powered MCO - MCO Pressurization Rates. 
WHC-SD-SNF-ER-014, Rev. 0 .

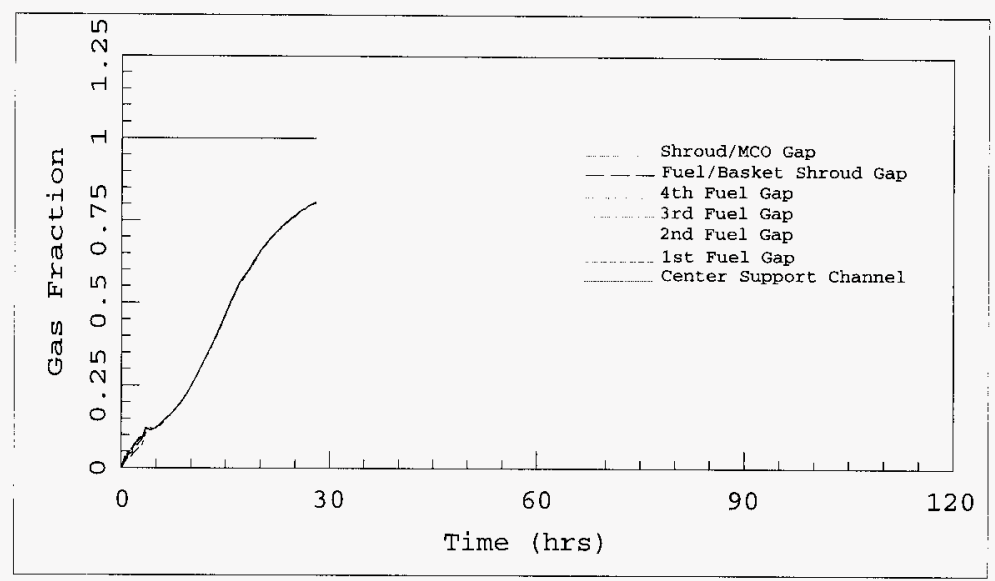

Figure 7.72 Case 2A - Failure To Drain - $55 \mathrm{~kg}$ of water - No Pressure Relief - Oxygen Free - Maximum Powered MCO - Hydrogen Gas Volume Fractions in the Top Fuel Basket.

\subsection{EQUILIBRIUM PRESSURE VERSUS WATER MASS.}

The equilibrium pressure of the MCO (the pressure the MCO will go to if all of the water is reacted and the MCo comes to thermal equilibrium with its environment) is a function of the water mass assumed to be in the MCO before any reactions take place, the free gas volume of the MCo, the fill gas, the fill temperature and the steady state temperature of the MCO for a given environment.

$$
\text { Peq }=\left(\frac{m_{f} R_{f}+m_{H 20} \frac{M_{H 2}}{M_{H 2 O}} R_{H 2}}{\text { Vol }}\right) T_{e q}
$$

Assuming that the $\mathrm{MCO}$ is filled with Helium at $25^{\circ} \mathrm{C}$ initially, the mass of helium in the MCO before any water reactions take place is: 


$$
\mathrm{m}_{\mathrm{HE}}:=\frac{14.7 \mathrm{psi} \cdot 0.55 \mathrm{~m}^{3}}{386 \frac{\mathrm{ft}-\mathrm{lbf}}{1 \mathrm{bm}-\mathrm{R}} \cdot \mathrm{tf}(77)}=0.09003 \mathrm{~kg}
$$

and the equilibrium pressure that the MCO will come to due to the generation of hydrogen from the Uranium/Water reaction is given by the following function;

$$
\begin{aligned}
& P_{\text {eq }}\left(m_{\text {H } 20}, T_{\text {eq }}, \text { Vol }\right):= \\
& \qquad\left(\frac{m_{H E} \cdot 386 \frac{f t-1 b f}{1 b m-R}+m_{H 2 O} \cdot \frac{2.016}{18.016} \cdot 766.4 \frac{f t-l b f}{1 b m-R}}{V o l}\right) \cdot T_{e q}
\end{aligned}
$$

The equilibrium pressure as a function of MCO hydrate water mass for two bulk MCO temperatures is shown in metric units in Figure 7.73 and English Units in Figure 7.74. The two temperatures shown in the figure have been chosen because they represent the expected MCO temperatures during the peak summer temperatures for the MCO stored in the transportation cask and for the MCO stored in the CSB storage tube.

The maximum amount of water that may be present in an MCO that will raise the MCO pressure to its design limit of 165 psia can be determined from these curves if we assume that sufficient time is allowed for the water reaction to go to completion. The amount of time required for the water decomposition to go to completion depends on the form the water is in. Surface bound water (hydroxides) comes off rather slowly, so water contained in the MCO in this form will come out only after long periods of storage, such as during interim storage. Water stored in the form of hydrates likely comes off more rapidly, but current methods for the rate of hydride decomposition have large amount of uncertainty in them, so it must be assumed that this water comes off easily. This water will react very rapidly at both transport and CSB staging temperatures, depending on 
the amount of reactive surface area there is on the uranium metal. The same is true for any free water in the MCO. It must be demonstrated that either the reactive surface area is sufficiently small that not enough water will react with uranium during the time period of interest to over pressurize the MCO or it must be demonstrated that there is no more water in the MCO than that which will over pressurize the MCO if all of the water is converted into hydrogen gas. The maximum amount of water that may be present in the MCO to remain below the MCO design pressure is $6.5 \mathrm{lbm}$ when the MCO is in the transportation cask and $5.5 \mathrm{lbm}$ when the MCO is in the CSB storage tube. These values are obtained by finding the intersection of the MCO design pressure with the pressure versus water mass plots in Figure 7.74 .

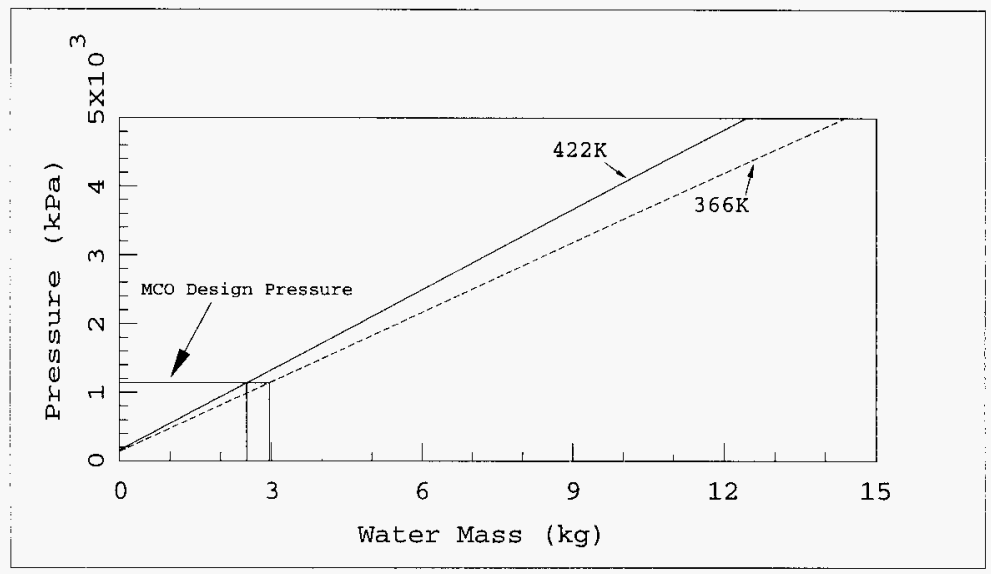

Figure 7.73 Maximum MCO Pressure As a Function of Initial Water Mass for Two MCO Temperatures. 


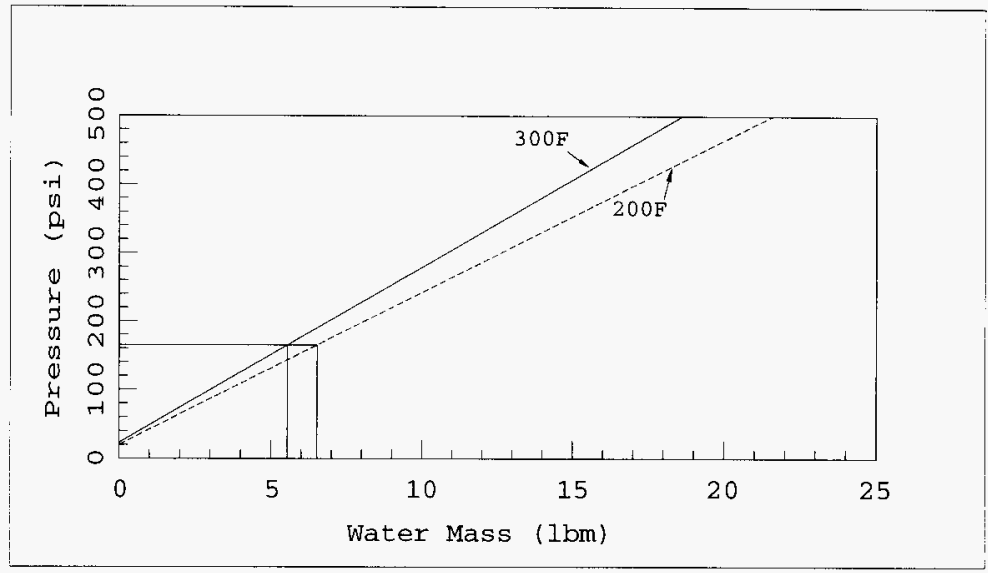

Figure 7.74 Maximum MCO Pressure As a Function of Initial Water Mass for Two MCO Temperatures.

\section{PRESSURE RELIEF FLOW RATES.}

Conservative estimates for MCO pressure in all stages of MCO transport and storage indicate that pressure relief will be required on the MCO. The maximum anticipated flow rate the relief device must handle, assuming a reaction area of $80,000 \mathrm{~cm}^{2}$ is provided in this section. The hydrogen generation rate as a function of temperature is shown in Figure 8.1 for each of the reaction rate equations used in the MCO pressurization study. The corresponding hydrogen gas volumetric flow and velocity in a one inch orifice of an inlet pressure of 150 psia are shown in Figures 8.2 and 8.3 . The release velocities required to keep up with the maximum anticipated hydrogen generation rates in a 1 inch orifice are only on the order of $2 \mathrm{~m} / \mathrm{s}$ at $150 \mathrm{psia}$. The volumetric flow at this pressure is $0.002 \mathrm{~m}^{3} / \mathrm{s}(4.2 \mathrm{CFM})$. However, significantly higher 
WHC-SD-SNF-ER-014, Rev. 0.

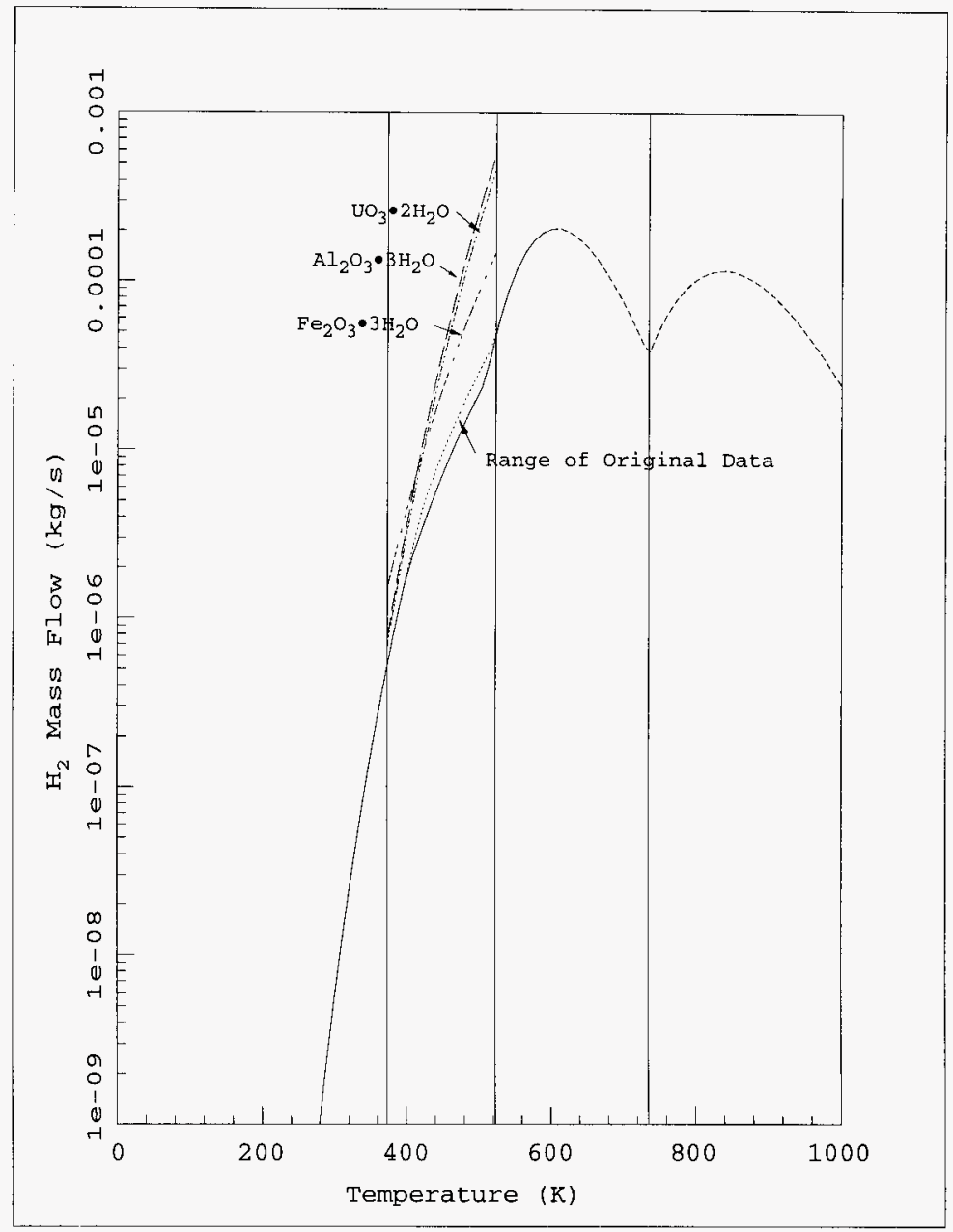

Figure 8.1 Hydrogen Mass Flow Rate Due To Pearce Oxygen Free Uranium/Water Reaction Using the Hydrate Equilibrium Pressures, $A_{R}=80,000 \mathrm{~cm}^{2}$. 
WHC-SD-SNF-ER-014, Rev. 0.

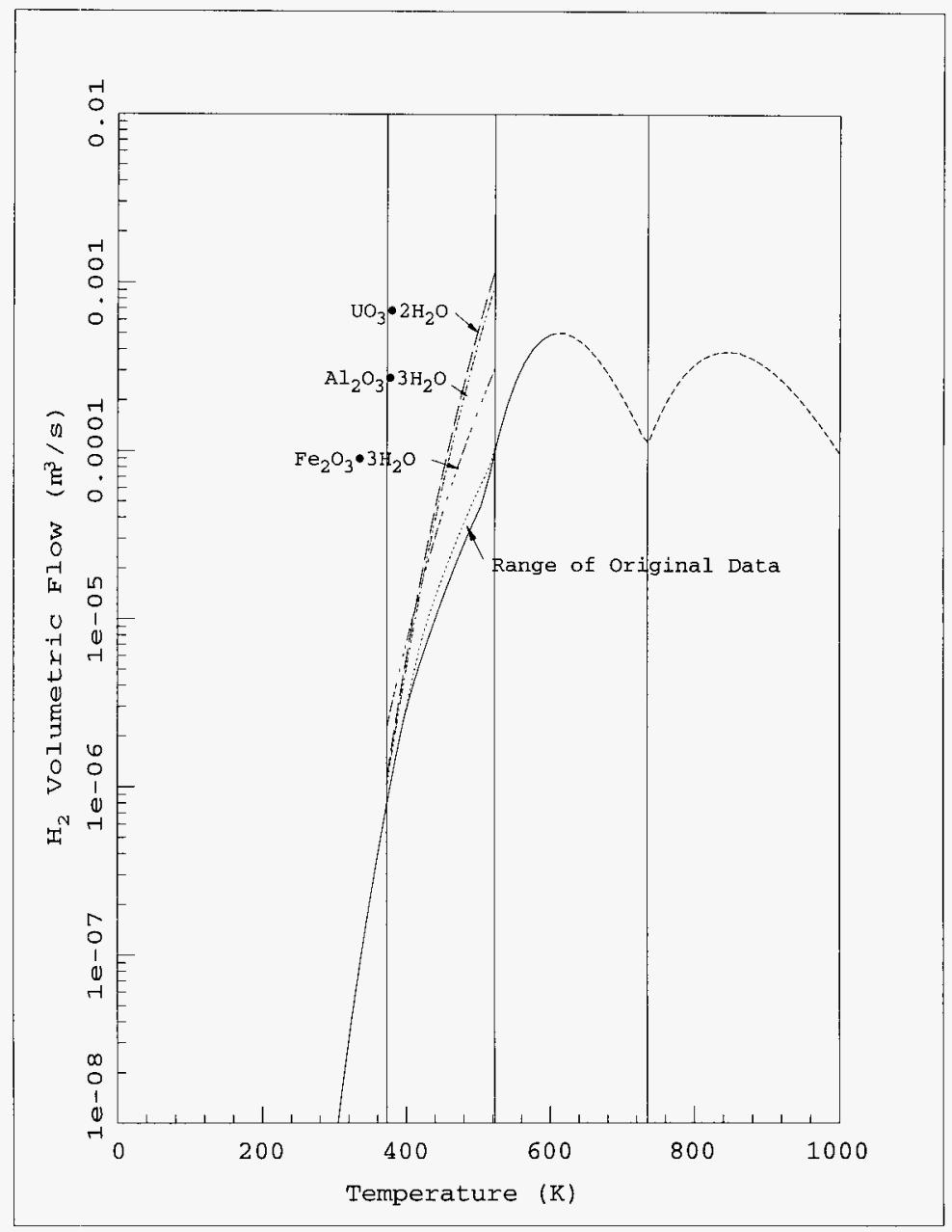

Figure 8.2 Hydrogen Volumetric Flow Rate at 150 psia Due to Pearce Oxygen Free Uranium/Water Reaction Using Hydrate Equilibrium Pressures. $A_{R}=80,000 \mathrm{~cm}^{2}$ 
WHC-SD-SNF-ER-014, Rev. 0 .

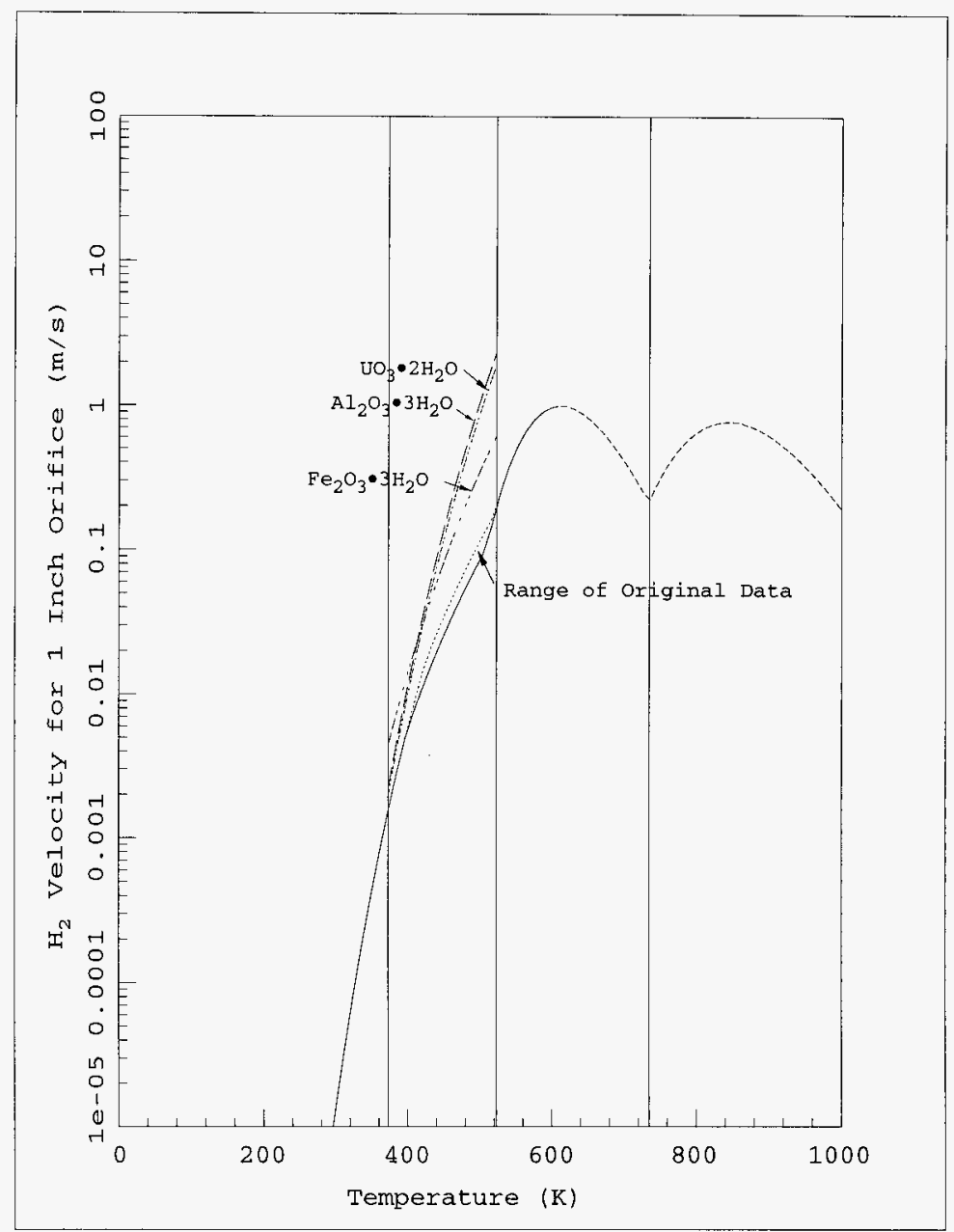

Figure 8.3 Hydrogen Velocity for 1 inch orifice at 150 psia Due to Pearce oxygen Free Uranium/water Reaction Using Hydrate Equilibrium Pressures. 
flows will result if a safety relief valve or rupture disk is opened at 165 psia since the large pressure difference across the valve will allow choked flow to develop across the valve until the difference between the MCO and the storage tube drops below the critical pressure or the valve recloses.

The sonic velocity of hydrogen gas is at typical MCO temperatures is obtained as follows:

$$
\begin{aligned}
& \mathrm{C}_{\mathrm{H} 2}=\sqrt{\mathrm{kRT}} \\
& \mathrm{C}_{\mathrm{H} 2}(\mathrm{~T}):=\left(1.404 \cdot 766.4 \frac{\mathrm{ft}-1 \mathrm{bf}}{1 \mathrm{bm}-\mathrm{R}} \cdot \mathrm{T}\right)^{0.5} \\
& \mathrm{C}_{\mathrm{H} 2}(\mathrm{tf}(482))=1740 \frac{\mathrm{m}}{\mathrm{s}}
\end{aligned}
$$

This is the velocity that will develop in the Mco relief orifice immediatly after it opens.

A simple MCO and storage tube GOTH model has been developed to evaluate the dynamic pressure response of the $\mathrm{MCO}$ and storage tube to the relief valve opening and to assist in sizing the relief valve orifice for both the MCO and the storage tube. This nodalization for this model is shown in Figure 8.4. Volumes 1 and 2 represent the gas volume $\left(17.66 \mathrm{ft}^{3} / \mathrm{MCO}\right)$ contained in the two MCOs that are contained in one CSB storage tube. Volume 3 represents the free volume of the CSB storage tube which is $38 \mathrm{ft}^{3}$. Junctions 1 and 2 and Valves 1 and 2 represent the relief valves on the Mcos. Junction 3 and Valve 3 represents the relief valve on the storage tube. Junction 4 and valve 4 represent the floor plug on the storage tubes. The MCO valves are assumed to open at $150 \mathrm{psia}$ and to reseat at 140 psia. The tube relief valve is assumed to open at 8 psig and close at 6 psig. The floor plug is assumed to lift at 11 psig and fall back down at 10 psig. Through iterative 


$$
\text { WHC-SD-SNF-ER-014, Rev . } 0 \text {. }
$$

simulations it has been determined that a 1/4 inch orifice is more than enough to relieve the MCO pressure during the peak hydrogen generation rate. Smaller orifices would be suitable expcept that orifice plugging becomes a concern for the smaller orifice diameters. A large orifice is required on the storage tube to relieve the pressure created in the tube by the flow coming from the Mco through the $1 / 4$ inch relief valve. The storage tube relief device must be able to handle a flow of $490 \mathrm{ft}^{3} / \mathrm{min}$. A one inch orifice without any other losses other than the orifice loss is required to keep the storage tube floor plugs from lifting.

The MCO and storage tube pressure response to several cycles of relief valve opening are shown in Figure 8.5. The velocity upstream of the orifices in a 1 inch tube are shown in Figure 8.6 for the MCO and tube relief valves. The velocity through the Tube cover plug is also shown and is zero. A blown up view of the tube pressure for one cycle of the relief valve opening is shown in Figure 8.7 . The velocity in a 1 inch pipe upstream of the $1 / 4$ inch valve for the MCO relief orifice is shown in Figure 8.8. The MCO and tube Hydrogen and Helium concentrations are shown in Figure 8.9, which illustrates the steadily decreasing helium concentration due to the purging of the helium from the tube by the hydrogen released from the MCO with each relief valve lifting. 
WHC-SD-SNF-ER-014， Rev. 0.

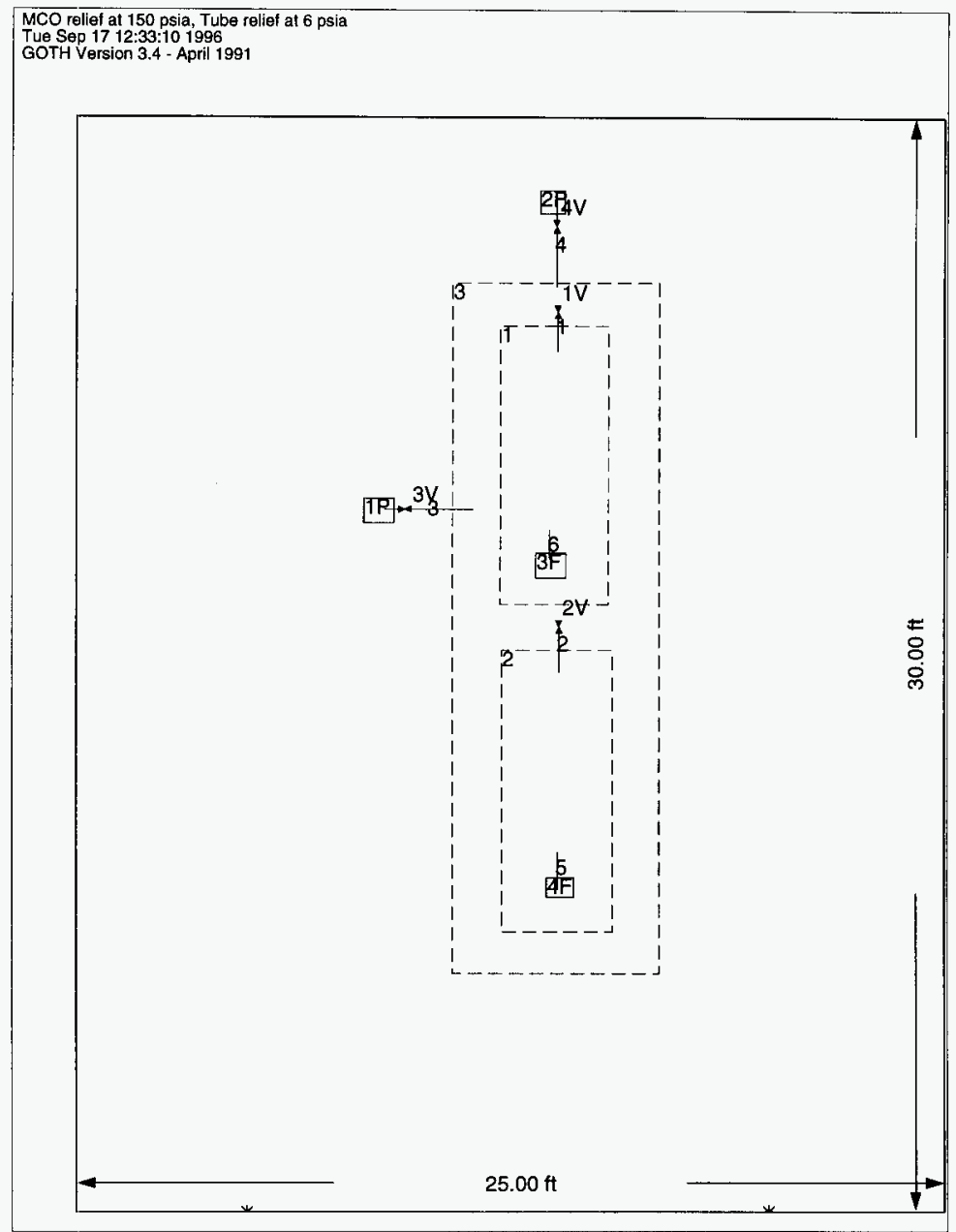

Figure 8.4 GOTH Model for MCO Pressure Relief. 
WHC-SD-SNF-ER-014，Rev. 0 .

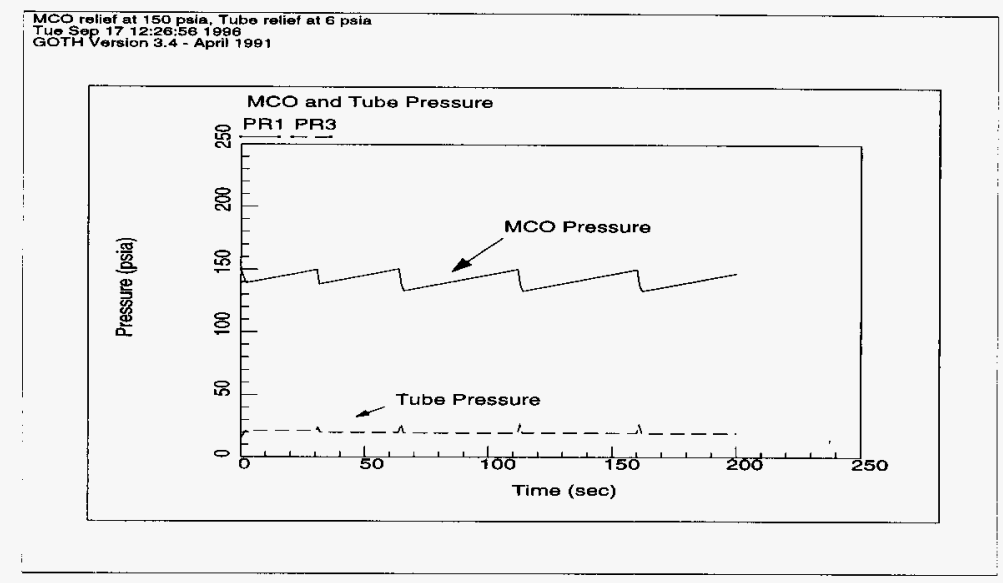

Figure 8.5 MCO and Tube Pressure with a $1 / 4$ inch orifice in the MCO Relief Valve and a 1 inch Orifice in the Tube Relief Valve. 
WHC-SD-SNF-ER-014, Rev . 0 .

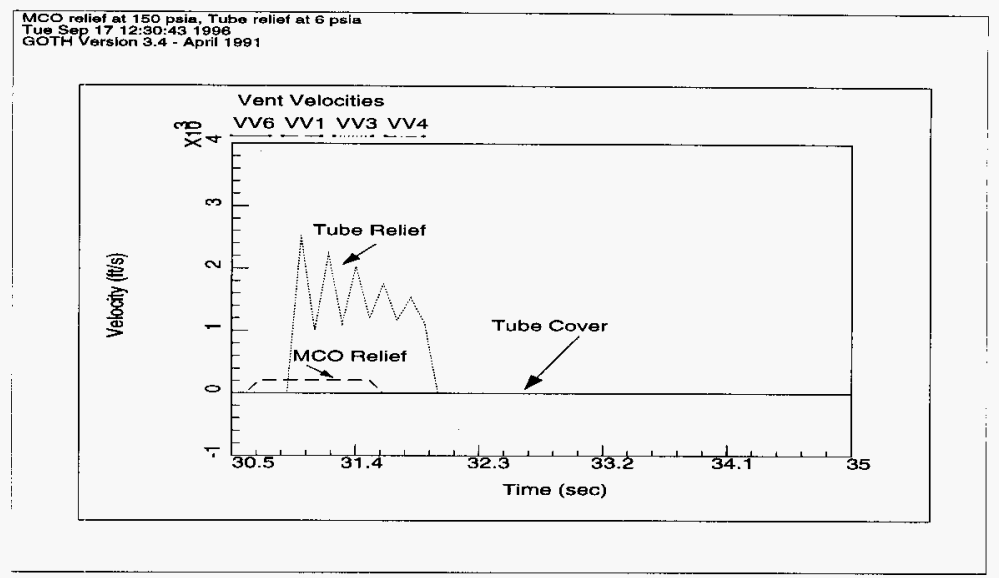

Figure 8.6 Vent Velocities with a $1 / 4$ inch Orifice in the MCO Relief valve and a 1 inch Orifice in the Tube Relief Valve. 
WHC-SD-SNF-ER-014, Rev. 0 .

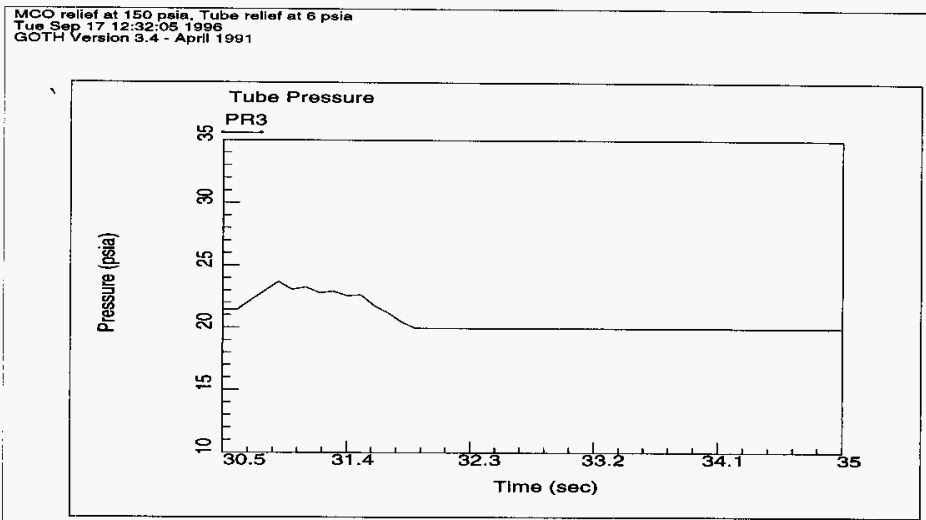

Figure 8.7 Tube Pressure with a $1 / 4$ inch Orifice in the MCO Relief Valve and a 1 inch orifice in the Tube Relief Valve.

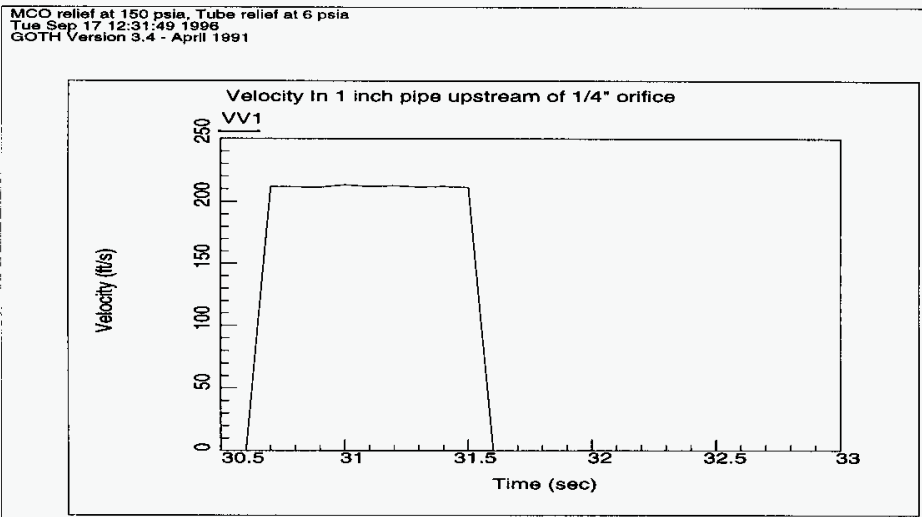

Figure 8.8 Velocity in 1 inch Pipe Upstream of $1 / 4$ " MCO Relief Valve. 


$$
\text { WHC-SD-SNF-ER-014, Rev. } 0 \text {. }
$$

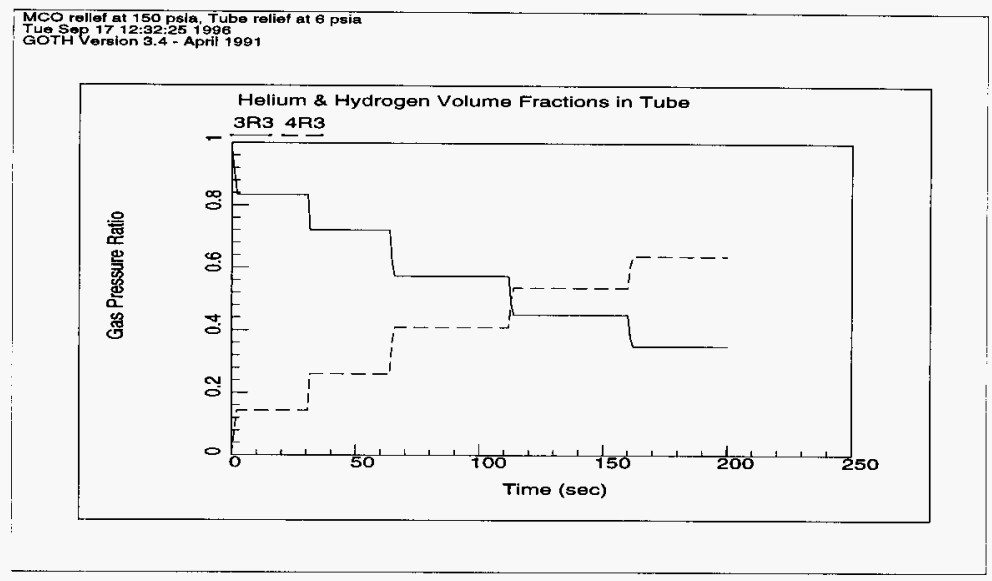

Figure 8.9 Helium (solid line) and Hydrogen (dashed line) Concentrations storage Tube.

\section{CONCLUSIONS.}

Results of the evaluation show that, if the reaction area is sufficiently large and if there is sufficient water present, over pressurization of the MCO will occur within a few hours after a given process is started given the highest environmental temperatures the MCO is expect to see. The MCO will eventually over pressurize if there is more than $2.95 \mathrm{~kg}$ of water during shipping and more than $2.5 \mathrm{Kg}$ of water during storage in the CSB, assuming that there are no reactions within the MCO that take up hydrogen. The issue is how long will it take for this to occur and this depends on the amount of fuel damage there is in the $\mathrm{MCO}$, what the reaction rate equation is and what the fuel temperatures are. Current bounding estimates for the reaction area in the worst case MCO and the amount of 
WHC-SD-SNF-ER-014, Rev. 0 .

water in the MCO will result in the MCO pressure exceeding the MCO design pressure in as little as 15 hours for transport from the basin to the CVDF in the event of a design basis fire, in 30 hours for the failure to drain during cold vacuum drying, in 14 hours for shipping to the CSB, and in 5 hours for staging in the CSB. The pressurization of the MCO during shipping from the basins and in the event of a failure to drain the MCo during vacuum drying are driven by a large supply of water and will require venting or some action to be taken to mitigate the conditions that lead to pressurization. Care must be taken to assure that sufficient gas volume is present in the MCO for shipping from the basins to assure even the short transportation times supported by the present analysis.

Temperature excursions can be eliminated during shipping from the CVDF to the CSB if it can be shown that the true reaction area within an $\mathrm{MCO}$ is less than $80,000 \mathrm{~cm} 2$ and this area is not concentrated within a small volume of the rubble basket. Peak temperatures resulting from temperature excursions can be minimized if it can be shown that the amount of water that can react with the uranium is small. Temperature excursions will occur during staging in the CSB for all reaction areas considered in this study but can be limited if it is shown that the amount of water in all forms present in the MCO during staging is small. The peak temperature for all cases considered is not expected to be much over $1000^{\circ} \mathrm{F}$, although this will require additional analysis to assure that this is the case and that fuel temperatures do not exceed $1250^{\circ} \mathrm{F}$ nor that MCO structure thermal limitations are not exceeded.

A summary of the key parameters and the results from the current evaluation are summarized in the following table. 
WHC-SD-SNF-ER-014, Rev. 0 .

Table 9.1 Summary of Key Parameters and Simulation Results for Cases Currently Considered.

\begin{tabular}{|c|c|c|c|c|c|c|c|c|c|c|}
\hline $\begin{array}{l}\text { Case } \\
\text { No. }\end{array}$ & Transient Description & $\begin{array}{l}\text { Decay } \\
\text { Heat } \\
\text { (watts) }\end{array}$ & $\begin{array}{c}\text { Corrosion } \\
\text { Product } \\
\text { Mass (kg) }\end{array}$ & $\begin{array}{c}\text { Residual } \\
\text { Water Mass } \\
\text { Fraction } \\
\text { (8) }\end{array}$ & $\begin{array}{c}\text { Scrap } \\
\text { Basket } \\
\text { Reaction } \\
\text { Area, } \mathrm{cm}^{2}\end{array}$ & $\begin{array}{r}\text { Time } \\
(t)\end{array}$ & $\begin{array}{l}\text { Pressure } \\
\text { At time, } \\
\text { (psia) }\end{array}$ & $\begin{array}{c}\text { Peak } \\
\text { Pressure } \\
\text { (psia) }\end{array}$ & $\begin{array}{c}\text { Peak } \\
\text { Temperature } \\
\left({ }^{\circ} \mathrm{F}\right)\end{array}$ & $\begin{array}{c}\text { Peak } \\
\mathrm{H}_{2} \text { Volume } \\
\text { Fraction } \\
\text { (₹) }\end{array}$ \\
\hline $1 \mathrm{~A}$ & Interim Storage (Bounding Case) & 929 & 300 & 1.5 & 800,000 & & & & & \\
\hline 1B & Interim Storage (high nominal) & 929 & 16 & 1.0 & 800,000 & $75 \mathrm{yI}$ & 25 & 25 & $<300$ & 35 \\
\hline $2 A$ & Staging (Bounding case) & 929 & 150 & 6 & 800,000 & $5 \mathrm{hr}$ & 140 & 320 & $>950$ & $>91$ \\
\hline $2 B$ & Staging (parametric case) & 750 & 150 & 6 & 80,000 & $18 \mathrm{hr}$ & 200 & 320 & $>1000$ & $>91$ \\
\hline $2 \mathrm{C}$ & staging (High nominal case) & 750 & 30 & 6 & 80.000 & $18 \mathrm{hr}$ & 200 & 200 & $>850$ & $>91$ \\
\hline $2 \mathrm{D}$ & staging (parametric case) & 750 & 70 & 6 & 57,000 & $22 \mathrm{hr}$ & 165 & 200 & 800 & $>91$ \\
\hline $2 E$ & Staging (parametric case) & 750 & 16 & 6 & 80,000 & $18 \mathrm{hr}$ & 70 & 70 & 480 & $<80$ \\
\hline $3 \mathrm{~A}$ & Shipping to CSB (Bounding case & 929 & 150 & 6 & 800,000 & $14 \mathrm{hr}$ & 100 & 320 & $>850$ & $>91$ \\
\hline $3 B$ & Shipping to CSB (high nominal & 750 & 150 & 6 & 80,000 & $90 \mathrm{hr}$ & 55 & 320 & 210 & 75 \\
\hline $3 c$ & Shipping to CSB (parametric) & 750 & 16 & 6 & 80.000 & $110 \mathrm{hr}$ & 60 & 60 & 210 & 75 \\
\hline $4 \mathrm{~A}$ & Failure to Drain water at CVDF & 929 & 150 & $55 \mathrm{~kg}$ & 800,000 & $30 \mathrm{hr}$ & 130 & $>>150$ & 320 & $>91$ \\
\hline $5 \mathrm{~A}$ & Transport from Basin to CVDF & 929 & 150 & Elooded & 800,000 & $30 \mathrm{hr}$ & 85 & $>>150$ & NC & $>91$ \\
\hline 58 & Transport Fire Basin to CVDF & 929 & 150 & flooded & 800,000 & $15 \mathrm{hr}$ & 100 & $>>150$ & NC & $>91$ \\
\hline
\end{tabular}


There is an unknown uncertainty in the application of the existing correlations to the decomposition rate of the metallic hydrates in addition to the rather wide scatter in the uranium/water reaction data on which the existing correlations are based. It must be shown that the amount of uranium reactive surface area that is in an MCO is sufficiently low (and not concentrated) to assure that the fuel temperatures will be in the stable temperature range, uncertainties included, if one wishes to avoid temperature excursions in the fuel. It is possible that temperature excursions are acceptable if it is shown that either 1) the amount of water in the MCO will not cause the pressure or temperature limits of the MCO or fuel to be exceeded or 2) the MCO has a pressure relief device sized to handle the maximum flows expected during the water reaction history and it can be shown the fuel temperatures enter a stable region as the reaction rate levels off at higher temperatures and the radiant heat rejection rate increases. This second option is acceptable if this occurs at an acceptably low temperature. There are indications in the present analysis that this will be the case but additional analysis is required before this conclusion can be reached.

The ability of the MCO to reject heat in the CSB storage tube is even poorer than in the transportation cask because 1) the CSB environment is at a higher temperature, 2) the tube surface area is smaller than the surface area of the cask and therefore has less ability to reject heat and 3 ) the storage tube is surrounded by other storage tubes that are at essentially the same temperature so heat rejection due to thermal radiation is minimized. Therefore, one would expect temperature excursions to occur for even lower reaction areas in the CSB. This means that the amount of water present the MCO when it reaches the CSB must be minimized to prevent temperature excursions in the fuel.

The stable operating range at low temperatures is shown in Figure 9.1. The chemical heat rejection capability of the system for transportation is shown by the straight lines in 
the figure. There are two such lines shown, one for the conservative estimate and one for the best estimate rate. The system is thermally stable in the region where the reaction heat generation curves (parabolic curves in the figure) fall below the heat rejection lines. A second stable region likely exists at higher temperatures. Data for this region is currently being generated.

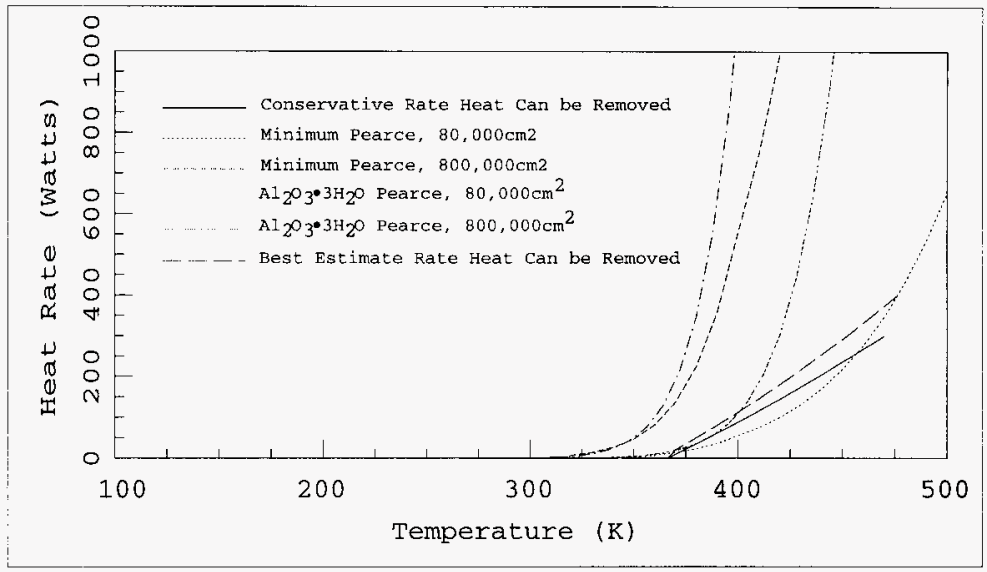

Figure 9.1 Comparison of Heat That Can be Removed Versus Heat That Can be Generated.

The equilibrium pressure of the MCO (the pressure the MCO will go to if all of the water is reacted and the MCO comes to thermal equilibrium with its environment) is a function of the water mass assumed to be in the MCO before any reactions take place, the free gas volume of the MCO, the fill gas, the fill temperature and the steady state temperature of the MCO for a given environment.

The equilibrium pressure as a function of MCO hydrate water mass for two bulk MCO temperatures is shown in English 
WHC-SD-SNF-ER-014, Rev. 0 .

Units in Figure 9.2. The two temperatures shown in the figure have been chosen because they represent the expected MCO temperatures during the peak summer temperatures for the MCO stored in the transportation cask and for the MCO stored in the CSB storage tube.

The maximum amount of water that may be present in an MCO that will raise the MCO pressure to its design limit of 165 psia can be determined from these curves if we assume that sufficient time is allowed for the water reaction to go to completion. The amount of time required for the water decomposition to go to completion depends on the form the water is in. Surface bound water (hydroxides) comes off rather slowly, so water contained in the MCO in this form will come out only after long periods of storage, such as during interim storage. Water stored in the form of hydrates likely comes off more rapidly, but current methods for the rate of hydride decomposition have large amount of uncertainty in them, so it must be assumed that this water comes off easily. This water will react very rapidly at both transport and CSB staging temperatures, depending on the amount of reactive surface area there is on the uranium metal. The same is true for any free water in the MCo. It must be demonstrated that either the reactive surface area is sufficiently small that not enough water will react with uranium during the time period of interest to over pressurize the MCO or it must be demonstrated that there is no more water in the MCO than that which will over pressurize the MCO if all of the water is converted into hydrogen gas. The maximum amount of water that may be present in the MCO to remain below the MCO design pressure is $6.5 \mathrm{lbm}$ when the MCO is in the transportation cask and $5.5 \mathrm{lbm}$ when the $\mathrm{MCO}$ is in the CSB storage tube. These values are obtained by finding the intersection of the MCO design pressure with the pressure versus water mass plots in Figure 9.2 . 
WHC-SD-SNF-ER-014, Rev. 0 .

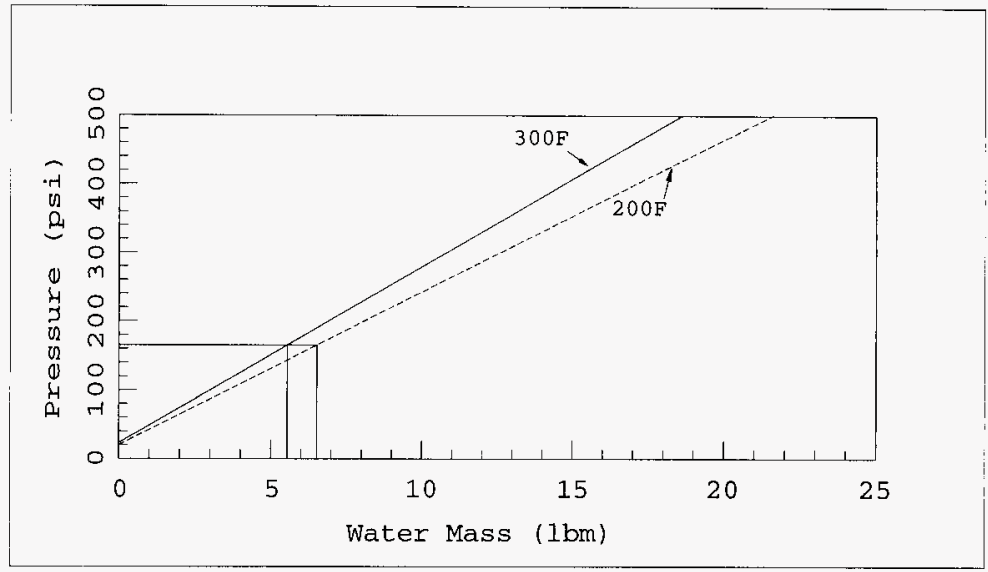

Figure 9.2 Maximum MCO Pressure As a Function of Initial Water Mass for Two MCO Temperatures. 


\section{RECOMMENDATIONS.}

Results of the evaluation documented in this report lead to the following recommendations:

1. A strategy needs to be developed to either show that the total uranium reaction area in an MCO is on the order of $80,000 \mathrm{~cm}^{2}$ rather than $800,000 \mathrm{~cm}^{2}$. This may involve implementing some kind of control during the loading process at the basin to assure that fuel which has been damaged by oxidation is distributed as uniformly as possible among all of the MCOs to be loaded at the basin.

2. Additional analysis needs to be completed to determine if there is a second stable operating range at higher temperatures that will prevent fuel temperatures from becoming excessively high if there is too much water and reaction area for stable operation at lower temperatures.

3. Additional effort needs to be made to quantify the amount of water in various forms that will be present at various stages in the process with less uncertainty than exists in the current estimates. This may require putting together an analysis methodology which consistently accounts for the amount of water present in the MCO as the MCO passes from one stage in the process to another.

4. Pressure relief devices should be designed and installed on the MCO during all stages of the process to prevent over pressurization of the MCO.

5. Additional analyses need to be performed to evaluate the effect of local high concentration of surface reaction area on MCO pressurization and fuel temperatures. 


\section{REFERENCES}

[1] M. Plys, Hydrate Decomposition, Fauske \& Associates memorandum to J. Wiborg, Westinghouse Hanford Company, May 17, 1996.

[2] M. Plys and B. Malinovic, Porous Medium Model of Particulate Bed Decomposition, Fauske \& Associates memorandum to J. Wiborg, Westinghouse Hanford Company, June 5, 1996.

[3] M. Plys, Fuel Oxide Hydrate Decomposition Model Equations, Fauske \& Associates Memorandum to J. Wiborg, July 19, 1996.

[4] T.D. Cooper, Spent Nuclear Fuel Project Recommended Reaction Rate Constants for Corrosion of $N$ Reactor Fuel, Westinghouse Hanford Company, WHC-SD-SNF-TI-020, Rev. 0, May, 1996.

[5] A.G. Ritchie, Journal of Nuclear Materials, Vol. 102, 1981, page 170 .

[6] A.G. Ritchie et. al., Journal of Nuclear Materials, Vol. 139, (1986) pp. 121-136.

[7] R.J. Pearce, A Review of the Rates of Reaction of Unirradiated Uranium in Gaseous Atmospheres, Report RD/B/6231/R89, Central Electricity Generating Board, Berkley Nuclear Laboratories, Berkeley, California, 1989 .

[8] Duncan, D. R., June 1996.

[10] Cooper, T., Surface Area Estimates for $N-F u e l$ in K-East Basin, WHC, July, 1996. 
WHC-SD-SNF-ER-014, Rev. 0.

[9] Cooper, T., Gas Generation Rates, WHC, July 1996.

[11] Pajunen, A., Bounding Particulate contents of an MCO. WHC-SD-SNFTI-023, Revision 1, July, 1996.

[12] Heard, F.J., Thermal Hydraulic Feasibility Assessment of the Spent Nuclear Fuel Project. WHC-SD-WM-ER-525, Rev. 0, Westinghouse Hanford Company, Richland, WA. 1996. 


\section{DISTRIBUTION SHEET}

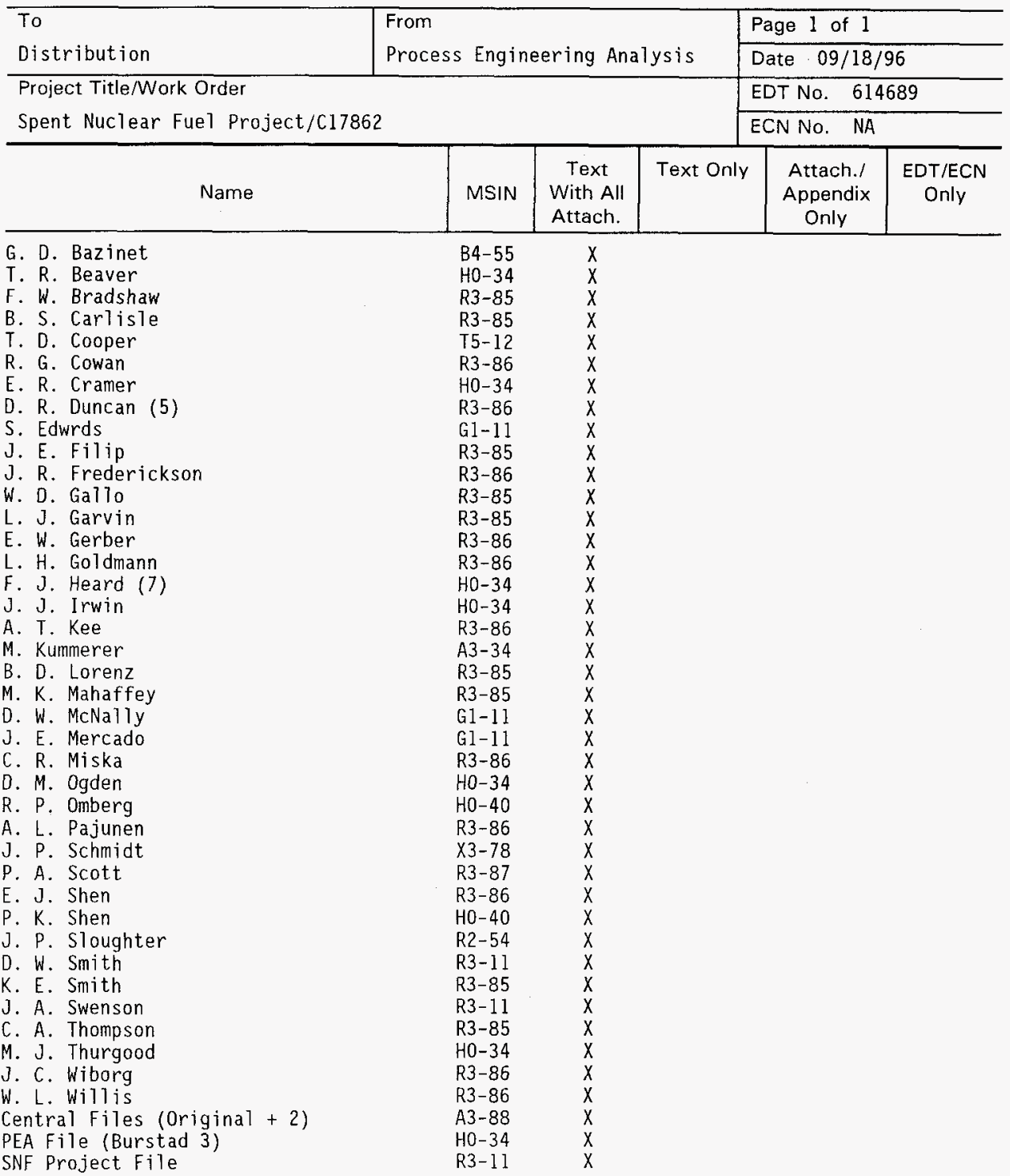

